

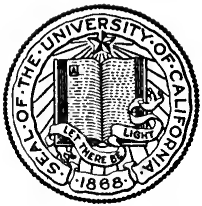

THE LIBRARY

OF

THE UNIVERSITY

OF CALIFORNIA RIVERSIDE 

THE SCIENTIFIC STUDY OF SCENERY 


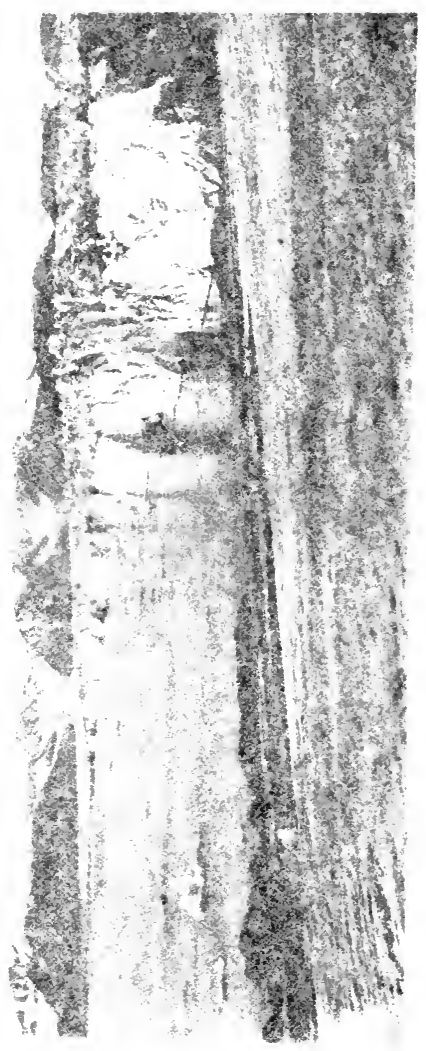




\title{
THE
}

\section{SCIENTIFIC STUDY OF SCENERY}

\author{
BY \\ JOHN E. MARR, M.A., F.R.S. \\ FELLOW OF ST. JOHN'S COLLEGE, CAMBRIDGE
}

WITH TWENTY-ONE ILLUSTRATIONS

AND NUMEROUS DIAGRAMS IN THE TEXT

NEW YORK: NEW AMSTERDAM BOOK CO.

LONDON : METHUEN \& CO. 


$$
\begin{aligned}
& \text { QE571 } \\
& M 37
\end{aligned}
$$




\section{PREFACE}

M ANY books, as Sir A. Geikie's Scenery of Switzerland, give an account of the origin of the scenery of limited areas, but I believe that there is room for an English work which treats of the origin of scenery in general.

Under the title The Scientific Study of Scenery I have written a work which may be regarded as an Introductory Treatise on Geomorphology, a subject which has sprung. from the union of Geology and Geography.

I have tried to make the work useful to the student, and also to rouse the interest of the general reader, and hope that I have not thereby rendered it unpalatable to both.

For those who desire to pursue the study of the subject, I have introduced numerous references to works of a more technical character. In addition to those cited in the text, I would refer the student to Professor J. Geikie's Earth Sculpture and Professor W. M. Davis's Physical Geography. These books have appeared since the text was written.

To Mr. Geo. Allen, of Ruskin House, I am in- 
debted for permission to make the quotations from Mr. Ruskin's works, and also for the use of the block from which Figure 3 is printed; I wish to thank Mr. W. G. Collingwood for leave to use this figure. My thanks are due to the Hon. D. W. Carnegie and to the Council of the Geographical Society for permission to reproduce the illustration of a Spinifex desert; the illustration in this work is from a copy (made by my sister, Miss C. Marr) of the figure in the Geographical Journal. Mr. A. W. Rogers, of the Geological Survey of Cape Colony, kindly sent me the photograph from which the plate of the Langebergen Mountains is taken, and Mr. R. D. Oldham, of the Geological Survey of India, that from which the plate showing the lake in the Garo Hills is copied. The plate illustrating Ingleborough Cave is from a photograph by $\mathrm{Mr}$. G. Towler, of Settle, Yorkshire, and that of the Wastwater Screes from one by Mr. Herbert Bell, of Ambleside. The other plates are reproductions of photographs by Mr. E. J. Garwood, to whom I offer my special thanks. In conclusion, I desire to express my indebtedness to a friend for kindly reading the proofs of my book.

$$
\text { J. E. M. }
$$

CAMBridge, September, 1899 


\title{
TABLE OF CONTENTS
}

\author{
CHAPTER I. \\ INTRODUCTION.
}

Scope of the Study-Attributes of Scenery . . . Pages I-7

CHAPTER II.

OF THE NATURE OF THE EARTH'S EXTERIOR.

Lithosphere, Hydrosphere, and Atmosphere-Rocks-

Divisional Planes of Rocks . . . 8-19

CHAPTER III.

PRODUCTION OF DOMINANT FORMS.

Accumulation of Material-Elevation and Depression-

Sculpture . $\quad$. $\quad$. $\quad$. $20-28$

\author{
CHAPTER $\cdot$ IV. \\ THE ATMOSPHERE.
}

Colour-Clouds-Cyclones and Anti-Cyclones .

$29-45$

CHAPTER V.

CONTINENTS AND OCEAN BASINS.

Production and General Structure of Continents and Ocean

Basins-Initiation of River Drainage . . . 46-54

CHAPTER VI.

MOUNTAINS.

Classification of Mountains-Folded Mountains-Faulted

Mountains .

CHAPTER VII.

MOUNTAINS (continued).

Formation of Watersheds-The Processes of Denudation . 


\section{CHAPTER VIII. \\ MOUNTAINS (continued).}

Details of Mountain Structure-Influence of the Sculpturing Agents-Influence of Rock Composition and Structure

-Vegetation on Mountains . • . Pages 94-1 12

CHAPTER IX.

VALLEYS.

Classification of Valleys-Angles of Valley Slopes-Valleys of Erosion.

$$
\begin{gathered}
\text { CHAPTER X. } \\
\text { vALLEYS (continued). }
\end{gathered}
$$

Complications of River Drainage-Waterfalls-Underground

Rivers

\section{CHAPTER XI.}

\section{LAKES.}

Classification of Lakes-Lakes formed by Accumulation of Material-Lakes formed by Earth Movement-Crater

Lakes-Lakes formed by Erosion . . . 158-187

\section{CHAPTER XII.}

LAKES (continued).

Topographical Features of Lake Shores and Lake Basins-

Islands in Lakes-Colour of Lakes

$113-13^{8}$

\section{CHAPTER XIII. VOLCANOES.}

Theories of Vulcanicity-Outlines and Structures of Volcanoes-Fissure Eruptions-Geysers-Mud VolcanoesEarthquakes

\section{CHAPTER XIV \\ PLAINS AND PLATEAUX.}

Formation and Characters of Plains-Formation and Characters of Plateaux - $231-247$

\section{CHAPTER XV.}

\section{DESERTS.}

Production of Deserts-Erosion of Deserts-Accumulation in Deserts--Vegetation of Deserts 


\section{TABLE OF CONTENTS}

CHAPTER XVI.

FROST, SNOW, AND ICE.

Hoar-frost-Snow-Glaciers

- Pages 272-296

CHAPTER XVII.

GLACIERS AND ICE-SHEETS OF VARIOUS REGIONS.

Norway-Spitsbergen-Alaska-Greenland . . 297-309

CHAPTER XVIII.

THE SIGNS OF FORMER GLACIATION.

Glacial Erosion-Glacial Accumulations and Deposits . 310-320

CHAPTER XIX.

THE OCEANS.

Oceanic Erosion-Formation of Coast-lines-Oceanic Islands

- Raised Sea-margins-Marine Vegetation-Ice in the

Ocean

Conclusion

- $32 \mathrm{I}-35 \mathrm{I}$

\section{CHAPTER XX.}

INDEX 


\section{LIST OF ILLUSTRATIONS}

King's Bay Glacier, Spitsbergen

Upper Surface of Cloud in Eden Valley

Langebergen, Mossel Bay District

Nunatak, Nordenskjöld Glacier

Hornsund Tind

The Drei Zinnen

The Matterhorn, from the Hörnli

High Force, Teesdale

Ingleborough Cave, Clapham, Yorks

The Ober-Gabelhorn from the Schwarz See

Märjelen See

Sty Head Tarn

Haweswater

Smallwater

Lago dell' Inferno .

Earthquake-lake, Garo Hills .

The Screes, Wastwater

Spinifex : Queen Victoria Desert, Western Australia
Frontispiece

- To face page $2 \mathrm{I}$

, 86

, 90

,109

, 109

, III

, $\quad 150$

" 156

, $\quad 159$

, $16 \mathrm{I}$

,, 166

,, $\quad 169$

, 169

, $\quad \mathbf{1 7 5}$

, 180

, 196

, 268

286

299

302 


\section{THE SCIENTIFIC STUDY OF SCENERY}

\section{CHAPTER I.}

\section{INTRODUCTION}

A WIDESPREAD appreciation of the beauties $\mathrm{A}$ of nature is not the least of the many beneficent changes which have marked the Victorian era, and with this appreciation has sprung up a desire on the part of many people to obtain some insight into the causes of scenery. Few persons at the present day are content to believe that the superficial features of the earth have always been as they are now, and the wish to know something of the changes which are responsible for the production of the existing features of the globe is a very natural one, and its fulfilment not only affords additional pleasure to a vast number of lovers of scenery, but gives them an insight into a noble aim of the natural sciences which is too often overlooked. These sciences are too frequently regarded from a purely philosophical or a merely economic standpoint, and their æsthetic side is ignored, though this is very valuable as a means of education. 
The scientific study of scenery is concerned with all the existing features of earth, sky, and sea, which are visible to the eye, quite apart from their relative attractiveness, which is indeed often a matter of individual taste, for a view which one person considers tame and uninteresting will produce feelings of profound satisfaction in another. It is well known that mountains which are now attractive to so many were generally regarded with repulsion or horror at no remote period; while a fenland flat which arouses little enthusiasm in some is contemplated with intense pleasure by others.

If we take this comprehensive view of the scope of our study, it will be seen that it covers a large portion of the field of physical geography; and indeed no better method of imparting the elementary principles of physical geography exists than that of teaching the student the significance of the earth's superficial features, especially those of the districts with which he is acquainted. When this is recognised, physical geography will take its proper place as a subject eminently adapted for schools, and as an introduction to a knowledge of geology of far greater interest to the bulk of educated persons than the dry details concerning rocks and fossils which are frequently supplied to them as an introduction to the science, details which naturally cause them to turn away from the pursuit of the study with a feeling of aversion.

In viewing any scene, the attributes which strike us specially are size, form, character, surface, colour, and movement, and of these attributes there is little doubt that form is by far the most important, and it will be most attentively considered in this work, 
though occasional references will necessarily be made to other attributes. The importance of form is so great that it is necessary to devote a few words to its consideration, but this will best be done by quoting the words of acknowledged masters of the study of scenery. Thus Ruskin writes: "We shall see hereafter, in considering ideas of beauty, that colour, even as a source of pleasure, is feeble compared with form "; ${ }^{1}$ while concerning magnitude Wordsworth observes that "a short residence among the British mountains will furnish abundant proof, that, after a certain point of elevation ... the sense of sublimity depends more upon form and relation of objects to each other than upon their actual magnitude." 2

As the four attributes size, colour, movement, and character of surface, or, as we may term the last, texture, will not be treated systematically, it will be convenient at this point to make a few further observations concerning them.

I. Size.-It is evident that mere size cannot add directly to the beauty of an object or group of objects, and the influence of magnitude of natural objects is dependent upon the imagination. The truth of this statement is well illustrated by an example given by Ruskin, which I may be pardoned for quoting at length :-

"Not long ago, as I was leaving one of the towns of Switzerland, early in the morning, I saw in the clouds behind the houses an Alp which I did not know, a grander Alp than any I knew, nobler than the Schreckhorn or the

1 Modern Painters, vol. i., part ii., sec. i., chap. v.

2 A Complete Guide to the Lakes, . . . with Mr. Wordsworth's Description of the Scenery of the Country, sec. iv. 


\section{4 \\ SCIENTIFIC STUDY OF SCENERY}

Mönch; terminated, as it seemed, on one side by a precipice of almost unimaginable height; on the other, sloping away for leagues in one field of lustrous ice, clear and fair and blue, flashing here and there into silver under the morning sun. For a moment I received a sensation of as much sublimity as any natural object could possibly excite; the next moment, I saw that my unknown Alp was the glass roof of one of the workshops of the town rising above its nearer houses and rendered aerial and indistinct by some pure blue wood smoke which rose from intervening chimneys.

"It is evident, that so far as mere delight of the eye was concerned, the glass roof was here equal, or at least equal for a moment, to the Alp. Whether the power of the object over the heart was to be small or great, depended altogether upon what it was understood for, upon its being taken possession of and apprehended in its full nature, either as a granite mountain or a group of panes of glass; and thus, always, the real majesty of the appearance of the thing to us, depends upon the degree in which we ourselves possess the power of understanding it. . . For though the casement had indeed been an Alp, there are many persons on whose minds it would have produced no more effect than the glass roof. It would have been to them a glittering object of a certain apparent length and breadth, and whether of glass or ice, whether twenty feet in length, or twenty leagues, would have made no difference to them; or, rather, would not have been in any wise conceived or considered by them. Examine the nature of your own emotion (if you feel it) at the sight of the Alp, and you find all the brightness of that emotion hanging, like dew on gossamer, on a curious web of subtle fancy and imperfect knowledge." 1

II. Colour.-It would be impossible in a work like the present to give a lengthy account of the infinite

1 Modern Painters, vol. iii., part iv., chap. x. 
variations in colouring produced by different atmospheric conditions, though something will be said upon this subject when we consider the atmosphere. But beyond this variation we find definite colours associated with particular objects, and these often play an important part in affecting the aspect of a scene. For instance, the colour of pure water is stated to be a greenish blue, as will be more fully described when treating of expanses of water. The colour of terrestrial surfaces is largely affected by the nature of the vegetation as well as by that of the rocks. Though foliage has a more general effect than flowers in giving colour to landscape, the influence of the latter is by no means small. The vivid scarlet of Poppy land, the purple tracts of heather in Highland districts, the richly coloured carpet of flowers in Alpine meadows before the hay is cut, are cases where a marked effect is produced. The foliage of trees and grasses need only be mentioned, though of the latter it may be remarked that the most striking effects are produced in rainy regions. The brilliant green of our Lakeland vales is due to the excessive rainfall, which in more ways than one must be accounted beneficial to the lover of scenery. It is to lowlier vegetation that we are indebted for some of our richest colouring. The changes which occur in the bracken of Westmorland are thus described by Wordsworth :-

"When in the heat of advancing summer, the fresh green tint of the herbage has somewhat faded, it is again revived by the appearance of the fern profusely spread over the same ground; and, upon this plant, more than upon anything else, do the changes which the seasons make in the colouring of the mountains depend. About the first week 


\section{SCIENTIFIC STUDY OF SCENERY}

in October, the rich green, which prevailed through the whole summer, is usually passed away. The brilliant and various colours of the fern are then in harmony with the autumnal woods : bright yellow or lemon-colour, at the base of the mountains, melting gradually, through orange, to a dark russet-brown towards the summits, where the plant, being more exposed to the weather, is in a more advanced state of decay." 1

The same writer refers to the effect of the lichens, which is also thus beautifully described by Ruskin :-

"As in one sense the humblest, in another they are the most honoured of the earth-children. Unfading, as motionless, the worm frets them not, and the autumn wastes not. Strong in lowliness, they neither blanch in heat nor pine in frost. To them, slow-fingered, constant-hearted, is entrusted the weaving of the dark, eternal tapestries of the hills; to them, slow-pencilled, iris-dyed, the tender framing of their endless imagery. Sharing the stillness of the unimpassioned rock, they share also its endurance; and while the winds of departing spring scatter the white hawthorn blossom like drifted snow, and summer dims on the parched meadow the drooping of its cowslip-gold,-far above, among the mountains, the silver lichen-spots rest, star-like, on the stone; and the gathering orange stain upon the edge of yonder western peak reflects the sunsets of a thousand years." 2

But though the colouring of rocks as seen in nature is so often due to vegetation upon their surface, the bare rock frequently possesses colour of its own, owing to the presence of organic matter, or of some compound of iron. The former usually

1 WORDSWORTH, loc. cit., sec. i.

2 RUSkin, Modern Painters, vol. v., part vi., chap. x. 
gives a grey-blue or black colour, while the colouring due to iron varies according to the particular compound which is present. The peroxide of iron produces a rich red, so well known in the red sandstones of Britain, the hydrated oxide gives yellow, orange, or rust-brown hues, while the silicate is green. The effect due to colouring matter in the rocks is specially well brought out in desert regions where the vegetation is scanty; for instance, it is very noticeable in the walls of the deep cañons of the western territories of North America.

III. Texture.-The important influence of texture is well illustrated by the frequency of such expressions as "fleecy clouds," "an oily sea," "soft and downy pasturage," in descriptions of scenery. It is largely determined by differences of shape, which are too minute to be detected in detail, though they produce a general effect upon the surface which is viewed, and on this account it is superfluous to do more than call attention to this attribute of surfaces as affecting scenes. Lustre largely depends upon the texture of surfaces, and may be conveniently regarded under this head.

IV. Movement.-The effect of movement in air, on water, or on land is often very noticeable as an attribute of a scene which may produce a feeling of exhilaration in the mind of the beholder. It is only necessary to refer to the effect of moving cloud, of the eddying torrent, the sea-wave, and the waving vegetation of cornfield, down, or mountain-brow as illustrations of the influence of motion upon scenery. 


\section{CHAPTER II.}

\section{OF THE NATURE OF THE EARTH'S EXTERIOR}

THE unknown interior of the earth is surrounded 1 by three envelopes, the lithosphere, hydrosphere, and atmosphere, of which the first and third are continuous, while the second is interrupted in places, and allows portions of the first to project upwards into the third. The lithosphere is that portion of the earth which is popularly spoken of as its crust, and is in the solid condition; the hydrosphere is liquid, and is composed of the oceans, rivers, lakes, and indeed all the surface waters of the globe; the atmosphere is the gaseous envelope which surrounds the lithosphere and hydrosphere, and extends for an unknown but limited distance outward from their surfaces. Portions of these envelopes are capable of passing from one state to another; for instance, parts of the waters of the hydrosphere enter into the composition of the lithosphere, or as aqueous vapour pass into the atmosphere; fragments of lithosphere-e.g., volcanic dust-are often suspended for a long period in the atmosphere, while the gases of the atmosphere are taken up by the earth's crust and the waters of the globe. This power which the envelopes possess of interchanging some of their components will be 
found to exercise a marked influence upon scenic effects.

It is unnecessary at present to touch more fully upon the characteristics of atmosphere and hydrosphere, but the nature of the lithosphere requires further consideration at this initial stage of our inquiries, for the features of the globe are notably affected by the composition and structure of the earth's crust.

The lithosphere is composed of rocks, which are aggregates of mineral particles, the term rock being used quite irrespectively of any consideration of hardness or coherence. Thus a geologist would speak of the loose sand of the sea-shore as a rock equally with the hardest granite or basalt. Rocks are divided into two great classes. The igneous class consists of rocks which have directly consolidated from a state of fusion, while the derivative class has been formed by accumulation of material on the surface of the earth, that material not having been in a state of fusion immediately before its accumulation. These derivative rocks may be composed of materials derived from the atmosphere (as carbonaceous accumulations such as peat and coal, formed of carbon compounds extracted by vegetation from the atmosphere, and ice derived from the aqueous vapour of the atmosphere), or they may be formed of substances previously contained in solution in the waters of the hydrosphere, and brought into the solid condition by precipitation or by the agency of organisms (for instance, rock-salt, gypsum, and many limestones and siliceous deposits), or they may consist of fragments broken from pre-existing rocks and carried by mechanical means to the position in 


\section{IO SCIENTIFIC STUDY OF SCENERY}

which they are accumulated (as sandstone and mud), or they may be due to a combination of two or all of these processes. The great bulk of the derivative rocks are accumulated in layers (generally, though not universally, at the bottom of sheets of water), and hence they are frequently spoken of as stratified rocks.

Igneous and stratified rocks alike may undergo considerable changes after their formation, and these changes are spoken of as metamorphic, and we meet, therefore, with metamorphic igneous as well as metamorphic aqueous rocks.

In the following chapter we shall call attention to the operations of certain agents which are responsible for the sculpture of the rocks of the earth's crust, and before studying these operations it is necessary to allude to various characteristics of rocks which influence the sculpturing processes.

If all rock had the same composition, and was absolutely homogeneous throughout, the agents which affect it would do so over the entire surface in the same manner, assuming that these agents worked uniformly, but a very brief inspection of the crust of the globe shows that the work is not performed in a uniform manner, even under conditions in which the agents can work uniformly, and accordingly it is clear that rocks differ from one another in certain respects, some being more durable than others. Some of the differences, such as difference of chemical composition, may be discovered in a hand specimen. This difference may be complete as between chalk and flint, the former being composed of carbonate of lime, the latter of silica, or it may be partial as between a calcareous sandstone and a 
ferruginous sandstone, one possibly composed of grains of silica cemented by carbonate of lime, the other of grains of the same material with a cement of oxide of iron. As some of these constituents are very soluble in ordinary water, others less soluble, and others again practically insoluble, it is clear that the influence of water upon rocks of different composition may produce very different results.

Other differences may be observed in a hand specimen between rocks of the same composition. Thus a siliceous rock may be practically homogeneous, like flint, or it may be composed of a number of grains cemented into a more or less hard sandstone. Mechanical differences of this nature, which are readily observable in a hand specimen, may be spoken of as differences of texture.

Again, when we examine the rocks of a country we shall certainly find differences which are not easily detected, if at all, in a hand specimen. Among the most noticeable are the divisional planes which cause rocks to break more readily in one direction than another. These may be spoken of as differences of structure. As these structural differences play a most important part in determining and controlling the action of the agents of sculpture, it is necessary to treat of them at some length.

To the geologist the difference between divisional planes is of prime importance, mainly with regard to the way in which they are produced, though for our present purpose their importance is commensurate with their effect upon superficial features; but as the planes produced in any one way generally give rise to similar effects, which differ from those caused by planes produced otherwise, it is quite convenient to 
classify these planes according to their origin, and they may be grouped under three heads:-(i) Planes formed during the formation of the rocks; (ii) those formed after formation by fracture; (iii) those produced by metamorphism. It is not easy in all cases to distinguish between (ii) and (iii), but there is no difficulty in effecting a practical separation between the two.

In class (i) we place planes of stratification and lamination, in (ii) joint-planes and fault-planes, and in (iii) cleavage-planes and planes of foliation. Between these planes we may now proceed to discriminate.

(a) Planes of Stratification and Lamination.-It is found as the result of observation that stratified rocks are accumulated in layers, which are separated by divisional planes; these when the rocks are formed lie generally in a horizontal position. These planes are planes of stratification, or when they are near together (say several in the thickness of an inch of deposit) planes of lamination, the latter being merely planes of stratification on a small scale. A plane of stratification, then, separates two beds or strata of rock. It need not necessarily be a plane of discontinuity, but may merely separate two beds of different composition, as mud and limestone, which are nevertheless welded together, but the majority of planes of stratification, and those with which we are here chiefly concerned, are actual planes of discontinuity along which rocks may be split. It is obvious that these planes are, strictly speaking, absent from igneous rock, but similar planes may separate lava flows from sediments which overlie or underlie them, and we may conveniently include such planes in this division. It was stated above that planes of stratification are 
usually formed as horizontal planes, but they are frequently found at all angles and even turned over, so that a bed which was once lower now lies above the original upper one. It is known that this is the result of movements of the earth's crust occurring subsequently to the deposition of the strata, which have produced a series of folds. A few words must be devoted to the nomenclature applied to these disturbed strata.

The greatest angle which an inclined stratum makes with the horizon is known as the angle of dip of the stratum, and the direction in which the stratum plunges down into the crust along the line of this greatest angle is the direction of dip. Imagine that the roof of a house whose ridge runs north and south is composed of a bent bed. Then the dip is east on one side and west on the other, and if the greatest angle of the slope is $30^{\circ}$, the bed would be said to dip to the east or west at $30^{\circ}$. A horizontal line at right angles to the direction of dip is known as the line of strike of the beds. Thus, in the above example, the ridge of the roof lies along the line of strike, which is always at right angles to the direction of greatest inclination, along which a stream of water would flow if it were poured upon the surface of the bed. The line along which a plane of stratification (or a plane of joint, fault, cleavage, or foliation) comes to the surface of the ground is spoken of as its outcrop, and the outcrop of the stratum is when the bed itself comes to the surface, in this case not as a line, but as a narrow belt bounded by approximately parallel lines of stratification, and a bed or divisional plane is spoken of as cropping out along such a belt or line. 


\section{I4 SCIENTIFIC STUDY OF SCENERY}

The folds into which inclined strata are thrown are known to geologists by different names according to their character, but it will be convenient to use less technical terms in the body of the work, though the technical names are given here for purposes of reference. Fig. I shows the character of some of these folds.

When the strata dip away on either side from an axis the structure may be termed a saddle (anticline), as in A I of figure, while when they dip towards an axis, as in A 2, we have a trough (syncline). When strata are horizontal, then dip in any direction, and once more become horizontal, we get a hogback (monocline), as in A 3. B I and B 2 show the method in which the strata of a saddle and trough crop out upon a flat surface (if the top of the fold be cut off). The arrow indicates the direction of the dip, and the numbers the angle. Thus the axes of the saddle and trough here run north and south, and the beds dip at an angle of $45^{\circ}$ east and west, away from the axis in the former figure, towards it in the latter. If the strata, instead of being folded around an axial line, are folded round a point, the saddle is replaced by a dome (B 3 ), and the trough by a basin ( $\mathrm{B} 4$ ). It will be seen that the section across a dome is similar to that across a saddle at right angles to its axis, and that of a basin to that of a trough, though the outcrop of the beds in plan is different. In nature the domes and basins are usually somewhat unsymmetrical, and we get every gradation from the ideal saddles and troughs to the symmetrical domes and basins. When a fold consisting of saddle and trough has been continued until the central part has been turned over, as in 


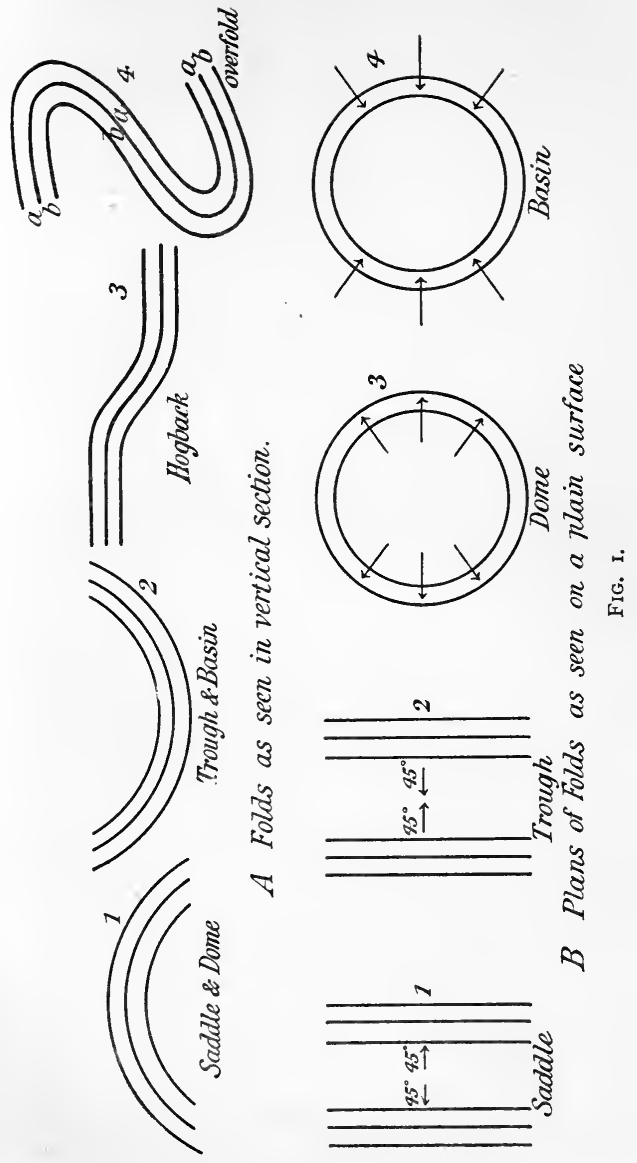




\section{6 SCIENTIFIC STUDY OF SCENERY}

A 4 (Fig. I), so that in that part the stratum $b$, originally below, now rests upon the stratum $a$, the fold is termed an overfold.

(b) Joint-planes.-In addition to the planes of stratification which separate strata, we often find a number of more or less regular planes running at different angles to the stratification-planes, and similar planes are found in igneous rocks. They may be, and in many cases have been, produced in different ways, but it is not our province to consider their mode of production. They clearly differ from the planes of stratification, and there is this important difference between them and cleavage-planes, that, whereas the rock between two contiguous joint-planes shows no tendency to split parallel to the jointplanes, that between adjoining cleavage-planes in a fragment of a cleaved rock may be split up into extremely thin plates, whose surfaces run parallel with the two cleavage faces with which we commenced; indeed, with delicate tools, the splitting process may be carried on almost indefinitely. The joints are often very irregular, but we frequently find the more important ones running with a considerable degree of regularity. The columnar jointing of basalt and other rocks is somewhat rare, and need not be now considered, but both igneous and aqueous rocks often show parallel systems of joints, which allow the rock to be broken with comparative ease into rectangular masses. These joints are termed master-joints. In igneous rocks three sets of master-joints, each at right angles to the other two, must exist, in order that the rock may be separated into rectangular blocks. In stratified rocks the planes of stratification already form one set of planes of weakness, and these 
rocks may be separated into rectangular blocks if two sets of joints exist. When the strata are horizontal the master-joints tend to be vertical and at right angles to one another. Thus if one set runs north and south the other will run east and west.

Very important to us is the relationship which frequently exists between the direction of the dip and strike of inclined strata and that of the masterjoints. One set usually runs parallel to the line of strike, the other in the direction of dip, the former being termed strike-joints and the latter dip-joints. Of these the strike-joints are usually more important than those parallel to the dip; also the planes of the strike-joints in inclined strata will in most cases be approximately at right angles to the planes of the strata. Thus if the strata dip at $30^{\circ}$ to the east the strike-joints may slope downwards towards the west at an angle of $60^{\circ}$.

(c) Fault-planes.-The existence of strata thrown into folds proves that in the circumstances in which the rocks were folded they had lost much of the rigidity which they normally possess; but, nevertheless, in many cases movement of the strata has occurred in a way which prevented the rocks from being accommodated to the new conditions by folding only, and they have become fractured, and the relative position of the rocks on the two sides of the fracture has been altered, the rocks on one side having been carried up or down relatively to those on the other side of the plane of fracture, giving rise to what is known as a fault, as illustrated in section in Fig. 2, where the portion of the stratum $c$ on the right of the section, which was once con- 


\section{I8 SCIENTIFIC STUDY OF SCENERY}

tinuous with $c$ on the left, has been thrown down, ${ }^{1}$ so that it now abuts against another bed. The fissure $X Y$ is an actual plane of discontinuity, comparable with a joint-plane, and indeed it is a joint-plane, along which differential movement of the rocks has occurred. Accordingly we often find one set of important faults which have a trend parallel to the strike of the strata and another set at right angles; these are strike-faults and dipfaults. To the student of scenery faults are of

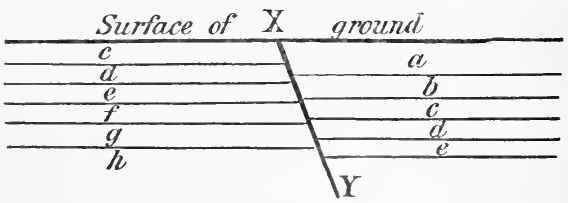

FIG. 2 .

importance chiefly because they frequently cause rocks of different degrees of durability to exist in apposition.

(d) Cleavage-planes.-When rocks have been subjected to intense lateral compression the particles of the rock become flattened in the direction of pressure and elongated in a direction at right angles to this, and the rock has a tendency to split into thin plates at right angles to the direction in which the pressure was applied. Rocks which possess this property are known as slates, and the planes along which fission occurs are cleavage-planes. As these

1 The side of the fault where the strata are relatively lower is termed the downthrow side, the opposite being the upthrow side. These terms are used for convenience, withont assuming that one side has been actually pushed downwards and the other upwards. 
planes are frequently parallel over wide regions and often highly inclined to the horizon, cleaved rocks are very prone to become affected by the agents of disintegration, whose operations will be subsequently considered, and a country occupied by slaty rocks often exhibits characteristic scenic features.

(e) Foliation-planes. - Many metamorphic rocks consist of felted masses of crystals, whose longer axes lie parallel, and the rocks exhibit a fissile structure, the planes of fissility being also parallel to the direction of the longer axes of the crystals. These rocks are termed schists, and the planes of fissility are spoken of as foliation-planes. There is no doubt that these rocks are closely related to slates, which also frequently exhibit a crystalline structure, and we find every gradation from slate to schist. In some cases the foliation-planes were originally stratification-planes, and in others planes of cleavage. Consequently the planes of discontinuity in schists are comparable with other planes, and the rocks are here placed in a separate class chiefly on account of their characteristic texture, owing to the parallelism of the more or less coarsely crystalline components.

It will be seen that the distinctions above given enable the rocks to be separated into classes closely comparable with those adopted by Ruskin. The igneous rocks largely contain his massive crystallines, the foliated rocks his slaty crystallines, the cleaved rocks his slaty coherents, and the ordinary stratified rocks his compact coherents. 


\section{CHAPTER III.}

\section{PRODUCTION OF DOMINANT FORMS}

THE changes which produce the characteristic 1 forms in sky, sea, and surface of the solid land are strictly comparable upon broad lines, and may be separated into three divisions, namely, accumulation, elevation and depression, and sculpture.

Accumulation is concerned with bringing together of the material which will subsequently be moulded into the various forms which delight the eye, whether of cloud, terrestrial water-surface, or dry land, and in each case the effect of accumulation is to give rise to comparatively level surfaces, which, in the absence of other change, would present a monotonous aspect. Commencing with the atmosphere, we find that it is divisible into layers whose surfaces are approximately parallel with the earth's surface, each layer, under conditions of equilibrium, having a temperature differing from that of the layers above and beneath, and accordingly capable of retaining a different amount of aqueous vapour. When this aqueous vapour condenses, it tends to accumulate in level layers, if the barometric and other conditions are uniform over wide spaces, and accordingly we have an accumulation of cloud with a flat upper surface. Turning to the hydrosphere, as water tends to seek 


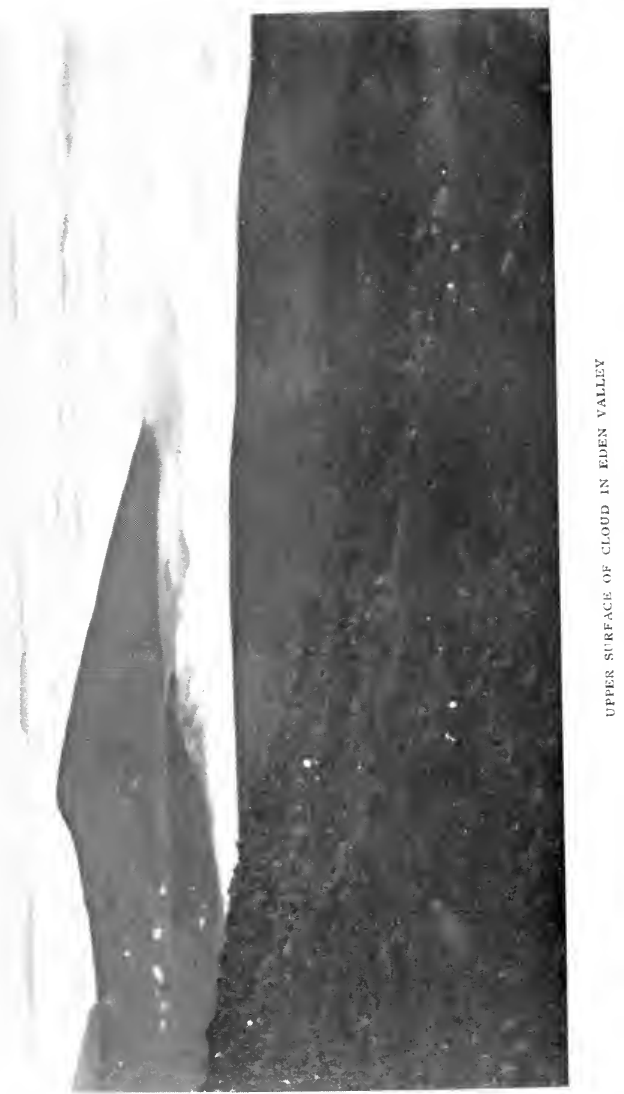


its own level, the sheets of water when at rest have also a flat upper surface. This flatness in the case of the lithosphere is caused by the accumulation of stratified rocks in horizontal layers, so that if the ocean, which is the great receptacle of sediment, continuously received deposit, and no other change took place, it would eventually be silted up, and converted into a level plane, whose surface would coincide with that of the present ocean surface, though, apart from this complete silting up, a flat surface is produced beneath the ocean-top by the level deposit of material.

Elevation and depression modify these monotonous surfaces, diversifying them by the production of dome and basin or ridge and trough, the former being usually more local than the latter. The ridge and trough structure is due to the formation of a series of waves, and air-waves, water-waves, and earth-waves are comparable with one another, though produced by different causes, which in each case bring about differential movement of horizontal surfaces in contact with one another. One layer of air moving over another throws the lower one into waves, which are often defined by the condensed aqueous vapour in the lower layer; air moving over water similarly throws the water into waves; and, lastly, differential movement of different layers of the earth's crust causes the rocks to be thrown into waves, which are often defined by the superficial contour of the ground, as well as by the folding of the planes of stratification. The identity of appearance of these waves is illustrated by the plate showing clouds in the Eden Valley, and Fig. 3 showing earth-waves in the Jura. The plate shows 
the upper surface of a fog, with waves produced by a light breeze. It was taken on a calm day in January, by Mr. E. J. Garwood, from the slopes of the Crossfell range, overlooking the Eden Valley in Westmorland. Fig. 3, reproduced from The Limestone Alps of Savoy, by kind permission of the author, Mr. W. G. Collingwood, is a bird's-eye view of part of the Jura mountains and the Alps of Savoy, near Geneva, and admirably illustrates the wave-like character of these mountain ranges. The similarity between the cloud-waves, earth-waves, and ordinary water-waves is rendered perfectly clear by these illustrations. Dome-structure may be produced in fluid as well as in solid media-witness the cumulus cloud, the geyser, and the laccolite-but the wave-structure is sufficient for purposes of illustration. As the result of this change the flat surfaces produced by accumulation are converted into surfaces presenting alternate convex ridges and concave hollows.

Further diversity is produced by the agents of sculpture. We need only mention in passing the effects of these agents upon air and water-waves, but must devote some consideration to the changes which are brought about by them upon the earth-waves.

The undulating clouds produced owing to differential movements are sculptured by winds and by differences of temperature. The wind breaks the masses of condensed vapour into fantastic forms, and a somewhat similar result is produced by the evaporation of a fragment of cloud here and the condensation of a portion of vapour there. The ocean waves are broken up by wind, ultimately producing the storm-wrack and spin-drift of the tempest-tossed sea. 


\section{PRODUCTION OF DOMINANT FORMS 23}

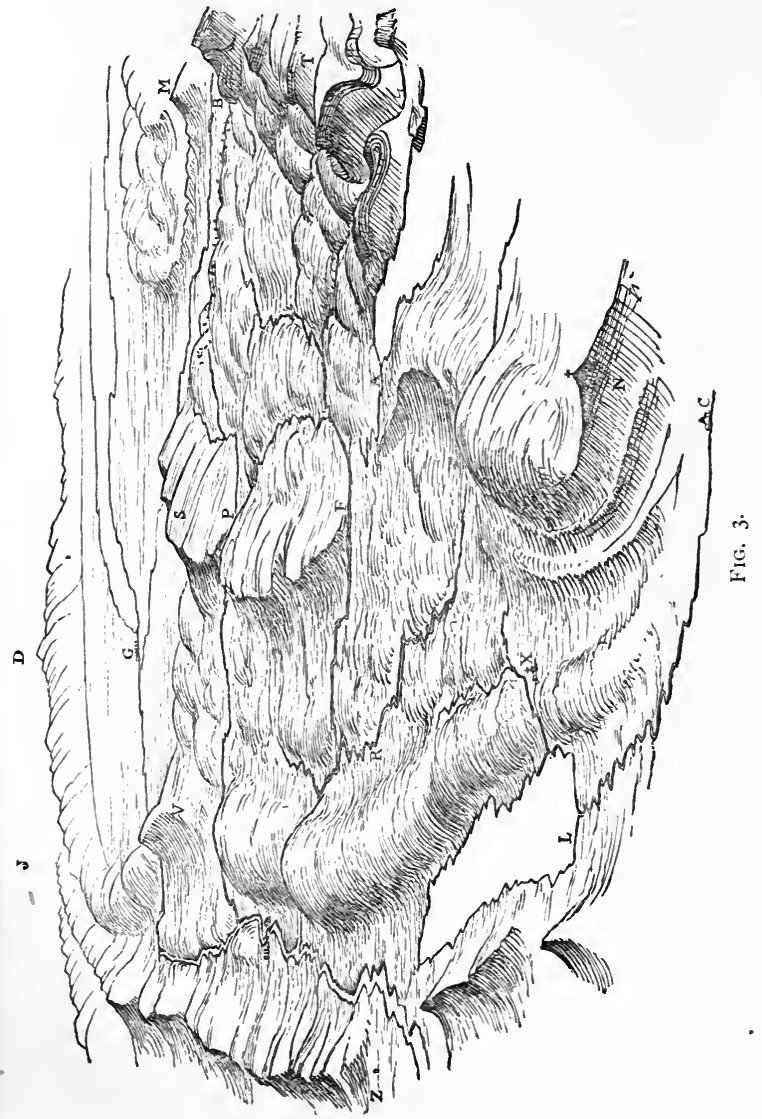




\section{SCIENTIFIC STUDY OF SCENERY}

Similarly the earth-waves are carved out by the graving-tools of nature, and the effects are generally similar to those produced on ocean-waves by the wind. Indeed, all writers upon mountain scenery have been led to compare the serried ranks of hills with the broken billows of a stormy sea. Let me quote an instance: "Suppose the sea waves exalted to nearly a thousand times their normal height, crest them with foam, and fancy yourself upon the most commanding crest, with the sunlight from a deep blue heaven illuminating such a scene, and you will have some idea of the form under which the Alps present themselves from the summit of the Weisshorn. East, west, north, and south, rose those 'billows of a granite sea,' back to the distant heaven, which they hacked into an indented shore."1

The scenery of the earth's crust is mainly dependent upon three things, namely, the structure of the crust, the nature of the sculpturing agent or agents, and the character of the climate. The processes of sculpture are known to geologists by the name of denudation. Denudation is the stripping of portions of rock from one place and their removal to another, and is performed by agents which are generally familiar to all. Among these agents may be mentioned change of temperature, wind, rain, frost, rivers, sea waves, and action of organisms, for the most part assisted by gravitation, as the result of which the material is carried from a higher to a lower level, and ultimately to the sea, if not checked. Thus the land is the great theatre of destruction by denuding agencies, and the ocean the great receptacle of the sediment produced by these agencies.

1 Tyxdall, Mountaineering in 1861 , chap. vi. 
Iet us take our stand at the foot of some mountain cliff on a winter day. The stillness of the frosty air is ever and anon broken by the fall of a fragment of rock from the cliff on to the slope beneath. This fragment has commenced its journey seaward. The spring freshet, generated by the melting of the snow, may wash one fragment into the mountain burn, there to be dashed against many a similar fragment, knocking off its asperities, and rounding it, while the broken portions are worn into particles of sand and dust. If we take up a position on some bridge in the lower reaches of the river during a heavy flood, we shall find the swollen waters turbid with the sediment produced by the breakage of the rocks above, and following the river still further to its junction with the ocean, may notice the sand banks and mud flats accumulating by the deposition of the sediment where the current of the river is checked upon entering the sea. Our rock-fragment and many another have now found rest until disturbed by other changes. If we travel far from our own country to the arid deserts of sub-tropical regions or the ice-bound hills of the arctic tracts, we shall notice that the agents are in some ways different, but the ultimate effects the same. The materials composing the crust are constantly being broken up, and carried from a higher to a lower level, where they are spread out to form fresh deposits. The agents, I say, are in some ways different, and here the effects of climate are noticed. Nature works in the wet way and in the dry way, to borrow an expression from the chemist, and where she carries out the processes of denudation in the wet way, in regions subjected to considerable rainfall, the scenic results differ in kind 


\section{6 SCIENTIFIC STUDY OF SCENERY}

from those characteristic of deserts and arctic lands, where much of the work is performed in the dry way.

The agents of denudation are at work over all parts of the earth's surface above sea level, though their effects are more marked in some places than in others. In one place rain is the principal agent, in another frost, in a third the brook or river, and accordingly one part of the surface is more worn than another, and the monotony of the wave-curve is broken by the removal of less material from one place than from an adjoining one. But the difference between the aspect of two places is further emphasised by the difference of structure. One rock is more durable than another, and resists the work of denudation to a greater extent. Some rocks are harder than others, and tend to stand out after denudation has been in operation for some time. Some are soluble, others practically insoluble, and in this case the insoluble rock will tend to form eminences, the soluble depressions. One rock may be separated into numerous blocks by planes of lamination, joints, and cleavage-planes, another may possess fewer divisional planes, and the former will be more easily worn away than the latter.

Again, though some agent of denudation is at work on all parts of the earth's surface, the amount of material which accumulates may be greater than that which is removed, and the character of the surface on which accumulation takes place will differ according to the nature of the accumulation. The talus slope at the base of the cliff, the alluvial flat by the riverside, the sand-dune on the sea-shore, the cone of the volcanic vent, are caused by excess of 
accumulation over material removed by denudation. Each has its own character, and tends to diversify the earth's surface.

We shall further find that differential movements of portions of the earth's surface produce their effects upon scenery over and above the development of the earth-waves. The earthquake shock tilts up parts of the earth and depresses others, producing fault-cliffs, landslips, and often damming back the waters of rivers, causing lakes. A similar ponding back of waters is produced by slower movements, which occur so gradually that we are not aware of them except by their effects.

As the results of accumulation here, of denudation there, of difference of climate in different places, of difference of rock-structure, of variations in the nature and energy of the denuding agents, of differences in the nature and amount of the materials which are accumulated, and, lastly, of the operation of earth-movements, we are presented with those diversified features of our earth's surface which it is our present object to study in detail. Here we meet with mountain chains, there with rivers meandering through their valleys; in one place is the desertfloor, in another the fenland flat. Anon we stand by the sparkling mountain tarn; again we wander along the salty borders of the inland sea. At one portion of the river-course we find the stream foaming amid boulders, or hurled boldly over the precipice, at another winding sluggishly through oozy swamps. At one time we may be standing above the seething cauldron of the volcanic vent, at another watching the apparently motionless sweep of the glacier. The eye may be gladdened by the 
vivid carpet of Alpine flowers or saddened by the monotonous hue of the desert scrub. We may gaze at the vivid colouring of the striped rocks of the American gorge or the white glint of the chalk cliffs of Albion, at the turbid waters of the Yellow Sea or the azure hue of the Alpine tarn. Over all is the ever-changing sky, with the clouds hurrying past, driven by the tempest, or wreathing languidly around the mountain-peak. Happy is the man who takes heed of these things, and pleasurable are the emotions which are excited by inquiry into the causes which have produced them! And lives there one who, communing thus with Nature, and admitted to some of her secrets, is not led to ponder with reverence upon the First Great Cause? 


\section{CHAPTER IV.}

\section{THE ATMOSPHERE}

THE atmosphere is a gaseous envelope, consisting I of a mechanical mixture of various substances surrounding the lithosphere and hydrosphere, and extending outwards to an unknown distance (probably not less than 200 miles) from the surface of the lithosphere. As is well known, it consists essentially of a mixture of about seventy-nine parts of nitrogen and twenty-one of oxygen; of these oxygen is by far the more important constituent; of the other components which are important with reference to our present inquiries may be mentioned aqueous vapour and carbon dioxide (carbonic acid gas), while the solid particles which are derived from the lithosphere and float in the air are also of importance.

Colours in the Sky.-The prevalent blue colour in the clear sky is produced in a way which is still a topic for discussion among physicists, and it would require a fuller acquaintance with physical principles than can be assumed here in order to present the reader with an intelligible idea of the suggestions which have been made to account for this blue colour. Lord Rayleigh many years ago suggested that the colour was due to the occurrence of solid 


\section{0 SCIENTIFIC STUDY OF SCENERY}

particles in the air. It is generally known that a ray of white light when passed through a prism is broken up into a number of coloured rays, the solar spectrum, varying from violet to red. The length of the waves of different coloured light varies, the waves of the red light being longest, those of the violet shortest. Now, just as a post standing in the water will stop and reflect the small waves and let the larger ones pass by, so the short waves may be stopped by particles which allow the larger ones to pass, and the short ones are reflected to the observer, and are visible to him as blue; as a result of this the sky appears blue. Recent experiments by Professor Dewar, however, show that the colour of pure oxygen is blue, and the colour of the air may be simply that of one of its most important constituents.

Whatever be the cause of the blue colour, the yellow and red colours seen at sunset are generally recognised as due to the obstruction of the rays of small wave-length. In this case the colour seen is due to transmitted, and not to reflected, light; hence it is the rays of greater wave-length, which are not obstructed by the particles, which appear to the observer. As the obstructing particles are found in greater abundance in the lower strata of the atmosphere, the effect of the obstruction is emphasised as the sun sinks lower, and the violet and blue colours are replaced by yellow and orange, and finally by red. ${ }^{1}$

${ }^{7}$ The rose-coloured glow seen on the higher Alps when the sun is below the horizon depends partly upon the above conditions, which are further complicated. The reader will find an explanation of the rosy glow given by Mr. J. Ball in a note appended to chap. vii. of Peaks, Passes, and Glaciers. 
Any occurrence which causes the existence of an abnormal number of the obstructing particles in the atmosphere will intensify the character of the sunset colours. Readers will recollect the remarkable sunset glows which were visible in our country as well as in others during the winter and spring following the violent outbreak of the volcanoes of Krakatoa in I883. There is evidence that the wave of air produced by the eruption travelled more than three times round the earth, and that fine dust from the volcano was carried with it, and there is good reason for supposing that the vivid sunset effects referred to above were produced as the result of the existence of this dust in the atmosphere. ${ }^{1}$

Nature and Forms of Clouds.-The importance of the presence of aqueous vapour in the atmosphere has already been noted. Different portions of the atmosphere contain varying proportions of aqueous vapour, the usual proportion being about I'5 per cent., and this when condensed forms cloud. It is evident that the atmosphere cannot contain an unlimited quantity of the vapour, and when it holds as much as it can carry without any portion being condensed it is said to be saturated.

It is also known that air when at a high temperature can hold more vapour than when at a lower one; hence condensation does not always take place at the same temperature: in other words, the dewpoint, or temperature at which condensation occurs, varies with the amount of aqueous vapour in the air. The condensation of the vapour gives rise to numerous droplets of water which compose clouds;

${ }^{1}$ See Royal Society Report on Krakatoa, 1888. 


\section{2 SCIENTIFIC STUDY OF SCENERY}

these when at a low level are termed fogs or mists. ${ }^{1}$

There are various ways in which the chilling of the atmosphere, which brings about condensation, may be effected, as (i) radiation; (ii) ascent of moisture-laden air into higher and therefore colder regions of the atmosphere; (iii) contact of moistureladen air with a cold body as the solid ground; and (iv) admixture of masses of cold and hot air.

The form of clouds depends to a large extent upon movements of the atmosphere, which are in turn due to differences of barometric pressure. The way in which these movements are set up will be referred to anon. But though winds produce marked effects upon the clouds, their primary shape depends upon movements which take place so slowly that they would hardly be termed winds, and these movements take place vertically as well as horizontally, the shapes of some clouds being largely due to vertical movements, those of others to movements in a horizontal direction, while others again are produced by a combination of the two sets of movements.

Clouds may be classified according to their shapes, or according to their modes of origin, but as the former is largely dependent upon the latter, the two classifications are similar. Nevertheless, there is still murh diversity of opinion as to the classification to be adopted. Clouds were originally classified by Mr. L. Howard in $1803 .^{2}$ He defined three primary types

1 Mr. J. Aitken (Trans. Roy. Soc., Edin., vol. xxx., p. 337) maintains that the presence of foreign bodies as particles of dust in the atmosphere is necessary to the production of condensation. This necessity has been questioned.

2 HowARD, L., Essay on the Modifications of Clouds. 
of cloud, namely cirrus, cumulus, and stratus, and four compound types formed by combinations of these : cirro-cumulus, cirro-stratus, cumulo-stratus, and nimbus; the last is a term applied to any cloud from which rain is falling, and can hardly be included among the other types, and accordingly we are left with three primary and three secondary types. ${ }^{1}$

According to their origin, Mr. Clement Ley classifies clouds as clouds of radiation, including some kinds of fog, clouds of inversion, as cumulus, clouds of interfret, as stratus, and clouds of inclination, as cirrus, and it will be most convenient to adopt this classification when considering the principal types of cloud.

(i) Clouds of Radiation.-The ground becomes cooled by radiation of heat into space, and when cooled below dew-point the air in immediate contact with the ground deposits its moisture as dew, but the air above this, containing solid particles, is also chilled, and the solid particles themselves become cooled by radiation. Accordingly moisture is deposited on the solid particles, giving rise to one form of fog. This may be complicated when low ground is surrounded by higher ground by intermixture of cold, vapour-charged air from the higher ground with that which immediately overlies the low country. The fog whose upper surface is seen in the plate showing clouds in the Eden Valley was of this composite character. Fogs due to radiation have

1 The reader will find an account of cloud-shapes and cloud-formation in Elementary Meteorology, by R. H. ScoTT, F.R.S. (International Scientific Series); in Cloudland, by the Rev. W. Clement Ley (Stanford, 1894); and in a paper by A. F. OsLer, "On the Normal Forms of Clouds," Report of the British Association for 1886 (Birmingham), p. 530. From these works the account of clouds given here is largely taken. 


\section{SCIENTIFIC STUDY OF SCENERY}

been termed "radiation fogs" by Herschel, to distinguish them from other fogs, which present affinities to other classes of cloud, for "clouds . . . are really nothing else but fog or mist, and the most solidlooking night-cap on a hill-top is found by those who are enveloped in it to be neither more nor less than a driving mist." 1

(ii) Clouds of Inversion.-These clouds are due to an upward movement of a portion of the atmosphere, which tends to produce interchange of air between lower and higher atmospheric strata. The upward movement is due to a mass of air in a lower stratum being rendered lighter than it was previously, either owing to its becoming charged with vapour, thus diminishing its specific gravity, or on account of its expansion when heated by the rays of the sun. As the rising column of air reaches higher altitudes, it becomes chilled, and some of the vapour is condensed, forming cloud, the base of which may be level. The process of condensation liberates heat, which causes further rise and condensation, until the upper part of the column becomes chilled below the temperature of the surrounding air, and a downward movement takes place at the top. In this way, speaking briefly, are formed cumulus clouds, which have not inaptly been compared by Tyndall to the steam escaping from the funnel of a locomotive. The friction of the particles of the minute droplets is sufficient to prevent them from falling when raised to the required height. ${ }^{2}$ These cumulus clouds are, in our country, essentially clouds of summer, and also clouds of the day-time.

1 Scotr, R. H. op. cit., p. 123.

2 For further account of formation of cumulus, see LEY, Cloudland, chap. i. and Fig. I. 
(iii) Clouds of Interfret are due to the existence of two successive strata of atr moving in different directions, or moving in the same direction, but with different velocities. A certain amount of intermixture will take place about the plane of junction, and if condensation occur, straight sheets of cloud-stratus -will be formed. As has already been seen, a series of waves will be developed on the bounding plane, as the result of movement, which may give rise to various complications. If the upper stratum, as is usually the case, is the colder, the wave-crests of the lower stratum will be at a higher level than the troughs, and therefore the air of the wave-crests colder than the air of the troughs. Accordingly condensation may occur on the wave-crests, and not in the troughs, thus giving rise to detached clouds, which, if the waves are linear, will run in parallel lines, while, if the waves are complicated, the clouds may be "cut up into small waves, ripples, and vortices like a 'choppy sea.' In this... case we have innumerable patches and flecks of cloud so often seen in fairly quiet weather in summer." 1 The wavy surface of the fog seen in the plate showing the upper surface of cloud in the Eden Valley is due to the movement of an upper stratum over a lower one, the latter in this case being the cooler, but here the waves are due to mechanical disturbance of air in which the vapour has already been condensed. Condensation in the crests of complex waves is undoubtedly the cause of one form of the cloud-group which is somewhat loosely spoken of as "mackerel-sky," and this particular form is termed stratus maculosus by Mr. Ley, though some writers upon clouds have ${ }^{1}$ LeY, C., op. cit., p. I3. 


\section{SCIENTIFIC STUDY OF SCENERY}

called the mackerel-sky cirro-cumulus. There is, however, another way in which a stratiform mass of vapour may be cut up into detached portions, as described by Mr. Osler, by a combination of lateral and vertical movements. Suppose that a sheet of stratus-cloud, produced by differential horizontal movement of adjacent strata, is bodily elevated as a result of vertical movement, greatest at one point, and dying out laterally; the original flat mass will take a gentle curved form, and will therefore occupy more superficial area than before, and the cloud will be ruptured in the same way as a pane of glass when struck by a stone. As Mr. Osler remarks, it "will be rent into fragments or small groups, and thus produce what is called a 'mackerel-sky,' just as a similar result is produced, but by the reverse action, in mud that has dried up and shrunk into small patches while the damp earth beneath remains expanded by the moisture it still contains."

As the result of vertical movement followed by horizontal movement, cumulus cloud, as noted by Mr. Osler, may be converted into a stratiform cloud, cumulo-stratus. "The friction of the earth from the irregularities of its surface, and the denser state of the lower air, causing it to flow less rapidly than that which is higher and more attenuated, the upper portion of a cloud moves more rapidly than the lower, and the cumulus shears over into a slanting position, and finally assumes the form of the cumulostratus, and, however reduced in depth or thickness the cloud may become by this flattening and somewhat attenuating process, the cumulus character, though much diminished, is seldom, if ever, entirely 
obliterated." The writer aptly illustrates this by reference to the flat brown cloud of smoke from a passing steamer, which came from the funnel in great rounded masses. We may sometimes observe one set of clouds having a linear arrangement perpendicular to the direction in which the wind is blowing, while another set has a linear arrangement parallel to this direction. When the wind is slight, cloud waves are developed at right angles to the direction in which the wind is blowing. With a strong wind, we often notice bars of stratiform cloud running parallel to the wind's direction, and if the wind be strong near the earth's surface and gentler above, two sets of stratiform clouds may occur at the same time, the upper with lines at right angles to the wind's direction and the lower arranged in lines parallel to it.

The cloud-banner, which is often observed on the lee-side of a mountain, is a particular form of stratus, condensation only taking place in the upper, fastermoving stratum when it is chilled below dew-point by contact with the cold surface of the mountain. As is well known, though the cloud is often stationary, it is constantly changing its substance, fresh vapour being condensed against the mountain as the previously condensed vapour becomes evaporated some distance on the lee-side of the mountain.

(iv) Clouds of Inclination.-The principal clouds of inclination are cirrus, which are formed high above the earth's surface. In the rarefied atmosphere at these heights, when water vapour is condensed into cloud, it can fall, owing to its weight, to lower parts of the atmosphere, and if these are moving more slowly than the upper layers, as will probably be the 


\section{8 \\ SCIENTIFIC STUDY OF SCENERY}

case, the upper part of the cloud moves faster than the lower, which lags behind, thus giving rise to the characteristic curved form of the cirrus or curl-cloud. As the condensed vapour falls still lower it gets to a stratum in which the air is sufficiently warm to allow of the re-evaporation of the condensed matter, and thus the cloud probably ends in a point. It is known, from observation of the characters of haloes and mock-suns, that these elevated clouds of inclination are often formed of spicules of ice, and not of drops of water.

There is general agreement as to the mode of origin of the primary types of clouds, but enough has been said to show that the various processes which form and shape the clouds may act in combination, and when we add to this the modifications which are produced by winds, changes of temperature, and other minor causes, after the clouds have once been formed, we need not be astonished at the infinite variety presented by cloud outlines, which, while rendering the sky a subject for profound contemplation and reverence by the lover of scenery, causes the student of cloud-classification to experience a feeling of bewilderment when he is confronted with the great differences in the nomenclature adopted by different writers in their treatment of secondary and complex cloud-types.

Distribution of Clouds.-It has already been noted that certain clouds occur at some times and seasons more than at others; in other words, clouds have a diurnal as well as an annual distribution; but, besides this distribution in time, we have a distribution in space, both horizontal and vertical. With regard to the vertical distribution, it is easily seen that clouds 
of different types do not exist at the same height; many of us have been in or above stratus or even secondary types of cumulus, and still found cirrus far above us. The following may be taken as the average heights for the primary types of cloud :-

Stratus

Cumulus

Cirrus
3000 to 20,000 feet.

$$
\text { - } 4000 \text { to } 10,000 \text {," }
$$$$
\text { - } 25,000 \text { to } 30,000 \text {, }
$$

The horizontal distribution of different kinds of clouds in space is affected by the time-variations, but over and above this it is specially affected by types of weather, and the connection of different types of clouds with weather variations is a matter of such great importance to us that it is remarkable how little interest is evinced in it by the majority of people. The local shepherd "can discern the face of the sky" and foretell the weather with considerable accuracy as the result of close observation of the changes in the heavens, but comparatively few people are weatherwise owing to their knowledge of these changes, and most of us base our prognostications on the changes of the barometer, and are apt to speak lightly of the weather reports in our daily papers, though these are drawn up as the result of barometric observations over wide areas in addition to numerous observations on the character of the sky in these areas. We read that "a cyclone is approaching our shores," and if we give more thought to it, we are probably satisfied with a further statement that "showery weather may be experienced in our northern and north-western counties," and may give no heed to the glorious changes in the canopy of clouds which are likely to 


\section{0 SCIENTIFIC STUDY OF SCENERY}

accompany the passage of this cyclone. Let us briefly consider the probable nature of these changes. It will be necessary at the outset to say something about cyclones.

The atmosphere is heated by the sun, but it is transparent to the direct rays of the sun, and receives its heat from the dark rays given off by the earth's surface. Accordingly the lower strata of the earth become most heated, and the temperature falls as one passes from sea-level to higher altitudes. Now, heated air expands, and a given bulk becomes lighter when heated, on account of this expansion, and also because hot air can hold more water vapour than cold, and the water vapour is lighter than the air which it displaces. The lighter heated air tends to rise, and accordingly, if one spot in the earth's surface is heated more than the surrounding area, the air above the spot rises, and the column of air above that spot is higher than those above the surrounding places, and the top of this elevated column will flow out at the top of the atmosphere in order to restore equilibrium, just as water will flow from one vessel to another when the surface of the water is at a different level in the two vessels if the barrier between them be removed. As a result of this, the columns of air around the column which rose owing to expansion will contain more air than they did originally, and these columns will therefore press on the earth's surface with force greater than that exerted before the disturbance of equilibrium. We have, in fact, a point of low barometric pressure, surrounded by a ring or area of high barometric pressure. This system is not yet in equilibrium, and equilibrium is restored by the movement of 
air from the ring of high pressure to the point of low pressure just above the surface of the earth. Air, then, tends to flow upwards and outwards in the higher regions of the atmosphere from areas of low pressure to areas of high pressure, and to flow downwards and inwards in the strata immediately overlying the earth's surface from areas of high pressure to areas of low pressure. It is the latter movements which specially concern us.

If the earth were stationary, the movements would be in straight lines, but, owing to the earth's rotation, the movements are really spiral. The earth is rotating on its axis from west to east, and the air is carried round with it. Thus a point on the equator performs a journey of about 24,000 miles per diem, and the same is the case with a particle of air just above it, while a point at the poles is stationary, and points situated between pole and equator perform a longer or shorter journey according to their nearness to, or remoteness from, the equator. Now, a particle of air moving in a northerly or southerly direction retains for some time the initial velocity which it possessed owing to the movement of rotation. Suppose a particle of air in the northern hemisphere to be travelling from north to south; it proceeds from a place with relatively small velocity to one with greater, and accordingly appears to lag behind, and, instead of reaching a point due south of its startingpoint will, reach one south-westward of it. Again, a particle in the same hemisphere travelling from south to north starts with considerable velocity, communicated by the earth's rotation, and travels to a point where the velocity of a point on the earth is less than its own; so it appears to advance instead of 


\section{SCIENTIFIC STUDY OF SCENERY}

lagging behind, and, instead of reaching a point due north of its starting-point, will reach one to the northeastward. In each case the wind is deflected to the right of its direct course, and this is so with all winds in the northern hemisphere, except those blowing due east or due west. It will be found that in the southern hemisphere the winds are similarly deflected, but to the left of their direct course. In the case of a point of low pressure surrounded by a ring of high
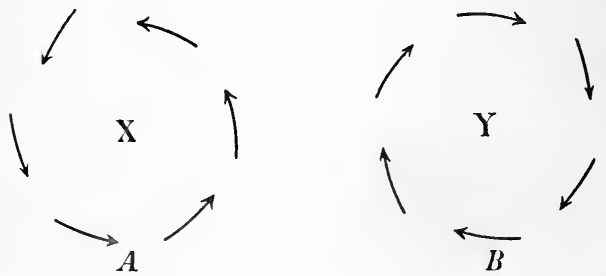

Fig. 4.

A. Cyclone. X. Low-pressure point.

B. Anti-cyclone. Y. High-pressure point.

Arrows show direction of wind.

pressure area the winds to the north of the point are deflected westward, those to the south of it eastward, and air does not flow in directly to the point of low pressure from all surrounding points, but flows in spirally in a direction contrary to the direction of movement of the hands of a watch in the northern hemisphere. Such a system is called a cyclone (Fig. $4 A$ ).

A cyclone, then, is a system of winds blowing in spirally downwards towards a low pressure area from a surrounding area of high pressure, and the 
winds move in a direction contrary to the hands of a watch in the northern hemisphere, and in the direction of the hands in the southern hemisphere.

Conversely an anti-cyclone (Fig. $4 B$ ) is a system of winds blowing spirally upwards to a high pressure area from a surrounding area of low pressure, and in this case the winds move in the direction of the hands of a watch in the northern hemisphere, and in the contrary direction in the southern hemisphere.

The velocity of the winds of a cyclonic system is generally much greater than that of the winds of an anti-cyclonic system, and accordingly cyclones are often accompanied by gales and storms, anti-cyclones by calm.

The centre of a wind system is not usually stationary for any length of time, but has itself a more or less definite path, which, in the case of our islands, is usually in a north-easterly direction along a line running south-west and north-east; hence we so frequently read of cyclones approaching our shores from the Atlantic.

The shape of the system may be circular, or may be elliptical. In the latter case, when the longer axis of the ellipse is a considerable multiple of the shorter diameter, only one side of the ellipse is likely to occur over our islands at once; this forms a figure in the shape of a V, and accordingly we speak of the half of an elongated cyclone as a $V$-shaped depression, while that of an elongated anti-cyclone is known as a col, or ridge between two $\mathrm{V}$-shaped depressions.

Now the type of cloud over our islands and elsewhere is largely dependent upon the nature of the wind system which affects the areas. 


\section{SCIENTIFIC STUDY OF SCENERY}

An anti-cyclone is usually marked by quiet weather; the long periods of dry weather in summer, the prolonged fogs of autumn, and frosts of winter occur during the prevalence of anti-cyclonic conditions. Clear skies or fogs are frequent accompaniments, or, if the sky be cloudy, we find a haze and belts of stratus, with cirrus in the higher regions. Anti-cyclonic conditions are by no means always conducive to fine scenic effects, and in mountain regions especially the hills are apt to be obscured by haze for days together, and the colouring is frequently monotonous.

When a cyclone passes, there is often a definite relationship between the different portions of the cyclone and the nature of the cloud. In front of an advancing cyclone, gossamer-like threads of the secondary cloud of inclination known as cirro-filum are seen, followed by a thicker mass of veil-like cirrovelum. This is followed by the nimbus or complex mass of cloud, from which rain is discharged. The centre of the cyclone is marked by alternate patches of blue sky and broken clouds. In the rear of the cyclone cumulus is abundant, especially on the south side of the system, with stratus on the north side; and, lastly, we have bands of cirrus and its secondary, cirro-macula. ${ }^{1}$

Thunderstorms occur when an area is occupied by a low-pressure system, though the system is not always of the same nature. Most of our summer thunderstorms are accompaniments of small, shallow depressions (that is, depressions where the pressure in the centre is not very different from the pressures around), while other thunderstorms occur along the

${ }^{1}$ See diagram, LEy, C., Cloudland, Plate VI., facing p. 176. 


\section{THE ATMOSPHERE}

edges of deep, cyclonic disturbances, and may occur at all seasons. ${ }^{1}$

${ }_{1}$ Besides electrical phenomena, there are various optical phenomena, as rainbows, mock-suns, haloes, which are of interest to the student of scenery, but, on account of their comparative rarity, it is unnecessary to treat of them in a work like the present. The reader will find an account of them in Mr. R. H. Scott's Elementary Meteorology, chaps. $x$. and $\mathrm{xi}$. 


\section{CHAPTER V.}

\section{MAIN FEATURES OF CONTINENTS AND OCEAN BASINS}

$\mathrm{T}$ is generally recognised that the land surfaces 1 of the globe are essentially areas of denudation or destruction of rock, and the ocean basins, regions of reception and deposition of sediment, in other words that rock-strata are on the whole manufactured in the oceans, destroyed on the dry land. The oceanic origin of the major portion of the strata which now form our land surfaces is amply proved by the general occurrence of the remains of marine organisms within them, and the comparative rarity of terrestrial or fresh-water organisms. We have thus indisputable proofs that our land masses have not always existed as dry land, but that large tracts of them have been submerged beneath the ocean waters. Proofs are also forthcoming, though they are naturally not so patent, that tracts of present ocean-floor once existed as dry land, but as the student of scenery is not directly concerned with the aspect of the oceanfloor, it is unnecessary to enter into this matter at length.

Admitting that extensive tracts of dry land have been submerged, it is necessary to account for their emergence, which may be brought about in two ways : either by movement of the water, or upheaval 
of the outer part of the lithosphere above water-level. Our first thought would naturally be that the level of the mobile ocean rather than that of the apparently stable earth-crust would be changed in order to produce the land masses, but a number of facts prove that it is the land which has risen above the ocean level, and not the latter which has changed. Prominent among these, and sufficient for our purpose, is the fact that the strata, originally laid down in horizontal sheets, are now found inclined at various angles, sometimes vertical, or even overturned, and as these strata compose the lithosphere, the statement that the strata have been moved is the same as the statement that the lithosphere has been moved. The cause, or rather causes, of this movement do not directly concern us in our present inquiry, and there is a considerable amount of uncertainty on the subject in the minds of geologists, though the contraction of the earth's crust is generally considered to be the most important factor in producing earth movement. The earth is hotter inside than outside. Now a cooling body contracts more when suffering the loss of a given amount of heat if it be at a high temperature than if at a lower one; accordingly the hot interior of the earth would contract more than the cooler exterior, and tend to shrink away from it, but the weight of the exterior would prevent the formation of a space, and the exterior would settle down in wrinkles, just as an apple wrinkles owing to the loss of more moisture from the interior than from the rind. Whether this be the true explanation or not, inspection of the earth's crust shows that it has been wrinkled into a wavy surface, very like the surface of an ocean 


\section{SCIENTIFIC STUDY OF SCENERY}

ruffled by the wind. In places we find evidence of alternate ridges and troughs; in other places, where the movements have been complicated, the earth is like an ocean surface affected by a choppy sea, two or more sets of movements having occurred at different angles, and just as the major waves of the sea are often accompanied by minor ripples on their surfaces, so we find minor folds of the earth's crust superposed upon the larger ones. Every earth-wave may be looked upon as composed of two parts, a trough and an arch, with a septum common to the two, and as in the case of the seawave, so with the earth-wave, there is a tendency for the slope of the septum to be steeper than that of the other portions of the wave, as shown in Fig. 5 .

In this case the wave system as a whole has moved in the direction indicated by the arrow. Now a movement of this character, if on a sufficiently large scale, might give rise to an ocean basin in the trough and a continental uplift on the arch, assuming that the crust had previously been exactly at sea-level, and we may briefly inquire if there is any evidence that continents and ocean basins are due to movements of this nature. ${ }^{1}$

It requires little study of geological literature to discover that as a general rule the most elevated parts of continental masses are those in which the strata have undergone most disturbance in comparatively recent geological times; the flat tracts of Russia are composed of horizontal strata, the sloping plateaux of North America of gently inclined strata,

${ }^{1}$ A very suggestive account of the structure of continents and ocean basins will be found in Professor Lapworth's address to section C of the British Association, Rep. Brit. Assoc., Edinburgh, I892, p. 695. 
the craggy summits of the Alpine chains of highly contorted rocks, and further study shows that if we omit the minor complications, and take into account the main features, the contours of the land masses, apart from the modifications produced by denudation, tally with the slopes which would be formed as the result of the various uplifts of which we have independent evidence. The structure of the lithosphere beneath the oceans is, from the facts of the case, hidden, but comparison of the land and

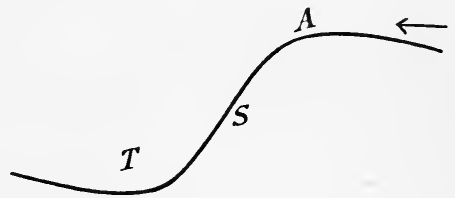

Fig. 5 .

A. Arch. T. Trough. S. Septum.

ocean features shows that one is complementary to the other, as well shown in Professor Lapworth's address, to which reference has just been made :-

"The surface of each of our great continental masses of land resembles that of a long and broad arch-like form, of which we see the simplest type in the New World. The surface of the North American arch is sagged downwards in the middle into a central depression which lies between two long marginal plateaux, and these plateaux are finally crowned by the wrinkled crests which form its two modern mountain systems. The surface of each of our ocean-floors exactly resembles that of a continent turned upside down. Taking the Atlantic as our simplest type, we may say that the surface of an ocean basin resembles that of a mighty trough or syncline, buckled up more or less centrally into a 


\section{0 SCIENTIFIC STUDY OF SCENERY}

medial ridge, which is bounded by two long and deep marginal hollows, in the cores of which still deeper grooves sink to the profoundest depth. This complementary relationship descends even to the minor features of the two. Where the great continental sag sinks below the ocean level we have our gulfs and our Mediterraneans, seen in our type continent as the Mexican Gulf and Hudson Bay. Where the central oceanic buckle attains the water-line we have our oceanic islands, seen in our type ocean as St. Helena and the Azores. Although the apparent crust-waves are neither equal in size nor symmetrical in form, this complementary relationship between them is always discernible. The broad Pacific depression seems to answer to the broad elevation of the Old World, the narrow trough of the Atlantic to the narrow continent of America."

Similar movements on a smaller scale, as will be eventually pointed out, account for our mountain uplifts and valleys of depression, and even the volcanoes which modify portions of the lithosphere owe their geographical distribution to supplementary phenomena connected with the production of these great earth-waves.

If a continent were composed exclusively of stratified rocks, and produced by one uplift of a set of stratified deposits originally laid down horizontally on the sea-floor, and if the uplift were unaccompanied by denudation, the surface of the continent would be completely covered by the uppermost stratum, and the bedding planes separating the strata would lie in curves parallel to the surface of the ground. Study of our continents indicates that they are of a much more complex character, and due to alternate uplifts above and de- 
pressions beneath the ocean level. Each depression will allow of the accumulation of sediment; each uplift raises these sediments to form land, and as that land is always subjected to denuding agents, these sediments will be partially swept from the land, and the edges of the strata will abut against the surface, just as if we curved a number of sheets of paper into an arch, and cut off the top of the arch: the edges of the sheets, which may be taken to represent strata, would abut against the surface produced by the cutting process. Subsequent depression would admit of the deposition of more horizontal strata on the upturned edges of the earlier ones. Such an arrangement of strata is known to geologists as an unconformity, and the frequency of unconformities among the stratified rocks of our land surfaces shows that many portions of our continents have been submerged and elevated again and again, and that each land surface is as a rule not the result of a simple uplift, but that they have grown by a process of accretion of fresh masses of land at different times. In these circumstances it will be well to leave the actual structure of our main land surfaces for the present, and to consider the events which would occur, and modify the land masses, if we commenced with a simple uplift of horizontal sediments.

An ideal symmetrical uplift around a central point would give rise to a dome-shaped mass of land highest in the centre, and sloping away to the sea all round, with a coast-line forming a perfect circle. A section through the uplift would show the surface existing as a simple convex curve, and the planes of stratification beneath it running parallel to the curve as shown in Fig. 6. 


\section{SCIENTIFIC STUDY OF SCENERY}

It will be more convenient, however, if we imagine the uplift as occurring around a horizontal straight line instead of above a point, in which case the result would be a long ridge, highest above this axial line, and sloping to the coasts, which in our imaginary continent would form two parallel lines. A section of this uplift at right angles to the axial line would be precisely similar to the section across the dome, shown in Fig. 6.

We may now consider the relationship of the strata to the continent. The axial line of the continent is also that of an anticlinal arch or saddle of

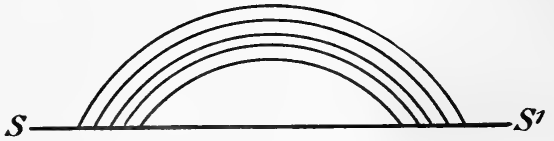

FIG. 6 .

$S S^{\prime}=$ Sea-level.

the strata, and the strata dip away on either side of that line towards the coast, while the strike of the strata is parallel to the axial line, and therefore to the longer axis of the ideal land mass. It will be seen that the main watershed is immediately above the axial line, and accordingly the primary drainage systcm of the continent will be divided along a line coinciding with that from which the strata dip on opposite sides in different directions. The rain falling on the continent will determine two sets of rivers, running from the watershed to either coast. Thus, in the case of a simple uplift, there is a direct connection between the folding of the strata and the initiation of the river system. If there were no 
inequalities on the surface, the rivers would run as straight lines in the direction of the dip of the strata from the watershed to the sea-coasts. ${ }^{1}$ It will be eventually seen that these rivers cut into the strata and carve valleys for themselves, thus exposing the junction between different strata on the earth's surface, and also producing secondary watersheds between adjoining rivers. Now, the strata are of different degrees of hardness, and it will be found that the tributary streams tend to cut along the softer strata, and accordingly run at right angles to the primary rivers, and parallel to the strike of the strata. The primary rivers are known as consequent streams, being consequent upon the uplift, while the first-formed tributaries, which we shall here alone refer to, leaving the consideration of subsidiary streams to a future chapter, are termed subsequent streams.

The formation of these subsequent streams and their valleys will give rise to tertiary watersheds separating the subsequent streams, and accordingly in the case of a symmetrical and simple uplift, such as we have described, a river-system of the following character will be initiated (Fig. 7).

An ideal continent then owes its existence and broader physical features to its main uplift; its mountain masses and plateaux, with the intervening broad depressions, are due to the formation of minor earth-waves; if it possesses volcanoes, they will probably occur with definite relationship to the major uplift; and the minor features are due to sculpture

1 All the primary rivers need not rise at the watershed, but some may rise at various points between the watershed and the sea. For the sake of simplicity, these may be at present ignored. 


\section{SCIENTIFIC STUDY OF SCENERY}

by denuding agents, and to occasional accumulation mainly in the hollows: while an ideal ocean owes its broad features to its main depression; its smaller elevations and depressions are due, as before, to minor earth-waves ; volcanoes may modify it, and its coast-

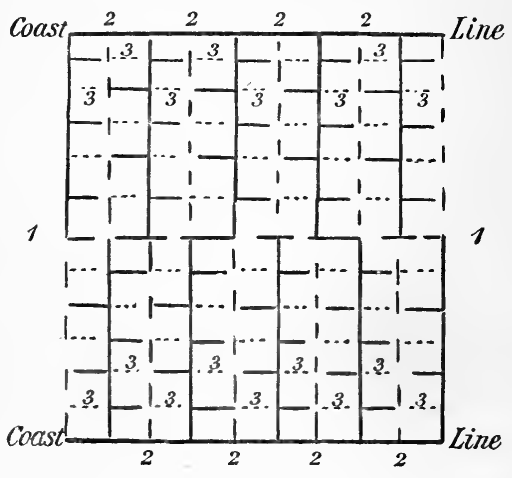

FIG. 7 .

I, I = Main watershed. 2, 2 =Secondary watersheds. 3, 3=Tertiary watersheds.

lines will be affected by erosion; but the principal minor modifications, unlike those of the land, are produced, not by denudation, but by deposition, which tends to fill up the inequalities by the formation of blankets of sediment, producing extensive plains of deposition upon the ocean floor, ready upon uplift to give rise to portions of new continents. 


\section{CHAPTER VI.}

\section{MOUNTAINS}

T $T$ is obvious that as a valley, whether of move1 ment or of erosion, is complementary to a mountain, the origin and structure of the two are closely connected, but it will nevertheless be convenient to consider the two apart, though the reader will remember that much of what is written concerning mountains must be taken into account when considering the details of valley structure and valley formation.

Mountains and hills have been classified, according to their formation:-(i) by accumulation; (ii.) by upheaval; (iii.) by circumdenudation. The hills of accumulation are formed by piling of material on the earth's surface, and the chief hills formed in this manner are volcanoes, while minor hills of accumulation are known as sand-hills or sanddunes. Each of these will be more appropriately considered in later chapters, and we may here confine our attention to the hills of upheaval and circumdenudation, which constitute by far the largest proportion of the mountains of the globe.

It is convenient, in our classification, to separate hills of upheaval, produced by uplift of portions of the earth's crust, from those of circumdenudation, due to the erosion of portions of that crust, 


\section{SCIENTIFIC STUDY OF SCENERY}

thereby leaving intervening portions to stand out as hills above the general level of the eroded portions, but a moment's reflection will convince the reader that an ideal hill of upheaval or of circumdenudation cannot exist. The agents of erosion affect all parts of the surface of the land, and therefore, however nearly a hill may approach to an ideal hill of upheaval, it must owe some of its surface features to erosion, whereas, in the case of strata formed beneath the ocean, initial uplift is necessary before the agents of erosion, whose operation is essentially restricted to the land masses, can come into play. Nevertheless, as some hills owe most of their character to uplift, and others to circumdenudation, the division is useful, though it must be distinctly understood that a complete gradation can be traced from the hill which is almost entirely due to uplift, with very slight modification due to erosion, to one which is blocked out by erosion from an elevated tract of plateau region, in which the uplift has been so uniform that the outline of the individual hills owes practically nothing to uplift, but nearly everything to erosion.

Our study of hill structure will be simplified if we consider the effects of uplift first, and those of erosion subsequently, though it must be remembered that in nature erosion commences with uplift, and operates simultaneously. As soon as the future hill-top has emerged above the water, the agents of erosion begin the work of destruction, and this destruction goes on while further emergence takes place; and accordingly, in order to have hills at all, the uplift must occur in such a way that 
erosion cannot keep pace with it; otherwise the potential hill would be reduced to a level, while the rocks of which it was composed were pushed up.

Before discussing the variations of hill structure produced by upheaval, a few words are necessary concerning the rate of operation of upheaval and other agents which are occupied in producing various scenic effects. We have every reason for supposing that when the race to which belonged the flint man of Abbeville and of Kent's Cavern occupied Europe the occupants gazed on hill and vale possessing much the same features as those which they now present; and if a palæolithic artist had represented Snowdon or Skiddaw on a piece of ivory, its outline would be recognisable as identical with that which it at present exhibits; indeed, long before the appearance of man in Britain, the physical features of our country were essentially those of the present time. It is evident that no important change has taken place in historic times, and the geologist has to deal with æons to which historic times are but as a day.

No definite idea of the duration of geological time can be given; its vastness becomes impressed upon one as the result of observation of geological phenomena; the geologist finds that the agents which are working at the present time are sufficient to account for all the phenomena of the stratified rocks with which he is acquainted; but finding how slowly these agents do their work, and how insignificant are the changes which have occurred during periods of time which to an ordinary man seem enormous, he is led to infer that immense periods must have elapsed in order to explain all 


\section{SCIENTIFIC STUDY OF SCENERY}

the changes, inorganic and organic, with which he is acquainted.

The casual observer, noting the strata of a mountain slope thrown into violent folds, zigzagging across the face of a cliff like a series of whip-lashes, might easily suppose that these folds are due to rapid and catastrophic movements; but experiment will show that under ordinary conditions the comparatively rigid rocks cannot be bent as the result of sudden application of pressure-they will snap across-whereas if pressure be applied slowly they may be bent into sharp folds. A simple experiment may be tried with an ordinary stick of sealing-wax. If one tries to bend it suddenly, it will break across; but if pressure be applied very slowly, it may be bent into a complete circle with the fingers alone. Experiments of this nature do not necessarily indicate that folding cannot take place rapidly when the rocks are far below the earth's surface and affected by the pressure of thousands of feet of superincumbent rock, but they show that under certain conditions rock folding can be produced by slow pressure, and not by rapid movement, and therefore that violent contortion of the strata is by no means proof of rapid movement. We have much further evidence of the slowness of movement on a large scale, but it is beyond our scope to enter fully into this question, which the reader will find discussed in the larger works devoted to the study of geology.

Passing now to a consideration of the types of uplift which give rise to mountain masses, we may divide them at the outset into two, the uplift produced as the result of folding of the rocks and that due to fracture, or, in other words, mountain uplifts 
are due (i) to folding; (ii) to faulting. It will be seen in the sequel that the one is often accompanied by the other, but it will make mountain-structure clearer to the reader if we omit consideration of all complications in this place, and take ideal forms into consideration.

Commencing with primary forms of mountain masses due to folding, we have the dome and the ridge, the former being the result of the bending of the strata into a dome, while the latter is caused by their curvature into a saddle. ${ }^{1}$ The symmetrical dome is comparatively rare on a large scale, and, so far as we know, is produced by vertical upthrust of strata, especially when igneous matter in a state of fusion is introduced beneath them. If this matter is brought up from below at a definite point and forced between strata, it will tend to be thickest above the point at which it enters the plane of stratification along which it spreads, and to thin out on all sides, so that it would have the general shape of a mushroom, the stalk being represented by the molten matter which flowed up the pipe, and the upper part of the mushroom by the mass which was forced along the plane of stratification, and if the mass were perfectly symmetrical, its outline would be a circle. The strata would be arched above it, the planes of stratification lying parallel to the convex curve of the surface of the ground and also to the upper surface of the igneous mass. To an igneous mass producing an elevation of this nature Dr. G. K.

1 The rocks are spoken of as strata for convenience, and to emphasise the relationship which exists between surface contours and direction of planes of stratification, but it must be noted that the component rocks of mountain masses need not necessarily be stratified. 
Gilbert has given the name laccolite, and as laccolites present us with the most symmetrical cases of uplift known to us, they have furnished us with much information important to the student of scenery, and we shall frequently have occasion to refer to them hereafter. The typical laccolites are found constituting the Henry mountains, situated in Southern Utah, and are described by Dr. Gilbert. ${ }^{1}$

The ideal ridge will differ from the laccolitic uplift, inasmuch as the strata are bent round a horizontal straight line instead of round a point, but a crosssection drawn at right angles to the axial line will show a convex curve similar to that furnished by a cross-section of the surface of a laccolite. It will be seen that the ideal ridge does not exist in nature, for it would go completely round the earth, and no mountain chain does this. The ridge-like elevations are, strictly speaking, elongated domes, of which one axis is very much longer than the other; but remembering this, it will be simpler to treat of the structure as that of a true ridge, to which it often approximates in the parallelism of its two sides for very long distances. The symmetrical ridge is, however, not common in nature, the normal ridge being usually steeper on one side than on the other, as in the ocean wave, where the septum is steeper than the other slopes, and a symmetrical ridge would really be a combination of two waves with a trough on each side of the uplift. Some of the ranges of the Jura mountains approximate to the type of a symmetrical ridge.

${ }^{1}$ See Gilbert, G. K., Geology of the Henry Mountains (United States' Geographical and Geological Survey of the Rocky Mountain Region, Washington, 1880), a work to which frequent reference will be made in these pages. 
extension of the upper strata being indicated by the curved line. This complication will be found to be important when we enter into details concerning mountain and valley outline.

Before discussing uplifts due to fracture, it will be necessary to say a few words concerning the minor folds which frequently accompany the main fold producing an uplift, and produce very marked effects upon the features presented by a mountain region such as the Alps. When the lateral pressure which produces the folds is comparatively slight, the minor folds are often fairly symmetrical, but as it increases in intensity, the earth-waves are compressed into narrower folds, and the entire rock mass loses greatly in horizontal extension, but gains proportionately in height, giving origin to what is known as a mountain range, the major fold forming the crest, and the harmonic minor folds constituting the flanks of the range. ${ }^{1}$

Now towards the foot of this range the minor folds remain fairly symmetrical, but nearer to the centre the effect of the lateral thrust and counterthrust is complicated by the weight of the mass above, which presses the upper parts of the minor folds towards the base of the mountain range, and accordingly the plane surface which lies between the axial line and the summit line of a ridge or the bottom of a trough, which is vertical in the case of a symmetrical uplift, is forced out of the vertical and made to dip inwards

1 Quoted from a paper by Professor LAPwORTH in the Geological Magazine, dec. ii., vol. x, entitled, "The Secret of the Highlands," part ix. of which gives a summary of the work of HeIM, Mechanismus der Gebirgshildung, published at Zurich, 1878 . The reader will find admirable illustrations of Alpine structure in the atlas of the latter work. 
towards the centre of the range, and the strata forming the septum of each wave become inverted. This occurs on each side of the main axis, and gives rise to the well-known fan structure which characterises mountain ranges of Alpine type, as illustrated in Fig. 9.

This fan structure may be repeated, giving rise to a mountain system, composed of more or less parallel mountain ranges, each of which is composed of a central crest and lateral flanks. Such a system is

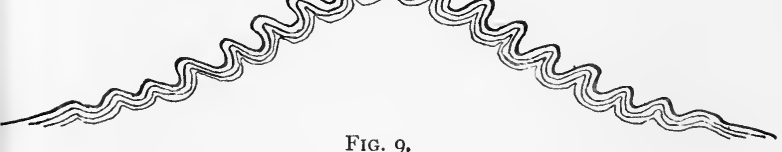

FIG. 9.

Showing the structure of a mountain range of Alpine type, without denudation.

found in the Alps complicated by countless minor convolutions and fractures, but nevertheless composed of strata so arranged as to allow of the recognition of the fan structure on a large scale. For instance, in taking a traverse from north to south, starting at the Lake of Lucerne and travelling to the plain of Lombardy, we traverse three definite ranges having a general fan structure. On the north is the Aar range, separated from the central Gotthard range by the newer rocks of the Urserenthal, while the Gotthard range is separated from the Tessin range on the south by the newer rocks in the valley in which Airolo stands. Similarly to the west of this the great Bernese Oberland range is separated from that 
of the Alps of the Valais by the upper portion of the Rhone valley, containing newer rocks.

There is one type of unsymmetrical fold to which allusion has not yet been made here, known as the hogback, or monocline. A monocline is sometimes spoken of as half an anticline or half a syncline, with strata on either side of it. In reality a monocline consists of a complete earth-wave, the septum of which is inclined at a high angle, while the other slopes approach to horizontality. The monoclinal fold gives rise to steep, curved slopes overlooking gently sloping surfaces, as typically shown in the "hogbacks" of the western territories of North America. When two hogbacks occur facing in opposite directions, and a comparatively level tract between them, we have the "Uinta type" of mountain folding, typically developed in the Uinta mountains of North America, the general structure of which is diagrammatically shown in Fig. IO.

In summing up this part of our subject we may say that the principal types of mountain structure produced by folding are as follows:-

I. Simple Types.

(a) Symmetrical.

(a) Domes . . e.g. The Henry mountains.

(b) Symmetrical saddles "Some of the Jura mountains.

(c) Uinta type . " The Uinta mountains.

(b) Unsymmetrical.

(a) Hogbacks . . e.g. The "hogbacks" of the western territories.

(b) Unsymmetrical saddles. e.g. The Mendip hills.

2. Compound Type.

Alpine type . . . e.g. The Alpine ranges. 
The classification is not altogether satisfactory, for, as already seen, the symmetrical saddles and the Uinta type should be looked upon as compounded of two earth-waves, and the hogbacks are really of the nature of unsymmetrical saddles, of which one slope is so small as to appear practically horizontal, but the grouping we have adopted distinguishes between different types each of which exhibits very definite features, and the features of those types which are placed in the same subdivision possess important points in common.

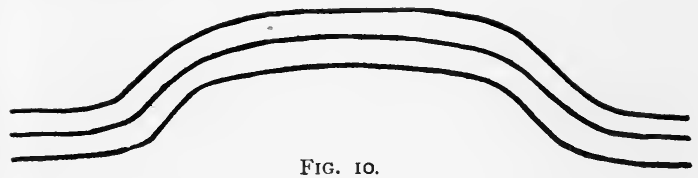

We may now proceed to consider uplifts which are primarily due to fracture, and must observe at the outset that fracture is the outcome of folding carried to excess, so that the strata will no longer yield by bending. If a rock were a mathematically rigid mass, we could completely separate fracture from folding, but in a mass which is not absolutely rigid a certain amount of folding precedes fracture. If one examines a broken iron bar, it will be often seen that the particles of the bar are slightly bent at the broken part, owing to the production of an incipient fold before fracture occurs, and the same is often noticeable with rocks. Accordingly every type of fold has its accompanying fault, which replaces the septum of the fold. A simple earth-wave, consisting of saddle and trough, where the strata dip 


\section{SCIENTIFIC STUDY OF SCENERY}

away from the axis of the saddle and towards the axis of the trough, has its septum replaced by what is known as a normal fault, in which the plane of the fault dips downwards towards the side of the trough, while the septum of an overfolded wave or sigmoidal flexure, in which the strata of the septum are inverted, is replaced by an overfault or thrust-fault, the plane of which dips downwards towards the side of the saddle, and a monoclinal fold or hogback is replaced by a monoclinal fault, which in the case of a normal monocline is normal, and in that of an overfolded monocline is reversed. This is illustrated in the following figure.
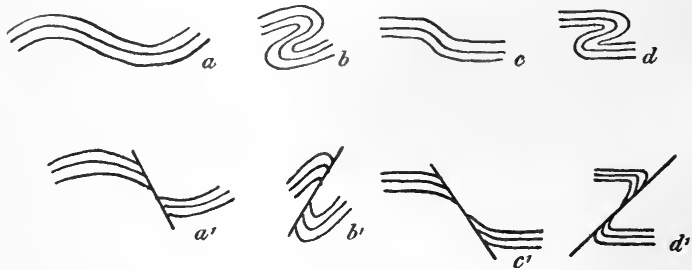

FIG. II.

a Symmetrical Earth-wave.

$a^{\prime}$ Normal Fault.

$b$ Overfold.

$b^{\prime}$ Faulted Overfold.

c Normal Hogback.

$c^{\prime}$ Monoclinal Fault.

d Overfolded Hogback.

$d^{\prime}$ Reversed Monoclinal Fault.

The main difference between a folded uplift and a faulted one is that, whereas the fold gives a convex surface to the uplifted region, the face of the fracture tends to be a plane surface, having the inclination of the determining fissure. Accordingly, if denudation did not occur, uplifts, where the folding is replaced by faulting, would be marked by the occurrence of 
straight cliffs. It is clear that the arrangement represented in Fig. I I $a^{\prime}$ would give rise to a hillrange and valley of depression of exactly the same nature as those produced by the arrangement Fig. I I $a$, except for the difference just alluded to. The best cases of ridges and valleys determined by fault scarps have been described by the explorers of the western territories of North America. These ridges and valleys have usually been profoundly modified by denudation, but the features due to movement are still ascertainable. Admirable examples have been described by Professor J. W. Powell in his Geology of the Uinta Mountains, and the nature of the movements and the resulting features are well shown in Figs. 3 and 5 of that work. In the lower part of the latter figure, a restoration of part of the region is given showing the nature of the country as it would appear if displacement had not been accompanied by denudation, and it tallies very well with the actual features as shown in the upper portion of the same figure. The district has been broken up into a series of blocks bounded by rectilinear margins-the faults-and differential displacement of these blocks has occurred, some being elevated as compared with others, and also portions of one block being tilted up more than others, or one portion of a block being uplifted and another sagged down. The country, as observed by Powell, much resembles the surface of a mass of ice the blocks of which are "crowded in an eddy of a northern river at the time of its spring flood," and it is significant that a district of the character we are describing is often marked by great intrusions of igneous rock forced up from below, so that the 


\section{SCIENTIFIC STUDY OF SCENERY}

structure suggests the buoying up of a mass of the earth's crust above a reservoir of molten rock and settlement of the cracked parts of the crust to different degrees in the molten mass below.

In our own country an illustration of this type of displacement is furnished by the Pennine chain, and it is especially well exhibited in the northern part of the chain, which overlooks the lower part of the Eden valley. This portion of the Vale of Eden is a valley of depression, separated from the uplift of the Pennine Chain by the great Pennine fault, which has determined the existence of the great scarped cliff which faces westwards, a cliff specially noticeable to anyone travelling northwards by the main Midland line between Settle and Carlisle. The present features are due to denudation, but the uplift of the Pennines and depression of the Vale of Eden were undoubtedly determined by the faulted earth-wave which exists in the area.

If the fault be small, and the rocks on either side easily denuded, the fault scarp may be destroyed, or never called into existence. For instance, the Isle of Wight is marked by a monoclinal fold or hogback with the septum partly replaced by a thrustplane, but denudation has prevented the formation of a fault scarp, and the ground on the uplifted side of the fault, though higher than that on the other side, slopes down towards it with a comparatively small gradient. On account of the frequency with which denudation has levelled the ground on either side of a fault fissure, English geologists have perhaps been prone to overestimate the power of denudation to obliterate all inequalities produced by faulting. In areas where the fracture is recent, 
especially if agents of denudation are not very powerful, as in desert regions, the actual cliffs may be, and sometimes certainly are, directly due to faulting, as shown by Gilbert in the case of certain cliffs of the Great Basin region of North America, in the neighbourhood of Great Salt Lake.

It will be seen that, as the result of earth movement, the land surfaces would possess convex curves among the hill ranges, and concave curves in the valleys of depression, due to folding, and linear straight-faced cliffs, as the result of faulting. The fact that these surfaces are only rarely found indicates that the existing superficial features, though indirectly due to earth movement, have been profoundly modified by other causes, and it remains to be seen what these causes are, and how they have produced the actual features presented by the principal tracts of the land surfaces. 


\section{CHAPTER VII.}

\section{MOUNTAINS (Continued)}

$\oiiint \begin{gathered}\text { AVING considered the general structure of } \\ \text { mountain ranges and mountain systems, we }\end{gathered}$ are in a position to discuss the nature of the modifications which they undergo, and the character and origin of individual mountains. As the result of uplift, mountain ranges are caused, but if the uplift be equal, as in the case of our ideal ridge, the ridge would be terminated at the summit by a horizontal line - the watershedding linefrom which the streams would flow away on either side. This watershed would be precisely similar to that which we described in Chapter V., as forming the main watershed of a continental uplift, and the drainage would be initiated and secondary watersheds developed as described in that chapter.

It will be found that the modifications which result in the formation of isolated mountain peaks from mountain ranges are due to the agents of denudation, which also greatly modify the general character of the range itself, and it is necessary, therefore, at this point to pay some attention to the effects of denudation.

We noted in the third chapter that the agents of denudation operated in the dry way and in the wet way according to the climatic conditions of the 
region in which they are at work. Work in the dry way predominates in desert regions and the regions of "eternal frost," though even there the effects of water are not entirely eliminated, but over the greater part of the earth's surface water action is dominant, and as there is reason to suppose that many areas now affected by desert conditions and others covered by a mantle of snow and ice were not always under these conditions, we must admit that the action of water is of paramount importance in effecting denudation, and its results must therefore be considered at the outset, the characteristic features of denudation in the dry way being discussed subsequently.

The laws of water denudation have been very fully illustrated by Dr. Gilbert as a result of study of the simple conditions which exist in the uplifts of the Henry mountains, and much of the following description is abstracted from his monograph upon those mountains. It has already been stated that the mountains are in the form of domes, marked by intrusion of a mushroom-shaped mass of igneous rock beneath the uplifted strata, but it will be convenient if we consider the case of drainage impressed upon an ideal ridge rather than upon a symmetrical dome.

Watersheds. - The ideal ridge consists of an arch of strata bent symmetrically around a horizontal axial line, so that, if it be supposed that the ridge be cut in two along a vertical plane extending from the axial line to the parallel horizontal straight line which would form the top of the arch, one side of the ridge would be the exact counterpart of the other, and its surface would form a slope approaching horizontality towards the summit (though it would not 


\section{SCIENTIFIC STUDY OF SCENERY}

be absolutely horizontal except along a mathematical line-the watershedding line), sloping more steeply at some distance away from this line, and approaching horizontality towards the bottom of the valley of depression, the central line of which would be again horizontal, so that the steepest part of the mountain slope would be the centre of the septum. This is shown in Fig. 12, representing a section across the uplift.

The thick line $a a$ indicates the ideal surface of the

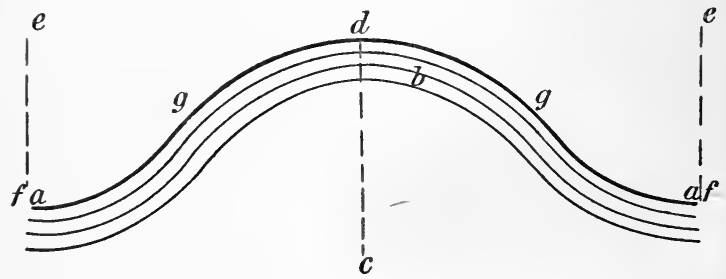

FIG. 12.

ground, $b$ the strata of which the uplifted tract is composed, $c$ the point at which the axial line is cut in the section, $d$ the watershed, $c d$ the line in which the bisecting plane is cut in the section, $e e$ the points at which the axial lines of the two depressions are cut in the section, $f f$ the sections of the lines of the bottom of the depressions, and $g g$ the steepest parts of the slopes at the centres of the septa.

The rain which falls upon the actual watershedding line would remain stationary; there is no reason why it should flow down one side more than the other, but rain falling on either side of the water- 
shedding line would tend to flow down that side. In nature the water as a rule does not flow directly it reaches the ground, for all rocks can absorb water to a greater or less extent, and consequently the streams which course down the mountain-side do not rise absolutely beside the watershed, but some little distance below it on either side. We must now state a very important principle, to which we shall have to refer again and again, namely, that when conditions are uniform, and agents are acting with uniformity, the results will be symmetrical, and accordingly all departures from symmetry must be accounted for when we have evidence of conditions which are generally favourable to the production of symmetrical features. We have postulated the existence of a symmetrical uplift which we will suppose to affect homogeneous rocks, and if the rainfall is uniformly distributed it follows that the sources of the streams will arise at points equidistant beneath the watershedding line on either side, and that these points must be equidistant from one another, so that drainage of an equal area of ground which has absorbed the water will issue from the springs at which the streams arise. The only symmetrical arrangement is that shown in Fig. I3, which represents a plan of a watershed, $x y$, with springs issuing from the points $a b c, \ldots$ and giving rise to streams flowing along the dotted lines in the directions indicated by the arrows. It will be seen that streams rise alternately on either side, and that if three adjoining points, as $a b c$ or $b c d$, be joined by lines, the resulting figure is an equilateral triangle.

It will be ultimately seen that the streams tend to carve out valleys, and that the erosion com- 


\section{SCIENTIFIC STUDY OF SCENERY}

mences as soon as the water issues from the spring, and accordingly valleys will be cut along the dotted lines in Fig. I4, and the ground from $a \quad b$ downwards along the dotted lines will be rendered appreciably lower than the ground between the springs and the watershed. The action of the

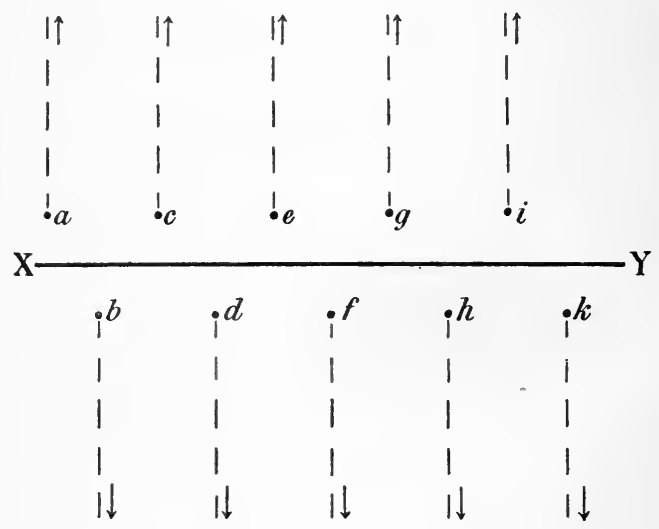

Fig. 13.

$\mathrm{X}, \mathrm{Y}=$ Watershed.

$a, b, c, d, e, f, g, h, i, k=$ Points of issue of water from springs.

weather, assisted by gravity, will prevent the formation of a vertical cliff above $a b$; material will slip down from the ground above, and be carried away by the stream; and half-funnel-shaped valley heads will be formed around the springs, each having a semi-circular outline in plan, the springs marking the centres of the semi-circles. This 
arrangement is shown in Fig. 14, in which the zigzag line $x \quad y$ represents part of the primary watershed (the zigzag character of which we are about to explain); $a b c$ the springs, and the dotted lines the streams flowing from them; $\begin{array}{lll}2 & 3\end{array}$ secondary watersheds, which will also become zig-

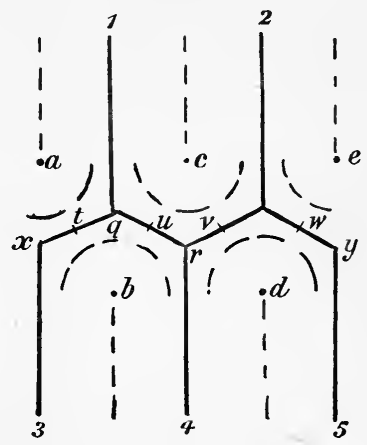

FIG. 14.

$s q r$ s $y=$ Main watershed.

$a b c d e=$ Points of origin of springs.

I 2345 =Secondary watersheds.

Dotted semi-circles $=$ Incipient half-funnel-shaped hollows. $q r s=$ Culminating peaks.

$t u v w=$ Cuts or passes.

zagged, though for simplicity they are represented as straight; and the dotted semi-circles, the summits of the half-funnel-shaped slopes above and around the springs. These half-funnel-shaped terminations of valleys are frequent on a large scale as the cwms, combes, and cirques, which form so marked a feature of many upland regions. As the valley 


\section{SCIENTIFIC STUDY OF SCENERY}

becomes deepened, the funnels will be cut further and further back, and at last those on the two sides of the watershed will interfere with one another, and produce a change in the direction of the watershed, which, instead of remaining straight, will now run as a zigzag line, the curves becoming converted into straight lines, as in this way only can symmetry be maintained; the watershed will now run along the zigzag $q r s y$. The point $t$, in the centre of the line $x q$, will be equidistant from the points $a b$, and accordingly the greatest erosive influence will be exerted here, and less and less erosion will take place as the result of weathering and the action of gravitation as one passes along the line to points more remote from $a$ and $b$, until we reach $x$ and $q$, where the least erosive influence is exerted; the points $x$ and $q$ are situated at the end of the line, and from them secondary watersheds extend on either side of the main one. Accordingly $t$ will be the lowest point of the portion of the watershed represented by the line $x q$, and $x q$ the highest points, the intervening points being of intermediate heights, and if action be symmetrical, the line will appear in section as a curved line. Accordingly the watershed as seen in section will present the appearance shown in Fig. 15, the letters in which correspond with those of the plan Fig. I4.

This change in the character of the watershed is of primary importance to the student of scenery, for when conditions are uniform, and symmetry therefore maintained, the mountain-tops will appear at the heads of the main valleys, while the cols or passes will notch the watersheds at the sides of the valleys, and from two adjoining mountain-tops 
secondary watersheds will extend in opposite directions. In nature we often find many departures from uniformity of conditions, which produce marked modifications of the ideal watershed described above, but there are a very large number of cases where the departure from uniformity is too slight to modify the natural arrangement to any great extent.

As an illustration of the production of the arrangement of mountain, valley, and col described above, we may consider the district in the neighbourhood of Monte Rosa, which shows it fairly well, though there are several minor complications. Leaving these

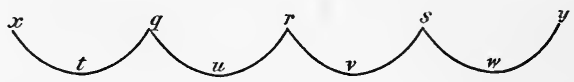

Fig. 15.

out of account, we have the Matterhorn dominating the head of the Val Tournanche, and sending off the secondary watershed on which the Weisshorn is situated. (This is modified by the line of weakness which has allowed the valley in which the $\mathrm{Z}$ mutt glacier is placed to cut through it.) On either side of the Matterhorn, at the upper end of the Val Tournanche, we have a lateral col, the $\mathrm{Col}$ Tournanche to the west, the Theodul to the east. From the Matterhorn the watershed trends southeastward to another culminating point, the Breithorn, which dominates the Visp Thal, and sends ridges to the south, though here the structure is complicated by minor valleys, themselves dominated by minor ridges, and accordingly the watershed does not turn to the north-east, as it would if uniformity had prevailed. The next culminating 
point is Monte Rosa itself, dominating the head of the Val de Gressonay, and sending to the northward a secondary ridge, which culminates in the Mischabelhörner. This secondary ridge exhibits a zigzag watershed, with very marked approach to symmetry, the culminating points, marking the angles of the zigzag, occurring in the following order from south to north: Strahlhorn; Rimpfischhorn; Allelinhorn; Alphubel; an unnamed point just north of the Mischabeljoch; the two Mischabelhörner; Süd-Lenspitze; Nadelhorn; Ulrichshorn; Balfrin. It will be furthermore noted by referring to a map that the more marked ridges are given off alternately from these culminating points with considerable regularity.

In the case of a dome-shaped uplift, the primary watershed will be a point at the centre of the dome, and the streams and secondary watersheds will radiate from this point like the spokes of a wheel. The drainage of the English Lake District is determined and limited by watersheds of this nature, though more symmetrical domes with more accurately radial drainage are found among the Henry mountains.

A mountain range or mountain complex consists of mountains sculptured from an uplift or uplifts, of which the height is usually comparatively small as compared with the length, though the relation of height to length varies considerably, being proportionately large in sharp uplifts of Alpine type, and small in the plateaux, from which are sculptured those hills which most truly approach the ideal hill of circumdenudation. Further, the height of neighbouring tracts of the uplifts will not vary to any great extent, and accordingly neighbouring moun- 
tains formed by the sculpture of an uplift by denuding agents will not vary in height to any great extent, and no mountain, except one of accumulation, can be higher than the surface which would be produced by uplift alone. It will be eventually seen that position of watersheds may change owing to conditions of asymmetry, but with a symmetrical uplift, as erosion by streams on the watersheds is nil, the watersheds are not lowered to any great extent, and the mountains which are carved from the uplifted mass tend to have their summits remaining for long periods at a height not much lower than that of the original watershed. As the original primary watershed is higher than any parts of the gradually sloping secondary watersheds, the mountains situated along the line of primary watershed tend to be higher than those situated along the secondary lines, and the latter, under uniform conditions, will be lower and lower, the more remote their position is from the primary watershed. Thus we find the highest mountain of the Alps, Mont Blanc, on the primary watershed of the complex, and the highest point of the Lake District, Scawfell Pike, situated about the centre of the system of radial drainage lines. Taking the case of a secondary watershed, that which starts between the Val d'Herens and the Val d'Anniviers, in the Valais, and afterwards separates the two branches of the latter valley, though modified by complications where it joins the main watershed, has the following crests, varying in height as one passes from south to north, away from the main watershed:-Dent Blanche, 4364 metres; Grand Cornier, $3969 \mathrm{~m}$; ; Bouquetin, $3484 \mathrm{~m}$.; Pigne de l'Allée, 3404 m. ; Garde de Bordon, $3316 \mathrm{~m}$. 


\section{SCIENTIFIC STUDY OF SCENERY}

Departure from uniformity is caused by a number of things, among which may be mentioned, as of special importance, want of symmetry in the uplifts, difference of structure and texture of the rocks, some of which are more easily denuded than others, and variation in the character and amount of denudation in different places. The influence of these in producing variation from the uniform types will be considered in the sequel. Though their influence tends to complicate the ideal structure which would be produced if the conditions had been uniform, this is usually only masked, and not destroyed, and when once it is detected, it is much easier to account for the causes of departure from uniformity than would be the case if the laws of mountain formation under uniform conditions had not previously been grasped.

The Three Processes of Denudation.-Thus far we have mainly inquired into the importance of uplift in the production of mountain ranges and mountain systems, and have only referred incidentally to the action of erosion or denudation. We have now reached a stage in which it is necessary to consider more particularly the operation and influence of the erosive agents.

The agents of erosion are many, and the more important may be grouped as follows: atmospheric or meteoric agents, including changes of temperature, wind, and rain ; streams and rivers; glaciers and seawaves. As previously observed, the influence of rivers is of paramount importance to the student of scenery, not only on account of the capacity of individual rivers as agents of erosion, but also because of the great frequency and general distribution of rivers over land areas. It is found as the result of observation, 
and might readily be inferred, that rivers erode not so much by the direct action of the water on the riverbed as by the friction of the sediment transported by the river against the rocks which compose the riverbed. Now the majority of rocks are in a solid and compact state, with their particles more or less firmly welded together, and before they are in a condition for transport by streams they must be broken up. This fracture and comminution of the solid rocks is chiefly carried out by atmospheric agents, and is therefore spoken of as weathering, and rock weathering is the first process in the work of denudation. Detailed accounts of the effects of weathering will be introduced more appropriately in various subsequent parts of this volume. It is sufficient for the present to understand that, as the result of weathering action, we are furnished with a supply of broken and comminuted rock material, which is capable of being taken up and washed away by rivers. The latter process is spoken of as transportation, and, owing to gravitation, the transported material is carried from higher to lower levels, and, if unchecked, ultimately to the sea, where it settles down to form new deposits. During the process of transportation the transported material is rubbed and knocked against the bed of the river, gnawing it away and thus adding to the amount of material to be transported, and at the same time deepening the bed of the river. This action is termed by the American geologists corrasion, a term which is coming into general use. The three processes of ordinary denudation in a country with an abundant supply of rainfall and drained by rivers are, therefore, weathering, causing the comminution of solid rock, transportation of comminuted fragments 
of particles, and corrasion of the river-beds by these particles. During these processes the larger fragments have their asperities knocked off and are converted into rounded pebbles, and the finer particles are converted into grains of sand, the very finest into mud.

Every river possesses a certain amount of energy, which enables it to do work, and the work which it performs is of a twofold nature, namely, transportation and corrasion. Its energy is not unlimited, and accordingly every river can only do a certain amount of work, which may be entirely transportation, or transportation and corrasion, according to circumstances. The amount of energy of any river depends upon two circumstances, its volume and its velocity. Other things being equal, the velocity is dependent upon the inclination of the river-course; the steeper the slope the greater the velocity. Now, imagine a river running down a uniform slope having an angle of, say, $30^{\circ}$ along all parts of its course, and further suppose that the volume of this river is the same along all parts of that slope. Let that river be supplied with the exact load of sediment which it is capable of carrying, neither more nor less ; all the energy of the stream will be utilised in carrying this sediment, and no energy will be available for the process of corrasion. Accordingly the river will carry its material along the slope, and no other change will take place. Let the volume and velocity remain as before, and take away some of the sediment, and some of the energy of the river will be rendered available for corrasion, and the bed of the river will be corraded by the remaining sediment, and though the slope will remain uniform, it will 
be lowered by corrasion along its whole extent. If, instead of taking away sediment, we add to the original amount of it, the river will be supplied with more material than it has energy to transport, and the surplus material will be deposited uniformly upon the slope until the river is left with the amount of sediment which it is able to carry, and this it will transport along the uniform slope, raised above its original level by deposition of sediment.

If now, instead of imagining the slope to be a uniform slope of $30^{\circ}$, we suppose that the average slope is at that angle, some parts being more and

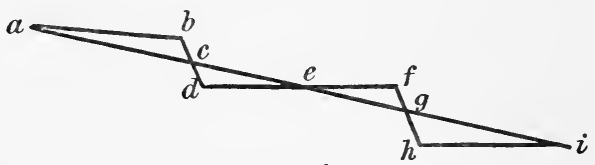

FIG. 16.

some less, as shown by the unbroken zigzag line in Fig. 16, and further imagine that the river is supplied with the maximum amount of sediment which it can carry without corrading or depositing, if its slope were uniformly one of $30^{\circ}$, then, as the parts $b d, f h$, are at greater slope than the mean, the velocity of the stream is increased along here, and corrasion will occur, while along $a b, d f, h i$, the slope is less than the average slope, and the velocity of the stream will be diminished, so that the stream cannot carry all its load along these portions, but will deposit some of it. These processes of corrasion and deposition will occur along the alternating steep and gentle parts of the river-course until equilibrium is established and the stream has formed a uniform 


\section{SCIENTIFIC STUDY OF SCENERY}

slope of $30^{\circ}$ by the erosion of the portions included in the triangles $a b c$, efg, and deposition of material to fill up the parts shown by the triangles $c d e, g h i$. This slope will form a straight line, $a c e g i$, corresponding with that existing in our original stream of uniform slope, and on the establishment of equilibrium material will be transported as before, neither corrading nor being deposited. A river which has established equilibrium in this way is said to have reached its base-line of erosion, and no further work of erosion or deposit can occur until the conditions are changed, causing alteration of its velocity, volume, or load of sediment.

Our ideal uplift presented a convex curve having different slopes along different portions (see Fig. 12), and rivers having the same volume, other conditions being equal, would tend to cut valleys, having uniform slopes along the valley bottoms until the base-line of erosion was reached. But the volume of a river varies along different parts of its course, being greatest where it is discharged into the sea; and as we pass up from the sea towards the source, and leave more and more tributaries, which swell its volume, behind us, the volume of the main stream becomes less and less, until at the watershed it is nil. Remembering that, other things being equal, the corrasion varies with the volume, it is clear that corrasive power is strongest where the volume is greatest, and there the river will make its slope flatter, while it will be less and less flat where the volume is smaller and the corrasive power less. Accordingly when it has established its base-line of erosion this line will be a curved one, ever increasing in steepness from the sea to the source. If we imagined two 
rivers rising opposite to one another in the watershed, a section along their courses would consist of two concave curves, as shown in Fig. I7, which would replace the convex curve of uplift shown by the dotted line.

It has been seen that at the extreme summit of the river-courses the streams rise at some distance below the watershed, and the degradation of the ultimate slope is produced by weathering and slipping of material which tends to lower the watershed, though,

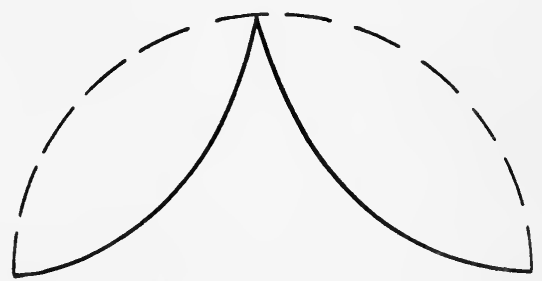

Fig. 17.

if the conditions be uniform, it will be situated vertically below its original position. The streams in the secondary watersheds will act in the same way, and, as the secondary streams have their velocity increased by increase of declivity when the primary stream lowers its level, their erosion will be increased, and the secondary watersheds will be thus modified, and their summits tend to be made parallel with the curve of the main stream. In this way a mountain uplift will be carved out by stream erosion into a series of slopes of the character represented in Fig. I 7 ; and viewed from a distance, though we are not looking at the actual stream courses, but at the 
watersheds occurring between adjoining streams, the outline of a mountain carved out by water erosion from solid rock will present the curves seen in this figure. As erosion progresses the curve will still remain, though it will be rendered flatter, but it will always retain its character, being flattest at the mouth of the river and steepest at the watershed. It need hardly be observed that the curve is not confined to the mountain uplifts; it must be produced when the river traverses gently sloping ground, though in this case it will not be practically distinguishable from a straight line.

The curve of river erosion produced in this way may be modified by a number of causes, but they usually produce minor effects, and amidst all the variations of outline, precipice, scree-slope, crag, and pinnacle, which modify mountain slopes, the denudation curve may be detected, if the main agent of denudation in the district is the river, and the work has proceeded for a period of time sufficient to enable the streams to establish or to approach to the establishment of their base-lines of erosion. The importance of the curve of river denudation as influencing mountain scenery cannot be overestimated. Mere size, though impressive, does not produce the sense of beauty which is felt when viewing the harmonious curves of hills whose outline has been determined by stream erosion. The adjoining plate is a reproduction of a photograph of the Langebergen, in Mossel Bay district, Cape Colony, which well illustrates the outline of hills whose sculpture has been wrought by stream erosion, and it will at once be seen how much of their grace they owe to the beautiful curvature of their slopes. 


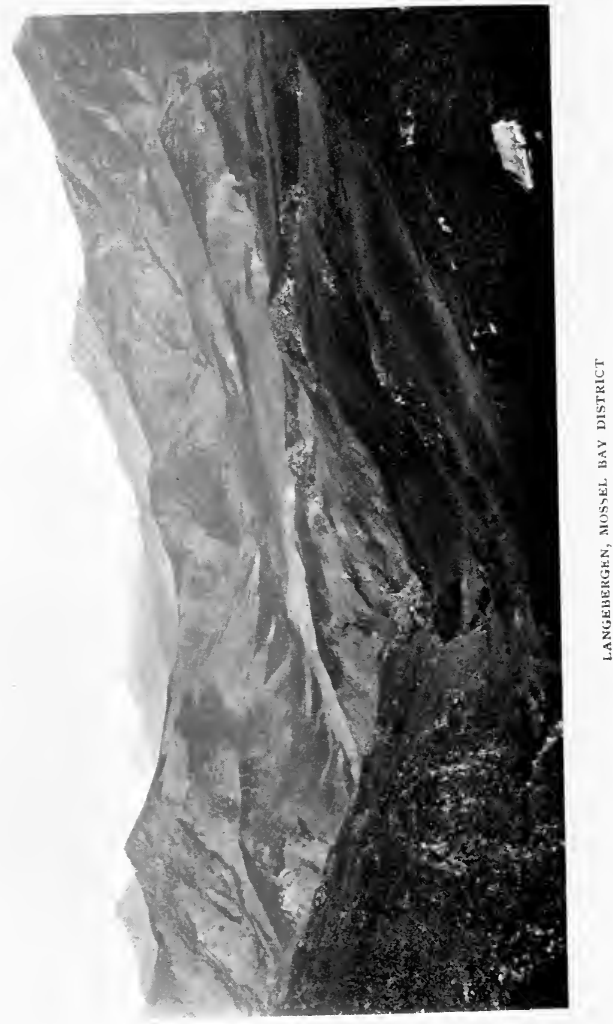




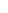


We may now take into consideration other causes which affect mountain outline on a large scale, and first may take note of hills in districts which are affected by stream erosion, which, while possessing the curve of stream erosion in the basal portion at each side, present a convex curve at the summit, as shown in Fig. $18 a$. This is a very common outline, and it is obvious that the curve of erosion is modified or replaced by a curve due to some other cause. I have for some years taken note of hills possessing this outline, and they are fairly numerous; the Moels of the Welsh hill system, as Moel Eilio, between Carnarvon and Beddgelert, show it, at any rate on
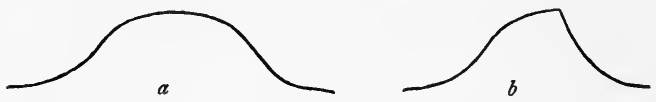

FIG. 18.

one side, and it is very perfectly shown on a small scale by the little Dunmallet, at the foot of Ullswater, and by the larger Mell Fells near it. In all cases where I have observed it, the portion of the hill occupied by the convex curve is covered by vegetation, often by a thick accumulation of peat, while the lower part exposes bare rock, and this coincidence is so frequent that it would appear that the change of curve is produced by the presence of vegetation. Now where this vegetation grows corrasion is not taking place, or bare rock would be exposed, and the action of weathering is dominant, for the mass of soil is, like the skin of the body, constantly destroyed on the top, replenished from beneath. The removal is effected by wind and inconstant rain runnels, the 
renovation by weathering of the rock beneath. It is well known that a square mass tends to become rounded by weathering, as seen in the granite tors of Devon, and as can be experimentally shown by subjecting a cube of limestone to the action of acid, or more simply by dissolving a cubical block of sugar in a cup of tea, for at every edge a given mass presents twice as much surface as a cubical mass of the same size which is exposed away from the edge of a cube. Thus a cube-shaped mass having a diameter of one inch, forming part of a large cube, presents two sides having a diameter of one inch if situated at the side of the main cube and only one if away from the side, while it exhibits three at the corners; consequently the corners wear away faster than the sides, and the sides faster than the general surface away from those sides, and a rounded form is developed. Now if we suppose a block of country of a generally rectangular form bounded by four depressions, the top of the block being occupied by vegetation, in the absence of corrasive action, this block would be modified at the edges and corners by weathering action, and a rounded form would result. This explanation receives confirmation by the frequent occurrence of hills having the outline of Fig. I $8 b$, where one side has the true water erosion curve to the summit, while the other exhibits the compound curve. This is frequently seen, as, for instance, on the above-mentioned Moel Eilio when viewed from the north-west, the curve of water erosion being on the north-east side, facing Llanberis, while the compound curve faces the south-west. In the English Lake District, the outline is frequently seen, as in Red Screes, near the head of the Kirkstone Pass, where 
the eastern face possesses the stream-erosion curve and the western face the compound one, and on Steel Fell, near the pass of Dunmail Raise, between Windermere and Keswick, where the respective curves occupy the same position. The rule amongst our British hills, where this outline is frequent, is that the stream curve should be on the east or north-east face of the hill, and the compound curve on its west or south-west side. It is well seen all along the Helvellyn and High Street ridges in the Lake District, and I believe that it is due to the fact that the south-west slopes in our country are under meteorological conditions allowing of extensive growth of vegetation on the west and south-west slopes, while its growth is checked on the east and north-east sides.

It now remains for us to consider the dominant outlines of mountains in regions where stream erosion is insignificant, and nature works in the dry way, namely, arctic and desert areas. Commencing with consideration of arctic regions, we have the arctic type of hill outline excellently exhibited in the case of the Greenland hills. It can hardly be supposed that the main forms of the mountains have been blocked out by denudation acting in the dry way, for, in the absence of water action, we know of no agent which is capable of carving out valleys and leaving the intermediate portions to stand out as ridges and mountains. Some writers have asserted that glaciers are capable of performing this work, but we shall subsequently see reasons for supposing that they are incapable of the task. We must therefore suppose that a country like Greenland owes its mountains mainly to upheaval, the details of sculpture 


\section{SCIENTIFIC STUDY OF SCENERY}

only being executed by denuding agents, or that at some far-distant time the country enjoyed a milder climate than its present one, and that the blocking out of the individual mountains was then performed by stream erosion. The latter supposition is more probable; but, be that as it may, inspection of the mountains shows that their present outline has not been determined by stream erosion, for the curve of stream erosion is absent and replaced by straight lines, which give the mountains an appearance which is aptly described by the term applied to this structure, namely, "house-roof structure." Illustrations of this structure have been given by $\mathrm{A}$. Kornerup, ${ }^{1}$ and it is very well shown in the accompanying plates, of a hill projecting through Nordenskjöld glacier, and of Hornsund Tind, in Spitsbergen, taken from photographs kindly furnished by Mr. E. J. Garwood.

The principal agent which produces this structure is frost, acting along the divisional planes of the rocks. The water percolates along these divisional planes, freezes, and in so doing expands, and wedges off angular fragments of rock, which fall down the slopes of the hills and accumulate there, forming screes. We have already seen that stratified rocks are specially affected by three sets of divisional plaines, namely, planes of stratification, and two sets of joint-planes at right angles to the planes of stratification and to each other. Let us suppose that the planes of stratification are tilted at an angle of $45^{\circ}$ in one direction and the joints at the same angle in the opposite direction; the frost will work along these planes, and produce a symmetrical

1 Meddelelser om Grönland, part ii., plate vii. 


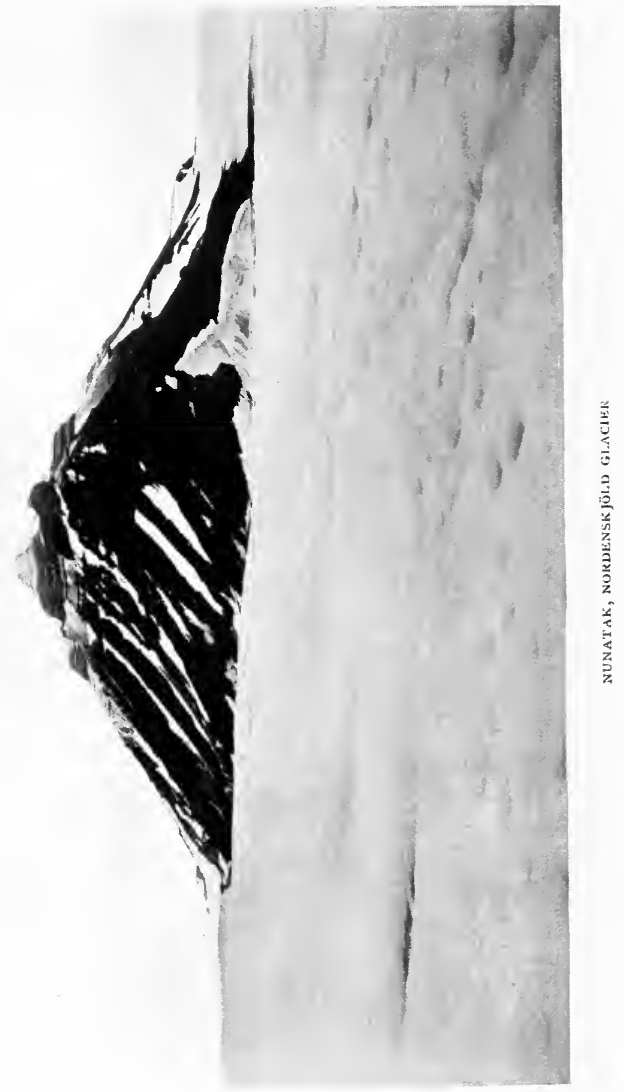


mountain with house-roof structure, as shown in Fig. I9 $a$, whereas if the planes of stratification are less inclined and the joint-planes at a greater inclination the resulting mountain will be unsymmetrical, as in Fig. $19 b$.

In some parts of Greenland this house-roof structure has been brought to a very perfect state as the result of frost action, ${ }^{1}$ and the higher peaks of Spitsbergen show it very well, though the stream line of erosion

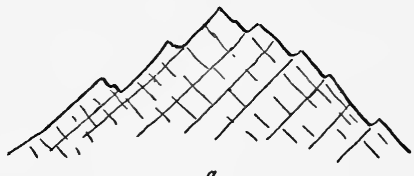

$a$

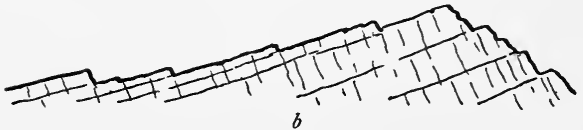

FIG. 19.

is often found in the lower parts of the islands, where stream action is very pronounced. (See frontispiece). The upper peaks and aiguilles of the Alps are also frequently marked by the possession of house-roof structure, but there is every reason for supposing that at no distant date the Alps were subject to the action of ordinary stream erosion in parts which are now permanently above the snow line and occupied by

1 In parts of Greenland, valleys with parabolic section are found, and appear to be due to denudation of rocks effected by a curved system of joints. See figure by KORNERUP, Meddelelser om Grönland, part i., fig. 16. 
snow and ice, and the curves of water erosion in many cases do not seem to be completely obliterated, though partly masked, by the subsequent action of frost. The outline of the Dents de Veisivi shows the frost outline very well as seen from Evolena, as does also the beautiful Dent Blanche, on the opposite side of the Ferpècle glacier, and a very perfect example of a frost-formed aiguille, the Aiguille de la $\mathrm{Za}$, is seen on the ridge of which the Veisivis form the termination.

Denudation in desert regions is also carried on essentially in the dry way, and though the agents are different, the resultant mountain forms are similar to those of arctic regions. The differences of temperature between day and night are very pronounced, as radiation at night causes the temperature to fall to a low point, and the rocks are subject to alternate expansion during the heat of the day and contraction during the cold nights, which causes large fragments to split off the cliffs and fall to a lower level.

"Dr. Livingstone found in Africa ( $12^{\circ}$ south latitude, $34^{\circ}$ east longitude) that surfaces of rock which during the day were heated up to $137^{\circ} \mathrm{Fahr}$. cooled so rapidly by radiation at night that, unable to bear the strain of contraction, they split and threw off sharp angular fragments from a few ounces to 100 or 200 pounds in weight. In the plateau region of North America, though the climate is too dry to afford much scope for the operation of frost, this daily vicissitude of temperature produces results that quite rival those usually associated with the work of frost. Cliffs are slowly disintegrated, the surface of arid plains is loosened, and the fine débris is blown away by the wind." 1

${ }^{1}$ GeIKIE, Sir A., Text-book of Geology, 3rd edition, p. 329. 
The wind in these regions plays the part of transporting agent in lieu of the rivers of areas enjoying a humid climate or the glaciers of arctic regions, and clears away the débris, which would otherwise accumulate to such an extent as to mask the solid rock over which it lay.

We have now considered the main causes of the general features of mountains of upheaval and circumdenudation. Ridges, domes, and plateaux are uplifted owing to earth movements, and these are alike sculptured by surface agencies, so that a series of minor ridges is developed in the direction of the greatest slopes, while both the primary ridge of a simple saddle-shaped uplift and the minor ridges determined by the formation of the consequent valleys are further carved into individual peaks, separated from each other by cols or passes. 


\section{CHAPTER VIII.}

\section{MOUNTAINS (continued)}

\section{DEAILS of Mountain Structure. - We have seen that two primary types of mountain out-}

line exist, according as the mountain mass has been hewn out of the solid block by the sculpturing action of running water, without modification by any other agent, when the double denudation curve is produced, or whether it has been finished in the dry way by the action of frost, or by alternate expansion and contraction owing to rapid and marked changes of temperature. The characters of mountains formed according to the two types are recognisable at a distance, but when we are on the mountain the general outline is often concealed, and we notice minor effects, which, though on a small scale as compared with the bulk of the mountain, are sufficiently important to produce a marked influence on the scenery. A cliff 500 feet high on a mountain 15,000 feet high may appear as a mere notch at a distance, hardly affecting the general character of the mountain outline, but when we are stationed near the base of that cliff it is an object sufficiently imposing to contemplate with feelings of awe.

The minor features of mountain ranges and mountain-masses are due to two principal causes, namely, the character of the sculpturing agent and the nature 
and structure of the component rocks. The influence of these we may now proceed to consider.

Influence of the Sculpturing Agents.-Little- need be added here to what has already been said concerning these, for the effects which are produced on a large scale are, to some extent, repeated on a smaller one. Running water when passing over a surface consisting of alternate hard and soft rocks, before it has established its general base-line of erosion, frequently establishes a temporary series of such baselines in the soft rocks, leaving the harder nearly in their original state for some time; accordingly we frequently find a mountain-side defined by alternate precipices and curves of erosion. The work of frost, though most marked in Arctic and Alpine regions, is sufficiently pronounced in the upland districts of our own country on a small scale, and we find miniature house-roof structure and aiguilles among the hills of our island. The climbers who visit Wasdale Head, in the Lake District, to whom the Great Gable is so familiar, need not be reminded of the appearance of the roof-like "Arrowhead Rock" or the aiguille-like "Napes Needle," which furnish us with excellent examples of mountain detail produced by the action of frost.

The effect of wind is specially marked in desert regions, and we shall pay attention to it at greater length when considering deserts, but its action is sometimes noticeable on a small scale in our own country. The wind sweeps particles of sand near the ground, and carries them against the rock like a sand blast, fretting away the rocks, especially along the divisional planes, such as planes of stratification and joints, and accordingly we get fantastic pillars 


\section{SCIENTIFIC STUDY OF SCENERY}

formed with undercut bases standing from the cliffs, as seen in the case of the well-known Brimham Rocks, carved out of the millstone grit of West Yorkshire.

The fragments split from the cliffs, whether by frost or by alternate contraction and expansion of the rock surfaces, accumulate at the bases of precipices as screes, which often form apparently straight lines, corresponding with the maximum angle at which the loose fragments can rest. These screes frequently form prominent features of a scene ; witness the well-known screes of Wastwater, which rise about 1500 feet above the lake of that name. (See plate in a later chapter.) Screes which accumulate at the bottom of a valley often possess an outline similar to that of the curve of water erosion, and as the stream-courses often branch from the top of the screes, and run in many ramifications down them, it might be supposed that the volume of the individual runlets decreased from top to base, and that a convex curve should be produced; but although the streamcourses ramify, the discharge of water usually takes place down one watercourse at a time, so that the action of water may be neglected, and the curved form appears to be one normally produced by a selfsupporting pile of loose blocks, which, under the influence of its own weight, tends to spread outwards at the base; the larger fragments also tend to roll further down the slope than smaller ones, as they present less surface compared with their mass, and consequently are not so easily arrested owing to friction. These changes give rise to a logarithmic curve. $^{1}$ We find, therefore, that the apparently

1 See Mrlne, Professor J., "On the Formation of Volcanoes," Geol. Mag., dec. ii., vol. vi., p. 506. 
straight lines are not actually straight when closely examined, but form portions of a curve which approaches most nearly to the straight line near the summit of the screes, and rapidly flattens out near the base, and this is true of screes, whether accumulated along a considerable line of cliff or forming a detrital, semi-conical mass, whose apex is situated at the bottom of a gully or scree-shoot, from which the material is discharged, sometimes by running water, at other times owing to the action of frost and other weathering agents.

Other variations than those we have considered, which are due to differences in the nature or mode of operation of the sculpturing agent, are largely affected by the composition and structure of rocks, which we may now proceed to consider.

Influence of Rock Composition and Structure.Apart from all minor considerations, and whatever be the agent of denudation which is at work upon rocks, it may be laid down as a general law that rocks are denuded to a greater or less extent according to their relative durability; the harder rocks tend to resist denudation, and the softer ones to be worn away. As the ultimate result of subaerial denudation (i.e., of that denudation which is carried out over the general surface of the land by frost, rain, rivers, etc., as opposed to marine denudation, which is performed along coast-lines by the agency of the sea) is to reduce a country to a general base level of erosion which is so nearly a plain that it would be undistinguishable from one by the eyesuch a plain has been termed a peneplain by Professor W. M. Davis-and as a peneplain would be produced in softer rocks much more quickly than in those of 


\section{SCIENTIFIC STUDY OF SCENERY}

more durable texture, it is evident that hard rocks are likely to stand out as elevations in a country which has been subjected to denudation for long periods after the soft rocks have been reduced to a peneplain. Accordingly most hilly regions are composed essentially of hard rocks, though there are wide variations in the relative durability of the rocks which compose these regions, as well as those of the flatter tracts. Among the harder rocks the most noticeable are crystalline rocks, as granite, basalt, and the crystalline schists, also many sandstones and limestones, while consolidated muds and clays constitute the most important softer rocks. But, apart from the actual durability of the rock substance, denudation is profoundly affected by the character of the divisional planes which traverse the rocks, and these are of the utmost importance, as determining the details of scenery in both mountainous and more level districts. It will be impossible to separate completely the effects of rock composition and rock texture from those which are determined by the divisional planes which run through rock masses, but we may do so to some extent, and begin with a consideration of the influence of rock composition and rock texture upon scenery of mountain districts, premising that much that is said concerning this and also about the divisional planes applies equally to the scenery of lowland districts.

Beginning with the igneous rocks, we may note, in the first place, that their influence upon scenery is specially determined by their composition, and by the conditions under which they have consolidated. The composition is not only important on account 
of the different effects produced upon rocks of different composition by the agents of denudation, but also because the distribution of the rock mass is affected by its composition. Igneous rocks are divided into two main classes, according to their composition, namely, the acid class and the basic class; the rocks of the former contain a much larger percentage of silica than those of the latter, and rocks of the acid class are generally fusible at a lower temperature than those of the basic class. Accordingly the acid rocks, whether erupted on the earth's surface or forced between masses of rock below the surface, do not as a rule spread far from the place at which they are intruded or extruded, for they cool quickly; whereas the more slowly cooling basic rocks frequently spread over a wide area before finally becoming solid. Acid rocks accordingly occur very frequently in massive bosses, while the basic rocks are apt to give rise to extensive sheets of rock, of no great thickness as compared with their horizontal extent, and having their two limiting surfaces approximately parallel. There are many exceptions to this rule-for instance, in Skye and Mull great masses of basic rock are found as irregular bosses-but taking the two widespread types of the two classes, namely, the acid granite and the basic basalt (using these terms in a somewhat general sense), we find that they conform fairly closely to the above-mentioned conditions. We find accordingly that the granitic type of rock is often carved into massive hills and mountains, while the basaltic type frequently forms terraced hills and plateaux.

The texture of igneous rocks differs with the 
conditions under which they have consolidated, rocks being coarsely crystalline, finely crystalline, or glassy, according as they have been cooled very slowly, fairly slowly, or rapidly, and the difference of texture naturally produces some effect upon the action of the denuding agents, though no general rule can be laid down under this head, for difference of texture is comparatively unimportant as influencing the structure of mountains upon a large scale.

Of greater importance is the shape of the igneous mass, which is due to the mode of intrusion or extrusion. Intrusive rocks may occur as irregular bosses or laccolitic masses, which give rise to irregular or dome-shaped eminences when left standing as elevations owing to denudation of the softer rocks around, or they may be forced into vertical or nearly vertical cracks as joints or fault-planes, forming igneous dykes, or along horizontal or nearly horizontal planes of bedding, forming intrusive sheets or sills, or they may be poured out on the surface as lava sheets, or, finally, they may fill the approximately cylindrical shaft of a volcano. The horizontal or nearly horizontal sheets, often alternating with softer rocks, may be treated as hard strata, and produce the same effects on a large scale. The cylindrical plugs, often surrounded by a hardened mass of baked rock, frequently resist denudation, and stand out as marked elevations, after the surrounding rocks have been worn away.

The dykes merit a somewhat fuller consideration. They are forced between rocks as wall-like masses, and their effect upon scenery depends to a great extent upon their chemical composition. The 
processes of weathering are conducted in two ways, either mechanically or chemically. Hitherto we have not referred to the effects of chemical change on rock weathering, but as it produces marked influence on the character of the scenery, it is necessary to refer to it, and this is the most convenient place in which to consider it, as different kinds of rock are affected by the weather in different ways.

The rain which falls upon the earth is charged with various solvent substances, the most important of which is carbonic anhydride (carbonic acid gas), and the water falling upon soil containing vegetable matter extracts other solvent acids, so that this acidulated water is capable of dissolving certain rock constituents. In the case of many of the sedimentary rocks, the materials of which they are composed have frequently been subjected to the action of carbonated waters at different times, and much of the more soluble material has been leached out of them; but the igneous rocks, brought from the earth's interior, contain much soluble matter, and acidulated surface waters are capable of producing marked changes in them in certain circumstances. Some igneous rocks yield to the chemical action of the weather more readily than others; and accordingly, in the case of dykes, we find that they are frequently more capable of resisting the action of the denuding agents than are the rocks through which they have broken, especially when the denudation is largely mechanical; in these circumstances the dykes stand out as ribs of rock, looking like walls traversing the mountain slope. Anyone who has sailed down the Clyde and passed the island 


\section{IO2 SCIENTIFIC STUDY OF SCENERY}

of Great Cumbrae must have noticed two remarkable wall-like masses of rock standing out above the shore near Millport, one being known as the Lion Rock. These are dykes which have resisted denudation to a greater extent than the surrounding strata. On the other hand, many dykes are more prone to break up under the influence of chemical weathering than the rocks through which they are intruded; and, instead of standing out, they give rise to depressions which may run as trenches along comparatively gentle slopes or level surfaces, or form couloirs and gullies on the faces of steep slopes and precipices. Several gullies on the Scawfell group owe their existence to dykes which have been thus weathered. When weathering along a dyke proceeds to a sufficient extent, a mountain peak may be thus severed into two, with a deep gash between, an event which has occurred on Scawfell. The highest point, Scawfell Pike, is separated from its lower neighbour, Scawfell, by a deep rent, Mickledore, which, as pointed out by the late Mr. Clifton Ward many years ago, is occupied by a dyke which has weathered away more rapidly than the surrounding rocks.

The characteristic outlines yielded by different forms of igneous rocks may now be considered. Rocks of granitic type are often traversed by very regular quadrangular joints which give rise to hemispherical and pillow-shaped outlines, as the result of the action of the weather, for a reason already explained when describing the outlines of certain hills, mainly on account of the increased action of the weather at the edges and corners of the masses. Accordingly hills composed of granitic rocks are 
often dome-shaped in outline, and the pillow structure is characteristic of small upstanding masses, and is specially emphasised when the granite forms "tors," like those of Devon and Cornwall. Though this is the normal shape of granite hills, we find that many granites are traversed by a series of close-set parallel joints, which give rise to spiry crests, very different from the ordinary granitic outlines, as seen in the case of the granite of Arran, rising into the sharp crests and pinnacles of Goatfell, that of the hills surrounding the Bodethal, near Thale, in the Harz mountains, and specially in that type of granite known as protogine, which often forms the cores of Alpine uplifts, as, for instance, in the Mont Blanc massif.

It has already been stated that the basaltic type of rock, when occurring on a large scale, is prone to occur in sheet-like masses of wide extent, forming terraced hills, on which each sheet of basalt, usually well divided by vertical joints, gives rise to a precipice. The terraced hills of many of the western isles of Scotland, of parts of Greenland and other Arctic islands, of the Deccan district of India, and of portions of the western territories of North America are of this character. Another feature which, though not confined to basaltic rocks, is specially frequent in them, is the formation of columnar structure, due to shrinking of the mass while cooling, the columns usually standing at right angles to the cooling surfaces. I need only refer to the Giant's Causeway and Staffa to show that this columnar structure may produce locally considerable effect upon the scenery of a district. Another feature often found in basaltic rocks is a tendency to weather 


\section{IO4 SCIENTIFIC STUDY OF SCENERY}

into exfoliating spheroids, which often occur on a considerable scale.

The colour of granitic rocks is often sufficiently marked to influence the character of the scenery. Many of them are of a prevailing grey hue, owing to the admixture of white felspar with dark mica, while if the felspar is pink, a distinct pink colour is observable at a distance. The basic rocks are often dark, sometimes black, and as the result of weathering the iron silicates contained in the rocks are converted into oxides and hydrates, which produce the rusty oranges and browns forming so marked a feature in the case of weathered basic rocks.

Closely connected with igneous rocks are the fragmental rocks thrown out from a volcano. These consist of particles of various degrees of fineness, from the finest dust to blocks many feet in diameter. These volcanic ashes, when incoherent, allow water to percolate through them with ease, and are apt to retain their original form. Owing to their composition, they may be converted by chemical change into rocks of extreme hardness, and if well jointed, give rise to rugged eminences and precipices, the surfaces of which are peculiarly rough owing to the variation in size of the fragments and their different rates of weathering. The precipices of Scawfell, Great Gable, and other hills of the Lake District beloved by climbers, are composed of altered volcanic ashes, and to their texture is due that character which renders them particularly suitable for rock-climbing.

The group of rocks to which the term "crystalline schists" is applied presents many points of resemblance to igneous rocks, and indeed many of the rocks of the group are igneous rocks which have 
undergone alteration. They are particularly characterised by the possession of foliation-planes (see Chapter II.), and these planes are frequently curved in a very remarkable manner. As the crystalline schists are usually very durable, they tend to resist denudation, and stand out as mountain ridges and peaks. Owing to the closeness of the foliation planes, which causes the weathered rock to split into thin slabs, the crests of ridges and peaks of hills formed of schists are apt to be extremely jagged and serrated with fragments projecting like the teeth of a saw, and as the planes are frequently curved, the pinnacles and teeth frequently present curved outlines, recalling in many cases the projecting ribs of a wrecked vessel.

It was stated in Chapter II. that slates are closely related to schists, and that a gradation may be traced from one class of rock to the other. As a whole, slates are more finely crystalline than schists, and are more readily broken up by the action of the weather. The cleavage-planes of slates are more close-set and regular than those of schists, so that when slates do stand out the serrated structure of a ridge may be even more pronounced than that of a roof formed of schists, though the teeth may be on a smaller scale.

We may now turn to the consideration of the sedimentary rocks, which for our purpose may be divided into sandstones, shales, and limestones, and discuss the scenic effects of these in the order mentioned.

Sandstones are relatively hard, and when alternating with shales, as is often the case, tend to stand out, while the shales are denuded. The joints in 
sandstones are often very regular, and two sets run at right angles to the planes of stratification and to one another, and the deposits of sandstone frequently consist of beds of some thickness, the important bedding planes being separated from one another by a considerable interval of rock. Accordingly when mountains are composed of horizontal or nearly horizontal stratified rocks we find the sandstone bands marked by terraced cliffs and scarps, so well described by Miss Charlotte Brontë in the case of the characteristic millstone grit scenery of the West Riding of Yorkshire around her native village. Fig. 20 shows a diagrammatic representation of a hill composed of alternate deposits of nearly horizontal sandstone and shale, the sandstone being marked by dots and the shale by fine parallel lines, and a similar outline would be produced if the shale alternated with limestone or basalt.

As the result of change, sandstone is often converted into a hard white rock, quartzite, which is very durable, being prone to resist both chemical and mechanical denudation, and accordingly it often gives rise to eminences which frequently betray their character owing to their dazzling whiteness. Some of the quartzite-capped hills of Sutherland and Ross, where the quartzite reposes upon rocks of a prevalent reddish colour, sometimes appear as though capped with snow.

The upper surfaces of gently inclined sandstones, often laid bare to form gentle slopes, owing to denudation of softer beds above, may simulate to some extent the surfaces of granitic districts and present rounded outlines, though very frequently they are comparatively flat if the sandstone is 
sufficiently durable to resist weathering even along joints. The effect of wind on masses of sandstone will be most conveniently considered when we describe the characters of desert regions.

Shales are composed of very fine particles, and are generally affected by close-set planes of lamination. Jointing is also often on a smaller scale than in the case of sandstones, and as the result of weathering shales tend to break up into small prismatic fragments, which present many surfaces to the weather and cause the rock fragments to be further comminuted into an incoherent mud, which is readily washed to a lower level, and gives rise to a slope of loose

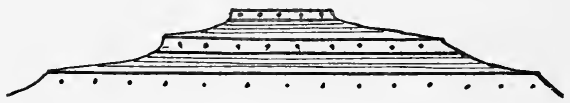

FIG, 20.

material on which vegetation will readily grow; accordingly shales are prone to produce gentle grass-covered slopes, separating the cliffs of more durable rock. On comparatively level surfaces, whether on the mountain-side or the lowlands, owing to the impervious nature of the shale, water finds a difficulty in penetrating into the ground, and in humid climates a tract occupied by shales is apt to give rise to rushy and marshy ground.

The peculiar features of limestone countries are due to the well-jointed and thick-bedded character of many limestones, and to their porosity and solubility. The rocks break along joint-planes, producing cliffs resembling those formed by sandstones. As limestone is fairly soluble in carbonated water, and 


\section{IO8 SCIENTIFIC STUDY OF SCENERY}

as solution occurs along the joint-planes more extensively than elsewhere, much of the drainage of limestone is underground, giving rise to caves, whose structure will be considered elsewhere. Owing to this underground drainage, limestones are often marked by absence of surface streams, and corrasion is of little account, and accordingly even soft limestones like chalk often stand out as hills. As the rain penetrates along joint-planes the limestone is often cut up into more or less quadrangular columns and pinnacles, and, owing to solution along fairly horizontal bedding planes, these pinnacles become fretted in an extraordinary manner. The small hollows on the general surface of a fairly horizontal tract of limestone hold the water, and solution takes place in these hollows, causing their gradual enlargement. Accordingly the surfaces of fairly level limestone tracts (known as "clints" in the north of England) present a rough, irregular surface, traversed by wide open fissures penetrating to a considerable depth, often filled by masses of hartstongue and other ferns, while the surface of the limestone is apt to be bare of vegetation, or if the limestone is impure a thin, dry soil is formed, which gives rise to a short, sweet herbage like that covering the chalk downs.

The characters of a limestone area are often developed in an exaggerated form in a region composed of the rock formed of carbonates of lime and magnesia, and usually spoken of as dolomite. The joints in this rock are frequently developed with extraordinary regularity, and give rise to those remarkable mural precipices and pinnacles which have caused a certain area of the Eastern Alps to be 


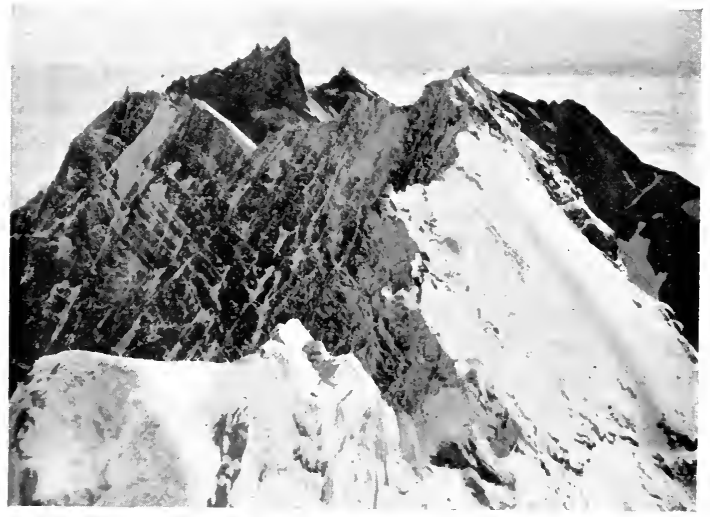

IIORNSUND TIND

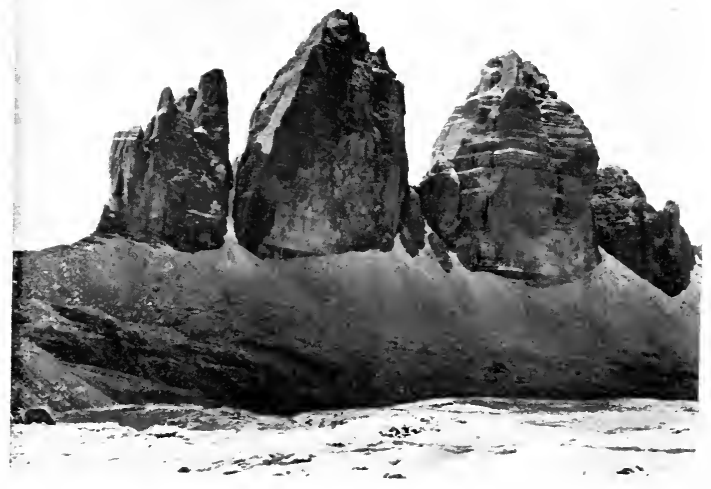

THE DREI ZINNEN 
spoken of by the title of "The Dolomite Mountains." The Drei Zinnen (shown in the plate) and the Funffingerspitze are well-known examples of this structure. Solution along bedding and joint-planes also produces very characteristic effects in detail, many of the summit ridges of the dolomite districts resembling piles of ruined masonry. The characteristic outline of dolomite rock, though specially well shown in the Eastern Alps on a large scale, is frequently reproduced on a small scale among the masses of dolomite which occur here and there among the crystalline rocks of the Valais and other parts of Western Switzerland.

Before leaving the present subject reference must be made to the quartz veins which frequently traverse rocks of many kinds, both aqueous and igneous. They have been deposited from solution along the various planes of weakness which traverse the rocks, and occur sometimes in regular bands, at other times in an irregular interlacing network of strings and knots. They frequently produce an effect owing to their conspicuous whiteness, but are also important to us because they often furnish a hard skeleton to rocks which are otherwise soft, causing them to resist denudation and to stand out as hills.

Passing from the influence of particular kinds of rocks upon scenery, we must still say something about major divisional planes which traverse great belts of rock of diverse composition, and also concerning the alternation of inclined rocks of different degrees of hardness. Divisional planes, such as faults or parallel systems of faults, act as planes of weakness along which denudation readily acts, and the same may 


\section{IIO SCIENTIFIC STUDY OF SCENERY}

be said of inclined soft strata. Complications thus arise in the drainage lines which modify to a considerable degree the initial drainage which was established in accordance with the laws which we have discussed. These complications will be more fully considered when we treat of the formation of valleys in greater detail, and they are referred to here in order to point out their effect upon mountains. We have seen that mountain peaks are normally formed along ridges, and that each mountain peak of a symmetrical mountain ridge is separated from adjoining peaks by cols, and stands at the head of a consequent valley, while a secondary ridge extends in a direction opposite to that of the valley. Accordingly most mountain peaks are merely the culminating points of ridges, with a long slope facing the consequent valley, and two arêtes, or ridges, stretching to the cols. A true pyramid is therefore rare, and when it occurs excites interest. If in any way the ridge which extends from a peak in a direction opposite to the conse-quent valley is cut through, the peak may become a true pyramid. On the flanks of the Pennine chain, in its course through Westmorland, four great buttresses-Roman Fell, Murton Pike, Dufton Pike, and Knock Pike-stand out from the escarpment. Two of these, Murton and Dufton Pikes, are true pyramids, and form very conspicuous objects from the main line of the Midland Railway. They were once the terminations of secondary ridges, coming from the Pennines; but owing to the existence of a fault between them and the main scarp of the Pennines, denudation has occurred along the plane of weakness, producing a depression, 



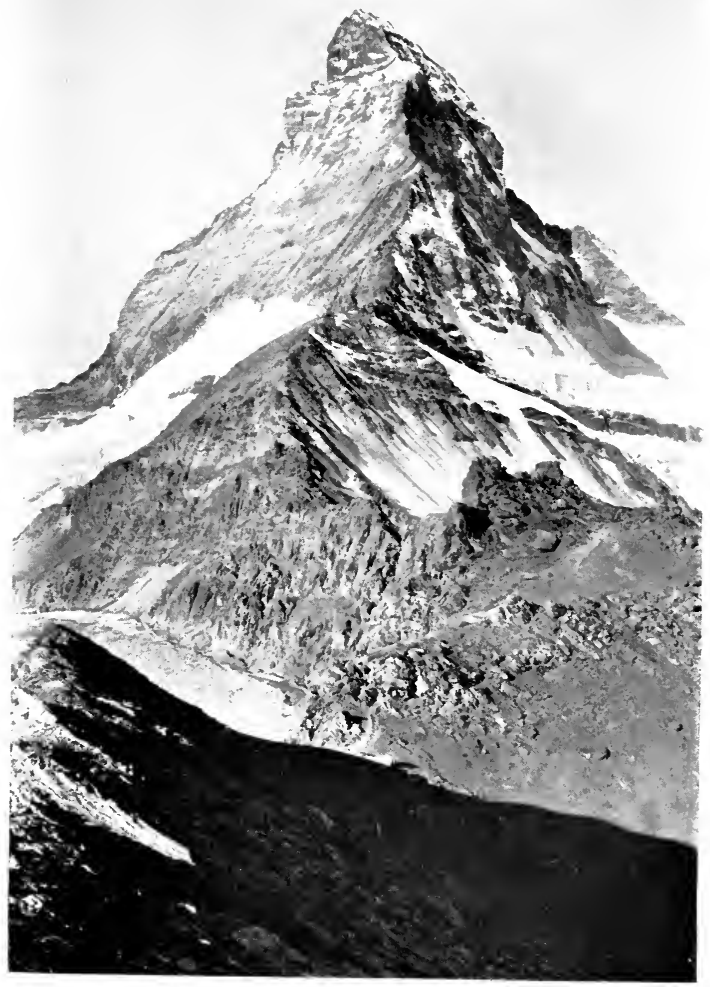

THE MITTERHORN, FROM THE HÖRNLI 
which has caused the Pikes to stand out as pyramids.

Still more striking is the case of the Matterhorn, that mysterious-looking pyramid which has excited the wonder of all who have gazed at its apparently unscaleable cliffs. It has already been pointed out that it occurs at the head of the Val Tournanche, and is separated from the Breithorn on one side and the Dent d'Herens on the other by cols, and that a secondary ridge once extended from it on which the Weisshorn stands. This secondary ridge has been cut through by the valley occupied by the $\mathrm{Z}$ mutt glacier, which owes its existence to a line of weakness apparently due to the occurrence of a belt of comparatively soft rock, which extends across the Zermatt valley beneath the valley occupied by the Findelen glacier. Accordingly we find the Matterhorn, formerly the end of a long ridge at its junction with the main ridge, now approaching the form of a true pyramid. (See the plate.)

Vegetation on Mountains.-It is well known that elevation produces its effect upon the character of the vegetation, and that a mountain near the equator rising to the snow line is occupied by zones of vegetation which, to some extent, represent the zones which are traceable when travelling from equatorial to polar regions. The detailed changes in vegetation vary with the geographical position of the mountains, but whereas the lower slopes of the mountains in all but arctic regions are frequently covered by belts of dense forest, these are replaced higher up by shrubby growths, still higher by grassy slopes enriched by numerous brilliantly coloured flowering 
plants, at a higher elevation by lichens, and at last by bare rock or perpetual snow. The peculiar type of vegetation which constitutes what is known as an Alpine flora exerts considerable influence upon the scenery owing to the peculiar conditions under which it grows. Supplied with abundance of water during the times of melting snow, and at other times deprived of an outward supply of water during long intervals, the growth of the plants is modified in various ways to meet the peculiar conditions. Specially interesting to us is the formation of the cushion-shaped masses of plants, often covered with a profusion of bright flowers. As in the case of species of Silene, Androsace, Petrocallis, and Eritrichium, these masses frequently occur in such abundance on rocky slopes and moraines, that they produce a very marked and pleasing influence upon the character of the scenery. 


\section{CHAPTER IX.}

\section{VALLEYS}

VALLEYS are of two kinds, namely, those produced by earth movement and those produced by denudation, though as in the case of mountains, so in that of valleys, the two processes work together. As the ridge of an earth-wave produces a mountain range, so the trough gives rise to a valley of depression, and when mountains are sculptured by denuding agents the intervening gaps are left as valleys of denudation.

Valleys of depression will coincide with troughs of the strata, or we may have one side of the valley defined by a fault which replaces the septum of the earth-wave.

Of valleys which are primarily defined by folding, we may mention in our own country the lower part of the Thames, between Windsor and the sea, while abroad a good instance is furnished by the upper part of the Rhone valley, between its source and Martigny, separating the Alps of the Bernese Oberland from those of the Valais. In each case the river runs along the bottom of a trough-shaped fold. An example of a valley produced by a faulted depression is that part of the Vale of Eden which lies between Kirkby Stephen and Carlisle, and an admirable example on a large scale in a foreign country is supplied by the Jordan valley, and its prolongation to the southward. 


\section{SCIENTIFIC STUDY OF SCENERY}

Though geologists are generally agreed that the majority of valleys are formed by erosion, and not by folding or cracking of the earth's crust, there are many people who will feel surprised when told that a river can carve out its own valley. Anyone who carefully considers the laws of erosion, as described in the preceding chapters on mountains, and sees how exactly the directions and structures of valleys of erosion agree with those which they should possess in accordance with those laws, will, I think, be compelled to admit that these valleys must have been carved by erosion, but it will perhaps be as well to give some evidence that rivers can and do erode their valleys, though we cannot afford space to treat the matter at great length.

In the first place, it may be remarked that many people have a very exaggerated notion of the slopes of valleys and mountains. Writers talk glibly of precipices and beetling cliffs when the prosaic surveyor finds that the general slope is perhaps less than $45^{\circ}$. Vertical precipices on a large scale are very rare, and, as before remarked, form comparatively insignificant features on a mountain-side when the mountain is viewed from a distance. Mr. Whymper notes that the east face of the Matterhorn, which looks so steep when viewed from the Riffel, slopes at an angle scarcely exceeding $40^{\circ}$, and he remarks :-

"Forty degrees may not seem a formidable inclination to the reader, nor is it for only a small cliff. But it is very unusual to find so steep a gradient maintained continuously as the general angle of a great mountain slope, and very few instances can be quoted from the High Alps of such an angle being preserved over a rise of 3000 feet." 1

1 Whymper, E., The Ascent of the Matterhorn, p. 228. 
On the accompanying figure (Fig. $2 \mathrm{I} B$ ) is shown a section through Mont Blanc and the valleys of Chamonix and of the river Doire, which is a portion of a section having the same vertical and horizontal scale given by the late $\operatorname{Sir} \mathrm{H}$. de la Beche in Plate II. of his Sections and Views Illustrative of Geological Phenomena, while above it $(A)$ is a section across Snowdon reduced from one of the horizontal sections of H.M. Geological Survey on

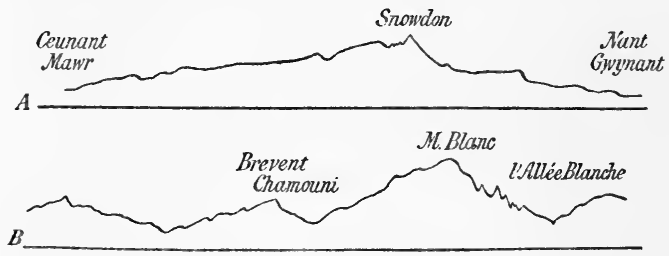

FIG. 2 I.

$A=$ Section across Snowdon from Llanberis to Gwynant. (After Sir A. RAmSay.)

$\mathrm{B}=$ Section across Mont Blanc. (After Sir H. DE LA Beche.)

In each section the vertical scale is the same as the horizontal scale. The scale of Section A is about three times as great as that of Section B.

the scale of six inches to the mile, horizontal and vertical. These are sufficient to show the comparative smallness of angles in slopes which appear to be very steep.

Examination of sections across valleys drawn to true scale will convince anyone that the majority of valleys are not mere cracks produced by fissuring of the earth's crust. It has already been stated that some valleys of depression are determined by lines of fault (though it can generally be proved that even 


\section{II6 SCIENTIFIC STUDY OF SCENERY}

these largely owe their present features to subsequent denudation), but as it is found that most valley bottoms are not occupied by faults, but that the rock runs unbroken across them, faulting is out of the question in those cases. Again, it might be supposed that valleys could be produced by bending of the strata into an arch which was ruptured at the summit, giving rise to a $\mathrm{V}$-shaped opening, and the coincidence of many valleys with lines of anticlinal folds of the strata seems at first sight to countenance this view. On examination, however, it is usually found that the slope of the strata is much smaller than it should be if this were the explanation of the origin of valleys. If a valley were formed by rupture of an arch composed of strata which were originally horizontal, and the rupture gaped to such an extent as to give the valley sides slopes of $30^{\circ}$, a slope which is above the average slope of valleys, the strata should dip away at an angle of $60^{\circ}$ on either side, whereas when the direction of a valley does coincide with that of the axis of an anticlinal fold the dip of the strata on either side is often quite gentle. There is one method of producing an open depression by earth movement which has perhaps not received the attention which it deserves. When an arch is formed the upper strata are bent into a larger curve than the lower ones, and cracks may be formed in the upper beds which do not extend to the lower ones; furthermore lateral sliding of the upper strata along a well-marked plane of stratification may take place, thus giving rise to a depression bounded by heights on either side. In rocks which have been subjected to much folding, it is probable that minor valleys have often been initiated in this 
way, but as a general rule we have abundant evidence that the action has not been responsible for the formation of valleys. It may be further remarked that the slope of a valley formed in this way should approach a plane surface, whereas the sides of valleys in regions which are marked by copious rainfall have the curve characteristic of stream erosion.

Anyone taking his stand on a height overlooking one of the Yorkshire dales, say the slopes of Ingleborough, will see the nearly horizontal escarpments of the harder strata sweeping in continuous curves round the sides and heads of the valleys, each major deposit obviously represented by the corresponding strata on the other side of the valley, and examination of such a scene will be more useful than pages of description devoted to the subject to convince an observer that the valley has been carved out by erosion.

But hitherto we have only put forward indirect proofs that running water can crode. We have discussed the ideal curve of stream erosion, and seen that the actual curve corresponds with it in areas where streams course over the surface of the country, and that the curves are absent where streams are wanting. Let us now examine the action of these streams, in order to see whether they are capable of exerting the requisite erosive power, for many writers, though admitting a limited erosive power to rivers, deny that these are capable of performing the work which geologists claim for them, and this is not to be wondered at, when the chances are that the first river which is examined will, under existing conditions, have reached its base-level of erosion in a country which has not recently uprisen. 
If we take our stand by the side of a small rocky gorge, we shall probably see a number of hemispherical or cylindrical hollows in the bed of the stream and semi-cylindrical shafts on the rocky walls, which are known as potholes. Those which are submerged, as well as those which are now high and dry, will probably be occupied by a number of water-worn pebbles. During a flood it will be seen that eddies are at work over these hollows, and that the pebbles are whirled round and round by the eddies, gradually boring their way into the rock, like the drill of a diamond boring machine. In time two contiguous potholes join, and so a whole number may coalesce, and by their coalescence the gorge is deepened, and some of the isolated potholes left dry above the existing stream-level. In this case it is seen how a gorge can be formed, and its size is merely a question of time, so long as the stream can work without reaching its base-level of erosion. Now take the case of a gorge below a waterfall, as, for instance, Niagara. We know, as the result of direct observation, that the falls are cutting backward; and we also know that the structure of the gorge is essentially similar through the whole of its extent, and accordingly writers are agreed that Niagara has cut out a gorge from 200 to 400 yards wide at the top, 200 to 300 feet deep, and seven miles in length, in times which are, in a geological sense, recent. ${ }^{1}$ Here is a gorge which, it is generally admitted, has been carved by the river which now occupies it. But we find every gradation from the waterfall, through the cascade and the rapids, to the

${ }^{1}$ For a full account of the formation of the Niagara gorge, see Lyell, Sir C., Principles of Geology, I Ith edition, vol. i., chap. xv. 
ordinary flowing river. The work is performed in each case in the same way, it is only the amount which is different; this amount, as we have seen, being dependent on declivity, when other things are equal. We may cite a few other instances of actual formation of small valleys which are known to have been formed by water action. "A great mass of débris was washed down from the sides of Blease Fell, on the east of the Lune, about two miles south of Tebay Junction, in the course of three or four hours during a thunderstorm, about the year 1858 . The rain excavated deep channels in the weathered rock of the hill-side, and spread the rubbish over some pasture land below. The débris still forms a striking object as seen from the train."1 Gilpin ${ }^{2}$ describes the occurrence of a "cloud-burst" in the Vale of St. John, in the Lake District, on August 22nd, I749, "which forced a new channel through a solid rock . . . and made a chasm at least ten feet wide." Again, in the same district, "an interesting gully is seen somewhat north of the top of High Street, where, as seen on the six-inch ordnance map, the Roman road is partially destroyed by a ravine, which has cut through it. The head of the ravine is a few yards above the road, and where it cuts the road it is about eighteen feet deep and I03 feet across at the top. It is excavated partly in loose rubble, but largely through rock in situ, though much affected by weathering. Some of the material may have been removed by landslip, but the greater part

1 Strahan, A., Mem. Geol. Survey, "The Geology of the District around Kendal," etc., p. 5 I.

${ }^{2}$ Observations on the Mountains and Lakes of Cumberland and Westmorland, vol. ii., p. 36 . 
was probably disintegrated by running water, which has also removed it."1 In Lyell's Principles of Geology (vol. i., chap. xv.) an example is given of a gorge "from fifty to several hundred feet wide, and in some parts from forty to fifty feet deep," which has been excavated by the river Simeto in a current of lava which, according to Gemmellaro, flowed from Etna in 1603 . "On entering the narrow ravine where the water foams down the two cataracts, we are entirely shut out from all view of the surrounding country, and a geologist who is accustomed to associate the characteristic features of the landscape with the relative age of certain rocks can scarcely dissuade himself from the belief that he is contemplating a scene in some rocky gorge of very ancient date."

These examples will suffice to show that rivers can erode, and the last is specially instructive. If a gorge forty to fifty feet deep can be carved out of hard rock in less than three centuries, how much greater effects can be produced during the vast intervals of time which we can prove to have elapsed since the initiation of many of our existing drainage systems.

In some of the examples cited, it will be noted that the work was done during periods of excessive rainfall, and it must be remarked that periods of flood are the times when the work of denudation is almost exclusively performed. The transporting power of a river varies, not directly as the velocity, but as the sixth power of the velocity, and accordingly the corrasive power of a river is enormously increased during periods of flood. This should be 
remembered by those who are inclined to minimise the importance of rivers as agents of denudation. In the forty years that have elapsed since the formation of the ravines on Blease Fell, near Tebay, the erosion which has occurred is as nothing compared with that which was then performed in a few hours.

In Chapter V. allusion was made to the initiation of the chief drainage lines of a country which had undergone uplift, producing a set of primary consequent streams running in a general direction at right angles to the axis of uplift, and therefore along the direction of the dip of the beds, and another set of secondary subsequent streams whose courses are directed along the strike of the strata, and approximately at right angles to those of the consequent streams. ${ }^{1}$ We have stated that the consequent and subsequent streams would, if conditions were uniform, run in straight lines, and the main direction of these streams often approaches the straight line, but in uplift of actual rocks thousands of minor inequalities would occur which would divert the stream now on one side, now on another, from its ideal course, and give it a sinuous track. The subsequent streams will only be approximately at right angles to the consequent streams, for although the secondary watershed between neighbouring consequent streams is parallel to the courses of those streams, the subsequent streams are also affected by the general declivity of the land towards the ocean,

1 The terms "consequent" and "subsequent" are applied to rivers by Professor W. M. Davis in a paper on "The Development of Certain English Rivers" (Geograph. Journal, vol. v., p. 127), which very clearly describes the initiation of a typical drainage system and its changes. 


\section{I22 SCIENTIFIC STUDY OF SCENERY}

and though this will probably be slight as compared with the slope between the secondary watershed and the bottom of the consequent valley, it will produce its effect, and cause the subsequent streams to run somewhat obliquely to the strike of the strata on their way to join the consequent streams.

Consequent streams, being in the direction of the dip, have the divisional planes of the rocks on either side of the stream bearing the same relations to the stream if conditions be uniform, but this is not the case with subsequent streams, and accordingly the cross-section of a subsequent stream is apt to be unsymmetrical. In an ideal uplift the subsequent stream will at first run over one stratum, the uppermost, but, its course being somewhat oblique, it will flow over different strata as it corrades its valley; though, as shown by Gilbert, in a region of inclined strata there is a tendency on the part of streams which traverse soft beds to continue therein, and there is a tendency to eliminate drainage lines from hard beds.

In Fig. 22 let $\mathrm{A} \mathrm{B}$ be the surface of the ground, on which a series of inclined strata, H S, crop out, and let $\mathrm{H}$ be hard and $\mathrm{S}$ soft strata. Suppose a subsequent stream running on a hard stratum at $X$, the cross-section of its valley at the outset being indicated by the semicircular unbroken line. The stream, if the hard rock be uniform, will corrade vertically downward till it reaches the softer rock below, and if this be also uniform, it will corrade downward through this also, as shown by the loopshaped dotted lines marking different stages of its progress. When it reaches the underlying hard stratum it will probably find it easier to cut sideways 
along the junction of soft and hard strata, as shown by the dotted lines to the right of the position of the original stream, and will tend to undercut the overlying hard stratum. At $Y$, where the stream is supposed to originate in the soft rock, it cuts vertically down to the junction with the underlying hard rock, and then cuts sideways as before, and a stream developed along the soft rock between $\mathrm{X}$ and $\mathrm{Y}$ would act similarly. Now we have seen (Chapter II.) that the master-joints of rocks run in two sets, respectively parallel with the lines of dip and strike, and as the overlying hard rocks are

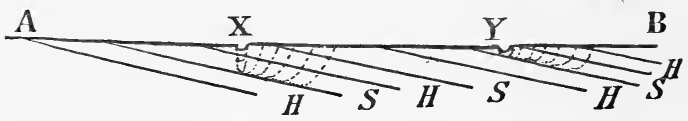

FIG. 22.

undercut they will be detached by the action of the weather and in landslips, and the material will fall into the stream and be transported. In gently inclined rocks the joints will be highly inclined, and accordingly every valley formed by a subsequent stream will, when the inclination of the strata is less than $45^{\circ}$, as is usually the case, have a gentle slope on one side, formed by the summit of a hard rock (and this slope will possess the direction and degree of inclination of the dip of the rock), and a steep slope on the other, corresponding with the inclination of the strike joints. Accordingly, after gently inclined rocks are affected by the corrasion of subsequent streams, a section across the country at right angles to the direction of flow of the subsequent streams will present the appearance shown 


\section{I24 SCIENTIFIC STUDY OF SCENERY}

in Fig. 23. The gentle slopes, $\mathrm{D}$, are known as dipslopes, and the steeper ones, E, as escarpments, and every escarpment in a district which has been formed by a simple uplift of strata above sea-level will face inland, and each dip-slope will slant down seaward. In many cases, especially with softer rock, the slope of the escarpment, and often the dip slope also, will be diminished by accumulation of loose material, but with hard rocks the escarpments often stand out as parallel lines of cliff, each cliff being limited to the hard stratum or set of strata to which it owes its origin. These escarpments, of course, give rise to tertiary watersheds, from which streams flow in

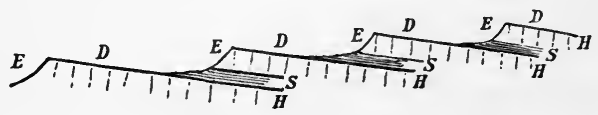

FIG. 23.

either direction. Those which flow down the escarpment in a direction contrary to that of the primary consequent streams are termed obsequent streams by Professor Davis; the other streams which flow down the dip-slopes will have courses parallel to those of the primary consequent streams.

When we meet with great belts of alternating soft and hard strata, the escarpments may recede owing to general degradation by weathering and the action of obsequent streams and their tributaries, and the escarpment may recede while the subsequent stream which determines it remains practically stationary; we then get an extensive plain occupied by the subsequent stream and its tributaries, and the courses of obsequent 
streams are lengthened by recession of the top of the escarpment. Thus we find the great plain of the soft lias and new red sandstone rocks of the east and south-east of England dominated by the westward-facing escarpment of the hard oolites. Approaching the east coast, we find that the dipslope of the oolites, sloping eastward, plunges down to another plain formed of the soft upper Jurassic clays. Another escarpment facing westward is frequently encountered, formed of the more durable lower greensand, the dip-slope of which in turn sinks to the plain of soft gault clay, which is overlooked by the great escarpment of chalk, again facing westward. These two salient escarpments, that of the oolites and that of the chalk, with their corresponding plains, formed in the way described above, form dominant features of the scenery of the south-east portion of England.

Owing to the tendency of the streams which run obliquely across harder and softer strata to eliminate their courses from the harder rocks, and to flow when possible over soft strata, a subsequent stream with an oblique course, indicated by the dotted line in the following plan, in which the outcrops of hard and soft strata are respectively represented by the letters $\mathrm{H}$ and $\mathrm{S}$, will tend to alter its course, so that it ultimately flows in the direction indicated by the thick black line, though it must be understood that the stream, with its altered course, would not be actually beneath the original one, as the whole has shifted laterally. (The arrow indicates the direction of dip of the strata.)

The formation of obsequent streams, and of the other tributaries to a subsequent stream which run 
down the dip-slopes, will give rise to another set of watersheds from which subsidiary tributaries may flow, so that a river system eventually may consist of consequent stream, with a whole network of tributaries, but with the formation of subsequent streams and their main tributaries we have obtained a sufficient insight into the development of a typical drainage system in an area affected by a symmetrical uplift.

Before considering the deviations of drainage which may be subsequently produced in different ways in an uplifted area, it will be convenient if

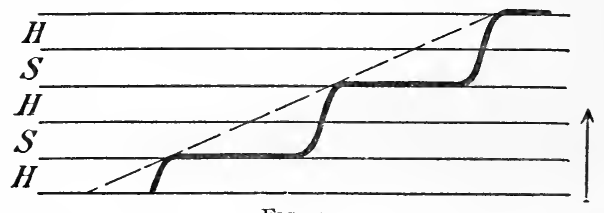

FIG. 24.

we devote a short space to consideration of the forms of river valleys as shown in cross-section.

The typical river valley is bounded by two hill slopes, each possessing the denudation curve, and if conditions are uniform, the cross-section of the valley will show an outline similar to that represented in Fig. $25 a$, while if we take a longitudinal section from the watershed to the mouth of the river, along the valley-bottom, the denudation curve will appear as seen in Fig. $25 b$, though here the lower part of the curve will probably approximate to a straight line for a considerable part of its course. ${ }^{1}$

${ }^{1}$ An English term for the line taken by the course of a river apart from its meanderings is much needed, and we are driven to use the German term Thalweg for this line. 
In the case of a consequent valley formed under uniform conditions, the curve will be bilaterally symmetrical, whereas in a subsequent valley the curve will be greater on the escarpment side than on the side of the dip-slope as seen in Fig. 23.

Writers sometimes speak of river valleys as I-shaped, V-shaped, U-shaped, and Y-shaped, according to the slopes, which roughly recall those of the letters with which they are compared, but all valleys of erosion will be ideally U-shaped, though the arms of the $U$ will depart from verticality and become
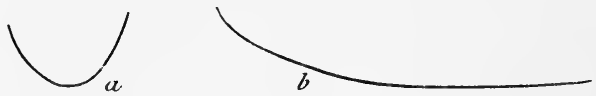

FIG. 25.

$a=$ Cross-section of a valley of erosion.

$b=$ Line of Thalweg.

separated to a greater or less extent, according to certain conditions controlling erosion, the principal of which are the nature of the rock, the character of the weathering, and the occurrence of earth movement, and of these the nature of the rock is really of importance mainly because the weathering is influenced by it, as soft rocks weather more readily than hard rocks.

If a rock resists weathering, the rivers will cut narrower valleys than when the rock is readily weathered. This is seen by the fact that narrow gorges are apt to occur in rainless regions, though there are many exceptions to this, and under suitable circumstances extremely narrow gorges can be formed in regions of considerable rainfall. It is also well shown by the formation of those peculiar structures 


\section{I28 SCIENTIFIC STUDY OF SCENERY}

known as earth-pillars in districts where the conditions are suitable for their formation, and as these earth-pillars, when well developed, are apt to excite the curiosity of those who see them, we may devote a short space to their description.

When a river runs through a compact homogeneous clay charged with large stones, as shown in Fig. 26, it cuts out a gorge with the characteristic denudation curve $a b c$. If the rainfall is great, and fairly vertical, the stones act like umbrellas, and protect the clay immediately beneath, while the

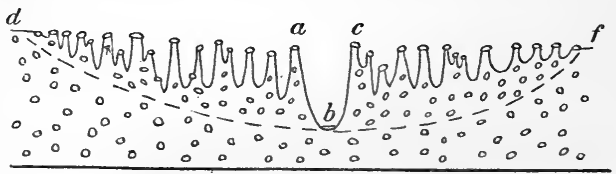

FIG. 26.

intervening clay is washed away by the rain and carried into the river. Accordingly the stoneprotected masses stand up as pillars, the sides of which are furrowed by rain trickles, and they often possess minor pinnacles and buttresses, due to other stones occurring in the mass of the column. Now, if the stones had not been in the clay, the whole of the clay would have been washed. away by rain action, and instead of the gorge $a c b$ we should meet with a wider valley, $d b f$. The pillars which occur near Botzen, in the Tyrol, are fully described and figured by Sir C. Lyell in his Principles of Geology (vol. i., chap. xv., and Plate II.); they vary in height from twenty to a hundred feet. The pillars near Stalden, above Visp, are well known, and 
some admirable examples are found at Useigne, in the Val d'Herens, where the process of formation is well shown. They are carved out of the material of the terminal moraine of the ancient Val d'Heremence glacier. This moraine has been carved out into sharp ridges by stream action, and the ridges are further cut up by rain to form the pyramids, which are cut through by the road to Evolena, on either side of the mouth of the Val d'Heremence, though the pillars of the upper group are more striking than those of the lower.

One of the most important conditions for the formation of a steep gorge is the occurrence of a swift stream which can corrade rapidly, in which case weathering action cannot widen the gorge to any extent while the river is deepening it. The swiftness of the stream may be due primarily to uplift, and this is no doubt the most important factor in producing steep-sided streams. When the upper part of a river-course is being elevated, while the lower part is stationary, corrasion will be increased, and a gorge will be formed. To this cause, as well as to the arid climate, the extraordinary cañons of the Colorado region are due. It follows that when a river has reached its base-level of erosion, and downward corrasion is stopped, the action of the weather will be very pronounced, and accordingly a gorge is not likely to exist for long periods in a rainy region when the base-level of erosion has been established. There are many secondary causes which increase the corrasive power of a river over parts of its course, and gorges may be carved out there; for instance, as already seen, a waterfall will form a gorge, and we shall show in the sequel that 


\section{I30 SCIENTIFIC STUDY OF SCENERY}

many waterfalls are due to secondary changes in river-courses.

When vertical corrasion and weathering are both at work, the width of the valley will depend on their relative importance; but when the base-level of erosion is reached, important changes in the action of the river occur, which must now be considered.

So long as vertical corrasion is in operation, lateral corrasion of the side of the river-bed is insignificant; but as soon as vertical corrasion is checked by the establishment of the base-level of erosion lateral corrasion becomes important, and the rivers work sideways instead of downward, though the width of the river is not necessarily increased thereby, for compensation is made for corrasion of one bank by deposition on the opposite one. We have already noted that the courses of streams are unlikely to be actually straight in nature, as the river, on its initiation, will be turned from side to side by minor inequalities. Imagine a portion of a river-course flowing in the direction indicated in Fig. 27, that is from $x$ to $y$, and that it has a slight $\mathrm{S}$-shaped curve owing to some inequality in its course. In the straight part of a river-course the centre of the stream flows more rapidly than the sides, and the top than the bottom, as the stream is retarded by friction against the bottom and sides. Now when the stream, after traversing a straight portion of its course, reaches the curve represented in the figure, the central swift part tends to flow on in the same straight line, and impinges against the concave bank at $x$, eroding it, while an eddy is set up, which causes the current to flow backward 
on the convex side, $x^{\prime}$, and to deposit material there. The same process takes place at $y$, and, as a result, the $\mathrm{S}$-shaped curve becomes emphasised, as shown by the dotted lines, and the river has a cross-section like that of $b$, Fig. 27, which is a section taken from $y^{\prime}$ to $y$ in $a$. The whole of the $\mathrm{S}$-shaped curve tends to work down the valley

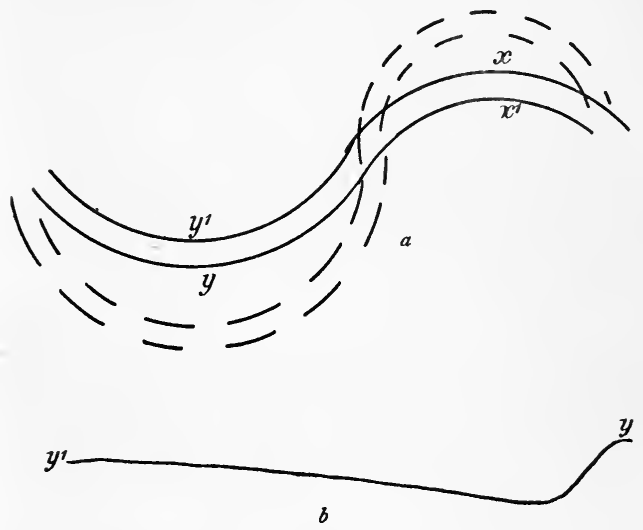

FIG. 27.

owing to the general slope of the Thalweg; and accordingly, when a river has reached its base-line of erosion, it tends to widen its valley, and to form a plane surface which slopes gently towards the ocean. Through this plain the river meanders in loop-shaped folds. During flood-times the river overflows its banks, and in the slack water of the flooded portions sediment is deposited in the form of alluvium, which may build up the floor of the 


\section{I32 SCIENTIFIC STUDY OF SCENERY}

valley to a considerable height above the level which it reached when the base-line of erosion was established. These alluvial flats mark various parts of river-courses, though they are usually more numerous in the lower portions. A cross-section of a valley under these conditions will be as follows :-

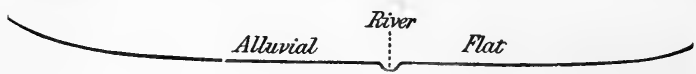

FIG. 28.

When the S-shaped folds have been growing for some time, they may form almost complete circles, and during floods the river may cut through the isthmus which separates portions of two loops, when the old course will be left as a crescentic lake.

"A multitude of such crescent-shaped lakes, scattered far and wide over the alluvial plain, the greater number of them to the west, but some of them also eastward of the Mississippi, bear testimony to the extensive wanderings of the great stream in former ages." 1

After the establishment of an alluvial flat by lateral corrasion accompanied by deposition the plain will remain unaltered in its general characters, though it may increase in width, so long as conditions remain the same. Should the power of the stream to exert vertical corrasion be restored to it in any way, it will again cut downward, and a valley within a valley will be formed, as shown in Fig. 29, in which $a$ exhibits a symmetrical cross-section, where the river-course happened to be in the centre of the alluvial plain at the time that vertical corrasive

${ }^{1}$ Lyell, Sir C., Principles of Geology, vol. i., chap. xix. 
power was restored, while $b$ shows an unsymmetrical cross-section, with the later part of the valley towards one side of the earlier portion. This diagram illustrates the character of the Grand Cañon of the Colorado, which is a valley within a valley. It is clear that the loops which were formed when the base-level of erosion had been temporarily attained will still be retained, and as a consequence of the pause, followed by downward erosion, we are furnished with those remarkable cases of narrow valleys which run with very winding courses, such as the two
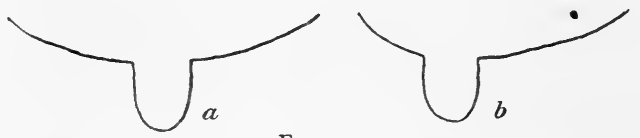

FIG. 29.

Crooks of Lune, above Lancaster and Kirkby Lonsdale, and the great bend of the Wear around Durham Cathedral.

Restoration of the power of a stream to corrade vertically may be due to several causes, the chief of which is uplift of the land along the upper course of the stream, which, as already pointed out, increases the velocity of the stream. Besides this there are minor causes, which are of importance, which may be briefly noticed, and some of their effects considered. Increase in the amount of rainfall, or diminution of the supply of sediment to a fully charged stream, or diversion of one stream into another (in ways to be presently described), thereby increasing the volume of the second stream, may restore the stream's power to corrade vertically. The most interesting of the minor causes, however, is 


\section{SCIENTIFIC STUDY OF SCENERY}

the existence of hard and soft rocks which alternate with one another along the course of a stream. Suppose that a consequent stream is flowing across alternate stratified deposits of hard sandstone and soft shale, as in Fig. 30. The shale is more readily denuded than the sandstone under ordinary circumstances, but a bed of shale cannot be corraded to an appreciably greater depth than the sandstone surface which occurs lower down the stream, or a pond would be formed filled with still water, which could

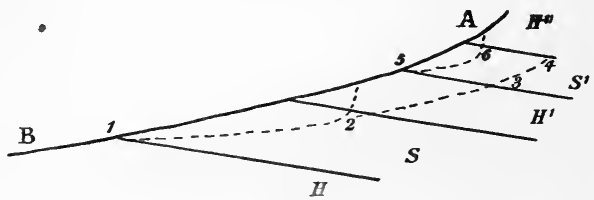

FIG. 30.

not corrade. Accordingly if, as in the figure, a consequent stream flows along the course $A B$ in the direction of the arrow, the soft shale $S$ between the two hard beds $H H^{\prime}$ may be worn down to a nearly level surface, as represented by the dotted line I 2, but it cannot be worn lower. The stream here will have formed a temporary base-line of erosion, and the same process will go on in the shale $S^{\prime}$. As the hard beds $H^{\prime} H^{\prime \prime}$ are not worn away so rapidly, the result of lowering the level of the upper surface of the shale $S$ will be that the slope of the stream is increased where the river passes from $H^{\prime}$ to $S$ at 2, and a gorge will be formed, and the river will gradually lower its bed along $H^{\prime}$, as shown by the dotted line 23 ; and 
then the portion of the stream running through the soft shale $S^{\prime}$ can be lowered, and formation of a gorge will commence in $H^{\prime \prime}$, the course of the stream being finally along the dotted line I 234 . It will be seen that the portion of the stream flowing over $S^{\prime}$, which had temporarily established its base-line of erosion, 56 , before the hard rock $H^{\prime}$ was corraded, is again capable of exerting a corrasive influence under the changed conditions, and the cross-section of that part of the valley situated over $S^{\prime}$ will appear as in Fig. 29.

It follows from the above that a valley initiated in a country composed of alternating soft and hard rocks will be occupied by a river alternately flowing over gentle slopes and more abrupt ones, and that corrasion of the abrupt slopes will cause the river to cut back into the gentle ones, producing the $\mathrm{Y}$-shaped cross-section, which may be repeated more than once. In the end hard and soft rocks will be cut down till the base-line of corrasion is reached, and accordingly alternation of rapids and cascades in a gorge with a sluggish stream along a flat can only occur in a young river or in an old one which has been affected by disturbing influences, for a rapid river which is charged with detritus and has been in existence for a long period will cut its channel till it has attained its base-level; for instance, the Colorado in a course of 1000 miles falls over 5000 feet, and yet no waterfall is met with through the whole of this portion of its course. To the subject of waterfalls we shall recur in the next chapter. It need only be stated that the valley is likely to be narrow in the hard rocks and wider where it traverses the softer ones. 


\section{I36 SCIENTIFIC STUDY OF SCENERY}

When a river temporarily attains its base-line of erosion, and subsequently becomes capable of corrading its bed vertically, if the main stream has a longer course than its tributaries it will probably possess a greater volume of water than that of each tributary, and may corrade to a considerable depth, while the tributaries exert little influence, notwithstanding the increase of slope. For a considerable period after the deepening of the main valley, the minor valleys will end as definite gorges some height above the floor of the main valley, and discharge their waters in a series of cascades or falls down the side of the main valley, and this period may be lengthened owing to minor causes. In a district like the Lake District many of the major valleys, like that in which Thirlmere is situated, rise from comparatively low cols, and the main stream is not supplied with a very large supply of sediment near its source. The tributary valleys rising amongst the frost-shattered ridges of the higher hills are supplied with a quantity of material for transportation, and their power of corrasion of the unweathered rocks in the lower part of their course is greatly diminished, as their energy is mainly available for transportation only.

Accordingly we find in the Lake District a number of tributary valleys occurring in the hearts of the ridges, and opening out far above the bottoms of the main valleys, discharging their waters down the slopes in cascades. They are specially well marked on the east side of Helvellyn, and a number of them also open into the upper branches of Borrowdale. 
Now, let the river of the main valley once more attain its base-level of erosion, and form an alluvial plain. The material which is brought down the hillsides by streamlets is deposited in the form of "dry deltas" when the velocity of the streamlets is checked on reaching the plain, and the major streams which issue from the upland valleys just described build deltas of considerable size, assuming the shape of half a cone, with its apex coinciding with the point at which the tributary stream issues from the hillside to tumble down the slope of the main valley, and accordingly a series of more or less symmetrical "alluvial cones" are formed around the mouths of these valleys.

The dry delta is, of course, formed whenever a rapidly running tributary charged with much material enters into a main river flowing over a surface so gently inclined that it cannot transport the sediment brought down by the tributary. Now the water of the tributary is impelled against the opposite side of the main river, producing corrasion of the bank there, and the formation of the dry delta drives the main stream to the opposite side of the valley, and, as a consequence, main streams tend to bend away from their tributaries where these join them. Admirable examples are found in the upper course of the Rhone valley, where it wanders through the flat marshes between Brieg and Martigny, the best being just east of Sion. Here the rapid Borgne, draining the Val d'Herens and Val d'Heremence to the south, drives the Rhone against its northern bank, while a little further east the Rière, flowing from the Wildstrubel group to the north, forces the Rhone to its southern bank near St. Leonhard. 


\section{I38 SCIENTIFIC STUDY OF SCENERY}

If a great quantity of débris is carried into a main valley in this way, it may ultimately result in the formation of a lake, occupying the portion of the valley above the junction of the tributary, a process which will be more fully described in a future chapter. 


\section{CHAPTER X.}

\section{VALLEYS (Continued)}

\} \mathrm { E } \text { have hitherto assumed that river systems } are initiated as the result of uplift of an area composed of stratified rocks which were originally horizontal. These river systems are described by Gilbert as consequent upon the uplift (the term consequent being here used in a wider sense than that in which it is applied by Davis), and we have considered the conditions of drainage which would exist in the case of a symmetrical uplift, which must be in accordance with the laws which control them.

We must now refer to the complications which will result owing to departure from uniformity.

In the first place, actual drainage lines may differ from those which would be developed under ideal uniform conditions, on account of differences in the hardness of rocks; any rock or any fracture or system of fractures which permits weathering and corrasion to occur more readily than among the neighbouring rocks tends, if other conditions permit, to give rise to valleys. Accordingly the ideal alternate tributaries entering a main stream are often partly replaced by two tributaries entering the stream at the same point, the production of these being determined by a plane of weakness, and-a matter of 


\section{I4O SCIENTIFIC STUDY OF SCENERY}

greater importance from our present standpointtributaries of adjoining rivers may start from the same position on the watershed, giving rise to a depression at the top, which is not placed laterally to the valley heads, but occurs at the heads, and accordingly a valley of this character is not dominated by a mountain peak, and the valley loses one of its principal scenic attributes. The valley of Thirlmere and the corresponding valley, in which Grasmere is situated, are separated by the pass of Dunmail Raise, which is of this character. The effect of planes of weakness in giving rise to pyramidal hills by severance of the lateral ridge has already been considered.

Another complication may be produced when a river has established its base-level of erosion. It has been seen that lateral corrasion becomes important; a river then eats into its banks, and it may eventually cut through the ridge separating it from an adjoining river, when the upper waters of the river at a higher level are switched off, and become tributaries to the river at a lower level, while the lower waters start from a freshly formed col. Many minor complications may result from this, such as increased erosive power of the one river, owing to increase of volume, causing deepening of its valley, and diminished erosive power of the other stream. The new col will not be dominated by a mountain peak, unless that at the head of the original valley is visible from the shortened valley. .

Other complications are produced according to what Gilbert terms the law of unequal slopes. In Fig. 3I, suppose the line $C A C^{\prime}$ to represent a section across an unsymmetrical uplift with a steep 
slope $A C$, and a gentle one $A C^{\prime}$. Weathering and corrasion will occur more extensively along $A C$ than along $A C^{\prime}$, and so, while a small thickness of rock, $C^{\prime} D^{\prime}$, is worn away on the side of the gentle slope, a much greater thickness, $C D$, will be denuded on the steeper slope, and the result is that the watershed is shifted laterally from $A$ to $B$, and any tributaries of the streams coursing down the

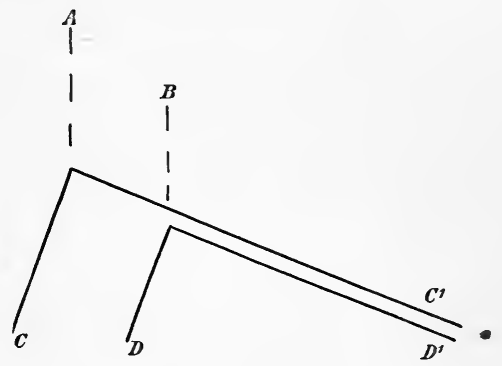

FIG. 31.

gentle slope and entering them between $A$ and $B$ will be diverted into the streams flowing down the steep slope. The recession of the watershed will be continuous all along owing to weathering, but will be most marked at the heads of the major streams, and accordingly we may have gorges cut into the side $A C$, extending backwards and forming deep gashes in the gentler valleys on the side $A C^{\prime}$, as is well seen in the valley of High Cup Gill, near Appleby, in Westmorland, which has cut far backward into a shallow tributary of the Tees. ${ }^{1}$ Here we have

See Geographical Journal, vol, vii., p. 607. 


\section{I42 SCIENTIFIC STUDY OF SCENERY}

another case of a valley which will not be dominated by a peak at the head.

The law of unequal slopes may control erosion when adjoining valleys are at different levels if the lower valley receives the waters of subsequent valleys. The subsequent valley falling into the lower stream will have greater erosive power than its neighbour over the col, and may gradually extend its course backward till it beheads the adjoining consequent stream, which will thus have its head waters diverted to the consequent stream existing at a lower level. In this way Professor Davis, in the paper cited in the last chapter, accounts for many complications in the drainage of East Anglia, and it is this process which appears to have severed the ridge extending northward from the Matterhorn, for at one time the stream in the Zinal valley seems to have had its source about the Tête de Valpelline, and ran northward over the Zinal Joch, and was subsequently beheaded by the river occupying the valley of the present $Z$ mutt glacier, which severed the ridge between the upper part of the original Zinal valley and the Nikolai-thal. Obsequent streams flowing down the steep faces of escarpments cut back their heads, often forming combes, but as the adjoining subsequent stream at the foot of the dip-slope is naturally at a lower level than that beneath the escarpment, actual beheading will only occur under exceptional conditions.

Change of drainage lines may occur owing to the existence of alluvial cones, though the results are insignificant to the student of scenery. If a cone be formed at the col separating two important valleys by a tributary entering the main valley close to the 
watershed, as the water shifts its position on the cone, deserting the channels which it has built up to some height above the general level, the water will flow now to one main stream, at another time to the other. A good case is exhibited on Dunmail Raise, where a tributary coming down the Helvellyn range has formed an alluvial cone on the watershed. The tributary drains towards Grasmere at present, but a small dry valley below the base of the cone towards Thirlmere shows that it flowed in that direction at no distant date.

The last mode of diversion of drainage lines to which we shall call attention is described by Gilbert under the name of ponding. Either by subsequent uplift or by formation of a dam, a lake is formed along a river-course. We shall discuss the formation of lakes in detail in a separate chapter. If the dam is lower than all the cols higher up the valley, the water issues from the lake over its original position, and no diversion of drainage occurs; but if a col exists higher up the valley with its notch at a lower level than that of the lowest part of the barrier, the water of the lake escapes over this col, and a permanent diversion of drainage takes place, the ponded valley being beheaded by the uplifted or accumulated barrier.

The main scenic effects due to diversions of drainage, causing beheading of one valley and addition to the waters of an adjoining one, are (i) production of pyramidal mountains by severance of a ridge, culminating in a peak; (ii) formation of cols or passes which are on the medial line of a valley, and accordingly the valley head is not dominated by a peak; (iii) production of dry valleys, often of 


\section{I44 SCIENTIFIC STUDY OF SCENERY}

considerable extent, beneath the new col, produced by diversion of the head waters of the valley into an adjoining valley: as these valleys, owing to absence of any large volume of running water, allow weathered material to accumulate, upon which a marsh vegetation often flourishes, they are apt to present a particularly desolate aspect; (iv) production of waterfalls, as described in the latter part of the chapter.

Drainage has been hitherto considered as though it were always due to emergence of strata from the sea, but we may have an uplift of a tract of land which has been reduced to a nearly level surface, or peneplain, by subaerial denudation, when the watershed will coincide with the axis of uplift, but will have no necessary relation to the inclination of the partly denuded strata, for they owe this inclination to a previous movement. We may now proceed to consider what Gilbert terms inconsequent drainage, which he divides into two classes, namely, antecedent drainage and superinduced drainage.

When an uplift takes place across a river-course, we have seen that the stream may be ponded back. If, however, the uplift is very slow, and the corrasive action of the stream rapid, the stream may keep its course open, notwithstanding the uplift, just as in a fixed saw, when a log is pressed up against it, the saw works in the same line, and cuts a fissure through the log. As the result of this process, rivers may run through mountains, and a gorge be formed. A similar result may follow owing to superimposed drainage, and it is in many cases difficult to distinguish one process from the other. The course of the Green river through the Uinta moun- 
tains has been ascribed by Powell as due to antecedent drainage, i.e., drainage antecedent to the uplift, and Medlicott and Blanford thus explain the course of the Indus and the Brahmaputra through the Himalayas. ${ }^{1}$

Superimposed drainage may occur as the result of formation of plains by lateral corrasion, this is the drainage superimposed by planation, to use Gilbert's expression; or the drainage may be imposed upon deposits, whether terrestrial, as alluvium, or marine, as ordinary sediments. Drainage in this case is

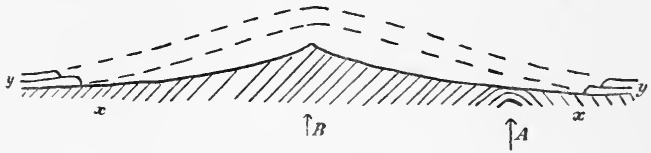

FIG. 32 .

superimposed by alluviation or sedimentation. Upon uplift the drainage will coincide with the axis of uplift, but when the superficial deposits have been worn away, the drainage will have no apparent relation with the inclination of the unconformable strata beneath the overlying eroded deposits; thus the axis of the anticlinal fold of a ridge need not underlie the main watershed. This is illustrated in Fig. 32, which is a section across the English Lake District. (See also Chapter VI.)

The older strata $x x$ were formerly bent into an arch with its axis about the head of the arrow $A$. These arched strata were denuded to an approximately

${ }^{1}$ It is only right to state that some cases of asserted antecedent drainage have been disputed by Professor W. M. Davis, but this is not the place to discuss controversial questions. 


\section{I46 SCIENTIFIC STUDY OF SCENERY}

level surface before the deposition of the strata $y y$ upon them. The latter were originally deposited horizontally, and subsequently uplifted around a point situated about the position of the head of the arrow $B$, and a radial drainage was initiated, which was consequent to the second uplift, and, as far as the rocks $y y$ are concerned, was an ordinary case of consequent drainage. The strata $y y$ have since been denuded over the centre of the district (their former extension being indicated by the dotted lines), and the drainage is superimposed upon the older strata $x x$ and is inconsequent so far as their axis of uplift at $A$ is concerned.

The original consequent and subsequent streams will run approximately in their original directions after they have reached the older rocks, but a number of minor streams will be developed, owing to the occurrence of planes of weakness among the older rocks which did not extend into the newer ones. Thus in the Lake District the consequent streams, as those occupying the Keswick, Coniston, Windermere, and Ullswater valleys, run in the direction which was determined by the uplift of the strata which have now been eroded, though they have undergone minor modifications as the result of the different nature of the rocks over which the streams now course, but tributary valleys have been developed, which owe nothing to the once overlying strata. Such a valley is the Vale of Troutbeck, determined by the occurrence of a great belt of broken rock, and accordingly marked by very steep, parallel sides, and a similar origin may be ascribed to the two valleys which start from Dunmail Raise.

When an area has been reduced to a plain sur- 
face by subaerial denudation, and widespread uplift occurs, the cycle of denudation begins afresh, as described by Davis, and the peneplain will be cut up by denudation, which may give rise to new hills, carved out of the plain, and marked at first by the possession of flat tops; to these Davis gives the name "monadnocks," from a hill in New Hampshire. An example is figured by Gilbert in his Geology of the Henry Mountains (Fig. 6).

Before leaving the consideration of the causes which may give rise to complications of drainage, one suggested cause may be referred to, namely, the rotation of the earth on its axis. Of this Gilbert speaks as follows :-

"The rotation of the earth, just as it gives direction to the trade winds and to ocean currents, tends to deflect rivers. In the southern hemisphere streams are crowded against their left banks, and in northern against the right. But this influence is exceedingly small. Mr. Ferrel's investigations show that in latitude $45^{\circ}$, and for a current velocity of ten miles an hour, it is measured by less than one twenty-thousandth part of the weight of the water. (American Fournal of Science, January, I86r). If its effects are ever appreciable, it must be where lateral corrasion is rapid, and even there it is probable that the chief result is an inclination of the flood-plain toward one bank or the other, amounting at most to two or three minutes."1

Waterfalls.-Reference has been made in passing to the conditions favourable for the formation of waterfalls, but on account of their prominent influence on certain types of scenery they deserve more than passing mention.

1 Geology of the Henry Mountains, p. 136. 


\section{SCIENTIFIC STUDY OF SCENERY}

As the ultimate effect of river denudation is the production of the base-line of erosion, it is clear that waterfalls can only exist in the courses of streams which have not reached the base-level, or which, having once reached it, have been subjected to some change which has restored the corrasive power of the streams over parts of their courses.

In the early history of a consequent stream a waterfall may be developed at any point where soft rocks are formed lower down the stream than hard rocks, so that the soft rocks may be readily denuded, and the hard rocks remain undenuded in the bed of the stream for a considerable time. Thus, if a dyke of igneous rock traversing soft shales be crossed by a stream, the shales below the dyke may be worn away, and a waterfall produced down the vertical wall of the dyke. Any mass of hard rock in contact with soft rock may thus cause a fall. A good example is furnished by Scale Force, near Buttermere, in the Lake District, which is due to the erosion of soft clay rock and the resistance of a mass of granitic rock, down which the water now falls. Many of the most impressive falls, however, are produced in gently inclined strata, and their formation merits fuller description.

Suppose a hard, well-jointed sandstone or limestone, $a$, rests upon the surface of a deposit of soft shale, $b$, as in Fig. 33. It has been previously shown that where the shale crops out in the bed of a stream of uniform slope the shale will be worn away to a greater extent than the hard rock, and the corrasive power of the stream will be increased at the junction, and a cascade or rapid produced. After the establishment of the cascade the action 
of the water becomes somewhat different. The water bringing sediment over the cascade begins to undermine the soft deposit, and, as in the case of escarpments, the harder rock overhangs, until a mass breaks away along dominant joint-planes, and the process starts afresh; a ravine is formed in this way, and the waterfall at the head of the ravine gradually recedes, thus lengthening the ravine. During the establishment of the cascade subsequent streams may form valleys along the strike of the

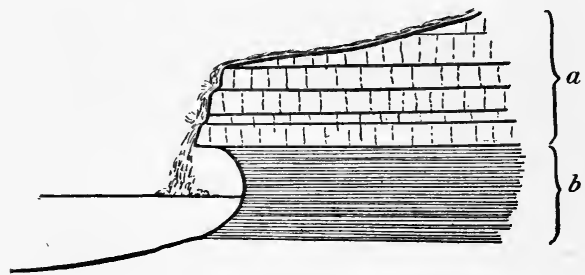

FIG. 33.

soft shale, giving rise to an escarpment, and it is often stated that a waterfall commenced at an escarpment, but with a young consequent river, waterfall and escarpment may be formed simultaneously.

Many of the best-known waterfalls are produced in the way described above. In England the numerous waterfalls of the Yorkshire dales, as Thornton Force, near Ingleton, and Hardraw Force, in Wensleydale, are due to the existence of masses of well-jointed limestone or sandstone upon shale, and High Force, in Teesdale, has been produced owing to the occurrence of a nearly horizontal sill of 


\section{I50 SCIENTIFIC STUDY OF SCENERY}

intrusive rock in soft sediments. (See plate.) Niagara is the classic example of a waterfall having this structure, and, as previously stated, a full description of its formation will be found in Sir Charles Lyell's Principles of Geology, while the geological structure and physical features of the country surrounding the gorge and fall are admirably illustrated in the coloured bird's-eye view of the falls and adjacent country which forms the frontispiece to the first volume of the same author's Travels in North America.

Owing to the sudden change of volume of a stream at the bottom of a cirque, $\mathrm{cwm}$, or corrie, causing sudden increased corrasion, the semicircular summit of the amphitheatre is often marked by a precipice, and any streams which rise on comparatively flat ground above the precipice are hurled down its side as waterfalls.

It has already been stated that under certain conditions a main valley may undergo further corrasion, which is checked in the case of tributary valleys, opening out far above the floor of the main valley; the tributary streams then flow down the side of the main valley as cascades. If the geological conditions are favourable, these cascades may be replaced by waterfalls. An example is seen in the case of the well-known Lodore, in Borrowdale, where the waters of the deep and narrow Watendlath valley are hurled down a cliff at the entrance to the main valley.

In a region where the streams have established their base-lines of erosion, deviation of the stream courses in any of the various methods described in the earlier part of the present chapter may give rise 


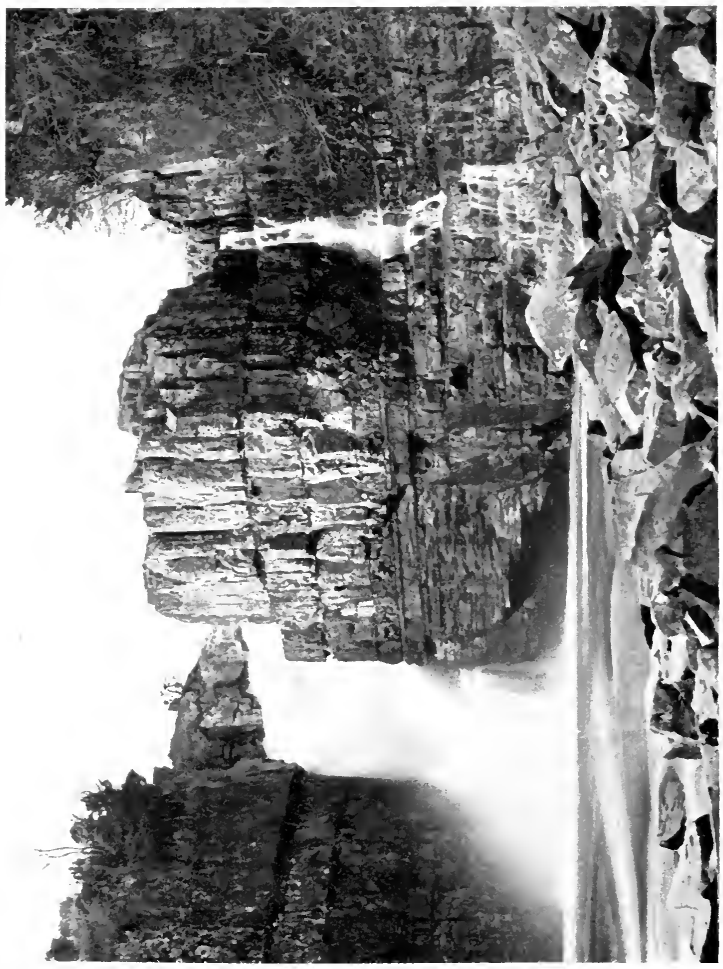


to waterfalls, either by diversion of the water over existing cliffs, or by the formation of falls by erosion of the softer rocks by the diverted stream. I have recently examined a large number of the minor waterfalls of Lakeland, and discovered that many of them owe their existence to recent diversion of stream-courses by the formation of dams of glacial detritus which have blocked the old courses of the streams. A pretty little example is seen in the Langstrath valley, one of the feeders of Borrowdale; it is described and figured in the Geographical Journal (vol. vii., p. 6I7, and figure on p. 618).

The course of the stream is often widened and apparently deepened just below a waterfall, giving rise to a deep, often more or less circular, pool, which forms one of the characteristic features of a waterfall scene. The widening is due to the production of eddies, which cause the lateral corrasion of the cliffs below the fall. The deepening is due to the force of the water dashing stones and sediment against the bottom and excavating a basin. How far this process can occur I am unable to state, as I have found no detailed description of the formation of a large rock-bound pool of this character, though that it can occur to some extent is proved by the formation of holes of some size below a waterfall. I have in recent years examined a large number of pools below minor waterfalls, and found that in many cases the pool is essentially due to accumulation of loose material some distance below the actual fall. The force of the stream is sufficient to carry away the transported sediment from the immediate foot of the fall, and a barrier is produced, damming back the waters to form a pool. This 


\section{I52 SCIENTIFIC STUDY OF SCENERY}

barrier is raised until an upward slope is made of sufficiently low gradient to allow the material to be carried up it by the swiftly flowing stream. If the stream flows through a narrow gorge beneath the fall, the force of the stream may be sufficient to carry the material through the gorge, and to form the dam at the lower end, when the gorge will be occupied by water of some depth. To this is due the very striking appearance of the gorge below the little fall in the Langstrath valley referred to above. A barrier has been formed at its lower end, and the gorge itself is occupied by deep water of extreme transparency, and of a lovely green hue, due to the nature of the rocks at its side and stones at the bottom.

Underground Rivers.-In districts which are largely occupied by rocks which are capable of being carried away in solution by water charged with solvents, an underground circulation may be established, giving rise to caves; and as the interior of these caverns is often of great interest and beauty, it is necessary to say a few words concerning their formation and structure, leaving the reader who is interested in the subject to gather further information from the second chapter of Professor Boyd Dawkins' work on Cave-hunting, in which the physical history of limestone caverns is considered at some length.

A porous, soluble rock like chalk permits drainage to take place underground to a considerable extent, and accordingly we meet with numerous cases of underground streams in a chalk district; hence also the general absence of surface drainage over the chalk, except when large streams contain a volume of water so great that only a portion of it can be 
absorbed. The chalk, therefore, is often marked by dry valleys, the origin of which has been a subject of dispute, though the suggestion of Mr. Clement Reid that they were formed at a time when the climate was sufficiently rigorous to freeze the water in the surface-pores, thus stopping the absorption of water and allowing the water to establish surface streams, satisfies all the requirements.

It is, however, in the case of hard and regularly jointed limestone rocks that we meet with the most striking effects of underground circulation, exhibited in our own country in the limestone rocks of Yorkshire, Derbyshire, and Somerset, and abroad by those of Belgium, Greece, and Kentucky.

We have already called attention to the formation of plateaux of limestone, with gaping fissures worn along the master-joint planes, by the action of acidulated rain water. The water coursing down the ordinary sediments, sandstones, and clays, which form the bed of the stream at a higher level, reaches one of these fissures, and plunges down it. A gyratory motion is given to the stones and sediment which it carries, and accordingly the stream bores a cylindrical shaft in the limestone, locally known as a "pothole"; but as this term has been used in a different sense, the term "swallow-hole" is best applied to these cylindrical shafts in limestone districts.

The water, after forming a "swallow-hole" to some depth, may reach a well-marked plane of stratification, along which it can penetrate, causing solution of the limestone along that plane, and giving rise to a cave. It will eventually issue at 


\section{I54 SCIENTIFIC STUDY OF SCENERY}

the side of a valley, where the bedding plane reaches the surface, as illustrated in Fig. 34, where $S$ is shale, $L$ limestone, in which the joints are represented by

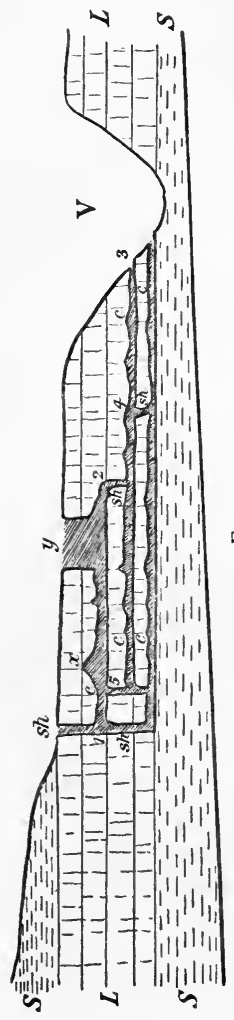
nearly vertical, the bedding planes by nearly horizontal, lines, and $V$ is a valley. The portions worn away by the water are indicated by black, $c$ being caves, and sh swallow-holes. The swallow-hole formed at the junction of the upper shale with the limestone may work as far as $I$, and then along the bedding plane from $I$ to 2 . If at 2 it meets with another wellmarked fissure, it may form another swallow-hole here, and proceed along a lower plane of bedding to $\therefore 3$, where it appears at the surface. $\stackrel{+}{m}$ In time a swallow-hole may be formed at 4 , and worked down to the junction with the lower shale until the water reaches the valley, when the upper portion of the cavern between 3 and 4 will be left dry. At a later period a swallowhole may be formed at 5 , and so on, and eventually the original swallow-hole will be deepened until it reaches the junction between limestone and shale, and the cavern will extend along this junction, the upper caverns and many of the swallow-holes being deserted by the water. 
The cross-section of the cavern will vary. The floor will probably be occupied by a stream which forms a bed by mechanical erosion, but the main portion of the cavern may be determined by the solubility of a particular stratum of limestone, which is greater than that of the overlying and underlying stratum, and fragments of the limestone may be detached from the sides along dominant joints, and from the top along a dominant plane of bedding, when the cave will possess a roughly rectangular cross-section. When the water percolates through important joints in the roof, these joints may be dissolved where the water hangs, thus producing dome-shaped expansions of the cave along these joints, as seen at $x$ of the figure. Sometimes a considerable portion of the roof may fall in, as at $y$, producing a shaft like a swallow-hole of gigantic proportions; such is the huge Helln Pot, on the west side of Ribblesdale, in Yorkshire; and by a continuation of this process and the removal of the fallen rocks of limestone the cave may be converted into a ravine. This is the origin of many of the ravines occupying the sides of our limestone uplands. From the sides of lateral caverns streams may pour into these huge shafts formed by the subsidence of the roof, as shown in Weathercote Cave, near Ingleton.

The beauty of the interior of limestone caverns is largely due to the formation of stalactites and stalagmite within them. The formation of a stalactite is well seen on the under-side of many bridges; the water which percolates through the masonry dissolves some of the lime of the mortar, and when it reaches the air redeposits it in pendent masses 


\section{I56 SCIENTIFIC STUDY OF SCENERY}

like icicles. The process as seen in the cavern is as follows :-Water percolates along a joint and dissolves some lime; when it reaches the roof of the cave the water is suspended as a drop, and this evaporates on the exterior, and a little film of lime is deposited as a ring round the drop, being prevented from forming at the bottom by the movement of the water. The next drop hangs to this ring, and a further ring is formed in continuation of the first; and so the process goes on, till a long, pellucid, strawlike tube hangs from the roof. Sooner or later the interior of this tube becomes blocked, and the water trickles down the outside, causing the formation of coat after coat of lime, until the stalactite exists as a thick cylindrical or conical pendent mass. In the meantime drops fall on the floor beneath the stalactite, undergo further evaporation there, and form deposits of stalagmite in sheets or bosses. The wall of the cavern is also bathed with moisture in places, and, owing to the evaporation of this, masses of stalagmite swathe the sides of the cavern like folds of drapery. As the formation of stalactites is mainly limited to the joint-planes they are often found running in linear series approximately at right angles to one another, and as the direction of the cavern is probably determined by the same joints, one set will be parallel to the length of the cavern, and the other will run across it. In the accompanying plate, from a photograph of a portion of the Ingleborough Cave at Clapham, in Yorkshire, taken by Mr. G. Towler, and reproduced by his permission, the formation of stalactites and stalagmite is well shown.

As caverns are liable to destruction by further operation of the cause which produced them-namely, 


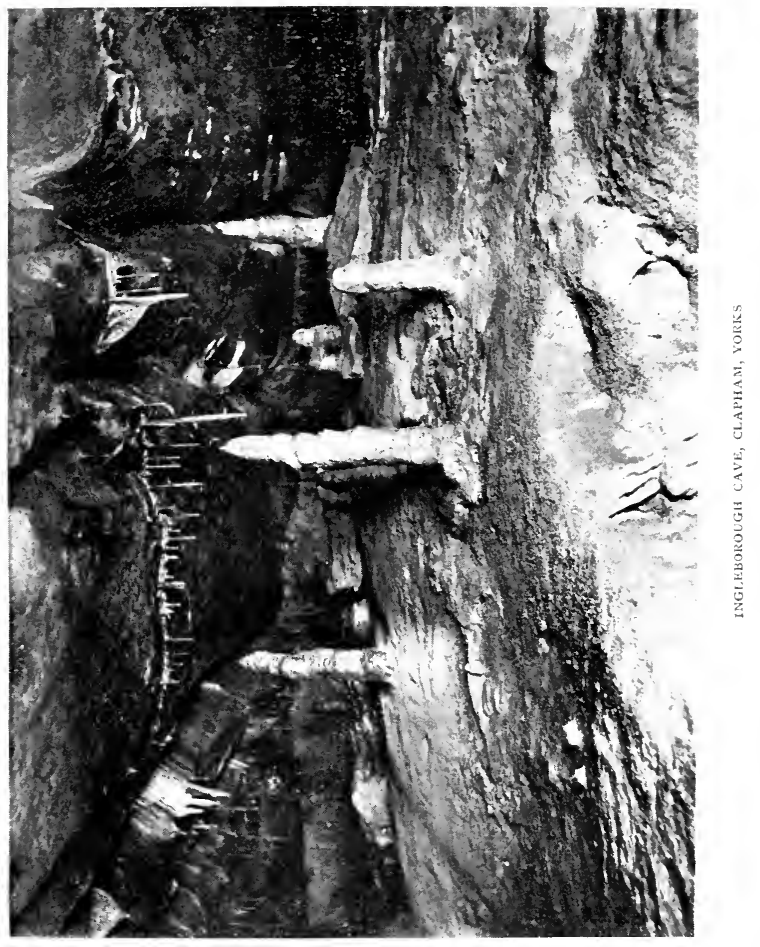



water denudation-and as the materials which are washed into caves tend to accumulate there, while the lime which is carried in solution is deposited as stalactite and stalagmite, and the cave may be eventually filled up by material deposited from solution, it is evident that caves cannot be very long-lived, and that all existing caves must be, geologically speaking, of recent date.

Before quitting consideration of caverns reference may be made to the remarkable ice-caverns, or glacières, which are the subject of a special work by the present Bishop of Bristol. ${ }^{1}$ These caves are found in several places, including the limestone districts of the Jura and the Pyrenees, and are remarkable as containing ice all the year round. They occur at high altitudes, and accordingly the air even in summer is not excessively warm. They are explained by Dr. Browne as follows: "Occurring at a lower level than the mouth, the ice formed in winter is kept from melting to any extent in summer because the warm, light air cannot displace the heavy, cold air beneath to a considerable degree, and the warm air which reaches the ice is deprived of its heat by the work of melting a small quantity of the ice, leaving the remainder to occupy the floor of the cave throughout the summer."

${ }^{3}$ Ice-caves in France and Switzerland, by Rev. G. F. Browne (1865). 


\section{CHAPTER XI.}

\section{LAKES}

THE study of lakes has received very consider1 able attention during recent years. The great works of Forel on Geneva ${ }^{1}$ and of A. Delabecque on the lakes of France ${ }^{2}$ have stimulated geographers to follow the pursuit of limnology, and in our own country the accurate and careful observations of Mill on the lakes of English Lakeland ${ }^{3}$ have supplied the student of scenery with much valuable material.

The existence of any hollow which is capable of retaining a considerable sheet of inland water may give rise to a lake, and as the requisite hollows may be formed in various ways, lakes may and do present considerable diversity of features.

We may commence with consideration of the conditions which may produce a lake. Granted that the requisite hollow exists, the formation and character of the lake depends upon climatic conditions. In an arid climate the hollow may be waterless, or if the rainfall is small, the bottom of the hollow may be occupied by a lake having no outlet, whereas if the rainfall be sufficient to fill the hollow to the height of

1 Forel, F. A., Le Leman.

- Delabecque, A., Les Lacs Français.

${ }^{3}$ M ILL, H. R., The English Lakes. 


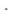




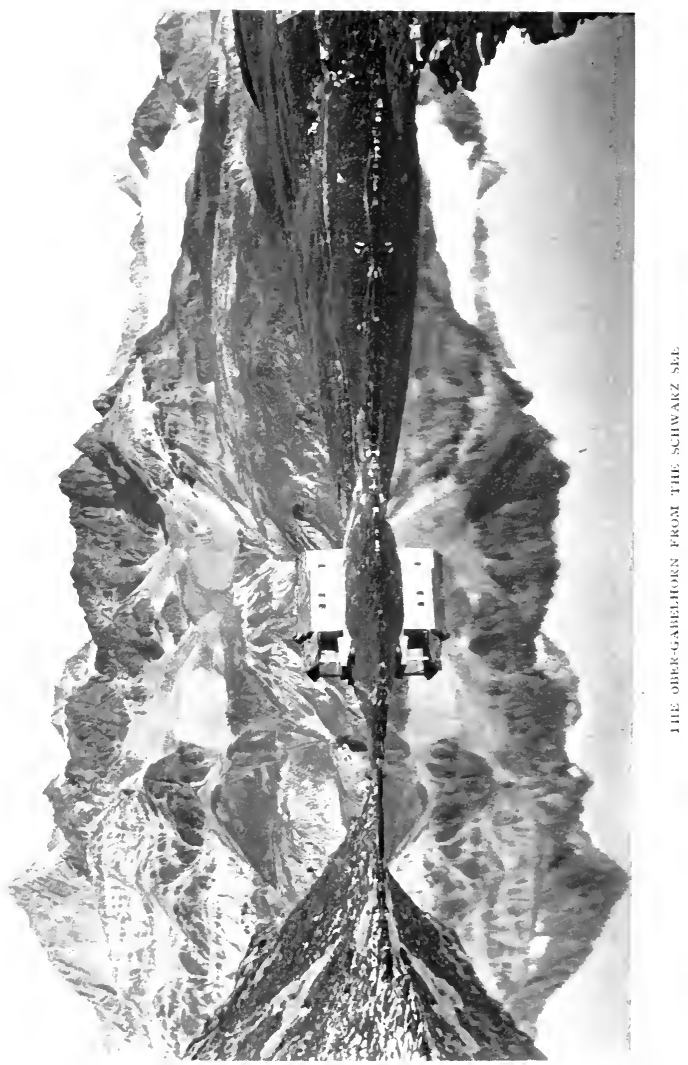


the lowest part of its rim an outflow will be established. The physical characteristics of the lakes of desert regions which depend upon climate will be discussed when we consider the features of those regions, and we shall here consider the conditions which are necessary for the formation of the hollows requisite for the accumulation of the waters of lakes.

A hollow adapted for the retention of water may be formed in four ways: (i) by accumulation of material above the existing surface of the earth to form a barrier or dam; (ii) by differential movement of a portion of the earth's crust; (iii) by volcanic action forming craters; (iv) by erosion.

(i) Lakes formed by accumulation of material are very widely distributed, and the material which forms the barrier or dam may be accumulated under very different conditions. In some cases the barrier may completely surround the hollow, as when the lake exists owing to unequal accumulation of extensive sheets of material. Such lakes are often found existing in the hollows of glacial drift, and are termed "kettle-holes" by American geologists. According to the late Professor Carvell Lewis, the meres of Cheshire are of this character. Small pools, many of which are dried up in times of drought, are frequently found among the moraine mounds of our upland regions; they usually present few features of interest in themselves, though they are often effective as a foreground to mountain views. The little Schwarz See at Zermatt occupies a hollow in moraine material, and its immediate surroundings are tame, but the view of the Ober-Gabelhorn as seen from the end opposite the little chapel is very impressive. (See plate.) 


\section{I60 SCIENTIFIC STUDY OF SCENERY}

When a region has been recently raised above sea-level, lakes may be formed in inequalities of the former sea-floor.

Again we may find the barrier blocking the stream of a valley, and giving rise to a lake which drains over the barrier, but unless the barrier is prolonged for some distance down the valley, or is composed of hard rock, lakes of this character are apt to be short-lived, for the water issuing from the lake erodes the barrier, and the lake is drained. At other times the water runs between the barrier and the original surface slope, and a barrier of this nature is also readily destructible. If the barrier be raised to a sufficient height, the lake level may be raised so that the water reaches a col which is at a lower level than the lowest part of the barrier, and lakes of this nature will, from the circumstances of the case, be much more permanent than those which have an outlet over a dam of more or less incoherent material.

We may now consider the nature of the material which may accumulate to form a dam sufficient to give rise to a lake. In the first place, we may take the case of ice, for though an icy dam is naturally unstable, ice-barred lakes present many features of interest. Avalanches of ice falling from the terminal cliff of a glacier may accumulate across a valley bottom to form a dam, which will allow the waters of a temporary lake to collect above it, as happened in 1818 in the valley of the Dranse, which was blocked by ice fragments falling from the Gétroz glacier, giving rise to a lake, the subsequent bursting of which caused a disastrous flood in the Rhone valley. At the junction of two glaciers a hollow 


$$
\text { - }
$$




\section{SCIENTIFIC STUDY OF SCENERY}

some miles in length, is situated in a valley stopped at both ends by ice; and to the north of the same glacier another valley is not only blocked by ice at its lower end, but a tongue of ice flows over a col in the centre and splits the lake into two, separated by a mass of ice. Further north are several large lakes, one apparently about fifteen miles long, which are blocked at their lower ends, and the water flows to the sea over cols situated at the heads of the valleys. The terraces formed by these lakes may form conspicuous objects in the landscape when the ice has vanished. It is well known that many writers have advocated the formation of the famous Parallel Roads of Glen Roy in this manner.

In Alaska some of the glaciers are in a very peculiar condition, which will be more fully considered in the chapters devoted to the scenic effects of ice. One of the results of this condition is, that the ice, while moving down the valleys, receives no addition from snow-fields at the head, and accordingly the tops of the valleys are free of ice. This is seen in some of the valleys which slope down to the Muir glacier, and the upper parts of these valleys are occupied by lakes, which are supported by the barrier of ice below. Berg Lake, formed in this way, is four miles long; and Main Lake, which runs across Main Valley, has a length of about seven miles. $^{1}$

In passing to the consideration of more permanent barriers, we may commence with one of the most durable, namely, lava poured out from a volcano, and crossing a valley, as described in the case of the

1 Cushing, H. P., "Notes on the Muir Glacier Region, Alaska," Amer. Geologist, October, 1891 . 
river Simeto. It is obvious that the drainage may be ponded back by the barrier, and a lake formed. M. Delabecque, in his work on the lakes of France, mentions one or two lakes which were formed in this manner, including the Lac d'Aydat, near Clermont-Ferrand, dammed by a basaltic flow from the Puy de Lassolas. In rare cases a volcano may actually be formed at the bottom of a valley in such a position as to form a dam. Two possible cases are cited and figured by Delabecque, namely, the case of Lake Chambon, near Clermont-Ferrand, and that of Montcyneire.

The remaining barriers to be considered are formed by the accumulation of more or less incoherent material, and accordingly, as above stated, the lakes are usually short-lived, unless the barrier is so high that the drainage is diverted over a col formed of harder rock.

Landslips may, and often do, give rise to lakes, for the amount of material is often so great, and the barrier is formed so suddenly, that the stream has no time to keep a passage open during the formation of the barrier. It may be remarked in this place that the lakes formed by incoherent barriers, and having their exits over the barriers, often have a longer existence than they would otherwise have, because the sediment of the river is deposited in the lake, and the issuing stream, being deprived of sediment, is incapable of producing much corrasion in a short time even if its bed be composed of more or less incoherent materials. The Lake of Derborence, to the north-west of Sion, in the upper part of the Rhone valley, is a good example of a lake formed by a landslip. It came into existence in 1749 as 


\section{I64 SCIENTIFIC STUDY OF SCENERY}

the result of a landslip from the Diablerets, and is blocked by a dam composed of huge angular fragments.

Near the sea-shore extensive sheets of water are often formed by the formation of barriers composed of beach deposit or blown sand. On the Atlantic and Mediterranean coasts of France a number of shallow lakes and lakelets exist, known as étangs, some of which are due to beach barriers, others to dams of blown sand, and some, as shown by Delabecque, belong to a different class, being caused to a large extent by subterranean solution. $\mathrm{He}$ mentions the étangs of Kerloch and Kergalan, on the Atlantic coast, and all those situated between Cape Béar and the Etang de l'Estomac, as well as that of Pesquiers, near Hyères, as being due to barriers of beach, while several on the coast of Morbihan, and all those between the Pointe de Grave and the "falaises" of Biarritz, are due to barriers of blown sand. The actual origin of these barriers, composed of sea-beach and sand-dune, will be considered in later chapters.

River deposits of organic and inorganic origin may form barriers which hold up lakes. Sir A. Geikie records the work of the beaver, which "by cutting down trees (sometimes one foot or more in diameter) and constructing dams with the stem and branches checks the flow of watercourses, intercepts floating materials, and sometimes even diverts the water into new channels. This action is typically displayed in Canada and in the Rocky Mountain regions of the United States. Thousands of acres in many valleys have been converted into lakes." 1

' Geikie, Sir A., Text-book of Geology, 3rd edition, p. 474. 
The formation of crescentic lakes owing to winding rivers in an alluvial plain, forming "cuts-off" and leaving the old windings as lakes and pools, was described in Chapter IX. It is to be noted that the water occupied its position before the formation of the barrier. The same is the case with the "broads" of Norfolk, whose origin is somewhat similar, though more complex. Their formation has been described by Dr. J. W. Gregory, and a reference to the literature of the subject will be found at the end of his paper. $^{1}$ He gives reason to suppose that the East Anglian rivers once opened into large estuaries like those of the Tees, Tyne, Thames, and the Wash and Humber. Owing to the peculiar tidal movement off the East Anglian coast, which comes from the north through a narrowing sea, the sediment is piled up by the tides on the north side of the mouths of the East Anglian rivers, and forms breakwaters, by which the force of the current of the rivers is checked, and they deposit their load of material against the inner side of these breakwaters, thus causing the estuaries to become silted up from their seaward terminations, instead of at the head only. This tract of silt "would, by the continuation of these operations, work its way gradually backward up the estuary, leaving a great sheet of water separated from the sea by a bank of alluvium; of this Breydon Water may be the diminished representative. But as the land worked further backward it would cross the entrance of branches of the estuary; the sediment would be carried along the central channel, upon the sides of which it would be deposited; it could thus cut off the branches either entirely, as in the case of Fritton Lake, or

1 Gregory, J. W., Natural Science, vol. i. (1892), p. 347. 
connected by a channel just sufficient for the escape of the surplus rainfall, as does the memorable Muck Fleet for the three great sheets of Rollesby, Ormesby, and Filby Broads." The barriers are increased and compacted by the abundant growth of marsh vegetation upon them.

Dr. Gregory also points out that those broads which lie along the courses of the main rivers are more complicated. One large broad is formed at first, and the main river forms a delta at its entrance. This delta grows outward along the course of the river, the sediment being strained off by the vegetation which grows on the banks formed on either side of the current. By degrees this barrier is formed right across the original broad, dividing it into two, and the process of subdivision may take place more than once. In this way he accounts for the formation of Wroxham Broad, and of six other broads to the east of it, along the course of the river Bure, all having been formed by the subdivision of one original large broad.

In the case of upland streams, lakes and tarns may be formed by the deposition of a delta by one stream where it enters another, if the main stream has not sufficient volume to carry away the sediment brought by the tributary. Anyone who has walked from Borrowdale to Wastdale, in the Lake District, over the Sty Head Pass, will remember a small tarn, Sty Head Tarn, near the head of the pass on the Borrowdale side (see plate). It is barred by a delta descending from the two Gables, and as the small stream into which it flows has no great volume, it has been unable to carry away the material brought down the Gables' slope, and the accumulated delta has driven 


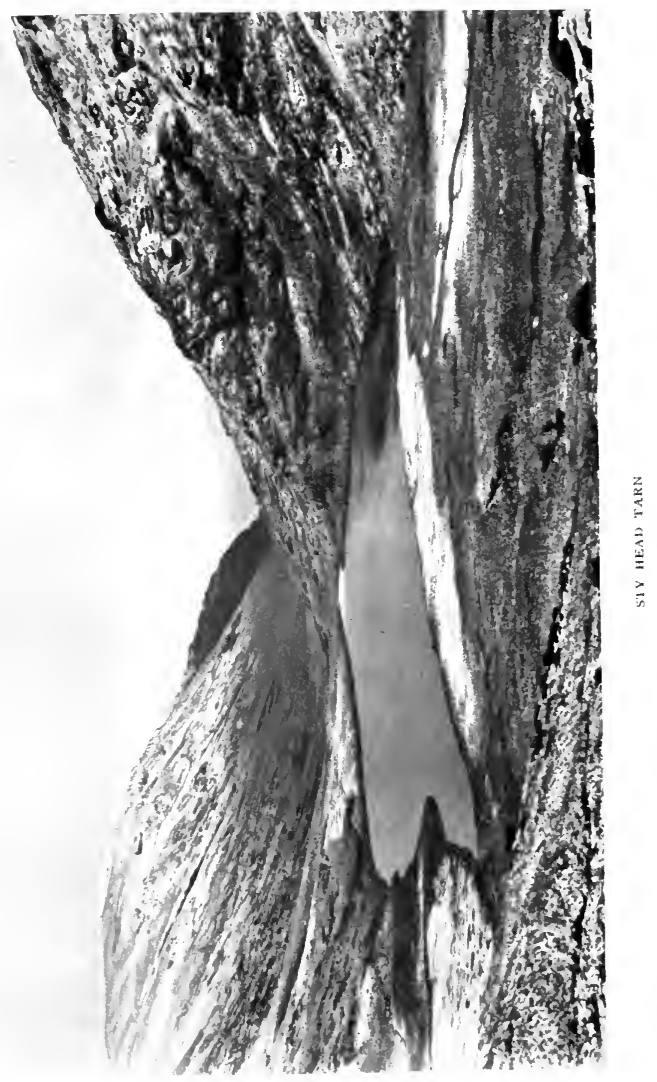




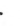


the main stream some way back and formed a barrier, which holds up the tarn, the waters from which now escape by a channel running between the margin of the delta and the solid rock on the other side. Lakes may be formed in this manner on a fairly large scale, especially when the upper waters of the main river are deflected by beheading, and accordingly the stream, owing to diminished volume, loses much of its transporting power.

It may be stated here that these deltaic barriers may in mountain regions resemble moraines so closely that it requires considerable care to distinguish them. The late Professor J. D. Forbes ${ }^{1}$ writes :-

"Between St. Nicholas and Randa several wild and bridgeless torrents have to be crossed, which, in bad weather, must make this route nearly impassable. ${ }^{2}$ I noticed particularly the mode in which a violent torrent accumulates boulders, forming a mound of blocks on either hand, which serves, in some measure, to restrain its fury, whilst the level of its bed is continually raised by the detritus which it accumulates; and when, by extraordinary freshes, the barrier is broken, the country on either side is, of course, deluged. I only speak now of the wildest and most powerful torrents descending at a great angle, and which act sufficiently on blocks to roll them with the aid of gravity for a great way, and chafe them into irregularly rounded masses, with a noise which everyone who has visited the Alps recalls as one of the most striking of natural sounds, accompanied, as it always is, with an impression of irresistible force. Now, these rocky accumulations have a very striking resemblance to the moraines of

1 Forbes, J. D., A Tour of Mont Blanc and Monte Rosa, p. 237.

2 This was written in 18,55 . 
glaciers, and this is a circumstance which it is well to be aware of, and which has not, I think, been prominently stated. In form these mounds resemble moraines, the external, and even the internal slope, being in both cases usually determined by the angle of repose of the blocks. The materials of both are also alike;-angular blocks, more or less rounded by friction, never quite smoothed or polished, angular gravel, and sharp sand. In the disposition of the materials I have not observed that regularity of arrangement which is said to distinguish water action from that of glaciers. On the contrary, the deposit of these torrents seems to be wholly devoid of layers of coarser or finer materials, and, as in true moraines, the largest blocks often lie uppermost. I may mention the great torrent descending from the Dent du Midi, which devastates the country above St. Maurice, as another example of this."

The dry deltas which descend from mountain slopes only differ from torrent deltas in the intermittent character of the water supply, and the falling of blocks split off by frost and changes of temperature in the dry season. They are intermediate in character between torrent deltas and screes, and may form barriers supporting lakes in the same way.

Screes also act as barriers in the same way if some of the material is sufficiently comminuted to prevent the water from draining through the interstices between the larger blocks. The tarn known as Goats' Water, on the side of the Old Man of Coniston, in the Furness district of North Lancashire, is dammed by screes, and I may call attention to two other tarns formed in the same way, which admirably illustrate the manner in which a lake supported by a barrier may have its drainage diverted from the 


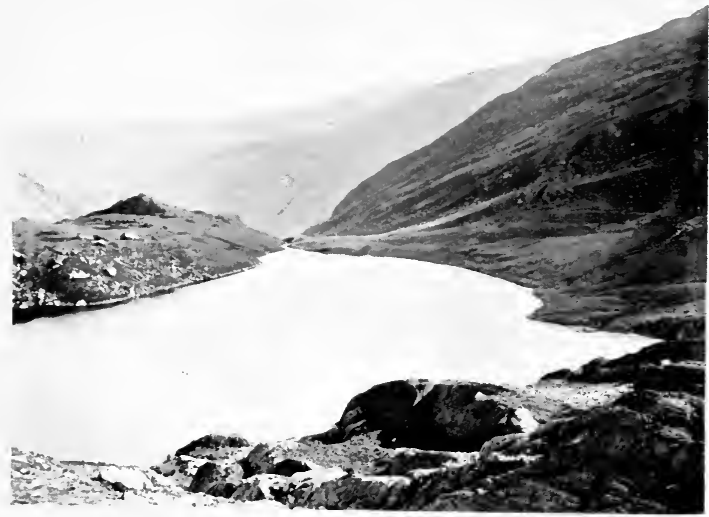

SMALI, WATER

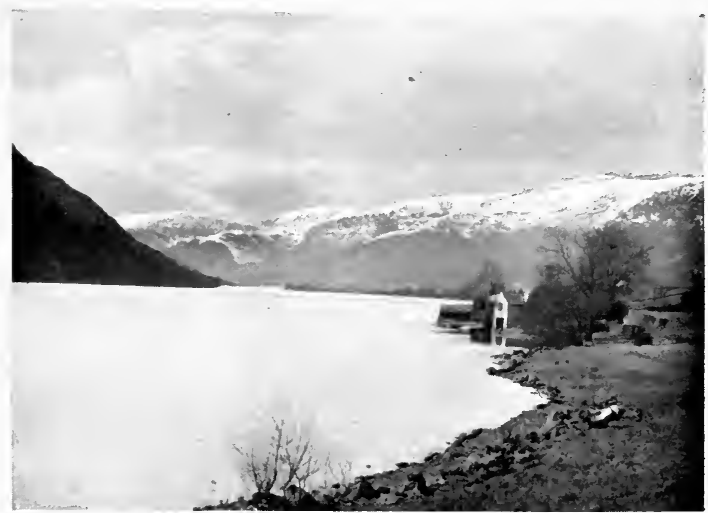


barrier, so that it ultimately drains over bare rock. One is situated in Ruthwaite Cove, a recess of Helvellyn, and is known as Hard Tarn. It is quite small and extremely shallow, but is surrounded by solid rock on all sides except at the main exit, which runs over a barrier of screes which has formed the tarn. The water now stands at such a height that in wet weather the water level stands just above a low depression in the rock, and accordingly there is here a wet-weather exit, along which a groove is being cut by the water. As the growth of the screes increases, the scree exit will be the wet-weather exit, and the normal exit will be over the solid rock, a state of things actually found in the tiny Ffynnon Frech, in Cwm Glas, on Snowdon, as described by Mr. W. W. Watts. ${ }^{1}$ The exit of each of these tarns will ultimately abandon the dam, and exist permanently over the solid rock, an event which has happened in the case of a large number of similar tarns and lakelets.

In many mountain regions the cwms and corries are occupied by great snow-slopes during the winter months. The fragments split from the cliffs above by the action of the frost come flying down the slopes, and form a crescentic barrier around the mouth of the cwm, which may hold up the water to form a tarn. Similar slopes on the sides of a hill may block a valley just as a delta or slope of screes does. The little tarn of Smallwater near Haweswater, in Lakeland, shown in the plate, seems to be due to this cause, and its exit is now permanently over solid rock, with the somewhat remarkable consequence that

1 Watts, W. W., "Notes on some Tarns near Snowdon," Rep. Brit. Assoc. for 1895, p. 683. 


\section{I7O SCIENTIFIC STUDY OF SCENERY}

the bottom of the original valley below the dam is dry, and the present stream below the exit runs for some distance in a shallow groove cut into the rock of the hill-side some height above the valley bottom.

We must now consider the barriers formed of glacial drift, which are the most important of the many barriers due to accumulation of material across a valley. A great number of lakes and tarns at home and abroad owe their existence to a barrier of this nature. I may mention Codale and Easedale Tarns near Grasmere, Devoke Water between Eskdale and the Duddon valley, Burnmoor Tarn and Sprinkling Tarn on Scawfell, Red Tarn and Keppelcove Tarn on Helvellyn, in Lakeland; Llyn Goch, Llyn Glas, and Llyn-y-nadroedd on the west side of Snowdon, and Llyn d'ur Arddu on its north-west side, in North Wales. Of larger lakes, Windermere, Bassenthwaite, Ullswater, and Thirlmere in Lakeland; the lakes of Llanberis, Gwynant, and many others, may also be due to great barriers of drift extending far down the valleys. Delabecque cites a number of French lakes formed by a similar barrier, as the lakes of Chalain, Chambly, Nantua, and others in the Jura, and Gérardmer, Longemer, Blanchemer, among those of the Vosges. Some of these lakes are produced by lateral moraines, others by terminal moraines, and others again by the great masses of "drift" which spread over extensive tracts of country.

The statement that lakes may be blocked by terminal moraines requires a word of explanation. As an extensive torrent always issues from the end of a glacier, it might be supposed that a passage through the barrier would always be kept open. 
No doubt this is often the case, but the stream does not always cut down to the solid rock, for we often find it rushing over moraine material for some distance below the snout of the glacier, and on the recession of the ice sufficient moraine may be left to form a barrier supporting the waters of a lake, and, secondly, even if the stream does cut through solid rock, the point of issue of the stream need not be situated just over the bottom of the original valley, and here again a barrier of moraine may occur, which gives rise to a lake.

The most striking tarns are those formed by a dam of moraine at the mouth of a cwm, the combination of lakelet and mural precipice being often extremely picturesque. The finest tarn in the Lake District, Bleawater Tarn, near Haweswater, forms a nearly complete circle. The outer semicircle is bordered by the retaining dam of moraine, while the inner one is formed by the fine cliffs which rise almost straight from the shores of the tarn, and tower up many hundreds of feet to the ridge of High Street.

Those lakes which were formed by drift, where the exit was over the original valley bottom, are usually drained quickly, as previously observed, and their sites marked by peat mosses, and the number of these moss-covered tracts in upland districts proves that the tarns and lakelets which survive are but a small proportion of those which once existed. Of lakes blocked by drift, of which the exit is now over solid rock, we may mention Burnmoor Tarn, Codale Tarn, Small Water, and Harrop Tarn in the Lake District, and of larger lakes Windermere and Bassenthwaite. Delabecque has shown 


\section{I72 SCIENTIFIC STUDY OF SCENERY}

that Longemer, in the Vosges, has a similar structure.

A word of explanation concerning the character of the drift-filled valleys is necessary. In many cases they are wide as compared with their depth, but in others we meet with depressions occupied by drift at the surface, which are narrow and tortuous, and if they are filled with drift to the bottom, which is necessary in order that lakes may be formed by them, the drift must be very deep; a depth of two or three hundred feet is often necessary. The existence of such drift-filled depressions may seem unlikely, but it must be remembered that in a glaciated region the waters of the streams issuing from the glacier are charged with abundance of minute angular particles of sediment, which are capable of cutting like a file, and these rivers must produce great vertical corrasion. Accordingly we frequently find that the valleys which have been occupied by ice comparatively recently are wide where the ice has recently receded, but that lower down the rivers which flow from the glaciers drain through extremely narrow gorges cut out by the streams, to which Desor has given the name roflas. The gorge of the Trient, near Vernayaz, in the Upper Rhone valley, is an example; and many others occur.

If ice passed over these gorges, they would readily become filled with drift, especially if the ice moved transversely to their general direction, and when filled up their detection might be a matter of some difficulty.

There is one particular case in which glacial drift may produce a barrier under somewhat exceptional 
circumstances which must be noticed. It has been seen that much of the drainage in a limestone region is subterranean. Suppose a stream to fall down a swallow-hole. The stream above the swallow-hole will erode its channel and gradually lower it, and if the swallow-hole should slant downwards, a portion of the limestone above it may become engulfed. Eventually the stream will fall into the hole at some distance below the general level of the surface. If the swallow-hole be partly or entirely filled up in any way, the subterranean drainage may be stopped or checked to such an extent that the whole of the water cannot be carried underground, when it will accumulate in the old channel to form a lake, until it reaches a level at which it can overflow. M. Penck has suggested that in regions which were formerly glaciated the orifice may be stopped with impermeable morainic material, forming a barrier. In this manner M. Delabecque explains the formation of the remarkable Lake Chaillexon, forming a part of the course of the Doubs, in the Jura, which is shown in Figs. 49, 53, and 104 of his work on the French lakes, while a plan is given in Plate VII. The lake is deepest at its lower end, where a submerged swallow-hole having a depth of $3 \mathrm{I} \frac{1}{2}$ metres occurs. The lake itself is sinuous in form, its banks rising in precipices of limestone on either side, with the corresponding beds easily recognisable in each precipitous cliff.

It is clear that the blocking of the swallow-hole by drift is not essential to the formation of a lake in a region of fissured limestone; if the swallow-hole in any way becomes too small to allow the whole of the drainage to be carried away underground, a 


\section{I74 SCIENTIFIC STUDY OF SCENERY}

lake will result, though glacial drift is likely to form the most efficient plug in closing or partially closing the orifice.

(ii) Lakes formed by differential movement of portions of the earth's crust may now be considered. Before discussing the formation of lakes owing to extensive movements of the earth's crust, produced by deep-seated changes, we may mention the origin of certain lakes produced by sinking of the superficial portion of the crust owing to the solution and removal of material beneath. We have already taken into account the action of acidulated water upon limestone rocks, and have seen that one of the effects was the giving way of the roofs of underground caverns, producing hollows above. These hollows would be admirably adapted for the formation of lakes were it not for the fissured nature of the limestone, which, as a general rule, permits the underground drainage of the water which would otherwise accumulate in the hollow, and give rise to a lake; and accordingly lakes formed by underground solution and removal of limestone appear to be comparatively rare, and lakes formed by solution of material beneath the surface are more frequently produced if rock-salt or gypsum be the material removed. Some writers have referred the formation of certain Cheshire meres to the solution of rocksalt, and it is a fact that the artificial removal of this material in the form of brine by introduction of water and artificial removal of the brine by pumping has caused serious subsidence in the Cheshire district, with occasional formation of sheets of water in the hollows. Many writers have referred the production of various lakes in Switzerland to 


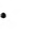




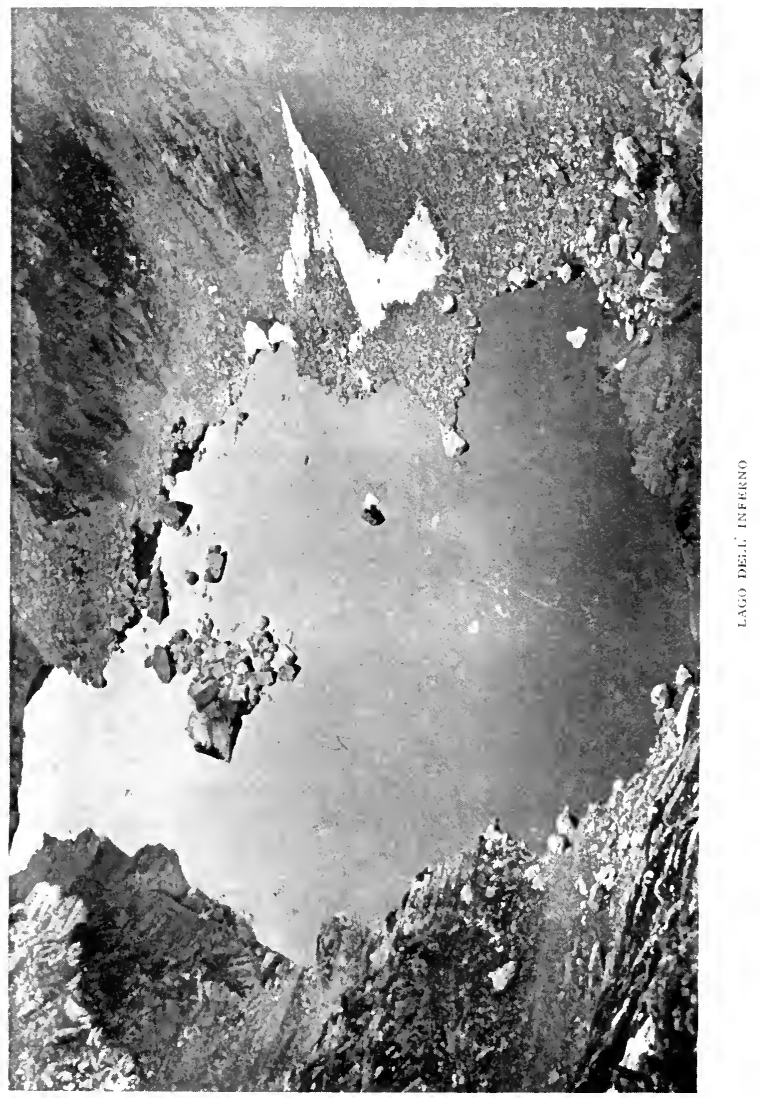


underground solution. M. Delabecque quotes cases of several lakes which he considers to be probably formed in this manner, for instance the Lac de la Girotte, the lakes of Tipies, and the Lac du Mont Cenis. It is, of course, difficult to obtain definite proofs that lakes have been formed in this manner, as the proofs are concealed beneath the ground; but when lakes are found in districts which are known to contain deposits of gypsum, rock-salt, or dolomite, and the origin of the lakes by any other process is not indicated, it is legitimate to attribute them, with a certain amount of probability, to the solvent action of underground waters upon the above-mentioned salts.

Mr. Garwood has furnished me with an illustration of a lake the production of which he refers to underground solution. (See plate.) This is the Lago dell' Inferno, at the foot of the Tre Signiori, a true rock-basin holding a lake about half a mile in length, and of considerable, though unknown, depth; the rocky barrier round the lake is well seen in the photograph.

We now arrive at the consideration of the lakes which show evidence of existence owing to the occurrence of those more widely spread foldings and fractures of the earth's crust whose nature we considered when discussing the character of continental and mountain uplifts.

The differential movement which results in bending of the earth's crust, accompanied by occasional fracture, is spoken of by the American geologists as "warping," the idea being that the crust of the earth becomes warped, just as the cover of a book when held in front of the fire. Now it is clear that 


\section{I76 SCIENTIFIC STUDY OF SCENERY}

if warping occurred in such a way as to cause the bending up of the portion of the earth's crust in the lower part of a valley, and if the stream was unable to keep its original channel open by downward corrasion, a lake would be produced by the process of ponding, in the manner described in the preceding chapter. It is clear that there is no $a$ priori objection to the formation of lakes in this manner, and it remains for us to see whether we have any indisputable evidence of lake formation by the ponding process.

One objection to the extensive formation of lakes by this process was long ago made by Sir A. C. Ramsay, who pointed out that a vast majority of lakes occur in regions which can be proved to have been glaciated in geologically recent times, whereas, if a majority be due to ponding, no such connection should be traceable. We have already seen that the formation of glacial dams may account for many lakes, and the association of lakes existing in live rock basins and not held up by a dam of accumulation, with glacial phenomena, was long ago satisfactorily explained by Lyell, who pointed out that ponding might be prevented in ordinary regions by the rivers keeping their waterways open during the period of uplift, whereas, if the uplifted tract were covered by ice and the latter were unable to corrade to the same extent as water, the barriers could be formed, and on the recession of the ice the rock basins would be ready for the reception of water to form lakes. ${ }^{1}$ We shall eventually call attention to the evidence which has been gathered during recent years bearing upon the erosive power

1 Lyell, Sir C., Antiquity of Man, 4th edition, p. 360. 
of ice, which points to the comparative impotence of ice as an erosive agent.

No one has ever seriously called into question the supposition that a large number of the great lake basins of the world originated as the result of differential earth movement. Among the basins which have been formed in this way are those of the Aralo-Caspian area, the Dead Sea, the large lakes of the interior of Africa, and those which occupy the Great Basin region of North America. These lakes, though their origin is generally similar, vary in matters of detail. Some of the fresh-water lakes of Africa may have been produced by conversion of part of the ocean floor into land, for $\mathrm{Mr}$. Edgar A. Smith has found shells allied to marine forms in the slightly brackish waters of Tanganyika, while others have probably been at no time connected with the ocean, but are due to the formation of basins by warping, the basins being afterwards filled with fresh water. Dr. Gregory has described some of the African lakes as occurring in a great depression, bounded by steep parallel sides, due to faulting. " "From the Lebanons . . . almost to the Cape there runs a valley, unique both on account of the persistence with which it maintains its troughlike form throughout the whole of its course of 4000 miles, and also on account of the fact that scattered along its floor is a series of over thirty lakes, of which only one has an outlet to the sea." The lakes of the Aralo-Caspian area were undoubtedly once connected with the open ocean, and have been separated from it by uplift, for some of them still have seals living in their waters, whereas we find

${ }^{1}$ Gregory, J. W., The Great Rift Valley (1896). 


\section{I78 SCIENTIFIC STUDY OF SCENERY}

evidence that the salt lakes of the Great Basin region of North America have at no time had any connection with the ocean. These lakes of the Great Basin of America are of peculiar interest on account of the very valuable detailed accounts of their characters and origin which we owe to the labours of the United States geological and geographical surveyors, and especially to G. K. Gilbert and I. C. Russell, whose monographs on the old lakes of Lahontan and Bonneville contain a host of information of the greatest importance to the student of the earth's history. ${ }^{1}$ The region of the Great Basin extends from the British possessions on the north to Mexico on the south, and though two rivers traverse it on their way to the ocean, the greater part of the area has no drainage to the ocean, and is occupied by barren tracts scattered over which are salt lakes. The old lakes of Bonneville and Lahontan have now disappeared owing to change of climate, but evidence of their former existence is furnished, among other things, by old lake shores at different levels. Each of these shores was naturally at a constant level when it was formed, but Gilbert and Russell have shown that they have since been bent by warping, so that the level of each terrace varies as one traces it laterally, and sometimes the change is sudden and marked by a fault scarp. The upper terraces have been deformed to a greater extent than the lower ones, showing that the process of warping has continued through long periods, and there is no doubt that the basin as a whole, as well as the two

1 Gilmert, G. K., Lake Bonneville, and Russell, I. C., Geological History of Lake Lahontan, monographs U.S. Geol. Survey, 1890 and 1885 . 
great lakes which once existed in it, whose history has been written, originated owing to the warping action.

Similar movements have also occurred around the great fresh-water lakes of Canada, as shown by Gilbert and more lately by Dr. J. W. Spencer, the deformation of the Iroquois beach around Lake Ontario and of the Algonquin beach surrounding Lake Huron being specially marked. ${ }^{1}$ The origin of the Canadian lakes is, however, still somewhat obscure, as "great changes in the drainage have been produced by glacial interference, to such an extent, indeed, that some writers have advocated the formation of the basins solely as the result of the production of glacial dams, though most students of these lakes consider their existence to be due to the operation of warping accompanied by glacial interference, the latter having caused diversion of drainage.

The origin of the Jordan depression and the Dead Sea is, as already stated, connected with that of the African lakes lying along the line of the Great Rift. Another fairly large lake, though a shallow one, which has been satisfactorily proved to be due to differential movement, is Lake Balaton (the Platten See), in Hungary. ${ }^{2}$

The origin of the great lakes which flank the Alps has been much discussed, and most writers are now agreed that they owe their existence chiefly to differential movement, though complications have also been produced by glacial interference with the river

1 Spencer, J. W., "Origin of the Basins of the Great Lakes of America," Quart. Jour. Geol. Soc., vol. xlvi., p. 523.

${ }^{2}$ An account of this by Professor J. W. JUDD will be found in the Geological Magazine, decade ii., vol. iii., p. 5. 
drainage. The lakes differ in some respects; thus Neuchatel, Bienne, Morat, and the lower portion of Geneva run parallel with the axis of a great synclinal fold or trough, while Thun and Brienz, Zug, Zurich, Wallensee, Constance, Como, Maggiore, Orta, and Lugano occupy valleys which are transverse to the main axes of folding. The transverse lakes, as pointed out by Heim, may be due to the sinking down of the great mass of the Alps by its own weight, causing relative depression of the heads of the valleys, though the shape of Como and Lugano suggests that they were formed in valleys which once ran northward. Deformation of terraces has also been noted in the case of the Alpine lakes; Heim and Aeppli record them on the sides of Zurich.

The existence of large lakes owing to earth movement has been satisfactorily proved, but it is a matter of considerable interest to inquire whether small lakes can be produced in the same manner. Minor movements in a direction transverse to a river valley are not likely to give rise to lakes if they take place slowly, as the rivers would keep their courses open, unless indeed the valleys were occupied by ice, but sudden changes, such as are productive of earthquakes, might well cause the required uplift. Mr. R. D. Oldham has observed cases of the formation of small rock basins which hold up lakes in the district affected by the great Indian earthquake of June I 2 th, I 897 . These lakes occur in granite rocks. Through the kindness of Mr. Oldham, I am able to reproduce a photograph of a lake formed during this earthquake. (See plate.) This particular lake (Thirn Hat, Garo Hills) is formed owing to the existence of 


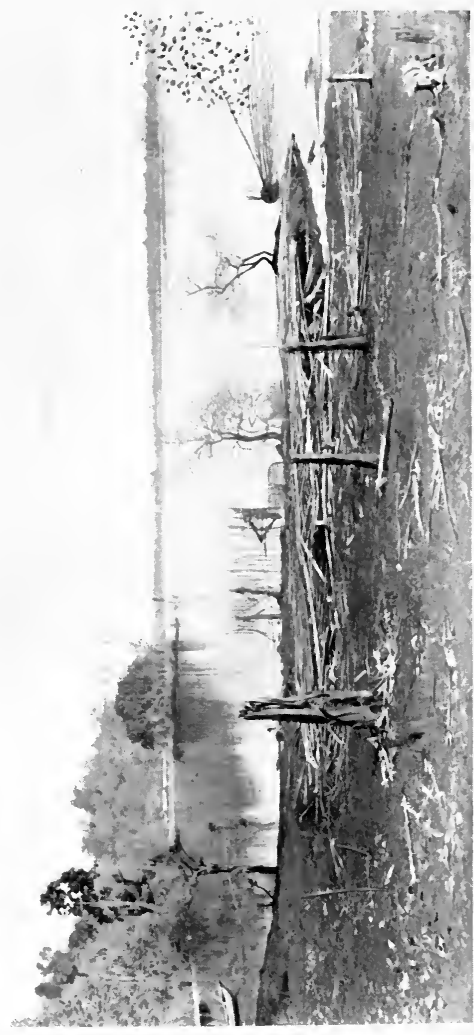

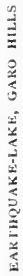



a visible fault, but some smaller lakes which he has observed, occurring in true rock basins, which were formed during this earthquake, show no external signs of faulting, as, for example, Naphak, in the Garo Hills.

The existence of small rock basins due to earthquake action is of great importance, and the possibility of the operation of earthquakes should be taken into consideration in discussing the origin of all lakes, large or small, which can be definitely proved to occur in basins margined by live rock around the entire sheet of water.

(iii) Crater Lakes. The formation of volcanic craters will be described in its proper place; it is sufficient to mention here that they may be formed as the result of accumulation, or of explosion, or of a combination of the two processes, and when the volcano is extinct, if the crater has not been breached or destroyed, and the material is not too porous to allow water to accumulate within it, a lake will be formed. Many well-known examples of crater lakes exist in various parts of the world, as the Lucrine lake and Avernus in the Phlegræan fields of Italy, the Laacher See in the Rhenish provinces, Gustavila in Mexico, of which a representation is given in Professor Judd's Volcanoes (Fig. 72), and especially those of Auvergne and Ardèche, which are described and illustrated by M. Delabecque. Six of them are shown in plan on Plate XIV. of his work on the lakes of France, namely, Lacs d'Issarlès, du Bouchet, de la Godivelle d'en Haut, Chauvet, de Tazanat, and Pavin. They present a remarkably regular circular outline, and the isobaths, or lines of equal depth, are also 
extremely regular. The largest of the six, Lac d'Issarlès, has a depth of 108 metres, and the comparatively small Pavin, with a diameter of about 800 metres, has a depth of 92 metres. A figure of the Lac du Bouchet is seen on p. 276 of the same work. Of the Lac d'Issarlès the late Mr. G. P. Scrope writes that it is one of those lakes which "differ from ordinary craters, not only in their greater dimensions, but in the nature also and disposition of their enclosure, which is usually of primary or, at all events, pre-existing rocks, merely sprinkled more or less copiously with scoriæ and puzzolana, little, if at all, elevated above the surface of the surrounding country."

(iv) Lakes formed by Erosion.-We now turn to the consideration of the formation of lakes by processes concerning which there has been a great deal of controversy. The agents which have been suggested as capable of forming rock basins by erosion of some of the surface material are wind, running water, and ice in the form of ice-sheets and glaciers. According to Gilbert, a number of small depressions are formed in the Colorado region by the action of wind upon rocks devoid of vegetation, and Pumpelly describes similar depressions occurring in the crystalline rocks of the region between the Siberian frontier and the Great Wall of China, which he attributes to the removal of weathered rock by wind-action. ${ }^{1}$

In a humid climate it is well known that rocks are weathered unequally according to the amount of vegetation which covers them. If a fairly flat surface, diversified by small slopes, is formed of

1 See Delabecque, Les Lacs Français, p. 313 . 
rock which is mostly bare, especially if the rock contains much soluble material, as in the case of many igneous rocks, the lichens, liverworts, and mosses, which retain the moisture, and hold it against the rock, at the same time supplying it by their decay with solvent organic acids, eat their way into the rock, and furnish a superficial soil, in which grass, heather, and other plants grow, and allow the process to continue on a larger scale. If for any reason the conditions should change and the vegetation die, the vegetable matter and decomposed rock beneath may be removed by the wind, giving rise to a small rock basin. Little basins of this character, a few feet or yards in diameter, are often met with in the English Lake District in every stage of formation. In some cases we may strip off the vegetation, and find the depression beneath, often containing some incoherent weathered rock particles; at other times most of the vegetation has disappeared, and only a little peaty material is left at the bottom of a pool. How far this process is responsible for the formation of pools of any size is unknown, but it should be taken into account when discussing the origin of small rock basins.

The other agent which has been considered capable of producing rock basins, often of considerable size, is ice, and it is necessary to refer to this at some length.

M. G. de Mortillet in I859 suggested that the Alpine lakes had been filled up with alluvial deposits and afterwards excavated by glacial action; and in the same year the late Sir Andrew Ramsay put forward his well-known theory that the basins had 


\section{I84 SCIENTIFIC STUDY OF SCENERY}

been scooped out of the solid rock by glacial action, and afterwards applied the theory to account for lakes in various regions, including even the great fresh-water lakes of Canada. Evidence in support of this theory was subsequently advanced by many writers, among whom special mention may be made of Mr. Clifton Ward, whose work on the lakes of English Lakeland was distinguished by the care which marked all the work of this lamented geologist, whose labours have been fitly recorded by Canon Rawnsley in his Literary Reminiscences of the Lake District. Many writers have attacked the theory from various points of view, and even at the present day there is a considerable diversity of opinion as to the capacity of ice to excavate rock basins, some denying it in toto, while others, admitting its power to hollow out small basins, as those in which many of our upland tarns lie, or even the larger lakes of an area like North Wales, deny its power to form basins like those in which the waters of the greater Alpine lakes are upheld.

We shall have occasion to speak about the asserted erosive power of ice in a chapter devoted to consideration of glaciers, and in the meantime may observe that in order to prove that ice can excavate a basin we must show, first, that the actual rock basin exists, and, secondly, that it cannot have been formed in any other way than by the erosive action of ice, which, by the way, will probably be found to be a matter of considerable difficulty. Not only must the contour of the lake shores be examined, but a complete survey of the subaqueous contours is also necessary. In only a few cases has this been done, notably by Mill and Delabecque; and 
we shall consider the results of their work and its bearing upon the question of glacial erosion in the succeeding chapter. In the meantime we may call attention to recent writings where the existence of rock basins of small size has been asserted, which it is difficult to account for as being produced by earth movement (though Mr. Oldham's observations on the rock basins produced by the Assam earthquake of 1897 must always be borne in mind). I mention recent writings only, because those who have studied these basins in recent years have been fully alive to the importance of establishing the existence of live rock all round the basin, and not merely where the stream issues from the lake, an occurrence which was wont to satisfy many of the earlier writers upon the origin of lakes that they were dealing with live rock basins, though we have had occasion to notice that the water often issues over rock as the result of diversion of drainage by glacial or other interference, and accordingly the dam of accumulated material may occur at any point around the margin of the lake.

Mr. H. P. Cushing, in a description of the Muir glacier of Alaska, ${ }^{1}$ describes a number of diminutive pools on the tops of low hills near the termination of the glacier, some of the hills projecting from its mass. The pools are very shallow, and only a few yards in diameter; and though the shores of some are partly formed of glacial débris, "some of them clearly occupy rock basins, rock in places being readily traced all round them." He states that all the basins which he saw "lie in small valleys on the mountain-tops, whose presence

${ }^{1}$ Cushing, H. P., American Geologist, 189 r. 
seemed to depend on the fissure systems and on the varying depths to which loosening of blocks had taken place"; and further, "That the glacier has done little more than to remove the loosened rock and polish the resulting surface is shown in a vast number of localities." The ice in this case appears to have removed blocks which had become detached as the result of weathering.

A paper by Professor Bonney ${ }^{1}$ is devoted to consideration of "Some Small Lake Basins in the Lepontine Alps." "He gives proofs of the existence of four rock basins holding the waters of the Lago di Tremorgio, Lake Ritom, Lake Cadagno, and Lake Tom, in the Val Bedretto and Val Piora. Sir John Lubbock $^{2}$ remarks of two of these: "Some of the smaller lakes in these regions, as, for instance, those of Cadagno and Tremorgio, are 'meres' or lakes of sinking, like those of Cheshire." But Professor Bonney, though he speaks with extreme caution concerning their origin, seems to admit the possibility of their formation by glacial erosion. Of Lake Ritom he writes: "This basin, then, the part which lies below the present contour line of 6000 feet (in round numbers), is the utmost that, in my opinion, can possibly be attributed to the erosive action of ice."

M. Delabecque, like Professor Bonney, is not a believer in the efficacy of ice as a former of lake basins on a large scale. In his work on the French lakes, ${ }^{3}$ when giving a summary of the various lakes

1 Bonney, Professor T. G., Geological Magazine, dec. iv., vol. v. (1898), p. 15.

${ }^{2}$ Luввоск, Sir J., The Scen ry of Switzerland, p. 448.

${ }^{3}$ Les Lacs Français, p. 343. 
of France formed in different ways, he concludes with a list of lakes due to the excavation by glaciers of the weathered parts of rocks, including all the lakes which cannot be attributed to any of the other causes which he has previously considered. The list is as follows :-

"In the (French) Alps: The lakes of Sept-Laux, the principal lakes of the massif of Belledonne (except Lake Robert), Lake Cornu, Lac de Rabuons, and most of the lakes situated in the eruptive rocks and crystalline schists.

"In the Jura: Lake de Paladru (?).

"In the Vosges: Lake de Retournemer.

"On the Central Plateau: Lake de la Crégut, de Laspialade, many of the small lakes of the plateau de l'Artense, and of the neighbourhood of Riom-èsMontagne.

"In the Pyrenees: Lacs d'Artouste, d'Arrius, de Miguelou, de Gaube, d'Estom, d'Espingou, de Saousat, d'Oo, the lakes of Port de Venasque, Lac Bleu or de Lesponne, the lakes of the massif of Néouvieille and of Caillaouas, Naguille, Lanoux, Garbet, Lers (?), Bassiés, of the waste of Carlitte, and generally the greater part of the lakes situated on eruptive rocks and crystalline schists."

He concludes, "I need scarcely say in conclusion that this list is far from being definite, and that the future progress of geology will certainly modify it." 


\section{CHAPTER XII.}

\section{LAKES (Continued)}

H ITHERTO, while speaking of the origin of -1 lakes, we have said little of the nature of the outlines of lake shores, or of the topography of their basins, and we may now proceed to consider the character of the shores and basins during different periods of the existence of lakes.

Topographical Features of the Shores and Basins of Lakes.-The features of a lake depend, in the first place, upon its origin, and, secondly, upon the changes which have taken place after its formation, some parts undergoing erosion, while others receive deposit. The diversity in the structures of lakes, due to difference of origin, has already been alluded to in passing. A crater lake often presents a circular outline, and may be very deep as compared with its horizontal extent; a lake of subsidence, due to underground solution, may vary extensively both as regards outline and nature of the hollow ; one formed by erosion of a rock basin would present a general basin-shaped cross-section; lastly, lakes formed by blocking of pre-existing valleys, whether by formation of dams of accumulation, or by differential uplift in a direction transverse to the valley (or, what comes to the same thing, sinking of the upper portion of the valley. in a downward direction), will 
be distinguished by possessing a continuation of the subaerial features of the valley sides beneath the margin of the lake. These lakes are indeed drowned portions of river valleys, and will at first possess the physiographical features of such valleys, which may be afterwards modified by erosion, and especially by accumulation. We may consider, in the first place, the subaqueous features of lakes of the last class, and then refer to their marginal topography. The original subaqueous features will naturally become masked in lakes which have received a supply of sediment for any length of time, and accordingly we cannot expect to find signs of features which were produced by subaerial denudation before the formation of the barrier in all lakes which form drowned parts of former river valleys; but we have several cases in which these features are developed to a sufficient extent to show that we are not dealing with examples of basins hollowed out by erosion. Dr. Mill's work on the English Lake District brought to light examples of submerged river valleys beneath the waters of some of the lakes. In Windermere "a channel about 100 yards wide ..., commencing off Ferry Head, runs close to the west shore, and spreads out to nearly the full width of the lake at Storr's Point. This channel suggests the remnant of an old river valley by its narrow and sinuous course." It has no doubt been modified by subsequent accumulation of deposit. In the same lake, a valley which enters near the head, in a direction at right angles to the long axis of the lake, is continued beneath the water in Pull Bay; and the Troutbeck valley, on the east side, is also found to run below the lake, though here the contour lines 


\section{I90 SCIENTIFIC STUDY OF SCENERY}

are modified as the result of subsequent deposition. Again, in Ullswater the Fusedale valley is submerged where it joins the lake, as indicated by the course of the sublacustrine contour lines around the bay at How town. In Ullswater and Crummock are excellent examples of subaqueous cliffs. Two soundings taken near the head of the former lake, at a distance of six feet from the shore, gave in one case a depth of forty-four, in the other a depth of forty-eight, feet; and in Crummock, "at Hause Point, on the right, the cliff ran sheer down, seventy feet being found eight feet off the rock." The floors of Buttermere, Crummock, and Wastwater are exceedingly flat for long distances, and suggest the existence of submerged alluvial flats formed before the conversion of valleys into lakes. Again, the existence of the ice-smoothed rock surfaces with a rough face on the lee sides, both above and below water, on rocky islets, as seen in Windermere and Ullswater, gives another example of the identity of subaerial and sublacustrine scenery in the case of the lakes of Lakeland. This identity of the scenery above and below water is strong evidence that the lakes of Lakeland are merely drowned lower portions of river valleys.

More striking subaqueous features are found in the Canadian lakes. Many of these have been recorded by Dr. J. W. Spencer, ${ }^{1}$ and some examples may be quoted from his works. In Lake Ontario he has "shown that a narrow buried channel, of ninety fathoms depth or more, extends for about

1 See especially Spencer, J. W., "A Short Study of the Features of the Lower Great Lakes during the Great River Age," Proc. Amer. Assoc. for Advancement of Science, vol. xxx.; also the same author, Quart. Jour. Geol. Soc., vol. xlvi. 
ninety miles from near Oswego to the seventyeighth meridian, and at a somewhat less depth (seventy fathoms) to near the meridian of the Niagara river. . . From the Canadian shore the lake bottom slopes gently, ... but from the New York side the slope for three or four miles is double that on the northern side, and then comes a plunge over the face of an escarpment. This escarpment is quite comparable with a subaerial escarpment, as that of the Niagara river. The escarpment can be traced for nearly 100 miles." Spencer has shown that Lakes Huron and Michigan also possess the characters of drowned subaerial valleys traversed by river systems. Huron possesses a submerged escarpment, 300 to 450 feet high, facing the north-east. Michigan "is in part bounded by vertical submerged escarpments, one of which, upon the eastern side, has a height of 500 feet."

Submerged valleys occur in Switzerland, at the heads of Geneva and Constance, but Forel has shown that these are due to deposition, and not to the existence of drowned river valleys of erosion; the denser water of the river, charged with very fine alluvial material, is bounded by walls of lighter water, and where it meets with these, deposits its alluvium in embankments which direct the course of the sublacustrine stream. ${ }^{1}$

The shore lines of lakes will at the outset be determined by the existing nature of the ground at the time of formation of the lake, in those lakes which are due to the drowning of a subaerial surface

${ }^{1}$ Forel, F. A., Le Léman, vol, i., p. 385 ; and Delabecque, A., Archives des Sciences Physiques et Naturelles, 4ème Période, vol. i., Geneva. 
by formation of barriers. Accordingly the relationship between depth and superficial extent will depend upon the relation between width and depth of the inequalities in which lakes are formed. Plateau lakes on the whole will be comparatively shallow, valley lakes comparatively deep. Moreover, the width of the lake, as compared with its depth, will, in the case of valley lakes, depend upon the character of the valley. Wide shallow valleys will produce wide shallow lakes; deep narrow valleys will give rise to deep and narrow sheets of water. Thus in the Lake District the comparatively narrow valleys above Ullswater and Windermere continue as deep and narrow river-like lakes, while the wide shallow lower part of Borrowdale is continued in the lakes of Derwentwater and Bassenthwaite, which present the same characteristics.

If the original valley was tortuous, the lake will be tortuous, like our own Ullswater, and the lakes of Lucerne, Como, and Maggiore.

Again, where tributaries have cut their valleys down to the level of the main valley, lakes formed by barriers will extend up the tributary valleys as bays, the bay running up the tributary to a greater or less extent according to the slope of the Thalweg. If the slope is steep, the bay will be relatively small; if gentle, the bay will form a deep indentation. Bays of this character naturally become filled by sediment, as we shall see presently, when the lake has existed for some time, but if the supply of sediment be small, and the bay large, the bay may remain for a considerable period. The plateau tarns of Lakeland and North Wales are frequently indented with small bays, corresponding with minor valleys. Among 
the larger lakes, we have already noticed the bays extending up the Pullwyke and Troutbeck valleys in Windermere, and the Fusedale valley at Howtown in Ullswater. In the Alpine region we may notice the two arms of Lucerne occupying tributary valleys, and the arm of Maggiore extending up the Val d'Ossola.

The outlines of lakes forming drowned portions of river valleys will at the outset be marked by considerable irregularity, abrupt angles being frequently observable where the original ground was uneven. This may be seen at the present day with the artificially raised Thirlmere, a useful object-lesson furnished by the Manchester Corporation to show the difference between a newly formed lake and one that has adjusted itself to a stable condition. These outlines will be subsequently modified as results of erosion and deposition.

Erosion does not exert any profound effect upon the shores of small lakes, though considerable erosive action occurs on larger ones, causing gradual recession, especially of the more salient points of a lake shore, with formation of cliffs. This is seen in the large Canadian lakes, and also those of Sweden, which are often stirred by storms of considerable violence. Mill gives a figure in his work on the English lakes showing effect of wave erosion on the incoherent material of the Troutbeck delta at Windermere. Small cliffs, simulating sea-cliffs, may be produced by erosion, and a consideration of the formation of cliffs may be deferred until we consider the action of the sea.

The most marked changes are produced by accumulation, which modifies to a very great extent the 


\section{SCIENTIFIC STUDY OF SCENERY}

original outlines of a lake. Thus Mill has contrasted the straight line of the south-east side of Haweswater, which is practically its primitive outline, with the extremely sinuous north - western margin, produced by subsequent accumulation of deposit.

The first accumulation to be considered is the beach which surrounds a sheet of water. Now lakebeaches merely differ from sea-beaches in the absence of tidal action, and their essential features are the same, and their structure and origin will be more fully considered hereafter. It is sufficient here to notice that beaches are formed by on-shore travel of loose material, tending to fill up the hollows between salient points by deposition of material, which assumes a concave curve characteristic of lakes which have adjusted themselves to conditions of stability. The curvature of bays is one of the most striking features in the scenery of a lake, and the angular outlines of a recently dammed lake like Thirlmere or the sheet of water at Tarn Howes, near Coniston, form a marked contrast to the flowing curves of a lake whose original angularities have been replaced by the concavities due to beach formation. The view of Haweswater in the accompanying plate shows the curved bays of the northwestern shore on the right, and the straight line of the south-eastern shore on the left, of the figure.

Next we have the delta, formed where a stream enters the lake. The velocity of the water is at once checked on entering, and it deposits its material, gradually converting a portion of the lake into a flat tract of land, which ordinarily forms a fan, with semicircular margin, though this margin may be greatly complicated in many ways, especially by 
the tendency of streams to deposit ridges on their sides and build out parallel embankments rising above the surface for some distance beyond the general margin of the delta. Moreover, the shallow waters in front of the deltas are frequently occupied by a growth of marsh and water plants, as reeds and water-lilies, which form a peaty surface sometimes sufficiently firm to give rise to land, beyond the general margin of the delta which is due to mechanical deposit of sediment, as seen at the head of Derwentwater. The plate with the figure of Sty Head Tarn, besides exhibiting a delta at the foot of the lake which originated the tarn, shows two others; that at the head, seen in the foreground, which has considerably diminished the size of the lake, and another on the left-hand side, with a minor delta growing out from it, forming a promontory.

When a very important river enters a lake between head and foot, it will build out its delta until the lake is converted into two sheets of water, connected by a narrow strait on the side opposite to that on which the delta is growing. Haweswater is thus converted into two sheets, known as High Water and Low Water, by the straits at Measand, where the lake is narrowed from a width of half a mile to about 100 yards. In the figure of Haweswater the Measand delta is seen as a dark straight line just above and to the west of the boat-house, and concealing High Water beyond it, the straits being visible between the delta and the dark slope on the left. As the outward growth of deltas of this nature proceeds, they may, and often do, eventually form completely across the lake, severing it into two, as in the case of Buttermere and Crummock, and Bassenthwaite and Derwent- 


\section{I96 SCIENTIFIC STUDY OF SCENERY}

water in the Lake District, the two lakes of Llanberis in Wales, and Brienz and Thun in Switzerland, to mention a few examples. When this happens the two lakes are separated by a flat alluvial tract, which may be completely submerged after heavy rains, when the lake level rises, an event which occurs not infrequently in the case of Derwentwater and Bassenthwaite.

Screes and dry deltas often encroach upon lakes, altering the original topography of their shores. The dimensions of many of our upland tarns have considerably diminished as the result of material slipping down the slopes or falling down scree-shoots into the water. The well-known screes of Wastwater, illustrated in the plate, have produced considerable diminution of the area of the lake, and also profoundly affected the scenery of its shores.

Lastly, we have avalanches of rock descending from the hill-sides in mountain regions and tending to diminish the area of the lake when they fall into the water surrounding the shore. A somewhat peculiar result of the fall of avalanches is described in Delabecque's monograph on the French lakes, the explanation of the phenomenon having been given by MM. J. Vallot and E. Belloc. In certain regions, as the Pyrenees, avalanches fall in winter and the early spring, and are arrested on the frozen surface of the lake. When it thaws the materials fall to the floor of the lake, and become rearranged to some extent, giving rise to a mound, which sometimes forms an island and sometimes a little secondary basin between the avalanche and the lake. ${ }^{1}$

By these various processes-deposition of sediment

${ }^{1}$ See Delabecque, Les Lacs Franfais, p. 364. 


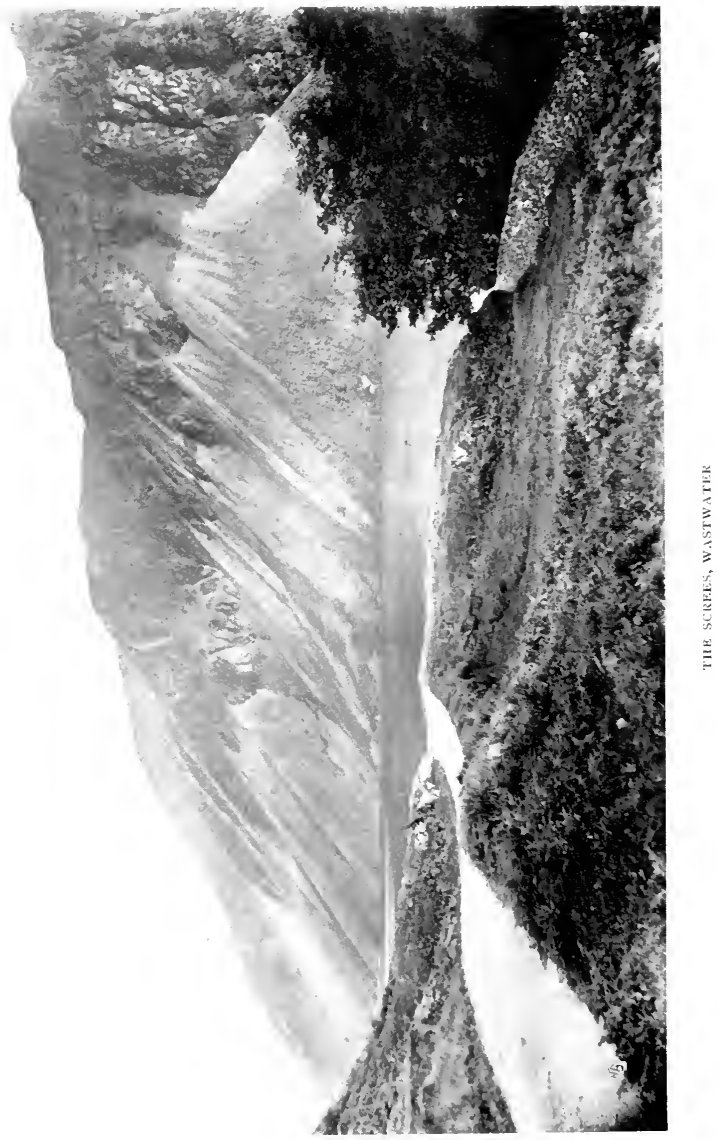



in deltas, formation of screes and avalanches, and general growth of vegetation in the shallows produced by growth of alluvium-lakes are gradually filled up. At the same time the top of the lake at the exit may become lowered by erosion, though, as before stated, the erosion is slight, owing to the general absence of sediment. Accordingly we find all stages from the existence of lakes in which the diminution of area has commenced, through those in which the tract of water consists of a pool surrounded by peat moss, to the final extinction of the lake and its replacement by turbary, or peat moss produced by growth of marsh vegetation on the flat alluvial tract caused by the silting up of the lake. These peat mosses are usually very abundant in mountain regions, and testify to the large number of lakes which once existed, and have now been destroyed by silting.

Islands in Lakes. - It is very doubtful how far islands can exist in lakes produced by erosion, though, assuming that erosion can produce lakes, the existence of isolated masses of hard rock among softer rocks might permit the formation of islands. In lakes produced by "drowning" of the bottoms of river valleys, any isolated hill standing above the general level of the valley would remain as an island. The rocky islands of Ullswater and Windermere seem to be of this nature; and, as pointed out by Mill, submergence of the Ullswater valley to the extent of another hundred feet would convert Hallin Fell into an island a mile in diameter. Other islands are produced by existence of incoherent material in ridges; thus, as suggested by Mill, the islands of Derwentwater, composed of masses of gravel, sand, 


\section{SCIENTIFIC STUDY OF SCENERY}

and clay, are probably ridges of glacial drift which stood out above the general level of the floor of the valley to a sufficient height to escape submergence. The formation of islands by avalanches subsequently to the time when the lake came into being has been described above.

The so-called floating islands, which are sometimes found, may be referred to, though they are of little interest to the student of scenery. One occasionally appears in Derwentwater, and the little lake Llyn-ydywarchen, between Carnarvon and Beddgelert, in North Wales, receives its name from a similar appearance. It would seem that these floating islands are simply masses of peaty vegetable matter on the floors of shallow parts of the lake, which, owing to accumulation of light gases, formed by decomposition of vegetable matter, are occasionally buoyed up to such an extent that they float upon the surface, until the gases are disengaged sufficiently to allow them to sink once more to the bottom. This is the explanation given by Jonathan Otley, the old Lake District guide (whose geological work has hardly received the recognition which it merits), in a paper published in the Lonsdale Magazine in 1820 (p. 15), and there is very little doubt that it is substantially correct.

Colour of Lakes. - The charm of lake scenery depends to a large extent on the limpidity of the water and the varying play of colours upon the surface. The transparency of the water is due to the deposition of sediment where the streams enter the lake, leaving the main mass of the waters free from sediment, except when violent floods bring very fine particles into a lake of no great superficial extent. 
The question of colour is more complex, and merits some consideration, especially as much diversity of opinion has arisen concerning the cause of colour in certain lakes. Over and above the ever-varying play of colour due to changes in the sky, we find that certain lake waters possess a very definite hue; the intense blue of Geneva, for instance, is known to everyone.

The water of lakes may be blue, green, yellow, or absolutely colourless. M. Forel has constructed a scale of colours for reference, made by mixing together ammoniated sulphate of copper and chromate of potassium. The scale extends from I. to XI., I. containing none of the chromate solution, while XI. contains 65 per cent. of the chromate and only 35 of the copper sulphate. The colours from I. to IV. of the scale are blue, those between V. and VIII. green, and IX. to XI. yellow.

Of blue lakes, we find in our own country two tarns on Snowdon-namely, Llyn-dur-Arddu and Glaslyn-of an intense indigo colour; and the larger Llyn Llydaw has much the same hue. In Switzerland, Geneva has already been referred to. There are also several small lakes, as the Blaue Seeli, near Kandersteg, and the Lac Bleu de Lucel, near Arolla. The cause of this colour has been a subject for much discussion. Sir H. Davy suggested that the waters of Genera owed their colour to the presence of iodine; and other writers have supposed that it was due to minute particles of glacier mud.

It is now known that the true colour for distilled water is blue. If distilled water be placed in a long tube, and viewed through the length of the tube, it will appear blue. Accordingly it is found that the 
water of the lakes just referred to is extremely pure, being free from any appreciable amount of organic matter, and also devoid of sediments.

In the Gazette de Lausanne for October, I887, Professor Forel describes the waters of the Lac Bleu de Lucel, a lake about 200 feet long and thirteen feet deep, fed by a spring which rises from the ground just above the lake. He finds that the waters of this lake are, so far as is known, the most transparent of all sheets of water, and they are devoid of life. I had the opportunity of seeing the lake in sunshine, and also when the sky was completely overcast, and under the latter conditions the colour was exquisite.

The green colour may be due to reflection of light from a sandy bottom through shallow water. Again, solution of organic substances, such as humic and ulmic acids derived from vegetable matter, may, as shown by Forel, convert blue water into green, or even into yellow or brown, when the water is surrounded by peat mosses. This accounts for the green colour of many of the upland tarns of our hill regions, which frequently occur in association with peat mosses due to their partial silting up. Again, a green or yellow colour may be produced by abundance of coloured microscopic organisms in the water, as suggested by Delabecque in the Lac de la Laudie, on the central plateau of France, which has a colour corresponding with No. XI. in Forel's scale.

Professor Spring has shown that blue distilled water rapidly loses its colour and becomes green, but that the addition of a small proportion of bichloride of mercury, which will destroy organisms, is sufficient 
to preserve the blue colour indefinitely. Again, water which does not contain organic impurities, but which contains minute particles of colourless mud, as glacier mud in suspension, gives a yellow tint to the water, which, combined with its natural blue, produces a green tint. To this cause he attributes the green colour of Neuchatel and Constance. If the glacier mud is very thick, the water will be rendered turbid and grey, as seen where glacier streams pour into a lake, or where, unfortunately, finely divided mud is produced by mining operations, causing the greyness which sullies the head of Ullswater. Lastly, it has been observed that some lakes, which are ordinarily green, occasionally become colourless, and Professor Spring has shown that this change is produced by the introduction of a fine reddish mud, coloured by oxide of iron, which neutralises the green hue, and renders the lake for the time being perfectly colourless.

On March 30th, I894, about I I.30 a.m., I noticed an interesting phenomenon on Windermere when looking up the lake from among the islands of Bowness Bay. The day was perfectly calm, and the fells at the head of the lake were seen dimly through a pearly blue haze. The sun was shining brightly on the islands in the foreground, with their graceful groups of birch, and on the light green larches mixed with the darker firs on Furness Fells. From the banks of the lake on either side a bar of prismatic colours, glowing most vividly, stretched out towards the centre, the red being next the shore, and the violet towards the middle of the lake. Looking about for an explanation, I found that the water around the boat was glistening from 
myriad points, and noticed that countless organisms, probably unicellular algæ, were floating in the surface waters. Each of these acted as a little prism, and produced the iris bars which gave so strangely beautiful an effect to the whole scene.

Effects due to mirage are often seen on lakes, but it is beyond our purpose to describe them in full. The fata morgana is often visible on Geneva, especially in the spring-time. A full account of the phenomenon will be found in Professor Forel's work Le Léman (vol. ii., pp. 5 I4 et seq.). 


\section{CHAPTER XIII.}

\section{VOLCANOES}

TOLCANIC hills and plateaux are produced by accumulation of material which has been brought from the earth's interior in a liquid or fragmental condition upon the pre-existing surface of the earth. It was formerly supposed that volcanic hills were due to uplift of a blister-like mass of the earth's crust, like the viscid bubbles which form upon the surface of a plate of hot porridge; but study of volcanoes in all states of dissection has abundantly proved that the hills are formed by accumulation, and the old "elevation-crater theory" has been abandoned.

To account for the extrusion of material in a molten state on the earth's surface, we must take three things into consideration, namely, the production of the molten material, the formation of lines or spots of weakness through which it is extruded, and the force which brings the molten matter to the surface; these we may refer to in the above order.

If the earth has, as generally supposed, consolidated from a once fluid condition, it is possible that some of the originally molten material has remained unconsolidated; but there is much evidence that the greater part at any rate of the rocks 
which are poured out on to the earth's surface in a molten condition have been solid, and have become liquefied. Liquefaction may be brought about in a solid rock by increase of temperature, diminution of pressure, or alteration of the composition of the rock, thereby lowering its melting point. At the surface of the earth the rocks are solid owing to the low temperature which prevails there. Observations have shown that the temperature increases towards the interior, but so also does the pressure, which tends to neutralise the effects of heat, and to keep rocks solid which, under the ordinary atmospheric pressure, would be fused. At a certain depth masses of rock may occur at a high temperature which are solid, but so near to the fusing point that minor changes may cause their liquefaction, and we may refer to the principal changes which have been claimed as capable of producing liquefaction. In the first place, transference of heat from one rock to another may produce liquefaction of a rock which was previously below its fusing point. Such transference must take place, but it is doubtful whether it can ever be a very potent factor in producing liquefaction.

Sir Humphry Davy long ago suggested that a rise in temperature might occur as the result of the heat generated by oxidation of masses of metals of the alkalies enclosed among the rocks of the interior; he was afterwards led to abandon the suggestion, but some recent writers have maintained that oxidation of metals existing in the elementary condition may cause evolution of sufficient heat to produce liquefaction. Mr. Scrope called attention to the effects which would be produced by formation 
of thick masses of sediment. It is supposed that surfaces of equal temperature (isogeotherms) occur approximately parallel to the surface of the earth. An accumulation of some thousands of feet of sediment would raise the isogeotherms correspondingly, and in this way the temperature of rocks previously in a solid state might be raised to their fusing points. Mr. R. Mallet supposed that after the crust of the earth became too rigid to adapt itself to contraction by folding it would do so by crushing, and that belts of crushed rock would be formed, and that the friction due to the crushing would generate heat sufficient to cause liquefaction.

Diminution of pressure might be produced by denudation of great masses of overlying sediment or by uplift of portions of the crust in domes and arches, relieving the pressure beneath the centres of the uplifts, or by actual fissuring of the earth's crust. It must be noted that, though denudation would remove the pressure, it would lower the isogeotherms, and similarly accumulation of sediment, while raising the isogeotherms, would increase the pressure.

Alteration of composition, causing lowering of the fusing point, was first suggested by Professor Guthrie as a means of producing fusion, and has been strongly advocated by Professor Judd, especially to account for certain phenomena connected with the great eruption of Krakatoa in 1883. Guthrie observed that certain salts were capable of forming unstable compounds with water, which he termed cryohydrates, and he suggested that analogous compounds might be formed out of some of the constituents of rocks. These cryohydrates have a lower melting 


\section{SCIENTIFIC STUDY OF SCENERY}

point than the corresponding anhydrous compounds.

The capacity of these various processes to produce the requisite fusion has been very fully discussed in many works and memoirs. It is, of course, impossible to enter here into the technicalities requisite for the comprehension of the various arguments, but enough has been said to show that liquefaction may be produced in more than one way, and the probability is that the complexities of volcanic phenomena can only be accounted for on the supposition that the causes which produce liquefaction are also complex.

The production of planes or lines of weakness, along which material may be extruded upon the earth's surface, has been already referred to when discussing the changes produced by movements of the earth's crust; it was then seen that fracture as well as folding frequently resulted from movements of the superficial covering of the earth. It now remains for us to call attention to the distribution of the planes of disruption, and to trace their connection with the distribution of volcanic vents. It has long been known that volcanoes are usually developed along definite lines, specially well seen in the case of the volcanoes which border the western coast line of the New World, but also easily traceable in other areas of vulcanicity. Now the most important of these lines occur along the septa of the great earth-waves, which are broken across by gigantic fault-planes, and it is here that volcanic activity is most rife. The reader will find this connection between the distribution of volcanoes and that of the great wave septa discussed in 
Professor Lapworth's presidential address to Section C of the British Association at Edinburgh (1892), from which the following sentences are quoted :-

"If we draw a line completely round the globe, crossing the Atlantic basin at its shallowest, between Cape Verde and Cape San Roque, and continued in the direction of Japan, where the Pacific is at its deepest, as the trace of a great circle, we find that we have before us a crust fold of the very highest and grandest order. We have one mighty continental arch stretching from Japan to Chili, broken medially by the sag of the Atlantic trough; and we see that this great terrestrial arch stands directly opposed to its natural complement, the great trough of the Pacific, which is bent up in the middle by the mightiest of all the submarine buckles of the earth-crust, on which stand the oceanic islands of the Central Pacific.

"The course of this line which we have indicated as forming our grandest terrestrial fold returns upon itself. It is an endless fold, an endless band. . . .

"Such an endless fold, again, must have an endless septum, which in the nature of things must cross it twice. Need I point out ... that if we unite the Old and New Worlds and Australia with their intermediate sags of the Atlantic and Indian Oceans as one imperial earth-arch, and regard the unbroken watery expanse of the Pacific as its complementary depression, the circular coastal band of contrary surface flexure which lies between them should constitute the moving master septum of the present earthcrust? This is the 'volcanic girdle of the Pacific,' our 'terrestrial ring of fire.'”

The great volcanic belts, then, will run parallel with our main coast-lines, forming the septa of the great continent-building folds. Other belts will lie along the septa of the mountain uplifts, giving rise 


\section{SCIENTIFIC STUDY OF SCENERY}

to lines of volcanoes bordering mountain uplifts, or will cause the formation of volcanoes along the fissures which break up the monoclinal folds of a plateau region.

Turning now to consideration of the manner in which the material is brought to the surface, either in a molten or in a fragmental condition, we are at once struck with the active part played by steam in many volcanic eruptions. The immense volumes of steam which are sent forth from Vesuvius during an eruption, which spread in the air with an outline resembling that of a stone pine, have long been familiar; and similar phenomena presented by other volcanoes prove that superheated water exists in the rocks below the earth's surface to a considerable extent, and this, when pressure is removed, is flashed into steam. This steam is capable of exercising great power in raising rocks, and it is obvious that much of the fragmental matter is hurled out of volcanoes as the result of explosions of steam, though it is not quite so clear that molten rock is forced out by the same agent. Nevertheless a large number of observed facts go to prove that this does actually occur. ${ }^{1}$

The importance of steam as a factor in producing volcanic phenomena is, perhaps, best shown by the observations made by Mr. E. Whymper in the Andes. When on the top of Chimborazo he witnessed an eruption of Cotopaxi.

"At 5.40 a.m. two puffs of steam were emitted, and then there was a pause. At 5.45 a column of inky blackness

1 On this subject the reader may consult Professor Judd's work on Volcanoes, chap. ii. 
began to issue, and went up straight into the air with such prodigious velocity that in less than a minute it had risen 20,000 feet above the rim of the crater. . . . The top of the column ... was nearly 40,000 fiet above the level of the sea. At that elevation it encountered a powerful wind blowing from the east, and was rapidly borne towards the Pacific, remaining intensely black, seeming to spread very slightly, and presenting the appearance of a gigantic 7 drawn upon an otherwise perfectly clear sky." 1

The column was formed of steam mixed with the volcanic fragments, and Mr. Whymper calculates "that, at least, two millions of tons must have been ejected during this eruption." On another occasion, when encamped on Cayambe, he "saw Cotopaxi pouring out a prodigious volume of steam, which boiled up a few hundred feet above the rim of its crater, and then, being caught by a south-westerly wind, was borne towards the north-east, almost up to Cayambe. The bottom of this cloud was about 5000 feet above us; it rose at least a mile high, and spread over a width of several miles. . . . I estimate that on this occasion we saw a continuous body of not less than sixty cubic miles of cloud formed from steam. If this vast volume, instead of issuing from a free vent, had found its passage barred, itself imprisoned, Cotopaxi on that. morning might have been effaced, and the whole continent might have quivered under an explosion rivalling or surpassing the mighty catastrophe at Krakatoa." 2

But though steam clearly plays the principal part

${ }^{1}$ The eruption is also of interest as bearing on the formation of stratus clouds.

${ }^{2}$ WhyMper, E., Travels anongst the Great Andes of the Equator, chaps. vii. and xviii. 
in many volcanic eruptions, there are many other cases where its action is as clearly secondary, and some other agent must be sought which is capable of raising rock from the earth's interior.

In areas where we find the rocks affected by monoclinal faults we frequently find extensive sheets of lava which yield evidence of having welled up from the interior and spread out with a tranquillity very far removed from the explosive violence of ordinary volcanic eruptions, as, for instance, in the plateau region of the western territories of North America. We have already seen that a region like that plateau region is composed of blocks tilted at various angles as though they had sagged down into a liquid mass beneath, and it is probable that during the process of faulting some of the molten matter below has been squeezed out through the cracks and spread tranquilly over the earth's surface above the fissure. Baron von Richthofen first maintained that such massive eruptions, as he named them, or fissure eruptions, as they are sometimes termed, had occurred.

It is, of course, possible that material may be brought up by a combination of the two processes, the sagging action of the earth's crust being aided by the presence of superheated water in the molten rock.

We have now considered the various processes which are necessary for the production of volcanoes, and may proceed to the consideration of the general character of the accumulations which are built up as the result of volcanic action.

The nature of the hills and plateaux which are formed by volcanic agency depends primarily upon 
the character of the emitted and extruded material, the violence of the action, and the character of the vents.

It has already been noted that material is brought out from volcanic vents in a molten or in a fragmental condition, and accordingly any volcano may be entirely formed of material in one or other of these conditions or of the two kinds of material in varying proportions. Commencing with the consideration of volcanic hills which are entirely composed of consolidated molten rock, we shall find that the outline of the hill very largely depends upon the condition in which the molten matter existed when it was extruded. We have seen that molten rocks may be divided into two main groups, the acid and the basic rocks, and that the latter are on the whole in a condition which enables them to flow further from the point or line of emission than the former, and the height of volcanoes formed of basic lavas is generally less when compared with the circumference than that of those composed of acid lavas. Many acid lavas, indeed, well up in a condition so viscid that they form a dome-shaped elevation covering the orifice, and marked with rugosities much resembling the products of a guttering candle. The reader will find descriptions of such domes, with illustrations, in the fifth chapter of Prof. Judd's Volcanoes. One of the best examples is the Puy de Sarcoui in the Auvergne district, of which the late Mr. Poulett Scrope ${ }^{1}$ writes that "in figure it is completely a flattened and rather elongated hemisphere, and is aptly compared by the mountain-shepherds to a kettle placed bottom upwards." Basic rocks often flow for a considerable

${ }^{1}$ Scrope, G. P., The Geology and Volcanoes of Ceniral France. 
distance from the point of extrusion of the lavas. Mr. Poulett Scrope suggested that the plain of the Malpais in Mexico, which has a slope of about $6^{\circ}$, was formed by extrusion of sheets of lava from points near its centre, each of these sheets gradually thinning away from its source and thus giving rise to a sloping surface. More striking examples, however, are furnished by the four great volcanoes of Hawaii, namely Mauna Loa, Mauna Kea, Kilauea, and Hualalai. An admirable monograph of these volcanoes from the pen of Captain C. E. Dutton has appeared in the Monographs of the U.S. Geological Survey. ${ }^{1}$ The mountains are composed of lava flows of a basaltic character, sheet lying above sheet, and there is a general absence of fragmental matter. Mauna Kea and Mauna Loa approach 14,000 feet in height, but "deep sea soundings in the vicinity have recently disclosed the fact that these volcanic piles are only the summits of gigantic masses rising suddenly from the bottom of the Pacific. . . . Mauna Loa and Mauna Kea, referred to their true bases at the bottom of the Pacific, are . . mountains not far from 30,000 feet in height." Of the two Mauna Loa is remarkable not only for its size-it "is certainly the king of modern volcanoes, no other in the world approaches it in the vastness of its mass or in the magnitude of its eruptive activity"-but also for its symmetrical outline and the gentle slopes of its sides, which attain an angle not greater than $6^{\circ}$. The mountain is marked by the existence of a remarkable crateriform cavity at its summit, to which allusion will be made subsequently; but this does not modify the general outline of the mountain, which appears

${ }^{1}$ Dutton, C. E., Rept. U.S. Geological Survey, 1822-3. 
to be due to the gradual thinning out of the various lava flows issuing from round this central point. As denudation has produced little effect upon this active volcano, we get an example of the true outline of a volcanic mountain formed by gradual piling up lava flows, sheet over sheet, which is a convex curve, here approaching to flatness on account of the great distance to which the individual lava streams have flowed; while in the hills formed of more viscid acid lavas the curve is still a convex one, but very much more pronounced, owing to the limited distance to which the lava has flowed from the point of its extrusion. When the volcanic hill is largely composed of fragmental material the structure will be different. If the volcano is a simple one, built up by ejection of fragmental material round a single vent, a conical hill will result, but the outline of the hill is not that of a true cone. Professor Milne ${ }^{1}$ has explained the reason for the existence of the actual outlines possessed by cinder-cones, i.e., cones formed of ejected fragmental material, and I have already referred to his work when discussing the slope of screes. He finds that many volcanoes built up of fragmental materials possess a surface "which would be produced by a simple logarithmic curve revolving about an axis-consequently such a heap would have a slope diminishing from the top to the bottom "thus generally resembling the curve produced by stream erosion. This curvature, according to Milne, would be produced by (i) "the tendency of a selfsupporting heap, under the influence of its own

1 Milne, J., "On the Form of Volcanoes," Geol. Mag., Dec. 2, vol. v., p. 337 ; and "Further Notes upon the Form of Volcanoes," ibid., Dec. 2, vol. vi., p. 506. 


\section{SCIENTIFIC STUDY OF SCENERY}

weight, to spread outwards at the base-this would tend to give a logarithmic curvature"; (ii) "the tendency during the building up of a mountain of the larger particles to roll further than the smaller ones"; (iii) the action of denudation. As he has examined many volcanoes in which the material is seldom found at a less angle than its proper angle of repose, he maintains that denudation cannot have played a very important part in determining the slope of those particular volcanoes, which must therefore owe their outline to the first two causes. Milne further notes that any hard core of a volcano, such as may be produced by ribs of once molten rock consolidated in cracks, will tend to contract the base of the mountain as compared with its height, just as the shape of a pile of sand poured upon a table will be altered if we first place a small box upon the table.

It would appear, then, that the shape of a symmetrical volcanic hill formed round a central orifice will be that of a plano-convex mass, with a circular line around the base, if the volcano be formed of emission of molten material, but that this will be replaced by a circular mass, whose cross section shows two logarithmic curves, ever increasing in steepness towards the summit of the hill where they - meet, when the hill is formed by accumulation of ejected fragments. (See Fig. 35 a.)

We have now to consider various causes which give rise to complications in the outline and structure of volcanoes, and may in the first place take into account the effect which is produced upon the appearance of the volcano owing to the character of the crater. It has been seen that in the case of 
volcanoes built up by emission of lava, the lava may entirely seal up the orifice from which the emission has taken place, so that no external sign of the orifice is visible. When volcanic hills are formed
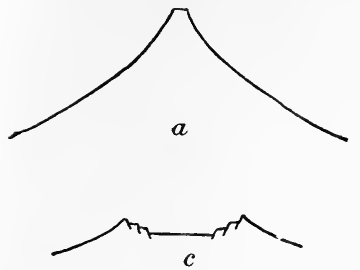
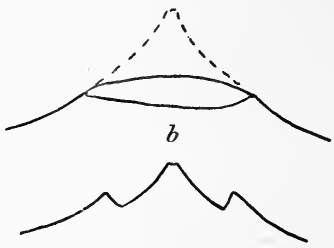

$d$

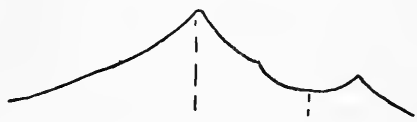

$e$

FIG. 35 .

a Outline of volcano formed of fragmental rock piled round a central orifice.

$b$ Outline of volcano truncated by paroxysmal outburst. The dotted line shows former lieight of hill.

$c$ Cross-section through a Hawaiian volcano, with caldera.

$d$ Volcano of type $b$, with inner crater built up inside truncated crater.

$e$ Compound volcano formed across two vents (indicated by dotted lines). The portion above the right-hand line has been removed by paroxysmal explosion or engulfment.

of fragmental material, however, some of the material falls back towards the orifice, and a hollow is formed around the orifice like an inverted cone, though having its slope determined in the same manner as the outer slopes; this hollow is the crater. When a cone is built up as the result of ejection of 


\section{SCIENTIFIC STUDY OF SCENERY}

fragmental materials, emitted with no great violence, the crater need not be very large, and the diameter of its upper rim need not therefore greatly modify the general conical form of the hill, as seen from a distance. The actual apex of the cone will appear to be cut off, as shown in the case of the cone of Cotopaxi, or that of Fusiyama, the latter so well known from representations on Japanese fans and other works of art, but the missing portion will form a very small portion of the entire cone, and merely gives the effect of a blunted point. In some circumstances, however, the crater becomes of very great importance as modifying the general outline of the volcano; this is specially well seen where eruptions of paroxysmal violence have occurred. In many early accounts of eruptions of excessive violence it is stated that the upper part of the volcano fell in, but there is little doubt that, as in the case of observed recent paroxysmal eruptions, it was not engulfed, but blown into the air in small fragments, which were dispersed far and wide around the volcanic hill. An explosion of this character may give rise to a truncated cone, containing a gigantic basin-shaped crater within (see Fig. $35 b$ ); the interior hollow of Vesuvius before the great eruption which destroyed Pompeii and Herculaneum was of this nature. The upper rim of the truncated volcano may be fairly regular, or may be of great irregularity, when from some points of view the volcanic character of the hill will be entirely concealed. Should the paroxysmal eruption which produced truncation be succeeded by comparatively feeble outbursts, allowing of fresh accumulation of ejected fragments, a new cone will be built up within the old crater- 
ring, and a cone within a cone so formed, as has happened with Vesuvius, where the modern cone is half surrounded by the partly destroyed old craterring, the surviving portion of which is known as Monte Somma. This type is illustrated in Fig. $35 \mathrm{~d}$.

Besides the ordinary craters, formed by rolling back of fragments to the orifice, and those due to paroxysmal explosions, there is another class of crater, apparently due to sinking of the upper portion of the volcano. This class is well represented in the volcanoes of Hawaii, and the craters of this type are spoken of as calderas. (See Fig. 35 c.) The best known is that of Kilauea, though another occurs on the top of Mauna Loa, and a gigantic though somewhat irregular one on the summit of Haleakala, on the island of Maui. The caldera of Kilauea is of a general elliptical shape, with a longer diameter of three and a half miles, and a shorter one of two and a half miles, surrounded by precipitous cliffs and varying in altitude from 300 to over 700 feet, according to the state of its floor. Haleakala possesses a V-shaped caldera, one limb of which is seven, and the other eight miles long; the precipitous walls rise to a height of 1500 to 2000 feet above a plain from three to five miles wide. Haleakala is no longer active, but the nature of the eruptions of Kilauea is well known. When empty the crater-floor is about 700 feet below the rim. It consists of an undulating mass of black rock, with a large pile of rocks near the centre. From it issue jets of steam, and where a crack occurs, the red glow of the molten rock is seen. But at times the molten rock gradually rises towards the rim of the crater until it is tapped at some point 


\section{I8 SCIENTIFIC STUDY OF SCENERY}

lower down the mountain, when the lava wells tranquilly out and flows for great distances until the floor of the crater is once more reduced to its normal level. Dutton quotes the following description given by Lieutenant Wilkes of the appearances of the crater when occupied by molten rock:-

"All usual ideas of volcanic craters are dissipated upon seeing this. There is no elevated cone, no igneous matter or rocks ejected beyond the rim. The banks appear as if built of massive blocks, which are in places clothed with ferns nourished by the issuing vapours. What is wonderful in the day becomes ten times more so at night. The immense pool of cherry-red liquid lava in a state of violent ebullition illuminates the whole expanse and flows in all directions like water, while the illuminated cloud hangs over it like a vast canopy."

There is no doubt that these calderas have originated in a manner different from that of ordinary volcanic craters, and Dutton gives reasons for supposing that they are due to successive sinking of slices of the walls along the lines of fissure into the molten mass below, a process which is still going on, and has given rise to a series of fault scarps and terraces around the sides of the crater. (See Fig. 35 c.)

Further complications in the form of volcanoes may be produced by the resistance of two or more adjacent orifices when the materials ejected from these coalesce to form a compound mountain, as has occurred in the case of the double Monti Rossi on the outskirts of Etna. Sartorius von Waltershausen has given reasons for supposing that Etna itself has been built up round two distinct axes of 
eruption, one coinciding with the present summit, the other being situated about the centre of the remarkable crateriform Val del Bove. ${ }^{1}$ Owing to the peculiar conditions we do not find two coalesced hills, but a deep depression around the second axis, namely, this Val del Bove. It is not clear how it was formed. Lyell supposes it to have been produced by paroxysmal outbursts, but Dutton compares it with the calderas of the Hawaiian volcanoes. (See Fig. $35 e$, and Lyell, loc. cit., Fig. 7I.)

There are many minor causes which tend to produce a want of symmetry in volcanic hills. The prevailing wind may cause more material to fall on the leeward side of a cone built up of fragmental materials than on the windward side, and accordingly the edge of the crater will be higher on one side than on the other, and in the case of small cones an appreciable amount of distortion may be thus produced. Again, parasitic cones are often formed upon the sides of larger volcanic hills, and may interrupt the regularity of outline, though if the primary hill be very large and the parasitic cones small, their effect at a distance will not be material in influencing the nature of the outline of the hill. One side of a volcanic cone formed of fragmental materials may be breached by a lava-flow, which finds it easier to break through the mass of more or less incoherent material than to rise to the lip of the crater. A number of small cones-the puys of Auvergne-are breached in this way, leaving a semicircular cliff around the source of the lava-flow.

The nature of the lava itself often produces marked effect upon the scenery of a volcanic district.

${ }^{1}$ See Lyel., Sir C., Principles of Geology, vol. ii., chap. xxvi. 
Owing to the relative abundance of alkaline compounds in the lavas and ashes, they frequently form fertile soils upon weathering, and many ancient lavas are covered by a luxuriant growth of vegetation, but the recent flow often presents a black, forbidding surface, the nature of which will vary according to the character of the lava, as is very well seen in the case of the Hawaiian lavas, as described by Dutton. Two forms of lava are found in Hawaii, known to the natives by the names of "pahoehoe" and "aa." The former is thus described by Dutton:-

"Imagine an army of giants bringing to a common dumping-ground enormous cauldrons of pitch and turning them upside down, allowing the pitch to run out, some running together, some being poured over preceding discharges, and the whole being finally left to solidify. The individuality of each vessel-full of pitch might be half preserved, half obliterated. The surface of the entire accumulation would be embossed and rolling, by reason of the multiplicity of the component masses, but each mass by itself would be slightly wrinkled, yet on the whole smooth, involving no further impediment to progress over it than the labour of going up and down the smooth-surfaced hummocks." It is produced by the surface solidifying while the interior of the flow is still liquid. The superficial crust cracks in numerous places, and little squirts of the fluid beneath are ejected through the fissures, which spread out and become quickly cooled, when the process is repeated. The "aa" "consists mainly of clinkers, sometimes detached, sometimes partially agglutinated together with a bristling array of sharp, jagged, angular fragments of a compact character projecting up through 
them. The aspect of one of these "aa" streams is repellent to the last degree, and may without exaggeration be termed horrible. For one who has never seen it, it is difficult to conceive such superlative roughness." The lava forming "aa" has the same composition as that which gives rise to "pahoehoe," and the difference is due to difference in the nature of the cooling. The mass of lava which forms "aa" is in a condition approaching consolidation, and it moves very slowly. During the movement "crushing strains of great intensity are set up throughout the entire mass, and its behaviour conforms strictly to that of viscous bodies. The superficial portions in part yield plastically to the strains, in part yield by crushing, splintering, and fissuring. The result is a chaos of angular fragments."

It has already been noted that difference of composition determines different rates of flow, and accordingly the surfaces of different kinds of lava vary considerably, and we have every gradation, from the comparatively smooth surfaces of some lavas, through the ropy and coiled tops of others, to the rough accumulation of clinkers which form the dreary "aa" of Hawaii.

A few remarks concerning the atmospheric effects produced during volcanic eruptions may not be out of place. It is well known that the smoke and flames of popular descriptions of volcanic eruptions are not actually due to combustion, the "smoke" being really dense volumes of discharged steam, which condenses into thick clouds, often darkened by the mixture of myriads of solid particles, while the appearance of "flame" is due to the reflection of 
the molten lava upon the clouds of condensed vapour. The condensed vapour usually issues as a vertical column, until it reaches a considerable altitude, when it spreads out as cumulus or stratus clouds, or varieties of these. Reference has already been made to the "stone-pine" arrangement of the Vesuvian vapour, and also to the remarkable mass ejected from Cotopaxi, recorded by Whymper, which at first formed a vertical column, then bent suddenly at right angles and proceeded for miles in one direction as a horizontal layer. The importance of the spread of minute particles of solid material through the atmosphere, in producing effects upon the nature of the sunset colours, as shown in the case of the great eruption of Krakatoa, has also been alluded to in a previous chapter.

In some cases there is actual combustion of gas, usually giving a pale, lambent flame, which produces no very marked effect upon the scene.

The scenic effects of different eruptions will vary considerably; but a good idea of one may be obtained by reading the following description of an eruption of Kilauea in 1883, witnessed by the Rev. W. Ellis, whose description of the scene is quoted by Dutton, it being noted that some terms used in the description are used in a very general sense. After describing the caldera, he proceeds as follows:-

"The bottom was covered with lava, and the south-east, north-east, and northern parts were one vast flood of burning matter in a state of terrific ebullition, rolling to and fro its fiery surge and flaming billows. Fifty-one conical islands of varied form and size, containing as many craters, rose either around the edge or from the surface of the burning lake, twenty-two constantly emitting 
columns of grey smoke or pyramids of brilliant flame, and several of these at the same time vomiting from their ignited mouths streams of lava, which rolled in blazing torrents down their black indented sides into the boiling mass below. . . . The grey, and in some places apparently calcined, sides of the great crater before us, the fissures which intersected the surface of the plain on which we were standing, the long banks of sulphur upon the opposite side of the abyss, the dense columns of vapour and smoke that rose at the north and south end of the plain, together with the range of steep rocks by which it was surrounded, probably in some places 300 or 400 feet in perpendicular height, presented an immense volcanic panorama, the effect of which was greatly augmented by the constant roaring of the vast furnaces below. . . . Between nine and ten in the evening the dark clouds and lava fog, that since the setting of the sun had hung over the volcano, gradually cleared away; and the fires of Kilauea, darting their fierce light athwart the midnight gloom, unfolded a sight terrible and sublime beyond all we had yet seen.

"The agitated mass of liquid lava, like a flood of melted metal, raged with tumultuous whirl. The lively flame that danced over its undulating surface, tinged with sulphurous blue or glowing with mineral red, cast a broad glare of dazzling light on the indented sides of the insulated craters, whose roaring mouths, amidst rising flames and eddying streams of fire, shot up at frequent intervals, with very loud detonations, spherical masses of fusing lava or bright, ignited stones."

The remarkable gentleness of the slopes of the Hawaiian volcanoes has already been noticed. If lavas possessing the liquidity of the Hawaiian lavas issued for a considerable distance along the length of a fissure, instead of from isolated points, the flatness would be increased, and the products of 


\section{SCIENTIFIC STUDY OF SCENERY}

vulcanicity instead of forming groups of hills would give rise to extensive horizontal, or nearly horizontal, plateaux. The massive eruptions of Richthofen are supposed to have produced plateaux of this nature, of which the best known are those of the Western Territories of North America, of the Deccan of India, of the Western Isles of Scotland, and the north-east portion of Ireland, and of various islands to the north of the Eurasian continent. Should the ground be uneven at the commencement of volcanic activity, the hollows will be filled with lava, and subsequent streams will flow over the comparatively even surface thus produced, sealing up the fissures from which the lava issued, and giving rise to stretches of flat country, through which rivers may flow in deep gorges and cañons, sufficiently narrow to prevent any interference with the general flatness of the prospect. Here is a description of one of these plateaux by the Snake River in Idaho, from the facile pen of Sir Archibald Geikie ${ }^{1}$ :-

"We emerged from the mountains upon the great sea of black lava, which seems to stretch illimitably westwards. With minds keenly excited by the incidents of the journey, we rode for hours by the side of that apparently boundless plain. Here and there a trachytic spur projected from the hills, succeeded now and then by a valley up which the black flood of lava would stretch away unto the high grounds. It was as if the great plain had been filled with molten rock, which had kept its level, and wound in and out along the bays and promontories of the mountain slopes as a sheet of water would have done. Copious springs and streams which issue from the mountains are soon lost under the arid basalt. The

1 Geological Sketches at Home and Abroad, No. xi. 
Snake River itself, however, has cut out a deep gorge through the basalt down into the trachytic lavas underneath, but winds through the desert without watering it. The precipitous walls of the cañon show that the plain is covered by a succession of parallel sheets of basalt to a depth of several hundred feet. . . . Riding hour after hour among these arid wastes, I became convinced that all volcanic phenomena are not to be explained by the ordinary conception of volcanoes, but that there is another and grander type of volcanic action, where, instead of issuing from a local vent, whether or not along a line of fissure, and piling up a cone of lava and ashes around it, the molten rock has risen in many fissures, accompanied by the discharge of little or no fragmentary material, and has welled forth so as to flood the lower ground with successive horizontal sheets of basalt. Recent renewed examination of the basalt plateaux and associated types in the west of Scotland has assured me that this view of their origin and connection, which first suggested itself to my mind on the lava-plains of Idaho, furnishes the true key to their history."

From the remarks made in the last paragraph, it will be seen that volcanic action produces its effect upon scenery even in areas where the volcanic forces are no longer in action, and we may briefly consider this effect.

The fragmental material ejected from volcanic vents, on account of its porosity, often resists denudation for a considerable period, as proved by the perfection of the puys of Auvergne, which are built of fragmental material, but denudation sooner or later produces marked effects upon the accumulations of an extinct volcano, be these fragmental or consisting of once molten rock. The tract of ground 


\section{SCIENTIFIC STUDY OF SCENERY}

formed of volcanic ejecta will be denuded in accordance with the ordinary laws of denudation, but as the volcanic rocks are often much more durable than ordinary stratified rocks, they frequently stand out after surrounding rocks have been worn away, giving rise to hills and plateaux. Of this nature are many of the Western Isles of Scotland. The portions which have escaped denudation may be covered up with sediment, and the latter may be again removed ages subsequently to its accumulation, once more exposing the volcanic mass to the action of surface agencies, and if they resist this action more than the surrounding sediments, they may again be formed into hills long ages after the extinction of the volcanic forces which produced them. The finest scenery of Cumbria and Cambria largely owes its character to the durability of volcanic rocks of great antiquity, which, having been for ages buried, have once again been exposed to the surface, and resisting denudation more than the surrounding sediments, have stood out as hill-masses, which thus owe their origin to ancient volcanic action, though only very indirectly. It need hardly be added that no traces of the original outlines of the volcano or volcanoes are preserved in these circumstances.

Hot Springs and Geysers.-Closely connected with ordinary volcanic phenomena are those of many hot springs, especially geysers, which are characteristic of volcanic regions, the heat being supplied from volcanic sources. Geysers differ from other hot springs in that the water is thrown into the air in the form of a fountain. There has been much discussion as to the exact conditions which are necessary for the emission to take place, but it is generally 
agreed that superheated water, flashing into steam on the removal of pressure, is the active cause of the phenomenon, and it is furthermore admitted that the water becomes heated in the tube, which is connected with the surface. Water gains admission from the surface to the interior of the earth in a volcanic district until it reaches a place where the temperature is above its ordinary boiling point at no great distance below the surface, frequently in the lower portions of a still warm lava current which has long solidified. The steam is forced up a fissure, and gradually enlarges the sides of the fissure, forming a pipe-shaped cavity. In this the water collects, and the pressure of the superincumbent water is sufficient to prevent the water below from boiling at the ordinary boiling point, and accordingly it becomes heated above $100^{\circ} \mathrm{C}$. In the meantime some of the water above is evaporated and the pressure lessened, until at last the diminution is sufficient to allow the superheated water to flash into steam, which violently expels the remaining water in the pipe into the air, causing an eruption of the geyser. The best-known geysers are those of Iceland, of the Yellowstone National Park of North America, and of the northern island of New Zealand. The "Old Faithful" geyser of the Yellowstone Park ejects a fountain of water to a height of over 100 feet about every hour. The fact that there are differences in action of geysers indicates that the exact cause of eruption is not always the same.

Geysers and other hot springs are also of interest to us on account of the accumulations which are formed by their agency. The hot water percolating through igneous rocks is capable of taking up various 


\section{SCIENTIFIC STUDY OF SCENERY}

soluble substances, which it cannot hold in solution when cool, and accordingly the substances are deposited around the springs in the form of sinter, which, in the case of geysers, tend to form rings enclosing a crater-shaped basin, in the centre of which is the orifice from which the water is ejected, and these rings may be built up to some height above the original surface to form conical mounds with the crateriform hollow in the centre, as seen around Old Faithful and the Giant Geyser of the Yellowstone Park.

When the springs issue upon the slope of a hill, the remarkable sinter terraces of volcanic regions are formed. The water flows down the hill, and upon cooling deposits its dissolved material, as a terrace, chiefly below the place from which it issues, but eventually at the point of emergence, which may then be sealed up, and the water will be compelled to find a vent higher up the hill. The process is repeated again and again, until a series of terraces are formed one above the other on the hill-side, and if a number of springs issue along a line these terraces will extend for considerable distances and hold up the water in a series of pools. The researches of Mr. W. H. Weed have proved that certain algæ which are capable of existing in hot water are largely responsible for the deposition of the dissolved carbonate of lime or silica, so that the process is not always a simple chemical one, but partly organic. ${ }^{1}$ The pink and white terraces of Rotamahana, New Zealand, destroyed by the great eruption of Tarawera in 1886, were the best

1 WeEd, W. H., Ninth Annual Report U.S. Geol. Survey, 1889, and American Journal of Science, vol. xxxvii., p. 351 . 
examples of sinter terraces, but many exist in the Yellowstone Park. The water often pours from the basin of one terrace into that of the one beneath, and permits of the formation of stalagmitic and stalactitic growths, which often add to the remarkable appearance of the terraces. The terraces vary in colour from the purest white to various shades of pink, orange, and brown, the colour being due to compounds of iron mixed with the lime or silica. Perhaps the most impressive are the marble-white terraces, which support pools of pure water having its characteristic bright blue tint.

Mud Volcanoes.-In many volcanic and some nonvolcanic areas, various gases issue from the earth's interior and throw up masses of mud, which form cones with central craters sometimes to heights of two or three hundred feet, which resemble miniature volcanoes. Small mud-volcanoes are found in Sicily, but some of the most important occur over a considerable area in the basin of the Lower Indus.

Earthquakes.-The effects of earthquakes may be briefly touched upon in this place, as many earthquakes are clearly produced by volcanic action, though others are as obviously not so caused. Striking as are the effects of earthquakes, as bringing about destruction of life and property, their importance to the student of scenery is rather on account of the assistance which they afford to other agents, than because of any peculiar features to which they themselves give rise. Besides elevating and depressing tracts of country, and thus assisting the slow secular movements of elevation and depression, they frequently produce extensive gaping fissures, which may remain open for a considerable 
period, and thus initiate new lines of drainage. Again they are often the cause of landslips, and shatter the rock in such a way as to accelerate the action of the weather. They may give rise to lakes by engulfment of portions of the earth's crust, or by the formation of barriers owing to landslips, and as these barriers are often incoherent they may be unable to withstand the pressure of the water which accumulates behind them, when the temporary lake will burst, causing a disastrous flood, during which much corrasion and transport may occur.

Submarine earthquakes often give rise to earthquake waves, which are much greater than ordinary wind-waves, and accordingly more destructive, and these waves will, therefore, materially assist the ordinary marine agents in denuding the sea-coasts of a tract of country which is affected by them. During the Lisbon earthquake of 1755 , the earthquake wave is stated to have been sixty feet high at Cadiz. Many of the inland waters of Europe were affected by waves due to the same earthquake.

Though the ruin produced by earthquakes is often very apparent, the operation of the ordinary agents is sufficient to heal the scars due to earthquake action in a comparatively short time, and accordingly, as above stated, no important scenic effects can be directly ascribed to earthquake action. 


\section{CHAPTER XIV.}

\section{PLAINS AND PLATEAUX}

THE production of a comparatively level surface 1 in a district which has previously been marked by very uneven ground, may be due either to denudation or to deposition, or to a combination of the two processes, and in these ways the minor plains of the earth's surface are formed. But as the sea is the great receptacle of deposit another event often takes place, causing the formation of a plain, namely, the uplift of the deposits which formerly existed upon the sea-bottom; when this uplift brings the deposits above the surface of the ocean, and the uplift is comparatively equable, a plain is the result, and some of the most important plains which occupy the earth's surface have been produced by uplift of marine sediments. The terms plain and plateau are used somewhat vaguely. A plain is in no case absolutely level over large areas, and considerable departure from an ideal level may exist, yet the area may be spoken of as a plain, especially if it occurs in a position which causes it to present a marked contrast to an adjoining hill region, as the plain of York, which is contrasted with the Yorkshire Wolds on the one side and the moors on the other. Again, a plateau is usually defined as an elevated plain, but the amount of elevation necessary to turn a plain 


\section{SCIENTIFIC STUDY OF SCENERY}

into a plateau cannot be stated, and the term plateau is often applied to a tract which is not more elevated than some other which would be termed a plain; for instance, if a very extensive tract of land sloped gently upwards from sea-level to a height of 3000 or 4000 feet above the sea, the whole might well be termed a plain, whereas if a small, flat level only 1000 to 2000 feet above the sea was markedly separated by steep slopes from the adjoining low ground, it would be called a plateau. Plateaux, and to a less extent plains, are often traversed by river valleys of considerable depth, and as the process of erosion goes on, the portions left between the valleys become more and more restricted, and a plateau will thus be carved into isolated hills often flat-topped. It is, of course, impossible to give any definite statement of the exact amount of erosion necessary to make the term plateau inapplicable to such a sculptured tract of land which was originally flat.

Any of the denuding agents, subaerial or marine, which are capable of corrasion and transport, are capable of giving rise to plains by corrasion in places and accumulation in others. The effects of wind, ice, and the sea will be considered in subsequent chapters, and we may here note the effect of rivers in producing plains by corrasion and deposit. It has already been seen that when a river has established its base-level of corrasion, lateral corrasion becomes effective, and the river commences to cut sideways at its curves, giving rise to flat tracts of planation, or, in other words, plains, which may be further modified by deposition of alluvium upon them. It has also been indicated that by lateral corrasion one river may tap another, and in this 
way the extent of a river plain may be largely increased. These plains will, of course, not be actually level, but will slope gently, though often imperceptibly, downwards towards the sea. The ultimate effect of this action, if unchecked, would be the general degradation of a continent by river action to form a peneplain, but as some checking process often intervenes, these peneplains are always restricted to portions of our continental tracts.

We have pointed out in a preceding chapter that, when a consequent stream traverses alternating hard and soft strata, the river valley tends to be widened along the softer strata, and remains comparatively narrow where the river traverses the harder rocks. Furthermore, the base-level of corrasion will be locally reached along the course over the softer strata, while vertical corrasion still occurs among the harder ones, and small plains will therefore tend to arise over the softer rocks as the result of lateral corrasion, often possessing a general elliptical shape, and dying out where the river course is situated upon hard rocks above and below. It will be difficult to distinguish the alluvial tracts so produced from small plains which have resulted from the infilling of ancient lake-basins with sediment, in the absence of direct proof of the fluviatile origin of the alluvium, and it may be suspected that many alluvial tracts which have been asserted to occupy the sites of ancient lakes are really the result of stream action only.

Many of our English rivers have formed fairly extensive plains where they traverse soft rocks; for example, the Yorkshire Ouse, where it flows over the Triassic strata of the Vale of York, the Great 


\section{SCIENTIFIC STUDY OF SCENERY}

Ouse, in its course over the Jurassic clays of the neighbourhood of Bedford, and the English Dee, which also traverses the Triassic rocks in the lower part of its course.

In the case of the large rivers of the continents, these river-plains are often very extensive, and form important features in the scenery of a continent. I will mention one example, that of the plain of the Mississippi, which has a length of over 600 miles in a straight line from its commencement above the junction of the Ohio to its termination at the river's mouth. Leaving the delta out of account, the plain above the head of the delta has a width of eighty miles at the mouth of the White river, and it varies between this and a minimum width of about thirty miles.

A feature may be noticed in this place, which is often of considerable importance in affecting the scenery of a river valley, namely, the existence of river-terraces upon the sides of the valley. If a river after producing an alluvial plain is subsequently enabled to corrade vertically, it deepens its valley, and the sides of the old alluvial plains are often left above the present river level as terraces. These terraces may be formed more than once, and we frequently see two or three terraces running along the sides of the valley, and generally parallel to the course of the stream. They usually have a flat upper surface (that of the old alluvial plain of which they were portions), and may slope down somewhat steeply. As they are generally composed of porous materials, and give a dry foundation and often a copious water supply, early settlements were frequently situated upon these terraces; for instance, 
some of the older parts of London are situated on the gravel terraces which there border the river Thames.

The mode of infilling of lakes by sediment and their ultimate conversion into plains has been considered in Chapter XII. Scores of such plains often mark the sites of former lakes in many regions, and a lake district often possesses lakes which are only a small percentage of those which, once existent, have been destroyed by infilling of their basins. It has been remarked above that there is considerable resemblance between these infilled lakes and the alluvial flats of certain reaches of rivers; the former, however, are more often marked by a covering of peat-moss over the sedimentary deposits than are the latter, for the shallow waters of the margin of a partially filled up lake favour the growth of vegetation, which rapidly gives rise to a layer of soil rich in humus, in which vegetation continues to flourish. Turbaries or peat-mosses marking the sides of filled-in lakes are frequently encountered in the upland regions of our hilly districts, and when surrounded by frowning crags produce a peculiar effect upon the scenery, especially if the lake be not completely filled in, when a pool or pools of dark brown water may be seen, often brightened by the blossoms of many a water-loving plant, as the waterlily and bog-bean, or the pale blue flowers on the raceme of the water-lobelia.

Let us now proceed to the consideration of those plains which are formed by the accumulation of sediment in the sea, and the ultimate conversion of the tract which receives this sediment into land, and we may first deal with the river-delta. 
The primary cause of the formation of a delta, whether in a lake or in the sea, is the check received by the river current when it enters the larger body of water. It has been seen that the transporting power of a current, other things being equal, is dependent upon its velocity, and as the velocity is suddenly diminished when the river enters comparatively still water, the transported sediment is deposited. In the case of the sea, should a marine current of sufficient velocity to carry away the material transported by the river sweep past the river's mouth, the formation of a delta will be prevented; or should such a current exert its influence subsequently to the formation of a delta, the further growth of that delta will be stopped, as has happened with the delta of the river Nile. When the river enters a narrow arm of the sea, as a fjord, the shape of the deltaic tract of land will be determined by the boundary walls of the fjord; and we may get tortuous and even branched strips of flat land surrounded by comparatively high ground, which originally formed the sides of the fjords, as seen, for example, in the case of the ancient fjords of Carentan, in France, and those near Christiansand, in Norway. ${ }^{1}$ As a general rule, the widening estuary of a river becomes filled up, and then the delta grows out with a convex front to the open water, giving the familiar $\Delta$-shaped form, in which the base of the $\Delta$ possesses the convex curve. The reason for the convex curve is as follows: The river deposits material on its floor, and during flood seasons on its banks, and accordingly the level of the river-

${ }^{1}$ For figures of these see RecLus' The Ocean, English edition, Figs. 54 and 55 . 
bed becomes raised, until it breaks through its banks and seeks a new course, when the same thing occurs. Accordingly, in time, every part of the delta is drained by the river, though the tendency of the stream to keep its initial direction causes the greatest amount of sediment to be deposited at the point situated along the line of the general course of the river, and there is less and less tendency for deposition to occur, as one passes away from this point on either side, the ideal resultant form being that of the arc of a circle. There is a general, though gentle, slope of the delta above the surface of the water, and a more abrupt sigmoidal slope below water, which will only affect the scenery in the case of deltas which have been laid bare. In many cases the actual outline of the delta is far more irregular than that of the ideal delta. The sides of the river current after it has entered the sea are not so swift as the centre, and accordingly deposition occurs more extensively at the sides, and two banks of deposit may actually be raised out of the water with the current flowing between them. When the river has deserted this channel, the channel itself will be silted up, and thus finger-shaped prolongations may extend into the sea beyond the general terminations of the delta. Such finger-like extensions are seen upon the delta of the Mississippi.

The diversion of streams is due not only to overflowing of banks during floods, but to obstruction by sunken timber or "snags," or even by extensive rafts of drift timber, which block the channels and cause accumulation of sediment against the upper sides. Hence we frequently find an intricate ramification of the streams of deltas well shown in the 


\section{SCIENTIFIC STUDY OF SCENERY}

compound delta of the Ganges and Brahmaputra. In the low-lying ground of the deltas marshy conditions often prevail, and accordingly an abundant growth of marsh vegetation usually characterises deltaic plains, the particular character of the vegetation depending upon the locality of the delta, and being largely dependent upon climatic conditions. The deltaic deposits of Greenland, due to the deposition of glacier mud at the heads of the fjords, are often devoid of vegetation, while parts of the delta of the Ganges are "overrun with reeds, long grass, the Tamarix Indica, and other shrubs, forming impenetrable thickets, where the tiger, the rhinoceros, the buffalo, deer, and other wild animals take shelter."1

The formation of lake deltas has already been considered; they differ in no essential particular from those formed along coast-lines, the main difference being due to the absence of effective tidal action in lakes, which affects the slopes of the subaqueous portion of the delta.

In many regions, where numerous rivers reach the sea along a limited tract of coast, we find a number of coalescent deltas giving rise to extensive tracts of new land, as, for instance, along the north-west shores of the Adriatic. "Here," states Lyell, "from the northern part of the gulf of Trieste, where the Isonzo enters, down to the south of Ravenna, there is an uninterrupted series of recent accessions of land more than 100 miles in length, which within the last 2000 years has increased from two to twenty miles in breadth." The same writer notes that "Adria was a seaport in the time of Augustus, and had, in

${ }^{1}$ Lyeld, Sir. C., Principles of Geology, Eleventh Edition, vol. i., chap. xix. 
ancient times, given its name to the gulf; it is now about twenty Italian miles inland. Ravenna was also a seaport, and is now about four miles from the main sea." 1 It is true that the rate of growth of this deltaic strip has increased since artificial banking of the lower portions of the river was resorted to, but it took place with considerable rapidity before this. The area of the great plain of Northern Europe is being gradually increased by the silting up of the sea margins by the detritus brought down by the rivers in that region.

Another method of formation of flat land by silting up of an area originally occupied by the sea, is owing to the deposit of sea-silt, which has not been brought down by the rivers of the neighbourhood, but borne from a distance. The English fenlands supply a good instance of a plain surface produced in this manner. Their origin has been discussed by Mr. S. B. J. Skertchly in the Geological Survey Memoir, treating of the district, and also in a work entitled The Fenland by that author and Mr. S. H. Miller. Skertchly shows that the fenland forms a portion of a bay which has been silted up, the remaining part, the Wash, being still occupied by the sea, and the silt which has converted the former bay into land is not mud brought down by the rivers of the district, but marine mud, largely due to the wash of the Lincolnshire and Yorkshire coasts, carried into the bay by the southward-moving tides. The process of silting is still proceeding at the south end of the Wash, but further south the silt dovetails into the peat, which is due to vegetable

${ }^{1}$ Lyell, Sir C., Principles of Geology, Eleventh Edition, vol. i., chap. xviii. 
growth, and there is no doubt that peat has been formed in some parts contemporaneously with silt deposits in others. That earth-movement has participated in the formation of the fens is shown by the occurrence of buried forests below present tidelevel, but these movements are merely accessory, and the deposit of silt and growth of peat upon it are the essential factors in fen-formation. When the silt has been raised to a height of about eight feet above mean tide-level the glasswort (Salicornia herbacea) begins to grow, and is only dry towards high water. This glasswort, by checking the flow of the water, assists in the deposition of the silt. When the flat has increased to a height of about eleven feet above mean tide-level it becomes covered with verdure, due to plants of more terrestrial habit. ${ }^{1}$

The actual peat is largely due to marsh vegetation, and Skertchly gives reasons for supposing that the forest growths which intervened at intervals occurred during periods unfavourable for the accumulation of peat. $^{2}$ The peat is not formed of Sphagnum, like that of bogs, but consists chiefly of the decomposed remains of various aquatic herbaceous plants." ${ }^{2}$

According to Skertchly the peat in some places is entirely made up of Hypnum fluitans. Other plants which contribute to it are various rushes and sedges, including Cladium mariscus, also the bladderwort, starwort, and arrowhead, while, in the shallow waters of the meres, a calcareous marl was formed by the growth of Chara.

The beauty of the fenland is the result of the atmospheric conditions and the nature of the vegeta-

1 See The Fenland, p. 223.

' Babington, C. C., Flora of Cambridgeshire, p. xviii. 
tion. The glorious sunrises and sunsets, and the magnificence of the cloud effects have frequently been described. The peculiar vegetation of the fenland has nearly disappeared, though the flora which once occupied the meres still brightens the ponds and dikes which are scattered through the cultivated tracts, and one piece of undrained fen, Wicken Fen, yet survives to show the nature of the former uncultivated plain. There one can still roam through the sedges and rushes, and observe the fronds of the marsh fern (Lastraa thelypteris) and the blossoms of many a fenland plant. The great pit at Roslyn, near Ely, filled with water at the bottom, gives some notion of the former appearance of the fenland meres. Anyone looking over the open spaces between the reeds from a boat, when the banks are out of sight and the water is covered in one place with the leaves and flowers of the yellow and white water lilies, in another with the pale yellow flowers of the bladderwort, and yet again with the beautiful yellow blossoms of the Limnanthemum, can well imagine that he is afloat on one of the meres of the pristine fenland, and the knowledge that the flat places of the earth may be filled with beauty is here brought home to one in a striking manner.

Marine deposits may give rise to plains as the result of uplift, and these plains will not differ markedly from those formed by silting up of former sea-tracts, except that in all probability the seaward slope will be somewhat greater. The coastal plain of the east coast of North America is of this nature, and it serves as a good example of this class of plain. 
The last plains to be considered are those which are termed plains of marine denudation. Their mode of production will be more fully considered when we discuss the operations of the sea at length. It will be sufficient here to remark that the erosive power of the sea is limited to the superficial portion which is affected by waves and currents, and as the depth to which these operate is practically the same in all places, the ultimate result of marine denudation is to give rise to a comparatively level surface coinciding with the downward limit of operation of the waves and currents. This, if uplifted, will be a plain of marine denudation, and it will differ from a peneplain mainly in the absence of weathered material upon its surface, whereas the peneplain will usually retain some of the products of weathering upon the rocks which underlie it.

The amount of the surface of the land which is of the nature of plain is very great. A great tract of plain extends from the western shores of Europe to the Altai Mountains in Asia, unbroken save by the Ural Mountains, and covering an area approaching 5,000,000 square miles, or nearly one-third of the Eurasian continent. As plains usually yield a soil which is pre-eminently cultivable, it is found that the population is extensively gathered upon the plains, and much of their surface is actually under cultivation. When uncultivated the scenery of a plain depends largely on the nature of the vegetation. We find one plain differing considerably over different portions of its surface, owing to change in vegetation, and the names which are given to plains are often determined to some extent by the character 
of the prevalent vegetation. The rolling grasscovered plains of North America are prairies, and in some places savannahs; the river plains of South America, overflowed during the rainy season and covered with grass, but dry during the periods of drought, are called llanos; in the same country the forest-clad plains are known as selvas, as in the basin of the Amazon; the thistly and grassy plains of Parana and La Plata, alternating with bogs and often parched during the season of drought, are pampas; in the Old World the belt of jungle between Hindustan and the Himalayas, due to the detritus brought down by the Himalayan rivers, is called tarai; the boggy flats of Siberia are tundras. The tundras and pampas approach the condition of deserts; the amount of vegetation is in parts very sparse, and there is a gradual passage into deserts.

The same plain may present different aspects in different parts. Thus the great plain of Europe and Siberia is cultivated river plain (polders) in one place, sandy heath in another, wooded flats in a third, and desert in a fourth. The most luxuriant vegetation cscurs on the plains in temperate regions, and in sub-tropical regions supplied with abundant rain; in sub-tropical regions of drought, the amount of vegetation rapidly declines, and the same is the case in Arctic regions. In the latter the vegetation becomes stunted, and we find plains occupied by copses of dwarf willows and birches rarely rising to a man's height, or by grasses, mosses, and lichens, intermixed with brightly flowering plants, often in cushionshaped masses.

Plateaux.-The elevated tracts of country known as plateaux may be due to (I) accumulation, (2) 


\section{SCIENTIFIC STUDY OF SCENERY}

elevation of a pre-existing low-lying flat tract, or (3) denudation of an elevated region to one level.

The principal plateaux of accumulation are due to the outflow of very liquid lavas which accumulate over one another in a series of sheets, each approaching to a condition of perfect horizontality. The great lava flows of the Deccan, in India, have produced a plateau of this character. The lava flows of the Deccan, according to Messrs. Medlicott and Blanford, have a thickness of about 6000 feet, and occupy an area of about 200,000 square miles, giving rise to plateaux of remarkable horizontality. Similar plateaux are found among the Western Territories of North America, as, for instance, in Idaho. As the mode of origin of these lavas has already been discussed, we need say no more concerning lavaformed plateaux.

Typical plateaux formed by uplift are also found among the slightly disturbed rocks of the Northwestern Territories. The rocks of this region are usually slightly inclined over wide areas, but broken up into blocks by faults, or uplifted by the existence of hogbacks, and accordingly we find plateaux "with broken edges where they are bounded by faults, flexed edges where they are bounded by monoclinal flexures, and escarpments where they are bounded by cañons or lines of cliffs." 1 Powell figures a series of plateaux north of the Grand Cañon of the Colorado. Of these, the most westerly, Shi-wits plateau, is bounded on the west by a cañon, on the east by a fault; the central one, the Kanab plateau, is faulted on the west, and cut through by a cañon in the centre, and above it rises the Kaibab plateau,

1 Powell, J. W., Geology of the Mista Mountains, p. 14. 
bounded on either side by a hogback or monoclinal fold. In Figure 5 he gives a bird's-eye view of a part of the Musinia zone of displacement, where a tract of country is broken up into horizontal or slightly sloping plateaux, each formed by a fractured mass of the earth's crust, bounded by faults on all sides.

Many of the great plateaux of the world, as that of Central Asia, are also due to uplift, though no doubt modified by denudation. In the case of these plateaux the scale is so large that considerable differences of level do not destroy the plateau-like character of the whole. We may find them cut up by deep valleys, and traversed by extensive mountain chains, and yet the plateau-structure can be discerned through these minor complications.

The uplifted area may be one which originally possessed horizontality before its uplift, owing to the accumulation of sediment, the formation of a peneplain by subaerial denudation, or the formation of a plain of marine denudation owing to the action of the sea. In each case, if the upward movement is one of sufficient extent to preserve a general horizontality of the upraised block of earth's crust, a plateau will result.

In the case of plateaux formed by denudation, as in those due to accumulation and the greater number of those originating in an uplift, general horizontality of the strata is a necessary condition for the production of the plateaux; and one need hardly observe that uplift must precede or accompany denudation in order that the strata may reach the required height. Indeed, with plateaux, as with mountains, though we can separate those due to uplift from 


\section{SCIENTIFIC STUDY OF SCENERY}

those due to denudation, the two processes must always take place; and a plateau will be placed in one or the other class, according as its salient features are primarily produced by uplift or by denudation.

Plateaux due to denudation are specially prone to occur when a comparatively level plane of demarcation separates overlying rocks, which are easily denuded, from underlying ones which resist denudation. They very frequently occur on the upper surfaces of limestone strata, which were succeeded by ordinary mechanical sediments. It has already been shown that limestones largely resist subaerial denudation, owing to the absence of surface drainage, and accordingly, while overlying mechanical sediments are cleared away by this kind of denudation, the limestone is left practically intact, except as regards minor changes. A considerable plateau of limestone, cut up by the valleys of the Ribble, Dale Beck, and some minor streams, ends in the neighbourhood of Settle, in Yorkshire. Some of the overlying mechanical sediments have not yet been destroyed, and stand up above the general limestone plateau, forming the summits of Whernside, Ingleborough, and Penyghent; and from the top of any of these hills the regularity of the limestone plateau may be noted. The peculiar effect of weathering along joints, giving rise to "clints," has already been described in Chapter VIII. These clints are specially well shown on the plateau of the Settle district.

Plateaux of denudation occurring on a larger scale are often irregular and present many inequalities.

Owing to the elevation of plateaux they are liable to be carved out by denudation to a greater extent 
than plains; and as the strata of a plateau-region so often approach horizontality, the hills which are formed from a plateau by erosion are apt to be tabular and flat-topped. Before the hill stage is reached the plateau may be cut up by deep narrow valleys, as in the case of the Colorado Region of North America. These valleys are often invisible until the traveller reaches their brinks; and accordingly the aspect of the plateau is that of a horizontal tract of country, though that country may be actually carved out to a considerable degree by the rivers which traverse it.

As the valleys widen, the intervening tabular hills, or mesas as they are termed in some parts of America, become more and more pronounced, and small isolated "outliers" standing away from the main cliff form "buttes."

The ultimate result of subaerial denudation acting upon a plateau, as upon a mountain district, will be to reduce it to a peneplain. 


\section{CHAPTER XV.}

\section{DESERTS}

THE effect of climate has been incidentally 1 mentioned more than once in the preceding chapters, but we must now take into account the influence of abnormal conditions of climate in affecting the scenery of certain regions of the earth. The principal conditions to which we must now pay attention are those of exceptional drought and of exceptional cold, and it is to the former that we owe the existence of deserts, while to the latter are due certain features which will be described in subsequent chapters.

No area of the earth's surface is absolutely free from precipitation of the aqueous vapour which is held in the atmosphere, in the form of either rain or snow, and desert regions are merely due to paucity of rainfall and not to its actual non-occurrence. As any inequality in the earth's surface causes vapourladen atmosphere to rise and become chilled, and thereby renders it incapable of retaining so much moisture as it could hold at a lower level, upland regions are apt to be favoured with much rain, and lowland regions are often comparatively dry. Hence, other things being equal, desert conditions are more liable to be developed in plains than in districts marked by great inequalities of surface, and 
geographers have frequently treated of plains and deserts as though they were very intimately associated. But a district may be very uneven, and if all the winds which blow over that district carry air charged with very little aqueous vapour, that vapour need not be deposited, even when the ground rises to considerable elevations. Deserts, then, though often coincident with plains, are also frequently found in hilly regions, though even then some of the processes which occur in desert regions, which will be immediately described, tend to level pre-existing inequalities.

Leaving out of account those barren regions which owe their barrenness to the condensation of vapour as snow and not as rain, we shall find that deserts occur most frequently in sub-tropical regions. In most tropical regions the rainfall during the rainy season is excessive, and we require something besides great heat for the existence of ordinary deserts, something which greatly reduces the annual rainfall, and produces long periods of drought. The conditions favourable for the existence of deserts on a large scale occur when an extensive mountain range separates a large tract of continent from the prevailing vapour-laden winds blowing from the ocean, and these conditions are fulfilled in all our great desert-regions. The vapour-laden winds strike the seaward side of the mountains, are compelled to rise, become chilled, and deposit a large quantity of their aqueous vapour. They reach the lee side of the mountains robbed of most of their moisture, and as they then pass from higher to lower levels they are able, when reaching the lowlands, to hold much more moisture than they actually possess, and 
accordingly the rainfall is exceedingly limited. The desert of Gobi in Asia is practically surrounded by mountains, which drain the winds of their contained moisture. The great Sahara Desert, occupying an area about two-thirds of that of Europe, is also shut off from the prevailing winds which cross expanses of ocean by mountain ranges, as is likewise the Kalahari Desert of South Africa. In North America a desert region in the North-west Territories is practically surrounded by mountains; in South America a desert region exists in Chili and Peru to the west of the Andes, for the moisture-laden winds there blow from the east. In Central Australia, again, we have a desert tract separated from the sea-by elevated land.

An examination of a map of existing deserts shows that they are chiefly confined to a belt of country lying between $20^{\circ}$ and $45^{\circ}$ on either side of the equator, that is between the belt of tropical rains and the regions of cold, and it is evident from this distribution that, apart from local causes, the deserts owe their existence to general meteorological conditions. Should these conditions alter, the distribution of deserts will be affected. At the present day we have our desert-belts as well defined as our glacial regions, but just as in past times glaciation has affected areas which now enjoy a genial climate, similar areas have formerly been marked by desert conditions. In the northern belt of deserts we find the desert area of Central Asia, and that stretching from the west coast of Africa into Arabia and Persia, and in the New World the desert regions of the western territories of North America. In the southern belt lie the Australian 
desert, the Kalahari desert of Africa, and the South American desert tracts.

The scenery of deserts, as of other areas, is largely determined by the agents of erosion and accumulation, but the characteristic features are due to the particular character of these agents in the desert regions. There are four different kinds of deserts, namely rock-deserts, gravel-deserts, sand-deserts, and loam-deserts. In the rock-deserts the agents of transportation are sufficiently powerful to remove the results of disintegration of the rocks, leaving a surface of bare rock; in the others the disintegrated material remains over the spot where disintegration has occurred, or it has been accumulated by transport from other regions, and the latter action is the cause of the more important desert tracts being covered by loose accumulations, for it is rare to find the material remaining on the spot where it is disintegrated.

If a desert region has acquired its present characters in geologically recent times, the present agents in operation in that region may not have been able to efface the features produced when other conditions prevailed, and it is of importance to determine how long an existing desert has possessed its present conditions. This is not always an easy matter to decide, but there is considerable reason for supposing that at no distant period the rainfall of the desert region of the North-western Territories of North America was greater than it now is, while recent research points to the prevalence of desert conditions in the eastern part of the North African desert tract through long periods of time.

It must also be borne in mind that the term desert is not one which can be strictly defined; a desert is a 
region where the rainfall is insufficient to allow of the growth of much vegetation, but there is every gradation from a desert region to one which we are apt to consider as one which possesses normal characters, and the amount of rainfall, though small in all deserts, is much greater in some than in others.

Erosion of Deserts. The peculiar character of deserts is not only directly dependent upon the scarcity of rain, but also indirectly by its influence upon vegetation, as pointed out by Gilbert in the following passage ${ }^{1}$ :-

"Vegetation favours the disintegration of rocks, and retards the transportation of the disintegrated material. Where vegetation is profuse there is always an excess of material awaiting transportation, and the limit to the rate of erosion comes to be merely the limit to the rate of transportation. And since the diversities of rock texture, such as hardness and softness, affect only the rate of disentegration (weathering and corrasion) and not the rate of transportation, these diversities do not affect the rate of erosion in regions of profuse vegetation, and do not produce corresponding diversities of form.

"On the other hand, where vegetation is scant or absent, transportation and corrasion are favoured, while weathering is retarded. There is no accumulation of disentegrated material. ${ }^{2}$ The rate of erosion is limited by the rate of weathering, and that varies with the diversity of rock texture. The soft are eaten away faster than the hard, and the structure is embodied in the topographic forms.

"Thus a moist climate, by stimulating vegetation, produces a sculpture independent of diversities of rock texture, and a dry climate by repressing vegetation produces a sculpture dependent on those diversities."

1 Gilbert, G. K., Geology of the Henry Mountains, p. II3.

2 That is, over the spot where the disintegration occurs. 
Owing to the character of desert climates rain and rivers play a minor part in the determination of desert features, and the main work of destruction and transport is due to changes of temperature acting directly, or indirectly in the form of wind. Disintegration is mainly caused by change of temperature, as already noted in Chapter VIJ., though it is assisted by wind, and to a minor degree by chemical weathering.

The changes of temperature cause the fracture of the rock, owing to its alternate expansion and contraction. Not only does the rock mass contract and expand as a whole, but it is known that expansion takes place in a crystal in different degrees along different crystalline axes, and this no doubt helps the fracture. The fracture is frequently assisted, owing to the presence of salts in the rock. Many rocks in desert regions were formerly deposited in the sea, and contain sea-salts, which, owing to the dry conditions, have not been dissolved or removed. These salts come to the surface, owing to capillary action, and being hygroscopic, are dry in the daytime and damp at night, and owing to the alternate change from wet to dry conditions, the rocks are cracked in much the same way as that in which they are cracked by frost in higher latitudes. ${ }^{1}$

Wind transports material, and produces much the same results in nature as are produced artificially by the sand-blast. Pebbles are gradually worn down, often presenting edges, rocks may be striated, and pebbles and rocks alike often have a polished

${ }^{1}$ See Walther, J., Denudation in der Wiiste, Abhandl. der math. -phys. Classe der K. Sächs Gesellsch. der Wissenschaften, bd. xvi, Leipzig, 1891. 


\section{SCIENTIFIC STUDY OF SCENERY}

appearance, as the result of the sand-blast. In the gravel desert of Morocco Walther describes the area as presenting a general varnished appearance, owing to the action of the sand-blast upon the little pebbles with which the desert is strewn.

The general absence of running water on the hills of desert regions is indicated by the absence of the characteristic curve of water erosion, and the production of house-roof structure, as seen in the picture of the Ras Muhammed desert in the Sinaitic Peninsula figured in Plate III. of Walther's paper on the Coral Reefs of that peninsula, and also in the outlines of the hills in the same peninsula figured on p. 389 of his paper on the "Denudation of Deserts." Another feature of desert hills is the absence of accumulation of loose material, such as screes and rainwash at the foot of the hills-the action of the wind being sufficiently powerful to remove the material. The mountains of deserts, therefore, have a character of their own; they differ from those of temperate regions in the absence of the curve of water erosion, and, although resembling those of Arctic lands in the general straightness of their sides, they have not the accumulation of loose material so frequently found at the foot of the hills of frost-bound regions.

The action of the wind removes the softer rocks, leaving the harder ones behind, as noticed by Gilbert, and also enlarges the lines of weakness, as joints and planes of stratification. In areas composed of horizontal strata, the soft rocks are removed, and the area lowered to the level of a harder stratum, which gives rise to a level plateau; this in turn gets cut up, and the whole region reduced to a lower level coin- 
cident with the surface of the next hard stratum, and the process of levelling is continued in the same way. One result of this weathering is to produce isolated columns, often undercut at the base, and etched into different shapes by the wind acting unequally upon rocks of different hardness, and accordingly the detailed scenery of desert uplands recalls that of a group of mountains composed of dolomite.

The effect of the wind on a rock presenting varying degrees of hardness is well seen in that from which the sphinx of Gizeh is carved out. The lower part of the sphinx has been affected by wind action, and as different parts of the rock differ in hardness, owing to the infiltration of iron compounds forming ring-shaped masses, the softer parts have been etched by the wind, leaving the harder parts outstanding in ring-shaped bands.

When rounded, hard masses occur in a rock on a flat surface, they not only stand out from the surrounding rock owing to the sand-blast, but a ridge of rock which is protected by them is left on the lee side, as shown by Walther in Fig. 55 of his work on the Denudation of Deserts, where manganese concretions in the Nubian sandstone of the Sinaitic desert have caused the formation of such ridges.

Certain outlines due to denudation are found on a small scale in some desert regions, which present difficulties with regard to their explanation. The clayey deposits of the neighbourhood of the Henry Mountains in the Colorado region, and the old lacustrine deposits of the country around the salt lakes of Utah and in parts of Wyoming, are known 


\section{SCIENTIFIC STUDY OF SCENERY}

as "Bad Lands." "This expressive name has been given to some of the strangest and, in many respects, most repulsive scenery in the world. They are tracts of irreclaimable barrenness, blasted and left for ever lifeless and hideous."' Those of Wyoming are carved into buttes and intervening depressions largely by wind action, whereas near the Henry Mountains rain has caused, the development of very regular water-ways, in which the Thalwegs present the normal curve of stream denudation at the base, whereas the summits of the ridges have a convex curve, though the nature of the rock appears to be the same at base and summit. Gilbert quotes these Bad Land ridges as exceptions from the ordinary law of water-erosion, which are as yet unexplained.

In some deserts, like that of Egypt, the flat ground is carved out into butte-like elevations from six to one hundred and fifty feet in height, known as "Zeugen." They consist of soft rock with a layer of hard rock at the summit, and beneath the hard cap the soft rock is carved into slopes which resemble the typical denudation curve, as shown in Fig. 36. Nevertheless, according to Walther, running water plays no part in their formation, as proved among other things by their most frequent occurrence in regions of least rainfall. He accounts for them on the supposition that they are due to wind action, assisted by chemical weathering. When a hollow has once been formed by the wind, weathering comes into play with different effectiveness on different parts of the slope. Immediately below the hard cap the rock retains what water it takes up, owing to the shade of the overlying hard cap, and accordingly

1 GeIkIE, Sir A., Geological Sketches at Home and Abroad, No. ix. 
chemical weathering is most pronounced there, and the rock is rendered less coherent, and is easily transported by the wind; below this the cap offers less and less protection, and the removal of the rock occurs in smaller and smaller quantity, until the curve is produced and the hard cap overhangs. As the shady side of the Zeuge is weathered to a greater extent than the sunny side, the Zeuge becomes crooked and the top breaks off, when all the soft material is removed, and the process is commenced

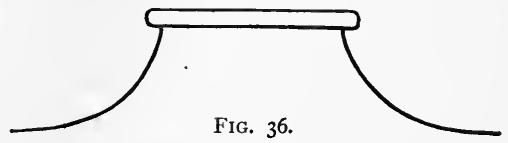

Ideal section across a Zeuge.

afresh at a lower level with another soft stratum surmounted by a hard one.

According to Walther, the influence of shade causing water to remain in shady spots longer than elsewhere, and thereby permitting chemical weathering to occur more extensively in the shade, is also responsible for the formation of extensive holes on the general surface of a rock desert. When these holes are once formed the shade in the interior becomes more pronounced, and accordingly the cavities grow wider as they proceed further down beneath the general surface of the rock.

The fretted nature of wind-worn rocks in a desert region is increased, owing to the production of a peculiar brown crust, which has been noticed by many writers, e.g. Messrs. Brindley and Floyer, which gives a sameness of colouring to many 


\section{SCIENTIFIC STUDY OF SCENERY}

deserts. This crust has generally been referred to the effects of weathering, but Walther gives reasons against its production by simple weathering action. It consists mainly of peroxides of iron and manganese, and rocks, like limestone, which do not contain these substances are covered by it, equally with those rocks which do contain them.

When cliffs of rock are covered with the brown crust, it scales off in vertical strips in some unexplained manner, possibly owing to the trickling of rain-water. The exposed parts are influenced by the denuding action of desert agents, as weathering in the shade and the sand-blast, while the encrusted parts resist this action. The first result is the production of window-like recesses in the exposed parts. As the backs of these recesses are in the shade, the action goes on sideways behind the crust-protected intervening parts, producing passages behind the protected portions, which then remain as pillars between the window-shaped apertures. Some of these apertures are large enough for a man to enter in a stooping position.

Again, when the upper part of an isolated butte is covered by the brown crust, this encrusted portion is protected, while the lower part is worn away, and a mushroom-shaped pillar is the result. The stripping of vertical patches. of the crust on the head of the mushroom allows of the formation of window-shaped cavities on the sides of the head, and projecting borders are frequently produced. Some of these mushroom-shaped rocks observed by Walther were over fifteen feet high, the brown summit occasionally projecting about a yard beyond the white stalk.

The formation of valleys in desert regions is 
effected in more than one way. The buttes of the Bad Lands of Wyoming are the outstanding portions of rocks, which have been carved into small valleys by the action of the wind, and Walther ascribes the main part of the formation of the wadys of the Egyptian desert to this cause, and believes that water plays a very subordinate part in their production, though the effects of the thunder showers which occur there must not be overlooked. In some desert regions, as that of Colorado, rainfall, though slight, gives rise to streams and rivers which produce the characteristic cañons. Owing to absence of vegetation, the water when it does fall is given off rapidly and not slowly, and, accordingly, can effect much transportation, and therefore corrasion, when the declivity is sufficient, whereas owing to the infrequency of rain, weathering is retarded. It is in these regions that we find the steep-sided gorges carved out of the arid plateaux, which are gradually cut up into flat-topped mesas and buttes, of which the sides are terraced by alternation of softer and harder strata, and the softer strata are carved into intricate forms.

"The water from the occasional rainfalls carves out innumerable little sinuous washes, which, in descending, come together, forming deep gullies. These keep on joining others, until the main drainage ourse of the valleys is reached. Between this network of washes are corresponding ridges, which in a favourable light give to the mesa-face the appearance of an elaborate and very artistic piece of ornamental carving." 1

1 The above quotation is from W. H. Holmes' Geological Report of the San Juan District; Ninth Annual Report of the United States Geological and Geographical Survey, p. 256. The structure is figured in Plate XLI, of that work. 
Accumulation in Deserts.-The accumulations and deposits of desert regions are formed in hollows of the dry land and on the floors of inland lakes. The most extensive accumulation of the dry land is blown sand, which often covers great expanses of a desert. The surface of the sand is often irregular, owing to the formation of sand-hills or dunes, which may occur with intervals of the underlying rock showing between them, or may merely form the summits of considerable thicknesses of blown sand. If an obstacle exists in an area over which sand is being blown, some of the sand will be arrested by the obstacle and form a little heap around it, especially if the wind varies in direction. Such obstacles are often furnished by the sparsely-scattered plants which can grow on a sandy tract. The sand accumulates around these, the top of the plant continues to grow above the sand, and eventually a little mound of sand is produced, from the centre of which the plant which caused the formation of the hillock projects. If the plants are fairly abundant a very characteristic appearance is presented by the innumerable monticules, each possessing its tuft of vegetation. Walther figures examples of these hillocks (Neulinge), which have been formed around tamarisks in the desert of the Sinaitic Peninsula.

Dunes of desert sand may be formed without any obstacle other than that furnished by the sand itself, as shown by Vaughan Cornish in a paper which treats of the formation of different kinds of dunes in detail,-a paper from which many of the facts recorded below are extracted. ${ }^{1}$ Desert sand

1 Cornish, V., "On the Formation of Sand-dunes," Ceographical Journal, March, 1897 . 
differs to some extent from the sand of coast sandhills or sand-dunes, in that the sand in the latter has been largely sorted by sea action, while desert sand contains particles of various sizes, from large grains to particles of dust. The former act as obstacles, and when the wind blows, the finer dust is heaped up against the coarse grains and a "ripple-mark" is formed on the surface of the sand; these "ripplemarks" do not differ materially from dunes save in size. The structure of a dune is largely dependent upon the eddy produced on the lee-side, as shown in Figure 37 (after a figure by Cornish),

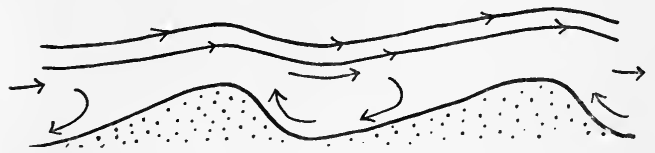

FIG. 37.

which represents a cross-section of two dunes and the directions of the air currents.

The height from the crest of the dune to the bottom of the trough in front is the amplitude of the sand-wave and cannot strictly be spoken of as the height of the dune, as part of the hollow is produced by excavation and not by piling up; it is only when a dune rests upon rock below that we can confidently speak of the height of a dune. The windward slope in the central part is one which will allow grains to be carried up by the wind; the lower part of the lee-slope is produced by excavation on the part of the eddy, while higher up is a straighter portion due to slipping of the incoherent grains, and this slipping may also modify the base by producing 


\section{SCIENTIFIC STUDY OF SCENERY}

a talus-slope. The descending air-current at the crest of the windward slope rounds off the upper part of that slope, and the lower part of the windward slope is, like that of the lee-slope, excavated by the eddy.

"Thus the normal profile left by the rippling of sand by wind has the following parts-viz., a windward slope, consisting of a concave and convex curve, and a lee-slope, consisting of a straight line and a concave curve."

Reversible wind tends to turn the top of the dune, and gives rise to a hill which is steep on the windward slope as well as on the lee side.

The dunes grow sideways as well as upwards, owing to the opposition of the direct current by an eddy. As the centre of the dune has a greater height than the sides, the sides travel forwards more rapidly than the centre, producing a crescent-shaped mound with the horns pointing to leeward. This is the form of the barchanes or medanos of many desert regions. They may be produced by an obstacle, or where part of a current of air is relatively feebler than that in the immediate vicinity. When the wind varies in direction these barchanes may take very complex shapes, with many horn-like projections pointing in different directions.

Dunes may, under different circumstances, lie longitudinally or transversely to the direction of the prevailing wind, the longitudinal type, as shown by Dr. Blanford, being associated with wind of greater force than that which determines the formation of the transverse type.

When stripes of wind of velocity different from that of the wind on either side produce barchanes, 
and the amount of sand in the sand-shower subsequently increases, the whole of the surface, except the deep excavations on the lee side of the barchanes, may be blurred or smoothed over, when these excavations will be left on an otherwise level surface of land as horseshoe-shaped hollows. Such hollows, known as fuljes, occur in many deserts.

Dunes vary in height, but cannot grow to an indefinite height, for the work of the wind at the summits of the dunes is assisted by gravity, while that of the eddy in the trough is opposed by gravity, and accordingly, after a time, more sand is accumulated in the troughs than can be piled up on the crests. When this occurs the general height of the desert is increased, and great thicknesses of sand may be accumulated with the dunes upon their upper surface. The highest dunes are not much over 600 feet above the lowest parts of the troughs. The character of one of these sand deserts, in which the sand has been accumulated to a great thickness, has been well described by Captain A. H. McMahon. ${ }^{1}$

"Marching viâ Darband and Amir Chah, we kept to the north of the Koh-i-Sultan, Damodun, and other mountain ranges. At times our journey lay through wide, open, level plains covered with black gravel, at others we floundered our weary way through broad expanses of deep sand-hills, which, near Amir Chah and other places, assumed the proportions of formidable sand-mountains. All the mountains we passed were apparently volcanic. . . . These mountains are all being gradually covered up and buried in sand, which is relentlessly creeping further and further up their sides. Many are already completely

1 McMahon, A. H., "The Southern Borders of Afghanistan," Ce,grathical Journal, April, 1897. 


\section{SCIENTIFIC STUDY OF SCENERY}

buried, and a high mountain of sand marks their burialplace. Others have their black peaks just appearing out of the white expanse of sand-slopes. Here and there a loftier mass still towers with its black crags high above the devouring waste around, but the sand banked up on their sides, in places sometimes 1000 or 2000 feet above the level of their base, foretells a similar fate in store for them. The general effect of the scene they present is weird and unnatural in the extreme."

The pebbly deserts, like that referred to by Captain McMahon as covered with black gravel, are in many cases the residue of former sand deserts from which the finer particles of sand have been subsequently blown away.

In some regions, especially those which lie to windward of areas which have formerly received accumulations of fine glacial mud, the wind-borne material consists of fine dust, which may be accumulated upon plains or in the depressions between hillranges, giving rise to steppes. When the steppes are plains the surface is flat, but when the fine dust is blown into depressions between hills the upper surface of the dust forms a catenary curve. The accumulations, which have been formed in steppes are known as loess, and there is evidence that in geologically recent times steppe conditions, marking widespread dry climate, prevailed over much more extensive areas than those which are now characterised by them. ${ }^{1}$ In many places the loess has subsequently been carved by water action into deep cañon-like-gorges, as in some parts of China.

1 For a discussion on the origin of the loess, see a paper by Baron von Richthofen, Geological Magazine, decade ii., vol. ix. (1882), p. 29:. 
Loam deserts frequently mark the sites of ancient lakes, some of which possessed no outlet, as already stated when noticing the character of some of the Bad Lands of the western territories of North America. These desert lakes often present features of interest. If the rainfall be insufficient to fill a depression to the height of the lowest point of outlet from the depression, the lake will have no outlet and its level will fluctuate, owing to variations in the rainfall of the region, for much of the water is removed by evaporation. Accordingly we find wellmarked shore lines accumulated where the surface was fairly constant in height for a sufficient time to allow of the accumulation of a beach. These lines of beach form a striking feature on the hill-sides around the Great Salt Lake of Utah and neighbouring lakes of the same region, and they have been frequently described and figured.

When complete desiccation of these lakes occurs the salts which were in solution in the water are deposited in crystalline sheets, often appearing like surfaces of ice in the desert. Such tracts of salt are found in the Shats of Algeria, and McMahon describes similar expanses in the southern borderlands of Afghanistan.

Accumulations of salt may, however, be formed in desert regions without the formation of a lake. The thundershowers of many deserts carry salt from the rocks to a lower level, and as the water evaporates the salt is left behind, and in this way sheets of salt may accumulate in depressions. Again, it has been seen that salt may be brought to the surface by capillary action, and accordingly we find some deserts, like the alkali deserts of North America, characterised 


\section{SCIENTIFIC STUDY OF SCENERY}

by coatings of salt, which form a whitish crust upon the surface of the ground. ${ }^{1}$

A word may be said concerning the atmospheric conditions of a desert region. Owing to the extraordinary dryness of the atmosphere the traveller can frequently see objects at great distances. Of the desert on the borders of Afghanistan, Captain McMahon writes, "The clear, dry, sparkling atmosphere, the deep blue, cloudless skies of the greater part of the year, and the almost boundless horizons produce feelings of exhilaration and a sense of freedom which go far to make up for the shortcomings of the country in other respects."

The mirage of the desert, like that of other regions, as the polar areas, the English fenlands, and the Lake of Geneva, is due to reflection from the surface of a stratum of air, where originally horizontal strata of different densities have been disturbed by differential heating or cooling from underneath. The reader who wishes for a fuller account of the phenomena of mirage may consult a paper by Professor Everett in Nature, November Igth and 27 th, 1874 .

Sand-storms occur during the prevalence of strong winds in desert regions. They may be due to wind blowing in one direction over wide areas when the sand is wafted on by the wind, and in these conditions sand-dunes are formed and increased in size. Some of the most remarkable and destructive sand-storms are cyclonic whirls of comparatively small size, which produce sand-pillars and cupolashaped masses of sand, often miles in diameter; the

${ }^{1}$ See GeIKIE, Sir A., Geological Sketches at Home and Abroad, p. 240 , fig. 25 . 
general circular mass may be complicated by minor spiral columns due to subsidiary spiral rotation of the wind on the margin of the main cyclone.

It has already been stated that desert conditions are largely due to the general absence of vegetation, but that which does exist in a desert has a character of its own, and produces considerable effect upon the scenery of those portions of desert which are occupied by a scant growth of vegetation. There are decided resemblances between the flora of the desert and that of high alpine or of arctic regions, and the resemblances are due to the existence of similar physical conditions in desert and arctic areas, namely, long periods of dryness alternating with short periods when there is a considerable supply of moisture. In arctic regions the dryness is due to cold and wind, and the moisture is supplied by melting of snow. In the desert the dryness is due to heat and drought ; the moisture is supplied during the short periods of rainfall and to some extent by night dews.

One effect of desert climate is that the plants occur in comparative isolation, often with considerable intervals of barren ground intervening between individual plants. Furthermore there is usually a special modification of the leaves of the plants, which enables them to resist the long periods of drought. The leaves are often scaly, sword-shaped or tufted, occurring in rosette-like growths; sometimes they are modified into thorns, and in some cases shoots devoid of leaves are found. The prevailing colour of the desert plants is grey-green, dirty green, or grey-white. Succulent plants, however, are frequently found, and some deserts possess a considerable variety of flowering plants. 
In the Egypt-Arabian desert the leaves of the grasses are short and stiff; plants with shoots devoid of leaves occur, as Ephedra; in Tamarix the leaves are modified into scales, and there are several thorny plants. Many bulbous plants are found, and in some parts flowering plants produce an effect upon the scenery, thus the storksbill (Erodium) when in flower gives a red hue to tracts where it grows.

The remarkable edible lichen Parmelia esculenta, supposed to be the manna of the Scriptures, grows in the desert from Central Asia to Algeria; fragments of it are detached from the rocks by the wind, and these fragments are blown into other places.

In the Kalahari desert of South Africa many of the plants possess tubers mimicking stones. There are many bulbous plants and various succulent plants, as spurges (Euphorbiaceæ); also xerophilous plants, that is, plants which flourish in a dry climate, as Mimosa and various Proteaceæ.

In Australia parts of the desert are occupied by the isolated stool-like masses of Triodia, there called Spinifex, with a few needle-like spikes projecting, as seen in the plate copied by permission of the author and of the Council of the Geographical Society, from a figure illustrating a paper by the Hon. D. W. Carnegie, "Explorations of the Interior of Western Australia." 1

In North America the deserts are rendered monotonous by the prevalent sage-brush, consisting of various species of Artemisia, especially $A$. tridentata. An interesting feature of these deserts is the sudden change from highlands, supplied with abundant water and rich in vegetation, to desert lowlands. $\mathrm{Mr}$. $\mathrm{H}$.

${ }^{1}$ Geographical Journal, March, 1898 (vol. xi.). 


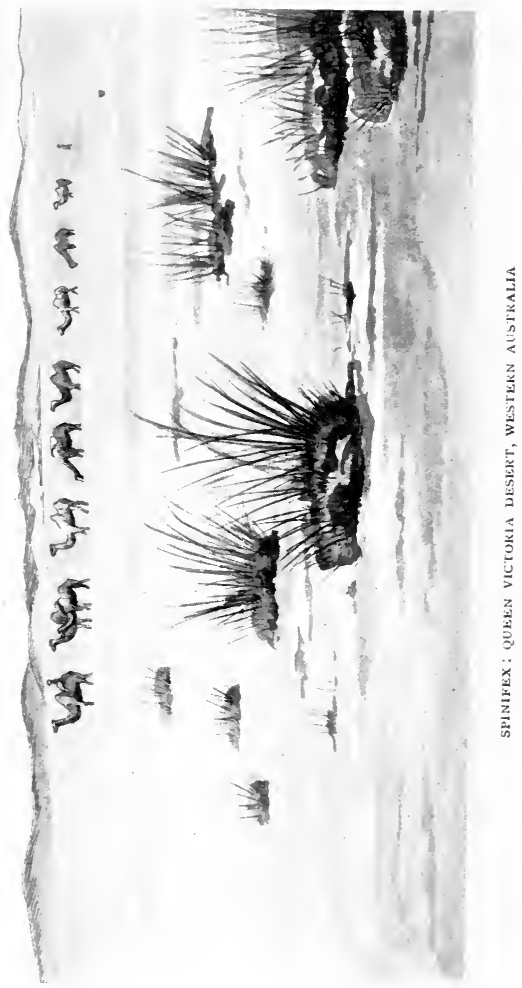



Gannett thus speaks of the Uncompahgre plateau, in the Grand River District ${ }^{1}$ :-

"Nowhere is the influence of vegetation on the character of the vegetation more plainly marked than on this plateau. In the interior, near the crest, the land is, to the Utes, one flowing with milk and honey. Here are fine streams of clear, cold water, beautiful aspen groves, the best of grass in the greatest abundance, and a profusion of wild fruits and berries, while the country is a perfect flower-garden. This extends as low as 7000 feet, below which the scene changes to one in all respects the reverse. Aspen gives place to piñon and cedar; the grasses, fruits, and flowers, to sage, cacti, and bare rock. The streams become confined in rocky cañons, turn muddy and warm, and gradually disappear. The game changes, black-tailed deer give place to the white-tailed species. Grouse disappear, while rattlesnakes and centipedes assert their proprietorship. In the place of an open, rolling country, we enter a district traversed by deep, narrow gorges, of abrupt precipices, a country difficult in the extreme to traverse without a knowledge of its few highways."

I have already quoted part of Sir A. Geikie's description of the scenery of the North American Bad Lands. Here is an additional extract from that writer's account :-

"There is a further feature which crowns the repulsiveness of the Bad Lands. There are no springs or streams. Into the soil, parched by the fierce heats of a torrid summer, the moisture of the subsoil ascends by capillary attraction, carrying with it the saline solutions it has extracted from the rocks. At the surface it is at once evaporated, leaving behind a white crust or efflorescence, which covers the bare ground and encrusts the pebbles strewn thereon. Vegeta-

1 Report U.S. Geological and Geographical Survey, 1875, p. 340. 


\section{SCIENTIFIC STUDY OF SCENERY}

tion wholly fails, save here and there a bunch of salt-weed or a bush of the ubiquitous sage-brush, the parched livid green of which serves only to increase the desolation of the desert."

In these alkali deserts, and indeed in any desert where there is a considerable amount of salt, the flora frequently presents resemblances to that of the salt-marshes around the sea-coast. Besides cacti and spurges, which also grow in the sand deserts, we find marsh-samphire (Salicornia), plantains (Plantago), and various representatives of the Chenopodiaceæ or goosefoot plants.

Oases occur wherever water issues from the ground to a sufficient degree to support vegetation. The water may be due to various causes, as relatively large amount of rainfall in some localities, or course of the underground water. The latter is probably often a cause of oases, as indicated by their frequent occurrence along definite lines, a distribution which often determines the routes of caravans. Various plants grow in these oases, including trees. In North Africa the date-palm is the only indigenous tree, though others have been introduced by man. ${ }^{1}$

Though the production of desert features on a large scale requires a dry climate, we find that an imitation of many of the characteristic features of a desert region may be developed in our own country upon a small scale. The nature of the sand-dunes of the coasts is similar in general characters to that of the desert dunes, and some of the attributes of

1 For a fuller account of the vegetation of deserts the reader may consult E. WARMING'S Lehrbuch der ökologischen Pfanzengeographie, Berlin, ISg6. 
desert vegetation occur among the plants of our coastal dunes. Tracts even more suggestive of sand deserts are found in some parts of East Anglia, at some distance from the sea, where the superficial deposits are formed of incoherent sand, which is readily blown about by the wind.

The alkaline and salt flats of desert regions have some resemblances to the salt marshes which occur in many of our estuaries; they are particularly well developed in the estuaries around Morecambe Bay, though some of these have been modified by cultivation. It has already been stated that several of the plants of salt-deserts, as Salicornia and Chenopodiaceæ, are also found in these maritime salt marshes.

Lastly we find simulation of rock deserts on a small scale among the Yorkshire moors, where the millstone grit, being very absorbent, frequently engulfs the rain-water as it descends, thereby limiting surface erosion by water, and causing chemical weathering, effect of change of temperature and wind to become dominant agents of sculpture. It is in such regions (as already noted in Chapter VIII.) that we find miniature representations of the wind-worn rocks of deserts, as, for instance, the Brimham Rocks, near Knaresborough, and the Cow and Calf at Ilkley. 


\section{CHAPTER XVI.}

\section{FROST, SNOW, AND ICE}

A LTHOUGH it is in alpine and arctic regions A that the scenic effects due to frost are most striking, the effects of frost in a country like Britain, under its present climatic conditions, are far from insignificant.

The first point to notice in connexion with frost is the exceptional behaviour of water as it is cooled down towards the freezing-point. It is well known that water contracts when cooled until it possesses a temperature of $39^{\circ}$ Fahrenheit, when it expands, and accordingly grows lighter. At a temperature of $32^{\circ}$ Fahrenheit, the freezing-point of fresh water, the change from the liquid to the solid condition is accompanied by a very considerable expansion (about one-fourteenth of its volume). One noticeable result of this expansion is the efficacy of frost as an agent of disintegration of rocks, as described in a preceding chapter. Another effect of great significance from the scenic point of view is that, owing to expansion occurring above freezing-point, the top water, after its temperature is reduced to $39^{\circ}$ Fahrenheit, becomes lighter, and therefore remains on the surface, so that the surface water freezes first, whereas, if contraction occurred as the temperature was lowered to the freezing-point, the 
cold water would continue to sink to the bottom, and the. whole of a water area would be gradually lowered to freezing-point, and a lake might thus be frozen solid, whereas, under the actual conditions which exist, the ice is formed upon the surface, and seldom extends to a very great depth in deep sheets of water. ${ }^{1}$

Water, like many other liquids, when consolidated, assumes a crystalline condition, the crystals belonging to systems termed by mineralogists the hexagonal and rhombohedral systems, and the compound crystals are also arranged in symmetrical shapes as well exhibited in many snowflakes, which show various six-rayed forms. The crystalline structure may also be frequently seen in the products of hoarfrost and in other cases where consolidation has taken place under conditions favourable for the free growth of the crystal-outlines, but even when invisible it is there, for instance, in the ice on the surface of a pond, as may be proved by suitable experiments. The beautiful patterns seen on our windows on a frosty morning owe their beauty to the consolidation of water in a crystalline condition. We may here briefly notice some of the processes resulting in the formation of ice which give rise to minor or transient effects upon scenery.

Hoar-frost is produced when the dew-point is below freezing-point, when the aqueous vapour is not condensed into minute drops of water, but the solid form is assumed. Hoar-frost, like dew, forms best on substances which are good radiators of heat, and accordingly it is prone to be formed on vegetation,

1 The exceptional conditions controlling the formation of "groundice," or "anchor ice," on the floors of water areas do not concern us. 


\section{SCIENTIFIC STUDY OF SCENERY}

hence giving rise to the picturesque appearance presented by trees which are laden with it.

Warm vapour-laden air coming in contact with frozen ground may have its vapour condensed and deposited in the solid form as "glazed frost" or "verglas," which is specially remarkable when rain falls. An interesting case of verglas is quoted from the Comptes Rendus of the French Academy by Dr. R. H. Scott, in his work on Elementary Meteorology, chapter vii. In mountain regions very remarkable effects are often produced, owing to the formation of ice crystals which are deposited on cold surfaces when a warm vapour-laden wind strikes against them. Irregular blocks of stone become covered with thick masses bristling with crystalline projections, and often assume very bizarre forms. This phenomenon may often be seen on our own hills in the winter and early spring months, but in higher latitudes or on higher altitudes it may be observed in the summer months. Mr. Garwood noticed a very striking case on Hornsund Tind, Spitsbergen. The projections, some of which were eighteen inches in length, grew out from a vertical face of cliff during about three weeks of continuous fog.

Ice is not only produced by contact of warm moisture-laden air with cold ground, but by the contact of cold air with warm ground. Owing to the fact that the air is not directly heated by the rays from the sun, but by the dark heat which is given off from the earth, we often find the earth's surface is warm when the temperature of the air around is below freezing-point. Accordingly any snow or ice which is resting on the earth may be 
melted, and if it is resting on a projecting surface the water will flow down and hang as a drop on the edge of the projection. The contact of the cold air may cause this drop to freeze when it is at rest, and the next water which descends will swathe this drop with moisture, which, freezing in turn, will increase the diameter of the frozen knob, while more water, hanging from the extremity of the previously frozen drop, will in turn freeze, thus lengthening the frozen mass. By a continuation of the process an icicle is formed, much as a stalactite of carbonate of lime is formed under the arch of a bridge or on the roof of a cavern. Large masses of pendent icicles are often thus formed in the neighbourhood of waterfalls or at the edges of overhanging banks of a stream. In mountain regions, conditions favourable for their formation occur in the interior of the fissures or crevasses of glaciers, and also on the under surfaces of snow cornices, the mode of formation of which will be subsequently considered.

The effects of hailstorm, though often very destructive, are not of great interest to the student of scenery, and we may now pass on to consider the formation and mode of accumulation of snow.

Snow, as is well known, is not frozen rain; the snowflakes are formed from aqueous vapour by consolidation before the vapour has given place to definite liquid drops. Snow will collect at the door of a crowded railway carriage containing foot-warmers, owing to the consolidation of the aqueous vapour in the carriage by the cold air coming through the apertures at the sides of the door, without any perceptible liquid water being formed previously, and the story of the St. Petersburg ball, where snow began to fall in the 
overheated room when the windows were broken to let in air, is often quoted.

The amount of snow which falls during a severe storm is often exaggerated, as the thickness of drifted snow is frequently taken as representing the thickness of the actual fall. According to Dr. Scott a foot of snow yields about an inch of rain, and as a fall of three inches of rain in a day is a rare event in most parts of our island, statements of the fall of many feet of snow during one snowstorm must be received with caution.

Snow is readily drifted by the wind, and collects in places where the force of the wind is diminished, so that a snowdrift may in many ways be compared to a sand-dune; not altogether, however, for Mr. Cornish states in the discussion upon his paper on "The Formation of Sand-dunes" that some observations which he has made "show curious differences between the tactics of drifting snow and those of blown sand." The effect of regelation, that property of ice which causes two pieces to cohere when in contact, must no doubt be taken into account when discussing the causes for the actual outlines of snowdrifts, as proved by the existence of snow cornices, which are portions of drifted snow projecting over the leeward side of mountain-ridges and summits, owing to the consolidation of the snow particles. These snow cornices to some extent record the existence of the wind eddies which are formed on the leeward sides of obstacles; they have a convex curve at the top, arching over, and a concave curve below where the eddy must exercise a destructive effect. They may project many feet beyond the actual rocky ridge of the mountain, 
and when fringed with icicles form very remarkable objects.

In some parts of the world snow is unknown, in other parts it only falls at intervals in winter and rapidly melts, while in other parts the snow lies all the year round. The elevation at which the annual amount of snowfall is just the same as the annual amount of snow melted is known as the snowline, and above it are the regions of perpetual snow. As is well known, the altitude of the snow-line varies according to latitude, though local variations often produce modifications; nevertheless in any one district the general level often approaches the horizontal so nearly that when viewed from a distance a horizontal straight line appears to be ruled across the mountains above which is perpetual snow, and below which there is practically none.

At the equator the snow-line has a height of about I6,000 feet, in the Alps it lies at about 9000 feet, in Norway at 5000 feet, while at Spitsbergen it has fallen to a few hundred feet above sea-level. It must not be supposed, however, that all elevations above the snow-line are covered with snow. When the slope of the ground is very great the snow can only lie in patches on the ledges and gentler slopes, or collect in the couloirs and gullies. Thus it is that many of the Alpine peaks, as the Matterhorn, rise above the snow fields as rocky eminences, only scarred here and there with snow. Owing to this, and as the gullies and variations of slope are usually dependent upon geological structure, we can often learn much of the anatomy of a mountain by observation of the lie of the snow, and this is the case also in regions below the snow-line if we 
examine them when snow has fallen. Thus the direction of the main lines of stratification and jointing is often indicated by lines of snow on a mountain. Again, as certain rocks during the melting of the snow absorb the water more quickly than others, the snow will lie on these absorbent rocks for a longer time than on other rocks, where the water being left on the surface dissolves the snow. Thus in early spring the western slopes of the Pennine Chain facing the Eden Valley are often marked by long horizontal bands of dark rock practically devoid of snow, separated from one another by snowy strips. These dark lines mark the shales, which, owing to their impervious nature, keep the water on the surface, while the intervening white strips are beds of grit, which retain the snow, though the grit slopes are often actually steeper than those occupied by shale. ${ }^{1}$

The effect of slope on the accumulation of snow may be well illustrated by contrasting the snowy dome of Mont Blanc with the rocky pinnacles of its attendant Aiguilles, the latter being at an elevation inferior to that of the topmost dome.

Ice is often formed on mountain sides, adhering to the rocks in extensive sheets, which lie at an angle far greater than that at which loose snow will repose. These ice slopes are well known to Alpine climbers, and they often present a marked feature in the scenery.

The snow-line being the elevation at which the annual amount of snowfall is just the same as the amount of snow melted, it follows that above the

${ }^{1}$ For effect of joints in retaining snow, see Meddelelser om Grönland, Part II., Plate VII. (facing p. I64). 
snow-line more snow falls annually than is melted, and accordingly the snow of one year would tend to remain and be added to the snow of the preceding year. Does this accumulation go on indefinitely? If it did, the higher regions would in time become buried in vast accumulations of snow. But there are other ways besides actual melting by which the heights are rid of an excess of snow. We have seen that snow is not frozen rain, that the particles are frozen before they form liquid drops, and similarly snow may disappear without the production of appreciable masses of water on the surface. During a prolonged frost snow that has fallen before the frost commenced, or at an early period of the setting in of frosty conditions, may be observed to diminish, and it may even disappear, without any appreciable liquefaction, just as a mass of camphor does. The process is known as sublimation, and owing to it some snow is vaporised even above the snow line. Again, on comparatively steep slopes, as the snow accumulates, large masses may break off and fall to a lower level as snow avalanches. These avalanches are well known in mountain regions; their fall is very impressive, and the piled-up banks of avalanche snow frequently form a marked feature at the bases of the slopes from which they have fallen. But just as the superabundant rain of upland regions is carried to the lowlands by rivers, the superabundant snow of highlands is chiefly brought to a lower level by those icy rivers named glaciers, the nature of which we must now consider.

In order that glaciers may exist, there must be conditions in an area favourable for their formation, and cold is the condition which naturally strikes one 
as most important; no glacier can be formed unless the temperature is sufficiently low to allow of the accumulation of a considerable quantity of snow. Secondly, the amount of aqueous vapour which is brought to the region from elsewhere must be large, in order to supply material for the production of snow. However cold a region may be, if it is also dry there will be no appreciable snowfall, and accordingly no glaciers. The importance of the supply of aqueous vapour is well illustrated by the Alaskan glaciers. The great glaciers of Alaska occur in the south, where the warm, moisture-laden winds of the Pacific Ocean strike the land, and are responsible for a large snowfall, and not further to the north, though it is colder, for there the winds have been robbed of much of their aqueous vapour, and blow over the colder tracts as dry winds. Thirdly, the physical conditions must be favourable for the accumulation of snow. It is clear that glaciers or the snow necessary for their production cannot form on a vertical cliff, and it is doubtful how far the movement which characterises glaciers could occur as the result of an accumulation of snow formed on level ground. It is among the inequalities of a mountainous region that we find the conditions most favourable for the accumulation of snow which will give rise to glaciers.

That glaciers move is well known to everyone, one very significant indication of their movement being furnished by the fact that they often descend far below the snow-line. Herein lies one of the most striking features of these ice-rivers from the point of view of the student of scenery, for we frequently find a marked contrast between the great tongue of ice 
at the extremity of a glacier and its immediate surroundings. The terminal face of the ice of the Tasman glacier in New Zealand is about 700 feet above sea level, and it "is hidden by a grove of Pines, Ratas, Beeches, and arborescent Ferns in the foreground." 1

As we ascend a glacier from its termination toward the watershed, we find the lower part below the snow-line devoid of snow and consisting of ice. Higher up the ice is covered by unmelted snow, the junction of the snowy and snowless portions being sometimes irregular, though there is often a marked contrast between the two portions as seen from a distance. Proceeding still higher the glacier ice is found to be replaced by a granular substance intermediate between snow and ice, known as névé or firn, ${ }^{2}$ and yet higher the névé gives place to ordinary

1 Ilochstetter's New Zealand, quoted by A. C. Seward, Fossil Plants as Tests of Climate. Cambridge, 1892.

2 The following description of the appearance of a Swiss névé is from the pen of Principal Forbes (Edinburgh Reviezv, April, 1842). "The névé or firn is the unconsolidated glacier. As we approach it the fissures of the glacier become generally rarer and always narrower. The elevation above the sea being already very considerable, perhaps 8000 or 9000 English feet, the winter's snow lies all summer on the surface of the ice, conceals the crevasses, and partly also the structure of the matter of the glacier itself; to discern which the snow must be carefully removed. It is a frequent, perhaps a general, characteristic of the transition from the glacier proper to the névé, that whilst the former presents a convex surface the latter is concave, and inosculates insensibly into the snowy steeps which clothe the sides of the upper glacier basins at these great heights. Magnificent is the prospect which these firns sometimes present. The surface is smooth and almost level, like an artificial floor stretched across a valley, whose sides evidently descend to a great depth beneath. It is a real platform - to compare great things with small, it is a theatre with the pit boarded over; and what a theatre! From that even, snowy carpet of dazzling white rise hundreds of nameless peaks on either hand, seeming to pierce a sky whose azure hue is so intense as to find no 
snow. How does the change from snow to névé and from this to glacier ice take place? The formation of névé from snow is sometimes stated to be due partly to melting and recrystallisation of part of the mass, and partly to pressure of overlying snow, but the process does not appear to be quite so simple. The névé is composed of grains, of which each grain is a truly crystalline particle.

"Regarded from a distance the névé appears to be very finely stratified, layers of comparatively pure blue ice alternating with white ones. On close examination this stratified appearance is seen to be practically wholly due to the distribution in layers of countless imprisoned airbubbles. ... After a fall of snow surface-melting leads to the production of a mass of more or less spherical granules of ice, the interstices between which are occupied by air. Further accumulations of snow lead to pressure, the granules are compressed, and much of the air may be expelled. But under certain conditions of weather a surface layer of snow may be melted, and, freezing again, may form an impervious layer, and the adjacent airbubbles be unable to escape, even under the pressure resulting from further falls of snow. Thus we have bands of air-bubbles parallel with the surface, and alternating with strata of blue ice which are comparatively free from air. Meteorological conditions will have a great influence upon the volume of air imprisoned." 1

match in nature save the gentian, which expands its lovely flowers close to the glacier. The sides, scathed by lightning and torn by the avalanche, scarcely permit a resting-place for the snow which accumulates in dazzling wreaths only in its sheltered nooks. Each of these pinnacles transported to an ordinary scene would seem one of nature's grandest objects, whilst here it is lost amidst the crowd of its fellows."

1 R. M. Deeley and G. Fletcher, "The Structure of Glacier Ice and its Bearing upon Glacier Motion," Geological Magazine, decade iv., vol. ii. (1895), p. 152. 
As the névé passes into glacier ice, the stratification is still preserved for some distance, though the bubbles are gradually expelled owing to the pressure by which the ice is affected. The névé grains grow, according to Hagenbach, by the absorption of the smaller grains by the larger ones, and at the end of a glacier the grains may be of very great size. In Spitsbergen "some of them in a block which had fallen from the Booming Glacier were four inches in diameter. These were much bigger than any we had seen in Switzerland; and the biggest that we remember recorded thence were some found by Forel on the Aletsch glacier, which were as much as three inches in diameter." 1

Special attention is called to the glacier grains, as they produce a very marked effect upon the appearance of glacier ice. The boundaries of the grains in the ice are usually extremely irregular. Often they are arranged in roughly parallel layers with their longer axes parallel to the layers, and we thus find the peculiar veined or ribboned structure of glacier ice, which has been compared to the cleavage structure of slates, and appears to have been produced in much the same way as the result of pressure, producing a rearrangement of the particles, or change of shape, accompanied by shear, which - gives rise to the lamination, or, as it might be termed, cleavage.

It does not follow that because the Swiss glaciers are produced by passage of snow into névé, and of the latter into glacier ice, that all glaciers are so

1 E. J. Garwood and J. W. Gregory, "Contributions to the Glacial Geology of Spitsbergen," Quart. Journ. Geo. Soc., vol. liv., p. 220. 
caused. According to Messrs. Garwood and Gregory ${ }^{1}$ "many of the Spitsbergen glaciers do not drain snow-fields, and the material of which they consist passes directly into the condition of névé-ice and glacier-ice. Thus at the head of nearly every glacier pass that we crossed (for example, Fox Pass, Bolter Pass, Flower Pass) we found no true névé or gathering ground for snow. In some cases such glacier-ice may have been formed by avalanches; but at least in one case this explanation is inadmissible, and we were forced to the conclusion that under arctic conditions snow may be converted into ice without pressure, and that the existence of glaciers does not necessarily postulate the existence of great snowfields."

The cause of movement of the glacier is a topic which has given rise to much controversy. Many theories of glacier motion have been suggested, some of which assign gravitation as the primary cause of the movement, while others maintain that the cause is heat. The theories which regard heat as of primary importance are those of Charpentier, Agassiz, Moseley, and Croll, while those which lay stress upon gravitation were enunciated by Saussure, Rendu, J. D. Forbes, and Tyndall. The theory of Forbes, which regards ice as a viscous substance, and therefore capable of movement, is the one which is generally accepted at the present day, and without entering into any discussion as to the exact physical conditions which constitute viscosity, it is sufficient for our purpose to note that whether ice is, or is not, strictly viscous, in the technical sense of the term, its motion is similar to that of a viscous substance.

${ }^{1}$ GarWOOD and GregORY, loc. cit., p. 200. 
The movement of ice as a viscous body does not, of course, prevent the action of thrusting, and this action undoubtedly produces minor effects in glacier movement, as shown by Garwood and Gregory in the case of the Booming glacier of Spitsbergen.

A glacier then moves like a river, and like a river its lower surface is retarded by friction against its bed, and accordingly, as is well known, owing to accurate measurements taken by many observers, especially by Forbes, it moves faster at the surface than at the bottom, and faster in the middle than at the sides. Furthermore, other things being equal, it moves faster on a steep incline than on a gentler one.

Owing to the differential movement of glaciers several phenomena are produced, which we may now proceed to consider. In the first place, in the region of névé the upper part often adheres to the underlying rocks, while at a lower elevation, where the frozen material is thicker, it is capable of freer movement, and is dragged away from the more firmly attached portion, and if the action takes place so quickly that the ice cannot adjust itself to the new conditions by re-arrangement of its particles the lower part is separated from the higher by actual rupture, producing a fissure at right angles to the direction of pull. Such a fissure, which often runs for a considerable distance on the sides of the higher peaks, is known as a bergschrund. The fissure is inclined inwards towards the higher part of the mountain. It may be upwards of thirty feet in width. The bergschrund is often partially choked with snow, and may have cornices, as well as actual snow-bridges in places, and the formation of icicles, in the manner previously 


\section{SCIENTIFIC STUDY OF SCENERY}

described, is peculiarly favoured by the shaded state of the interior of the bergschrund. Very often two or more of these fissures are parallel to one another at no great distance apart. They are often formed in snow-filled gullies or couloirs, where the slope suddenly changes.

The fissures which are seen in an ordinary glacier are known as crevasses, and are of three kinds, namely, transverse, longitudinal, and marginal. The transverse crevasses are produced when the slope of the glacier bed increases suddenly, so that the ice cannot accommodate itself to its bed without cracking. In other words, transverse crevasses are the result of an "ice-fall," analogous to the waterfall of a river. Such crevasses may be seen at the ice-fall of the glacier below the Scerscen and Roseg, as shown in the plate. The cracks are naturally at right angles to the direction of movement of the ice, and accordingly they are termed transverse. The broken ice is carried over these steep portions slice after slice. Local strain during the fall often causes further fissuring, at an angle to the main crevasses, and accordingly the ice may be broken up into fantastic pinnacles known as séracs. Below the ice-fall the ice moves more slowly, and the more quickly moving ice above is jammed against it. Furthermore the ice over the fall tends to take a convex curve on the surface, causing great tension of the upper portion, while below the surface becomes concave, causing compression of the upper portion. Owing to these causes the crevasses formed at an ice-fall are sealed up at no great distance below, though they are often marked by superficial furrows separated by ridges for some distance below the fall. It will be seen, there- 


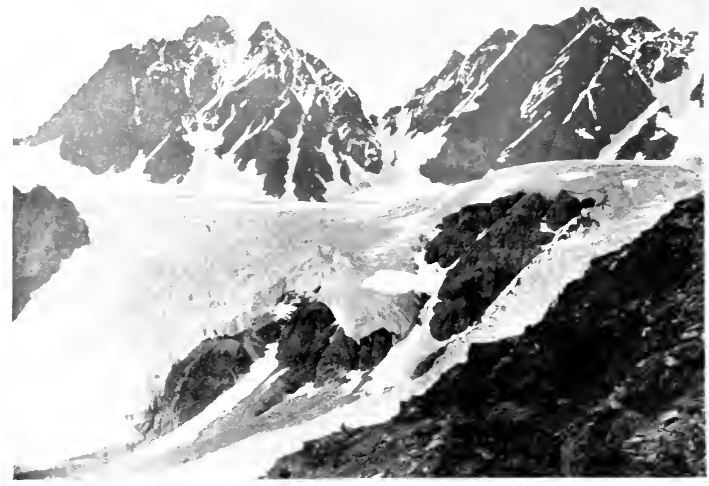

ICEFALL ON GLACIER BELOW SCERSCEN AND ROSEG ENGADINE

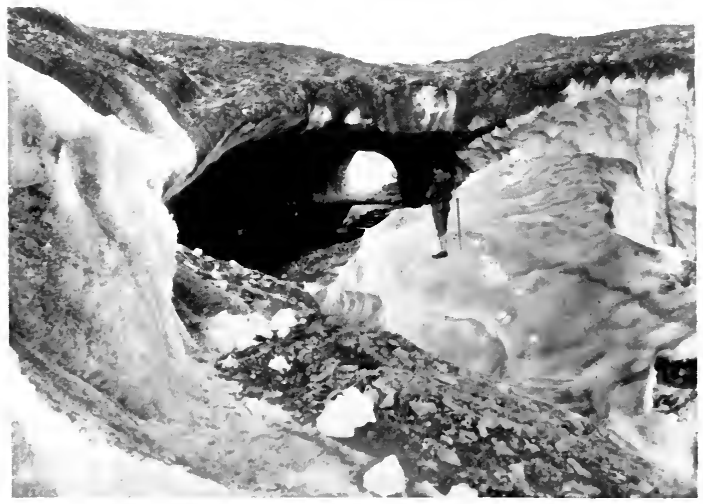



fore, that though an ice-fall is constantly marked by transverse crevasses, they are not the same crevasses. As one set moves down, and gets sealed up, another set is formed at the fall and takes its place, and so the process goes on. Below these icefalls the veined structure is frequently found, and Tyndall has spoken of them as structure-mills where the veining is produced.

The longitudinal crevasses occur where the glacierbed is somewhat suddenly widened below a narrow portion. Tension is here at right angles to the direction in which it occurred at the ice-fall, owing to the inability of the ice to adapt itself to its widened bed without fissuring.

Marginal crevasses start at the sides of the glacier and extend towards the middle, pointing up the glacier towards the middle. They are produced owing to the faster movement of the central portion when compared with that of the sides. The obliquity of the crevasses was first explained by $\mathrm{Mr}$. W. Hopkins, and a very clear explanation of it will be found in Tyndall's Forms of Water, paragraphs 267-275. If we imagine a circular portion of ice at the side of the glacier at any time, that circle as the result of differential movement will be converted into an ellipse, as shown in Fig. 38 , where $\mathrm{X} \mathrm{X}$ represents the rocky side of the glacier; the arrow points down the glacier; I represents the original circle, and 2 the direction of inclination of the ellipse produced by its distortion. The pressure will be greatest at right angles to the longer axis of the ellipse, while the greatest tension will be at right angles to the direction of greatest pressure, and accordingly the fissure will be produced along the direction of 
the shorter diameter of the ellipse $c d$, which, as will be seen in the figure, points obliquely up the glacier towards its centre. Owing to the coalescence of the marginal crevasses with transverse crevasses in the centre of the glacier, curved fissures are often seen, with their convexities pointing up the glacier.

When glaciers spread into a fan-like form at

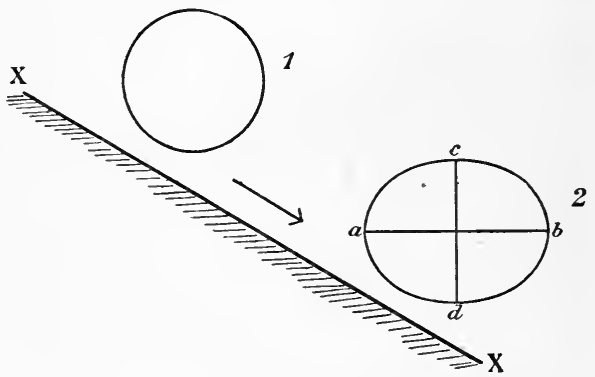

FIG. 38 .

their extremities, as they sometimes do, the transverse crevasses run in curves with their convexities pointing downwards, and the longitudinal ones become radial.

In very cold regions there is yet another way in which crevasses may be formed. At a very low temperature ice changes its physical characters, and becomes very inelastic, and as it contracts as the result of the lowering of the temperature, fissures may be produced. Mr. K. J. V. Steenstrup found that when ice was in this condition the mere pressure of a needle was sufficient to splinter off large pieces 
of ice in little fragments, which were thrown to some distance with an explosive sound. ${ }^{1}$

In considering the formation of crevasses only the differential movement of the ice has been noticed. The rate of movement of glaciers as a whole does not directly affect our present line of inquiry: it is sufficient to state that it varies in different glaciers as well as in different portions of the same glacier. Some glaciers only move a few inches per diem, while in other cases a rate of several feet in a day has been recorded.

In the upper parts of the glaciers, where the underlying ice is concealed by snow, the crevasses themselves are often concealed, or only revealed by the presence of slight undulations noticeable by the experienced ice-man. Further down the glacier they are open to the light of day, though often, like the bergschrund, crossed by snow-bridges; while in the lower reaches of the ice we may look down unchecked into their blue depths, until they are lost in the gloom of the interior.

The fact that many glaciers descend below the snow-line has already been noticed, and mentioned as one of the proofs of movement of a glacier, for if the ice were not replenished from behind it would be melted like the snow, and cease at the snow-line. Owing to movement the process of replenishment does go on, for the surface of the glacier is constantly being lowered by melting or ablation, as it is termed, and as it nevertheless often keeps the same general height for considerable periods of time, in spite of this ablation, it is perfectly clear that the com pensation for the melted portion is made by the

1 Meddelelser om Grönland, part vi. 


\section{SCIENTIFIC STUDY OF SCENERY}

addition of fresh material from the higher parts of the ice-world. Owing to the heat received from the rocks at the side of the glacier, ablation takes place more quickly at the sides than towards the centre, and accordingly a cross section of a glacier usually presents a convex outline of the surface.

As the result of melting, runnels and streams of water are often found on the surface of a glacier, especially on a summer day. When traced downwards they frequently disappear, being swallowed by the ice at a crevasse. Action takes place here similar to that described when discussing the mode of formation of swallow-holes in a limestone district. The water, often charged with rock-fragments, falls down the crevasse with a gyratory movement and wears out a cylindrical shaft, which may be excavated to the base of the glacier. These shafts, known as moulins, show the beautiful blue colour of ice, which is also exhibited in the crevasses. As the ice moves onwards, the crevasse, as before described, is sealed up, and a fresh one formed in its place. The old moulin is now deserted by the water, which excavates another shaft in a place situated a little higher up the glacier than the position now occupied by the deserted one, and as a result of the continuation of the process a line of several of these deserted moulins may be found below the position occupied by the active one. As a result of ablation and other changes, they gradually become shallower, and finally disappear.

The water which flows on the surface, and is swallowed up by crevasses, ultimately finds its way to the base of the ice, though as will be eventually seen, some of it may flow in the ice for long distances 
in englacial caverns before it finally reaches the bottom. This englacial and subglacial running water issues from the end of a glacier, often in a considerable stream, giving rise to a terminal cavern, frequently exhibiting the beautiful blue colour of the ice. It is advisable to abstain from entering these caverns without expert guidance, as the caverns are enlarged by the detachment of large masses of ice from the roof, often without any preliminary warning.

We have hitherto regarded the ice of glaciers as though it flowed onwards devoid of any burden, though it is well known that much material is carried down by many glaciers in the form of moraines, and we may now proceed to consider the character and mode of distribution of this material on and in the ice.

The action of frost in splitting fragments from the solid rocks has already been noticed, and it was seen that these fragments, when the slope is steep, roll down the hill-sides to the valley beneath. If the bottom of that valley is occupied by a glacier many of these stones will come to rest on the side of the glacier, retaining the angular shape which they possessed when split from the parent rock. The angular fragments will descend upon some parts of the glacier more frequently than on others, the greatest number falling down gullies which are spoken of as screes-shoots. But as the glacier moves along, each portion of the side in turn passes such a screes-shoot, and the material which is piled upon it there is carried lower down, while the process is going on afresh at the original place. Accordingly every part of the glacier side becomes fringed with an accumulation of loose blocks, giving rise to a 


\section{SCIENTIFIC STUDY OF SCENERY}

lateral moraine upon either side of the ice-river. When two tributary glaciers unite to form a single ice-stream, the adjacent lateral moraines also unite, and proceed down the centre of the main stream, thus producing a medial moraine, and when a glacier, as in the case of the Mer de Glace at Chamonix, is formed by the union of many tributaries, a number of medial moraines occupy the central portions of its surface. Now a glacier, like a river, tends to continue in its initial course, and when a bend occurs in its bed, the line of most rapid motion is diverted from the centre of the glacier towards the concave curve, and the medial moraine is carried with it. Consequently, when a glacier flows through a sinuous valley, the sinuosities of the medial moraines are greater than those of the actual valley, and the peculiar serpentine appearance of the moraines is emphasized.

The moraines on a glacier appear to consist of great ridges composed of detritus, rising high above the general level of the ice. This appearance is deceptive; the stones form a mere veneer upon the surface of a ridge of ice, the icy ridge being due to slighter ablation of the ice-surface beneath the moraine, for as rock is a bad conductor of heat, the ice beneath the moraine is protected from the rays of the sun.

The formation of this ridge may go on to so great an extent that the slope becomes too steep for the stones to rest on it, when they fall to either side, and as this process goes on the original ice-ridge may be melted, and replaced by a ridge on either side, which may undergo the same process. In this way the morainic material tends to wander laterally over the 
glacier, and the lower portions of glaciers are thus frequently covered with a mass of morainic matter which may entirely conceal the ice beneath.

When a glacier shrinks for many years in succession, as is the case with many Swiss glaciers, its general level is lowered, and the former height of the ice is marked by the original lateral moraines, while a continuous slope at the angle of rest of the loose material formed of the morainic material which was stranded during the sinking of the ice-surface stretches from the top of the old moraine to the present level of the glacier, which may be some hundreds of feet beneath it.

The medial moraines are sometimes engulfed by crevasses, and then reappear at some distance from the place where they were engulfed, owing to the ablation of the surface.

A certain amount of material, such as stones, sand, and very fine mud is carried beneath the ice, constituting the moraine profonde; it is chiefly of interest to us on account of the effect it produces on the underlying rocks, which will be noticed in a later chapter.

At the termination of the glacier all the rocky material which has been transported by the ice, whether on its surface, in its substance, or beneath it, is deposited to form a terminal moraine. As the centre of the glacier, owing to its more rapid movement, is carried further down than the sides before it melts, the termination of the glacier is often convex, with the convexity of the curve pointing down the valley. Accordingly the terminal moraine tends to assume a crescentic form, and if a glacier recedes, and there are pauses in the recession, a considerable 


\section{SCIENTIFIC STUDY, OF SCENERY}

quantity of material accumulates at the end during each of the pauses, and a number of crescents of morainic material may be formed one behind another.

The stream which issues from the glacier, and the streamlets which course down the valley sides, often issuing from the ends of minor glaciers, cause much re-sorting of the morainic material, often filling up inequalities of the valley, and giving rise to a fairly uniform surface of fluvio-glacial deposit, which occurs below the ends of many of the Alpine glaciers, while ancient fluvio-glacial deposits laid down during former extension of the ice, and subsequently denuded in the centre by the river, form shelves on the valley sides, frequently covered with a rich soil, and accounting for the presence of many of the Alpine pastures at considerable heights above the present valley bottoms.

Owing to the surface-wandering of morainic material, and other causes, detached fragments are often found on the ice, which may be of any size from blocks the size of a cottage down to the finest particles of mud. The large blocks, like the moraines, protect the ice beneath from the sun's rays. Accordingly a large block is often found standing on a pinnacle of ice, produced owing to this protective action, forming what is known as a glacier-table. This resembles to some extent the earth-pillars of which we have before spoken, and still more certain boulders which are sometimes found perched upon pinnacles of limestone which they have protected from solution, as the celebrated blocks of slate which rest on pinnacles of the mountain limestone at Norber, near Settle, Yorkshire. As the 
pinnacles of ice increase in height the sun gradually diminishes their thickness, and in the Alps, the rays being most powerful on the south side, the pinnacle is melted away more rapidly on that side, and the superincumbent capping-stone gradually acquires a slant towards the south, when it slips off, and a new table is formed, while the original pinnacle of ice may remain to the north of it for some time, though it is eventually melted.

Little collections of stone produce the same effect, giving rise to cones of ice, such as are frequent upon parts of the Gorner Glacier. The stones slip from these, as they do from moraines, when the slope of the cone has become too great. In parts of Greenland cones of this character occur with a height of sixty feet.

When the particles are small a different effect is produced. Rock, though a bad conductor, is a good absorber of heat, and as these small particles are thin the absorbed heat is partly conducted through them and melts the ice beneath, and accordingly small particles of stone gradually bore their way down into the ice, leaving a little pool of water above, and when they are abundant they produce a very noticeable honeycombed appearance of the surface of the glacier.

Lastly, we must notice the well-known dirt-bands of glaciers, first observed by Forbes on the Mer de Glace, which give such clear indication of glacier movement. They originate below an ice-fall, where the crevasses, though sealed up, give rise to alternate transverse ridges and furrows on the surface of the ice. Dirt is carried by wind and streamlets into the furrows, and as the ice moves onwards the ridges 


\section{SCIENTIFIC STUDY OF SCENERY}

disappear by ablation, but the dirt which has been swept into the furrows still remains, and owing to the more rapid movement of the central part of the ice, assumes the familiar curved appearance, the convexities of the curves pointing down the glacier.

The phenomena which have been described in the present chapter may all be studied in the Alpine regions of Switzerland, but there are many other glaciated areas which present scenic features of interest, sometimes of a different kind from those occurring in Switzerland, sometimes similar in kind, but on a larger scale. It will be convenient to consider these, by a cursory examination of some of the other glaciated regions of the world, and to this we may devote another chapter. 


\section{CHAPTER XVII.}

\section{GLACIERS AND ICE-SHEETS OF VARIOUS REGIONS}

ORWAY.-The glaciers of Norway form the
subject of a special work by the late J. D. Forbes, ${ }^{1}$ who states that their conditions and structure are almost identical with those of Switzerland, the main difference being the nature of the gathering ground for the snows. In Switzerland the snow collects at the heads of valleys, and by accumulation forms glaciers, while in Norway it forms on vast table-lands surrounded by mountain peaks, and the glaciers escape through the passes which form the notches to this mountainous ring surrounding each snowy plateau; accordingly the Norwegian glaciers are smaller as compared with their snowfields than are those of Switzerland.

A very beautiful glacier in Fjaerland, the Suphelle Brae, is a good example of a type of glacier which is also found in Switzerland, though not in so perfect a degree as in the present case. It is known as a remanie glacier, and is not connected with the snowfield, but is formed by the reconsolidation of masses of ice precipitated as avalanches from a glacier above. A figure of it will be found on Plate VII. of Forbes' work.

${ }^{1}$ Forbes, J. D., Norway and its Glaciers visited in 185r. Edinburgh, 1853. 
Spitsbergen. - An interesting paper by Messrs. Garwood and Gregory on the glacial geology of Spitsbergen, to which reference was made in the last chapter, gives some details concerning the ice of that region which are of interest to the student of scenery. Some of the Spitsbergen glaciers are of the Alpine type, ${ }^{1}$ others present examples of what is known as the piedmont type, which will be more fully noticed when we consider the nature of some of the Alaskan glaciers, while others are composed of a series of confluent glaciers, for which the authors adopt the name "inland ice-sheet," which has been used in another sense for the great icy pall which covers the interior of Greenland, which, however, they prefer to speak of as an "ice-cap."

The most interesting feature of many of the Spitsbergen glaciers is the nature of the termination or snout.

The ordinary Alpine glacier ends in a tapering snout curving somewhat gently down to the base, and though this is found in the case of some of the glaciers of Spitsbergen, many of them end in a vertical face of ice, forming what is known as a "Chinese wall," and having an overhanging cornice at the top. The authors give reasons for supposing that this is due to advancing ice, and that receding glaciers have the characteristic Alpine termination. The two kinds of ends are seen close together in

1 The Alpine glaciers, of course, differ from one another in detail, and have been spoken of as belonging to the first and second orders. There is no essential difference between them except that due to size and sometimes to inclination of slope, but there is a marked contrast between the large valley glaciers and the small glaciers adherent to the slopes and faces of mountains-hanging glaciers, as the latter are termed. 



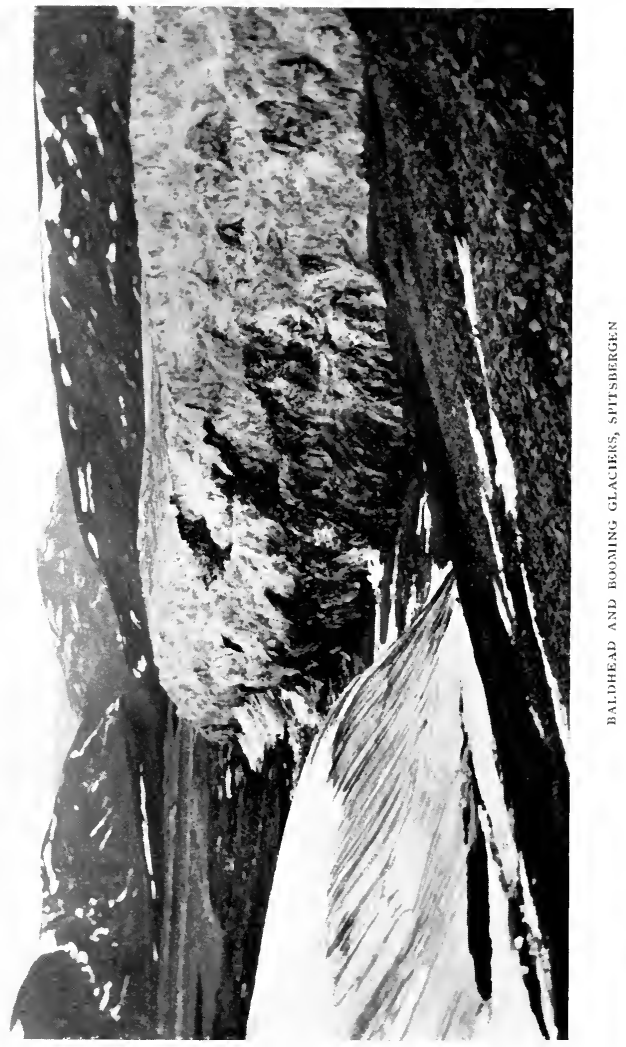


the case of the Booming and Baldhead Glaciers. (See the plate.) Baldhead Glacier on the left of the plate shows the tapering snout, while Booming Glacier has a Chinese wall. Some of the advancing glaciers have beneath the vertical face a talus of fallen blocks, due to the more rapid advance of the upper part of the ice, and the authors show that the upper ice moves over the talus, which becomes incorporated in the lower part of the glacier; this movement, owing to thrusting action, produces planes of discontinuity, and so "the glacier advances by an 'over-rolling' motion, the top layer falling to the bottom, and then working upward over other fallen masses." They further note that though the lower part of the Booming Glacier is advancing, it is diminishing near its source, "apparently owing to a diminution of the snowfall at its head." Now the upper surface of this glacier is saucer-shaped, having a concave cross-section in place of the normal convex one, and the authors believe that this shape is due to subsidence, "owing to the melting and solution of the lower layers of the ice."

Many of the Spitsbergen glaciers reach the sea and give rise to icebergs, as for instance King's Bay Glacier, represented in the frontispiece, from a photograph by Mr. Garwood. The origin of these icebergs will be considered when we discuss the nature of the Greenland ice-cap.

Messrs. Garwood and Gregory also notice the effect of marine ice as an agent of denudation. The effect of land ice in this connection will be considered in the next chapter, but it may be remarked here that as a means of polishing and striating rocks, the authors saw no means of dis- 
criminating between the effects of glaciers and those of floating ice.

Baron Nordenskjöld describes some remarkable features on the inland ice of North East Land, which are termed glacier-canals. They have a depth of forty feet in places, a breadth of from 30 to IOO feet, and mostly run parallel to one another, with an interval of 300 feet only between adjoining canals in places. The walls are very straight and steep. Nordenskjöld suggests that they are produced by faulting of the ice, due to alternate contraction and expansion of the ice owing to changes of temperature. ${ }^{1}$

Alaska.-Some of the Alaskan glaciers are of the piedmont type, and have been described by Messrs. I. C. Russell and H. P. Cushing. ${ }^{2}$ The Muir Glacier, described by Cushing, lies east of Mount Fairweather, and ends in the Muir Inlet of the Pacific Ocean. It lies in an amphitheatre, partly surrounded by a semicircle of mountains, from which icy tributary glaciers of the Alpine type pour, and give rise to a great mass of nearly inert ice-the piedmont glacierhaving a breadth of from twelve to over fifteen miles. As it approaches the inlet it is narrowed, and the ice is forced through a gap less than three miles wide. The inert ice is slowly rotting where it lies, and is extremely smooth. Some of the tributaries are also inert; for instance, the Dirt Glacier, the lower part of which is completely covered with débris. Two valleys, namely, Main Valley and Berg Valley,

I The Arctic Voyages of Adolf Erik Nordenskjold, 1858-1879; London, 1879, p. 258, and figure on p. 259.

2 Russell, I. C., Thirteenth Annual Report of the U.S. Geological Survey, and Cushing, H. P., American Ceologist, 1891. 
contain ice in an extremely remarkable state, perhaps. foreshadowed by the upper part of Booming Glacier in Spitsbergen. The glaciers occupying these valleys are retreating at the heads instead of at the snouts of the ice, the ice of Main Valley terminating abruptly, and holding up the waters of a lake which occupies the head of the valley (as noticed in Chapter XI.), though Mount Young, the highest mountain in the immediate vicinity, dominates the valley head. Similarly the glacier in Berg Valley holds up the waters of Berg Lake. The medial moraines of these glaciers stretch right up to the ice-cliffs overlooking the lakes, and there is therefore no doubt that the ice once extended upwards and has retreated from the valley heads.

The Malaspina Glacier, described by Russell, is also a piedmont glacier, supplied by tributaries descending from the Mount St. Elias range. The average length of the glacier is from twenty to twenty-five miles, but it has a breadth of about seventy miles and an approximate area of 1500 square miles. It consists of a nearly horizontal plateau of ice, the central portion being free from moraines and deeply crevassed, and having a broadly undulating surface. It possesses three principal lobes, each being a piedmont expansion of a large tributary glacier, and the lobes are separated by medial moraines. Part of the ice reaches the sea and forms icy cliffs, from which bergs break off, but other parts are separated from the ocean by a plain covered by glacio-marine, fluvio-glacial, and glacial deposits, occupied by dense forests, and pitted with morainic lakes.

The end of the Malaspina Glacier is largely covered 
with débris, due to spreading of morainic material in the way previously described, and also to ablation. Some parts of this moraine-covered portion of the glacier are clothed with dense forests and undergrowth of alder, spruce, huckleberry, ferns, etc. It is only on the inert or stagnant ice that these forests grow. They extend in places to a distance of four to five miles from the edge of the ice, and in many places the ice below them is not less than 1000 feet thick.

The inert, and partly inert ice of this glacier is drained by an extensive system of englacial rivers, forming caverns in the ice, which sometimes become choked with débris, an occurrence of considerable importance to the geologist. As the ice melts on the surface, portions of these caverns may be exposed, while intermediate portions are still arched over, showing tunnels of ice.

Mr. Garwood has subsequently observed these englacial rivers on the ice of Spitsbergen, and I am able to give a reproduction of a photograph of one of these in the accompanying plate.

It is interesting to notice that since glaciation commenced in the region, earth movement, accompanied by faulting, has occurred to such an extent as to raise portions of the glacio-marine deposits to a height of over 2000 feet above sea-level. These elevated parts (the Chaix Hills) projecting through the ice, furnish admirable illustrations of the typical mountain forms produced by the erosion of running water.

Greenland.-The great surface of inland ice of Greenland, long known in a general way, has been more carefully studied of recent years by Torell, 
Nordenskjöld, Nansen, Chamberlain, Peary, and Drygalski, among others; but a systematic exploration has been undertaken by a Danish Commission, and the results published in a valuable series of reports, entitled Meddelelser om Grönland, from which most of the following account is abstracted.

The inland ice or ice-cap of Greenland is estimated to occupy an area of about 20,000 square miles. It appears to form a gently sloping plateau, the inclination of which, away from the coast, seldom exceeds $I^{\circ}$ for any distance, so that the surface usually appears as a plain, as is well shown by Dr. Nansen's transverse section, drawn to true scale between Umivik and Ameralik Fjords. (See plate at end of volume ii. of The First Crossing of Greenland.)

As is well known, no rocky "divide" marks the centre of the country along the line of traverse taken by Nansen; on the contrary, nothing but snow and ice was seen after leaving the rocks of one coast until those of the other were sighted, and the extreme purity of the surface of the ice in other places where it has been explored leads one to suppose that a rocky "divide" is absent elsewhere. Next to extent of ice, the absence of superficial morainic material on the Greenland ice (save under exceptional circumstances to be noted presently) forms the great contrast between it and that of the glaciers of a country like Switzerland. The surface of the ice is also in many places free from crevasses for considerable distances, and accordingly the superficial rivers of the Greenland inland ice often attain a great size and volume, and when they do form moulins these are of exceptional magnificence. Here is a 


\section{SCIENTIFIC STUDY OF SCENERY}

description of this superficial drainage from Baron Nordenskjöld's pen. ${ }^{1}$

"At a short distance from our turning-point we came to a large, deep, and broad river flowing rapidly between its blue banks of ice, which here were not discoloured by any gravel, and which could not be crossed without a bridge. As it cut off our return, we were at first somewhat disconcerted; but we soon concluded that . . . it must at no great distance disappear under the ice. We therefore proceeded along its bank in the direction of the current; and before long a distant roar indicated that our conjecture was right. The whole immense mass of water here rushed down a perpendicular cleft into the depths below. We observed another smaller, but nevertheless very remarkable waterfall the next day. . . . We saw, in fact, a pillar of watery vapour rising from the ice at some distance from our resting-place, and, as the spot was not far out of our way, we steered our course by it in the hope of findingjudging from the height of the misty pillar-a waterfall still greater than that just described. We were mistaken; only a smaller yet tolerably large river rushed down from the azure-blue cliffs to a depth from which no splashes rebounded to the mouth of the fall ; but there arose instead, from another smaller hole in the ice, in the immediate vicinity, an intermediate jet of water mixed with air, which, carried hither and thither by the wind, wetted the surrounding ice-cliffs with its spray. We had thus here, in the midst of the desert of inland-ice, a fountain, as far as we could judge by the descriptions, very like the geysers which in Iceland are produced by volcanic heat."

On this expedition Nordenskjöld discovered a dust of volcanic material on the surface of the ice, accompanied by a brown polycellular alga and other

1 Nordenskjöld, A. E., loc. cit., p. 167. 
microscopic organisms. The powder, which he called kryokonite, and the accompanying organisms form "a most dangerous enemy to the mass of ice," owing to the part which they play on the surface-melting. "This plant (the alga) has no doubt played the same part in our country; and we have it to thank, perhaps, that the deserts of ice which formerly covered the whole of Northern Europe and America have now given place to shady woods and undulating cornfields."

Towards the coast the mountains gradually appear above the ice, first as islets of rock (nunataks) projecting through the icy surface, lastly as continuous ridges separating the fjords, into which the ice is finally discharged, as tongues which become greatly fissured, broken up, and finally carried away as icebergs. The ice towards its termination is often fairly steep, though even then usually gently inclined as compared with the surfaces of many Swiss glaciers. In the region of nunataks the surface of the ice is much fissured by transverse and longitudinal crevasses, depending, like the crevasses of Swiss glaciers, on inequalities of the bed of the ice; and where the ice can move in fan-shape, as in the case of the tongue known as the Frederikshaab Glacier, the crevasses are radial and tangential. Many very striking coloured illustrations of the Greenland crevasses are given in various numbers of the Meddelelser.

Of the various nunataks which have been described the most interesting are those of Jensen, situated about forty-five miles inland, to the east of the Frederikshaab Glacier. They form the summits of mountains having a height of about 5000 feet above 


\section{SCIENTIFIC STUDY OF SCENERY}

sea-level, and as the ice here is nearly as high, only the summits project. It is of interest to note that even these isolated pinnacles are partly clothed with a characteristic arctic vegetation, twenty-six species of plants having been found upon them, including Oxyria renformis, Saxifraga oppositifolia. S. cernua, S. nivalis, Papaver nudicaule, Draba alpina, Silene acaulis, Cerastium alpinum var. lanatum, and Potentilla nivea.

The ice is piled up on the inland side of the nunataks, like water on the higher side of a stone projecting above a river-surface, and a current of ice sweeps round each side of the rocky barrier, sometimes leaving a hollow below the barrier, which becomes filled with water, giving rise to a lake. Small tongues of ice are forced through the passes or cols between adjacent nunataks, and end on the ice below. At the junction moraines are found, often showing a crescentic outline (as well seen in the nunataks of Dalager, not far from those of Jensen, but nearer the coast). These moraines are of interest on account of the general freedom of the Greenland ice from moraine material, but also because their character shows that they are portions of the moraine profonde brought to the surface in exceptional circumstances.

In some of the Greenland ice-masses, as well as in those of Spitsbergen, stratified material is enclosed in the ice, and, owing to the differential movement of the ice, becomes faulted and also folded in a remarkable way, sometimes recalling the bands of an agate, as shown at the termination of the Njarartorsuak glacier in the fjord of Umanak, figured in Plate III. of the Fourth Part of the Meddelelser. 
Where the Greenland ice does not reach the sea, but terminates on low ground, the country between it and the sea often consists of a plain of fluvio-glacial deposits, presenting an extremely dreary aspect, a remark which may also be made of similarly formed plains in Spitsbergen. At other times the plains are due to accumulation of glacio-marine deposits, as, for instance, a portion of that traversed by Nansen at the head of the Ameralik Fjord after he had descended from the inland ice at the conclusion of his adventurous journey across Greenland.

We may here discuss the mode of formation of icebergs, which break off glaciers in many places where the latter reach the sea, as off parts of the Malaspina Glacier, off many of the Spitsbergen glaciers, as shown in Garwood's photograph of King's Bay Glacier (see frontispiece), and especially off the tongues of ice which project into the Greenland fjords.

It is now unquestionable that the fracture of the ice to form icebergs does not always take place owing to the same causes. In some cases, when the glaciers are terminated by a vertical face, fracture of the emerged part of the ice occurs, and gives rise to small icebergs, which fall with a splash into the water. In other cases, however, as in the ice of Jacobshavn Fjord, owing to the buoyancy of the ice, the ice of the central parts of the glacier floats on the water, and gradually becomes broken up along lines of crevasses, giving rise to a great quantity of icebergs. Some of the bergs of Jacobshavn Fjord were measured by Hammer. The highest was about 350 feet above sea-level, or more than I 50 feet higher than the upper edge of the glacier where it reaches the sea. Others were about half this height. 


\section{SCIENTIFIC STUDY OF SCENERY}

It is well known that when the berg is in a state of stable equilibrium, by far the greater part of its mass is below the level of the water. The proportion of the submerged part to that above sea-level differs according to the nature of the water, whether it is salt or fresh, and according also to the character of the ice. The proportion of emerged and submerged ice in the case of frozen sea-water floating in seawater, is about $1: 5.3$, but that of glacier-ice in sea-water is approximately $1: 9$. Accordingly icebergs may easily be stranded on shoals, even where the water is of some depth, hence the mass of icebergs which are often found stranded on the banks of Newfoundland, and on the shoal water which exists between the east coast of Greenland and Iceland.

The submerged parts of bergs melt much more rapidly than the emerged portions, and accordingly icebergs frequently capsize after the submerged part has been considerably melted. As the melting often takes place in an apparently capricious manner, this partly accounts for the fantastic forms which are often assumed by icebergs.

Huge as are the icebergs produced by the 'calving' of the Greenland ice-tongues, they are far exceeded in size by the great tabular icebergs which are shed from the almost unknown ice-cap of the Antarctic regions, one of which has been recorded with a circumference of two miles.

We may conclude this chapter with a few remarks upon the colour of snow and ice. The white appearance of snow, and of rough ice, is due to reflection of the sun from innumerable surfaces, and pure transparent ice, like water, is blue, as seen in the crevasses and moulins of glaciers, where the ice is in 
a state of purity, and is not broken up. The surface of snow and ice is often grey, owing to accumulation of dirt, which naturally increases in amount as evaporation or melting progresses. In some cases ice has a green tint, as described by Forbes in the case of the crevasses of the névé of the Viesch Glacier, and Garwood informs me that the crevasses of some of the icebergs of the Spitsbergen seas also exhibit a green hue, which must be due to some unexplained condition of the ice. Lastly, there is the red snow, due to the occurrence of an alga (Protococcus nivalis) upon the surface of the snow. This often colours extensive tracts of snow, and is especially noticeable when fresh snow has fallen over the coloured snow, and anyone treads through the new snow and exposes the coloured snow beneath, giving rise to the appearance of flesh-coloured footprints upon the white surface. 


\section{CHAPTER XVIII.}

\section{THE SIGNS OF FORMER GLACIATION}

NE cannot learn much of a watch by an inspection of its outer case, and similarly the work of existing glaciers is, to a large extent, concealed by the mass of ice beneath which much of the work is being carried on. I have, therefore, left the consideration of the products of erosion of ice, and of many of the effects produced by deposition and accumlation due to ice, to be taken up when we proceed to an examination of areas once occupied by ice, from which the ice has receded. It is true that many of the effects which we now have to consider may be noted at the termination of Alpine glaciers; but as they can also be observed, often on a more imposing scale, in regions more easily accessible to us than that of the glaciers of Switzerland, and especially than those of the ice-sheets of Spitsbergen and of the inland ice of Greenland, it is convenient to call attention to them when describing the results of glaciation in regions from which the ice has long since vanished.

The occurrence of an Ice Age, or Glacial Period, in times which are geologically recent is so well known, that it needs no further reference here save to remark that, owing to its recency, our country and other glaciated areas had already acquired physical 
features differing in no essential respect from those which they possess at the present day; and accordingly the influence of ice has been of minor importance from a scenic point of view, merely modifying here and there the main scenic features of an area which have been produced owing to the operation of other agents.

Signs of vanished glaciers in Britain were first detected by Agassiz before the middle of the present century, and his conclusions were afterwards verified by Dean Buckland. These signs may be considered under two heads, namely, features due to erosion, and those due to accumulation.

Glacial Erosion.-The signs of glacial erosion are very characteristic, and, in ordinary circumstances, readily recognisable. It is, however, even now a subject of dispute as to whether ice is or is not a very potent factor in producing erosion; and although it is easy to point to evidences of the erosive action of ice, no example can be cited which would be indisputably regarded as one of glacial erosion on a very extensive scale.

The main results of glacial erosion are the rounding, smoothing, polishing, and striation of pre-existing rough surfaces. These results are due to the passage of ice charged with rock fragments of various sizes, from large boulders down to the finest particles of dust, over its rocky bed. Owing to the great pressure, the rocks of the bed become ground down and smoothed, and if capable of receiving a polish, the fine particles of matter carried by the ice act like emery-powder, and produce a more or less polished surface. The angular grains of quartz score fine striations on the rock-face, and owing to the pressure 


\section{I2 SCIENTIFIC STUDY OF SCENERY}

and steady advance of the ice these striæ are usually of great regularity, many of them frequently running parallel to one another, and each being straight, as though formed with a ruler. Larger fragments of rock produce larger grooves, sometimes several inches in depth and width.

When a mass of rock projects above the surrounding ground, the ice of a glacier is pressed against the side facing the direction from which the ice comes, and this side undergoes the rounding and smoothing processes. The other side is protected, to some extent, from the action of the ice by the actual mass of rock, and the ice passes over it without rounding or smoothing it. This immunity from erosion may be increased by the accumulation of fragments broken from the other side, on the lee side, and these may act as a cushion protecting the rock beneath from the action of the ice. Furthermore, as Mr. P. F. Kendall has pointed out, the ice on the lee side tends to tear away fragments of rock from the parent mass, owing to the existence of divisional planes, as planes of stratification and cleavage, and especially of jointing, in the rock. Accordingly a projecting rock, after being acted on by a valley glacier, will be rounded and smoothed on the side facing the head of the valley, and rough and fractured on the side facing the lower end of the valley, as shown in the accompanying diagram, in which the dotted line indicates the original irregular rocky mass, and the continuous line the outline which results from glacial erosion. (Fig. 39.) Rocks which have been subjected to glacial erosion, and have assumed this appearance, are known as roches moutonnées, and show the most characteristic effects of 
glacial erosion. The upland valleys of the hilly districts of our own country-of Cambria, Cumbria, and the highlands of Scotland, for example-show these roches moutonnées in a very striking manner, and the experienced eye looking down the valley will readily note the contrast between the smoothed and rounded rocks of the valley floor, and lower parts of of the valley sides, and the jagged, frost-riven rocks of the intervening ridges and upper portions of the valley sides; so that there is no difficulty in ascertaining the height to which the ice extended in the

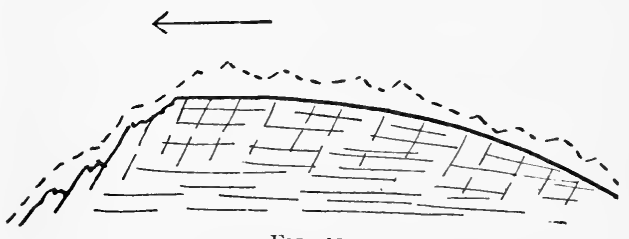

FIG. 39.

case of a valley in which the effects of glaciation have not been removed by subsequent denudation by streams and atmospheric agents. It follows from what has been said concerning the nature of roches moutonnées, that this contrast will not be marked by one looking $u p$ the valley, who is confronted with the rough lee sides of the same roches moutonnées. The nature of these ice-worn rocks will be seen in many of the figures illustrating an article originally written for Peaks, Passes, and Glaciers, by the late Sir Andrew Ramsay, and subsequently published separately under the title of The Old Glaciers of Switzerland and North Wales, where also the other effects of glacier action are admirably described. 


\section{I4 SCIENTIFIC STUDY OF SCENERY}

The tearing action noticed on a small scale at the lower ends of roches moutonnées appears to be produced on a much larger scale in the case of soft rocks, huge fragments of these being torn from the bed of the ice and transported for some distance, and in this way irregular hollows of considerable size may be formed.

Though the power of ice as an erosive agent has, as above remarked, been variously estimated, there is no doubt that the valley glaciers which once occupied our upland regions did little more than round off the minor irregularities of the original rocky surface. Pre-glacial escarpments may be often seen, as, for instance, in the beautiful little valley of $\mathrm{Cwm}$ Glas, on the side of Snowdon, and on the plateau in which Sprinkling Tarn nestles on the north side of Scawfell, where the original shape of the cliff formed by weather and stream-action is distinctly preserved, and the action of the ice has been merely that of sand-paper, rounding off the edges of the pre-existing cliffs.

Insignificant as the action of ice has been in many places in directly producing erosion, the indirect influence due to the large volume of water which escapes from the glaciers, and especially the angular nature of the material with which the water is charged, must not be overlooked. Daubrée called attention to the angular nature of the grains of sand with which glacier-streams are charged. This must materially increase the corrasive action of the glacierstreams, and it is no doubt owing to it, as suggested in the eleventh chapter, that those narrow, tortuous gorges known as "roflas" are so frequently formed by the streams of glacier regions.

Another interesting result of water-erosion in a 
district occupied by glaciers is the "giant's kettle," which resembles a pothole produced by a river, but is often on a larger scale, and is frequently found in spots where ordinary river potholes are not formed. The giant's kettle is formed at the base of a moulin, and is the continuation downward into the rock of the shaft penetrating the ice. It is produced by the gyration of stones carried down the moulin by the glacier-stream, and owing to the height of the fall these giants' kettles are often of great depth. The well-known glacier garden of Lucerne exhibits them in great perfection, and instances are not unknown in our own country, though they are often partly destroyed by subsequent denudation, and still more frequently filled up, partly by the stones which caused their formation, more particularly, however, by the material which has been subsequently introduced.

Glacial Accumulations and Deposits.-The accumulations and deposits which are due to ice are often of very considerable importance, on account of the effect which they produce on the scenery of a district. The upland valleys of our own country are often marked by the moraines which have been left behind on the retreat of the ice, in the way described in a previous chapter. The lateral moraines are naturally cut up, to some extent, by the streams which flow down the hill-sides, but the terminal moraines are frequently seen, often presenting the characteristic crescentic outlines, and consisting of hummocks composed of incoherent sand, gravel, and boulders, usually covered with vegetation. Special mention may be made of the moraine by the side of Llyn Llydaw, on Snowdon, of some extensive moraines in Greenup Gill and in the Rosthwaite alluvial flat in 


\section{SCIENTIFIC STUDY OF SCENERY}

Borrowdale, Cumberland, and more particularly of a moraine occurring beneath a crag, called Wolf Crag, on the northern slope of the Helvellyn range, which was formed by a small corrie-glacier. This moraine, which was noticed by the late Mr. Clifton Ward, is the most perfect moraine which the writer has seen in this country, and it is well worth a visit by those who are interested in glacial action. Along the summit of it runs the old hill-road from Patterdale to Keswick, and it may easily be reached from the latter place.

It has been noted in another chapter that morainelike accumulations may be formed at the foot of a corrie by the sliding of material down snow-slopes, and that moraines may be, to some extent, simulated in other ways.

Another very interesting effect of glaciation is the deposit of isolated blocks of rock, often of large size, on the summits and sides of prominent elevations. As the ice gradually recedes these blocks are left stranded in places where they could not have rested unless gently deposited. They are known as perched blocks, and produce a very marked effect upon the scenery of some valleys. They are especially noticeable in the Pass of Llanberis, and it is somewhat remarkable, as pointed out by Ward, that they are comparatively rare in the Lake District. Many of them occur, however, around Scawfell, especially on the plateau below Great End.

Away from the regions formerly occupied by valley glaciers we find extensive accumulations of glacial origin, known as boulder-clay or till. This boulderclay usually consists of a clayey or sometimes of a sandy matrix charged with angular and subangular 
fragments (the latter often striated) of various sizes, and the accumulation usually shows no signs of stratification. Some of it is undoubtedly the result of the melting of inland ice, and the deposit of the material carried beneath, within, and in some cases above the ice, upon the ground formerly occupied by that ice. In other cases it may be a glacio-marine deposit. Occasionally it has been laid down as ridges, locally known as drumlins, but it often forms an extensive deposit, the upper part of which is roughly parallel to the original surface of the ground, though minor inequalities are often concealed owing to excessive accumulation of material within them, and on account of this, as previously shown, extensive changes in the direction of our river-drainages have been brought about, and lakes have also been produced in many cases.

On account of the character of the boulder-clay, it frequently illustrates the nature of water-erosion, occurring subsequently to its formation, in a very marked manner. This is beautifully shown along the Yorkshire coast, especially when boulder-clay rests upon the chalk. The chalk has been worn away along dominant planes of stratification and jointing, but the more homogeneous boulder-clay above has been carved into little hills and ridges, showing the characteristic curves of water-erosion, and the ridges are so sharp that they imitate on a small scale the arêtes of an alpine region.

The existence of ridges of incoherent material which. has been accumulated upon the original surface, is very frequent in a region which has been subjected to former glaciation. Two kinds of ridges have already been noted, namely, the moraine and 


\section{I8 SCIENTIFIC STUDY OF SCENERY}

the drumlin. Other ridges consist of stratified deposits of sand and gravel, and are spoken of variously as kames, eskers, and assar, and to these we must now direct our attention. The terms kame and esker have been applied somewhat loosely to various kinds of ridges of stratified material, some of which are almost certainly of fluviatile origin, formed as ridges between two adjacent rivers, often, no doubt, emanating from a retreating ice-mass. Others, however, cannot be explained in this way, and though an attempt has been made to show that they are of marine origin, all the evidence is against this mode of their formation. Eskers of this nature are specially well-developed in the central plain of Ireland, and they resemble in all respects except size the asar of Scandinavia. They frequently ramify, and the tributary eskers join the main ones as the tributaries of a river join the main stream. Again, they often show the tortuous course of a river, sometimes possessing actual loops. The steep inclination of their sides, the general slope of the strata at the sides in a direction parallel to the surface of the ridge, and the frequent existence of erratic blocks of glacial character on their summits and sides, forbids the supposition that they were produced by ordinary rivers, and suggests formation by rivers which were confined at the sides by steep walls which have since disappeared. Again, they frequently run across irregularities of the ground, sometimes actually traversing the present valleys at right angles to their general directions, and passing over the intervening ridges which separate the valleys. For these and other reasons Hummel maintained that they were the result of accumulation 
in englacial streams, and Professor Sollas has subsequently applied this view to account for the principal eskers of the central plain of Ireland, ${ }^{1}$ and it is certainly supported by the recent examination of the Malaspina glacier, which induced Russell to adopt the same explanation, which, indeed, accounts for all the peculiarities of eskerformation and distribution.

The filling of hollows by boulder-clay is a potent factor in giving rise to a plain surface, as the result of the spread of boulder-clay over a pre-existing irregular surface; and the deposit of fluvio-glacial materials forms a still more pronounced plain. Reference has already been made to plains formed in this manner in extra-British territories, but it is a moot point how far some of our flats have been produced by levelling of irregular surfaces by fluvio-glacial deposit as opposed to true glacial deposits, whether terrestrial or marine. There is no doubt that some of the minor flats of an upland region owe their character to the accumulation of fluvioglacial deposit, but the late Professor Carvill Lewis maintained that much of the boulder-clay of the Eastern and Midland Counties of England was also of fluvio-glacial origin, a view which, though not generally accepted, has by no means been disproved.

One other possible result of glaciation may be noted. It is well known that many plants which are found in alpine regions are still found lingering in the upland regions of Britain. Among them may be mentioned Saxifraga oppositifolia, Gentiana verna, G. nivalis, Silene acaulis, and Lloydia serotina. Anyone who has seen the first-mentioned plant on the

1 Sollas, W. J., sci. Trans. R'oy. Dublin Soc., ser. 2, vol. v., p. 786. 


\section{SCIENTIFIC STUDY OF SCENERY}

rocks of some of the recesses of Snowdonia, occurring in great patches, with its reddish-purple flowers spread over a considerable space in the early spring, or who has seen the blossoms of the spring gentian, with their exquisite blue colour, lighting up the slopes of Teesdale, will admit that these flowers produce a distinct effect upon the scene. It has been maintained that these plants were distributed through the intervening lowlands during the cold of the Ice Age, and that on the amelioration of the climate they disappeared from the lowlands, but lingered on in the uplands. This explanation has, perhaps, not been completely proved to be the true one, but it may be mentioned as a possible cause of the existence in Britain of a group of plants which exercises a strange fascination on the mind of the botanist and of the lover of mountain scenery. 


\section{CHAPTER XIX.}

\section{THE OCEANS}

$\triangle$ PART from the play of colour upon the surface $A$ of the ocean, and the variety presented by the appearance of that surface, at one time glassy calm, at another ruffled by the wind, or churned into foam or spin-drift by the tempest, the effect of the present oceans in influencing scenery is confined to the coastlines which form the ocean margins, and to these we shall have to direct our attention more particularly.

Still water has comparatively little effect in changing the character of the surrounding land. A little chemical solution of rocks no doubt takes place, but it is a change which may be neglected for our present purposes, and we must devote attention to the changes which result from the ocean movements. These movements are of three kinds, namely, waves, tides, and 'currents, and each plays its part in modifying the scenery of the earth's surface, waves being specially effective as agents of erosion, while tides and currents play the chief part in transporting material which has already been eroded.

It is of importance to our inquiry that we should obtain some notion of the true nature of a wave, and a few words must, therefore, be here devoted to this topic. A wave has been defined as "a system of movements in which the several particles move to 


\section{SCIENTIFIC STUDY OF SCENERY}

and fro, or round and round, about definite points, in such a manner as to produce the continued onward transmission of a condition or series of conditions." The reader will notice that the condition or conditions are transmitted and not the particles. This is well illustrated when the wind is blowing over a hayfield or cornfield. The onward movement of the waves is clearly seen, but it is equally clear that the particles composing the blades of grass or corn do not move on with the waves, each one returning to its place after a wave has passed. Again, a cork floating on the sea bobs up and down as the wave passes, but there is no onward movement of the cork, if it be floating where the water is deep some distance from the land. As a matter of fact the cork does not merely bob up and down, it describes a circle, and a similar circle is described by a particle of water on the surface during the passage of a wave. A complete wave consists of a trough in front and an arch behind, and a wave-length is the distance from the crest of one arch to the crest of a succeeding one, or from any point on one wave to that point on the adjoining one which is moving in the same manner, while the amplitude of the wave is the vertical distance from the level of the wave crest to that of the wave trough. Supposing a particle to be situated in the centre of the front slope of an advancing arch of the wave. This particle moves forward through a quadrant of a circle till it is situated on the summit of the crest, it then moves backward.through another quadrant, until situated in the centre of the hinder slope of the advancing arch, still backward through another quadrant, until at the bottom of the trough of the succeeding wave, 
and then forward through a fourth quadrant, which places it in the centre of the forward slope of the advancing arch of this wave; it has now moved through a circle and reached its initial position.

Ordinary sea-waves are produced by wind blowing on the surface, and owing to the friction the water is thrown into a series of undulations, which may travel onwards beyond the area in which they were produced, with ever diminishing intensity; they are then known as ground-swell. Tidal waves, due to the action of the sun and moon, differ from windwaves in their length, which is enormous as compared with their amplitude, and accordingly particles are moved in flattened ellipses, and considerable forward and backward movements of bodies of water occur as tidal currents. When a tidal wave enters a narrow estuary the arch of the wave is forced forward upon the trough, giving rise to a bore or ægre, which breaks upon the shore of the estuary, and accordingly exercises effects comparable with those of wind-waves, which will be presently discussed. These bores are well known in many parts of the world, the best known being those of the Bay of Fundy in Nova Scotia, the Hooghly in north-western India, and the Severn in our own country. When the tidal wave, thus influenced by the shape of the coast, attains different heights in two adjacent tracts of water united by narrow straits, the difference of level is atoned for by a current flowing through the straits from the higher to the lower tract of water as a race. As the tract which has the highest tide has also the lowest, the direction of the race is reversed with change of tide. The eddies produced along the coasts in a race give rise to whirlpools like the well- 
known Maelström, and when the race is moving against a wind the resultant waves are of exceptional size and violence.

Ocean currents are produced in various ways. Some, as already stated, are due to differences in the height of the tide in adjoining areas. Others are marked by differences of saltness of adjoining tracts of water depending upon greater evaporation in one place than another, as in the case of the surface current flowing to the more saline waters of the Mediterranean from the less salt Atlantic Ocean, through the Straits of Gibraltar, or upon slight evaporation which cannot remove the excessive amount of fresh water poured in by rivers, as in the case of the surface current which flows out of the fresher Baltic to the more saline North Sea. The principal oceanic currents which flow upon the surface are, as is now generally agreed, due to surface winds. A temporary wind produces a temporary current, a periodical wind a periodical current, and a permanent wind a permanent current. All of these currents are important as transporting agents, which carry denuded material from one place to another.

Having briefly considered the nature of the principal agents of marine denudation, we may now turn to an examination of their effects. The principal work is the destruction of coast-lines and the removal of this material (as well as of that which is produced by the agents of subaerial denudation) to other places, where it is deposited.

The most effective agents in denuding the coastline are the waves of the sea. It has been seen that in the open ocean the effect of a wave is to give a particle a circular motion and to restore it to its 
original position when the wave has passed. As the wave reaches shallow water the lower part of the wave is retarded by friction against the bottom and the upper part moves over it, so that we find actual onward translation of particles of a wave, whether an ordinary wind-wave or one which belongs to the ground-swell, and the upper part is often carried forward until it breaks at the crest, causing a "breaker." Any solid matter suspended in the water, as a grain of sand or a pebble, likewise acquires this motion of translation, becoming hurled forward, and it is on account of these fragments of rock being hurled against the coast-lines that much of the waste of the coast is produced.

One often hears persons speaking glibly of waves running "mountains high," but, as a matter of fact, the greatest height attained by wind-waves does not appear to exceed fifty feet in the open ocean, though when the waves break masses of foam and splashes of water are frequently carried to heights of over IOO feet. "During north-westerly gales the windows of the Dunnet Head lighthouse, at a height of upwards of 300 feet above high-water mark, are said to be sometimes broken by stones swept up the cliffs by the sheets of sea-water which then deluge the building." 1

It is also important for us to have some idea of the depth below the general surface of the water to which the influence of these sea-waves extends. The reason why this is important will appear in the sequel, in the meantime it may be stated that the wind-wave is a superficial phenomenon. Although there is evidence of gentle movement being. produced

${ }^{1}$ Geikie, Sir A., Text Book of Geology, 3rd edition, p. 437. 
by waves to a depth of over 600 feet, the distance below the surface at which waves can produce appreciably erosive effect on hard rock is probably very much less than this, and various statements made by engineers seem to indicate that at a depth of considerably less than 100 feet the erosive effect of waves is practically unimportant.

The force of the waves has also been calculated in many cases. "A single roller of the ground-swell, twenty feet high, falls, according to Mr. Scott Russell, with a pressure of about a ton on every square foot. Mr. Thomas Stevenson conducted some years ago a series of experiments on the force of the breakers on the Atlantic and North Sea coasts of Britain. The average force in summer was found in the Atlantic to be 6 I I lbs. per square foot, while in the winter it was $2086 \mathrm{lbs}$, or more than three times as great. On several occasions, both in the Atlantic and North Sea, the winter breakers were found to exert a pressure of three tons per square foot, and at Dunbar as much as three tons and a half." 1

In considering the effect of waves, the influence of the comparatively rare, but exceptionally large, earthquake waves which sometimes break upon coasts must not be forgotten. They no doubt largely assist the work of erosion in regions subject to earthquakes.

That waves hurled against the coast-line with the force which has been indicated above must produce great destruction is obvious. Nevertheless, the destruction is largely due, not to the water itself, but to the solid matter which is held up by the

1 Gelkie, Sir A., loc. cit. 
water. This solid matter, which normally forms a beach, is not always present; the mode of its arrangement as beach-material will, be considered eventually. Where it is absent, as, for instance, where the sea coast plunges suddenly down into deep water, comparatively little erosion by wave action may be produced.

An ideal uplift, as has been observed, would consist of a tract of land having a convex surface sloping from the centre seaward, and the curve would be continued below sea-level; there would be

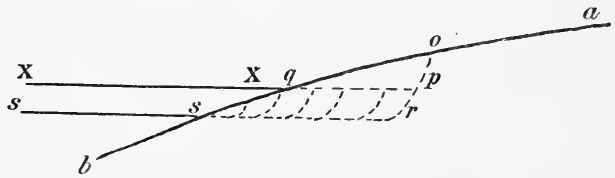

Fig. 40.

no sea-cliff. In Fig. $40,{ }^{1}$ let the line $a b$ represent part of such a land, $s$ being sea-level, and $\mathrm{X} X$ the height above which the waves could not act. The waves, charged with sand and pebbles, would gradually wear away the land as shown by the dotted lines, causing the upper part to overhang. (They would also wear away material below sealevel to the depth at which their erosive action became ineffective, but this action we may for the present ignore.) The overhanging portion could not be prolonged indefinitely, and eventually the upper part would fall away, giving rise to landslips. In nature it is usually removed more gradually, for reasons which will presently be stated. When the overhanging part $o p q$ had fallen and been washed

1 The lines X X and $s s$ should be horizontal in the figure. 
away, a sea-cliff, opr, would be produced, and the process would go on as before. If, therefore, the action of the sea-waves alone produced cliffs, we should expect to find a coast-line marked by cliffs, which overhang above the base in places, while in other places, where the material had fallen and been removed, there would be no overhanging. Now an overhanging cliff is comparatively rare, and it is obvious that some other operation or operations besides the action of the waves are concerned with the erosion of coast lines.

A good illustration of an overhanging cliff, undercut at the base by the waves, has recently been furnished by Mr. C. W. Andrews in Christmas Island, an island in the Indian Ocean. "The shore terrace slopes gently down from the foot of the first inland cliff to the sea-cliff, which is from fifty to eighty or more feet high, and is often undercut by the waves to a remarkable extent, so that it sometimes overhangs more than twenty feet." 1

On examining sea-cliffs we soon find that the outline of the cliff is largely determined by the nature and trend of the divisional planes by which the rocks are affected, especially the planes of stratification, and more particularly the joints. When the joints are inclined seawards a cliff is formed sloping towards the sea (Fig. 4I $a$ ), if the joints are vertical, though the cliff will probably not be vertical it will tend to consist of a series of steps, portions of which approach verticality (Fig. 4I b), while if the joints are inclined towards the land portions of the cliff may actually overhang. (Fig. 4I c.)

${ }^{1}$ ANDrews, C. W., Geographical Journal, vol. xiii., No. I (Jan., 1899), p. 24 ; see also illustrations on pp. 23 and 27. 
The dependence of cliff outline upon joints is thus well exhibited. ${ }^{1}$

As the upper parts of these cliffs are frequently above ordinary wave action, it is clear that their outlines at the upper parts are not directly determined by this action, and inspection of the cliffs will show that in many cases subaerial agents are responsible for their backward wear. But in addition to this there is another process which comes into play in the formation of sea-cliffs, to which we must briefly refer. The waves themselves wear away material more easily when affected by divisonal
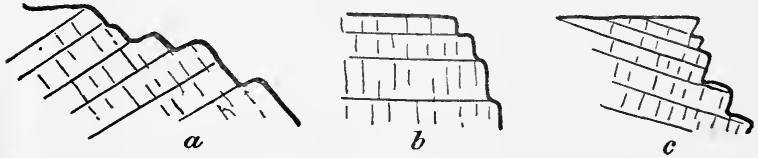

FIG. 4I.

planes than when it is not so affected. Suppose the cliff in Fig. 42 has a plane of stratification or an easily denuded stratum $s$, below high tide level $h h$, and above the level of low tide. The rock will be more easily denuded along this plane of weakness, and a cavern may be worn out, as shown by the shaded portion $c$. Such caves will be specially prone to occur where downward joints, traversing the cliffs vertically, coincide with a stratification plane at the base, and they are very numerous around sea-coasts. If another joint $j$ be encountered after the cave has been worn some distance inward, the erosive action

1 On this subject the reader may well consult an article by Sir A. Geikie on "The Old Man of Hoy," in his Geological Sketches at Home and Abroad, p. 26. 


\section{SCIENTIFIC STUDY OF SCENERY}

will be facilitated by it, and an upward extension of the cavern will be here formed, as shown by the shaded portion $c^{\prime}$. This may grow upward until it reaches the surface, when during high tide the water will be forced up, and issue on the surface of the cliff some distance away from the edge as a jet of water. This is a blow-hole or puffing-hole, and these blow-holes are often found behind high cliffs, even some way from the edge. Many of them occur

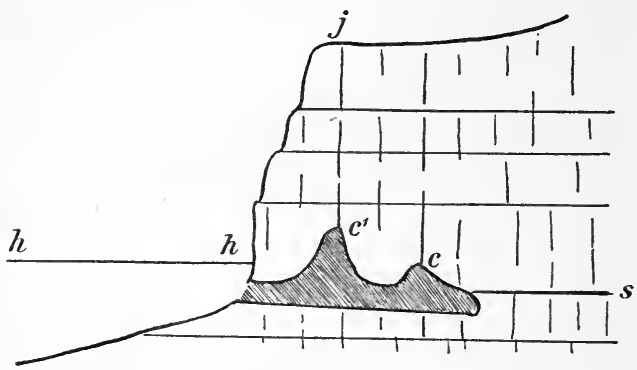

FIG. 42.

round the Irish coast, as indicated in the following description given by the late Professor J. B. Jukes in his Manual of Geology:-

"At the promontory of Loop Head, Mr. Marcus Keane has observed that considerable blocks of rock have been blown into the air on the formation of one of these puffing-holes, and that large holes, opening down into cavernous gullies, lead from one cove to another, behind bold headlands of over a hundred feet in height, showing how the land is undermined by the sea, and headlands gradually made into islands. One such square precipitous 
island, which is now at least twenty yards from the mainland, was said by the farmer who held the ground to have been accessible by a twelve-foot plank when he was a boy. Mr. W. L. Wilson, late of the Geological Survey of Ireland, found in the far part of the promontory between Bantry and Dunmanus Bays, dark holes in the fields some distance back from the edge of the cliffs, looking down into which the sea might be dimly seen washing backwards and forwards in the narrow caverns below. In County Kerry, Ballybunnion Head is completely undermined by caverns, into which the sea enters from both sides. The whole coast of Clare, and of the Arran Islands, is a succession of precipitous cliffs with vertical faces, the result of the sea acting on the large cuboidal joints that traverse the rocks. The celebrated rocks of Moher in that county, which rise with a perfectly vertical face to heights of more than 600 feet, afford magnificent examples of the way in which the ocean takes advantage of the joint structure to cut back into the land, however lofty or however hard and unyielding it may apparently be."

Much of the erosive action above described is due to the compression of air, when the waves enter the cave at high water. In Fig. 42 the cave $c$ being full of water, when a wave comes in, the water in the part $c^{\prime}$ rises and compresses the air above, and this sudden compression may force off a great mass of rock between the joint $j$ and the face of the cliff.

The dominant joints which run down the face of a cliff facilitate erosion, and determine the formation of the narrow chimneys which often seam the faces of a cliff.

When a mass of rock juts out as a promontory, a cavern may be drilled through this promontory, and on enlargement an arch will be formed. Such 


\section{SCIENTIFIC STUDY OF SCENERY}

arches are frequently found on our coast-lines, as for instance, on the Durham coast, that of the Isle of Wight, and that of Pembrokeshire. If the top of the arch falls in, an isolated "stack" or "needle" is formed, or the same may be due to the cutting through of a promontory along a vertical plane of weakness, without the preliminary formation of the arch. Examples of this are furnished by the Needles of the Isle of Wight, and the more remarkable Eligug Stacks carved out of the mountain limestone of the Pembrokeshire coast.

When the land is composed of soft rocks, subaerial erosion may produce a gentle slope above, just as it does inland, and then the sea-cliff is absent. This is seen in many parts of the east coast of England, which is largely composed of soft rocks. but even these, when devoid of divisional planes and composed of stiff clay, may give rise to cliffs, as in many places where the coast consists of boulderclay.

When the strata dip gently towards the sea, and porous strata rest on impervious, the conditions are favourable for landslips, just as they are inland, and accordingly landslips may and do occur in these circumstances, like that which recently took place at Sandgate, or the more classic one of Axmouth, in Dorsetshire, which produced a very marked effect upon the scenery, owing to the way in which the fallen mass became fissured and displaced.

It has been observed that the denuded material may or may not accumulate at the margin of the land to form beaches. If beaches are formed, their existence for some time facilitates erosion, as they furnish material which may be hurled by the waves 
against the land behind, but if the amount of material which accumulates is excessive, it acts as a breakwater, and retards erosion, instead of facilitating it.

We have now considered the formation of the sea-cliff with its attendant phenomena of chimneys, caverns, blow-holes, arches, stacks and needles, and are in a position to proceed to a consideration of the character of coast-lines as a whole and the way in which they are partly dependent upon the transport of material by the action of currents. In order to do this we must pay some attention to the mode of formation of beaches, which has only been alluded to in very general terms. Two important memoirs upon beaches have appeared, in which the student will find much information concerning their detailed structure, one by Dr. G. K. Gilbert, "On the Topographical Features of Lake Shores," 1 and the other by Mr. Vaughan Cornish, "On Sea Beaches and Sandbanks."

The first point to notice in the formation of a beach is the sorting of the material. It is generally known that the coarse material is mainly deposited near the shore, and the finer out to sea, and the explanation which is usually given to account for this is that the fragments are dropped according to their size and weight. Though this is true, it is by no means the whole truth, and many other causes contribute to the sorting, to some of which reference must be made, though the student should consult Mr. Cornish's paper for full details. When a wave

1 Gilbert, G. K., Fifth Annual Report of the U.S. Geological Survey.

${ }^{2}$ Connish, V., Geographical Journal, vol. xi. (1898), No. 5, p. 528 , and No 6, p. 628 . 


\section{SCIENTIFIC STUDY OF SCENERY}

breaks upon the shore, the forward velocity of the crest of the wave is greater than the backward velocity of the under part. The latter is often spoken of as undertow, though there are really two distinct movements. Now if the velocity of the onshore movement be sufficient to carry forward sand and pebbles, and that of the off-shore movement be sufficient to carry sand and not pebbles, the pebbles will be deposited on the beach, and the sand carried back. Again, when a pebble-beach is formed, much of the water percolates through the pebbles on its way back, and is unable to carry pebbles with it. The sand, kept in suspension for a considerable period by eddies, is often carried some way out, and owing to its inertia is borne for some distance onward, when the current is checked or turned, and settles in sandbanks. All the fragments, whether of pebble, sand, or mud, are moved while raised from the bottom by the eddies which are set up during the passage of waves. With the heavier pebbles, the period of lifting is short, with sand longer, but with mud so long that, according to Mr. Cornish, the mud forms an emulsion in the water, and "the transit of mud down the slope from the shore is not due to the action of gravity," but "the principal factor in determining the well-known direction of mud-transport is the diminution of intensity of bottom agitation from the shallows to the depths."

The cross section of a beach is often very complicated, small beaches being frequently superposed upon the larger ones, but the general profile of a beach as seen in cross-section is a flattened sigmoidal curve.

More important from the scenic point of view than 
the varieties of structure of a beach (which are fully considered in Mr. Cornish's paper) is the wandering of beach-materials along shore, which is determined by currents, whether tidal or due to the prevailing winds. A wind blowing towards the shore, and not at right angles to the direction of the coast, sets up a current which, when it reaches the coast, moves along it, parallel to its direction and in the general direction of the wind which caused it. Owing to this current the beach-material is gradually carried along the shore, and if the coast-outline is comparatively regular, the pebbles are swept along the pre-existing coast-line. When there is a deep indentation, however, the material is carried onward, owing to inertia, and builds up a shingle spit, which may be eventually carried right across a bay and convert it into a lagoon, or may be carried from mainland to island, or vice versa, or both, eventually converting the island into a peninsula, as has happened in the case of the Isle of Portland, which is now connected with the mainland by the Chesil Beach.

It will be seen, therefore, that if conditions remain uniform the tendency of the onward travel of shingle is to simplify coast-lines by obliteration of the indentations of the coast, which will usually be found on examination to owe their existence to subaerial denudation followed by depression.

Inspection of a map of many areas shows the frequent tendency of the coast-line to assume the form of a series of concave curves or bays, separated from one another by headlands or salient points, which are often, though by no means universally, formed by the meeting of two concave curves. If we 


\section{SCIENTIFIC STUDY OF SCENERY}

examine a map of England, we shall find these concave curves on a large scale, usually modified by the existence of minor bays along the line of each larger one. An examination of the geological structure of the country points to the conclusion that the larger bays were formed when the area was at a different level to that at which it now is, but this is a point which cannot be discussed here. The concave curve of the minor bays is that which produces so very marked an influence upon the scenery of many seaside localities, and we may briefly consider the cause of these concave curves, which are characteristic of lake-shores, as shown by Gilbert, as well as of those of the ocean.

The primary cause of alternating embayments and salient points is to be sought for by an examination of the geological structure of the region adjoining the coast-line. It is usually found that the dominant headlands or salient points owe their existence to resistance of the rocks of which they are composed to the agents of erosion, while the embayments are marked by the occurrence of more easily eroded rock in or towards the centres. Thus the great bay which extends (modified by many a minor indentation) from Cumberland to the north coast of Anglesea, has its limiting salients formed in the durable rocks of those districts, and the centre of the embayment occurs in the soft Triassic rocks of Lancashire and Cheshire; the bay extending from the south of Carnarvonshire to Pembrokeshire has its salients formed of the slaty rocks which are associated with hard igneous rocks, while the centre of the embayment in Cardigan is in rocks which are not penetrated by these hard igneous ribs; 
and, to give one more example, the bay between the Start and the Bill of Portland has its salients formed of the hard Devonian rocks on one hand and the hard Oolites on the other, while the centre is composed of soft Triassic, Liassic, and Cretaceous rocks.

In the case of bays formed in inland lakes, where the power of the waves is small as compared with that of sea-waves, the formation of the hollows which ultimately give rise to bays is often primarily due to subaerial erosion (a point which should be taken into account when considering the origin of lakes), and this is the case to some extent with many bays along the sea-coast, though here the action of the waves is often sufficient to produce marked erosion in the centres of the bays.

On a small scale, as has already been seen, the waves of the sea are capable of fretting the coast into irregular shapes, but it is perfectly clear that if a soft rock coming to the shore as a narrow strip be worn away, a time must come when the indentation penetrates so far inland as compared with its width that the water will be calm even during storms, and accordingly the erosion is checked, until the harder rocks on either side are worn away to a sufficient extent to allow of further removal of the soft rock, and beach material will tend to accumulate in these hollowed-out portions; so that as the result of differential wear and of accumulation in places, inequalities of the coast-line gradually disappear, and there is a tendency to development of a regular curved outline between the salient points. ${ }^{1}$

1 In some cases the salient points are replaced by convex curves, as, for instance, that which occurs on the Norfolk coast. A blunted foreland is due to scour off the original point. 


\section{SCIENTIFIC STUDY OF SCENERY}

The action of the on-shore currents may be in many ways compared with that of a river, if we compare the horizontal action of the former with the vertical action of the latter. It has already been remarked that in some cases the amount of shingle which collects on a foreshore is sufficient to check denudation, and there must be a point where neither denudation of the land nor deposition of shingle takes place. Any pre-existing indentation will produce slack-water and cause deposition of shingle, while any projection will tend to be cut away and recede backward, until eventually a marine denudation curve will be formed by deposition in embayments and denudation on salient points until equilibrium is established. The curve will differ from the denudative curve of running water, in being horizontal instead of vertical, and will sweep from one salient point to another, just as the denudation curve sweeps from ridge to ridge. ${ }^{1}$ In rare cases the conditions are such as to allow of the growth of salient points by deposition. They are spoken of as "cuspate forelands," the term foreland being used by American geographers to denote the flat ground formed by deposition in front of the original coast-line. A good example of such a cuspate foreland is Dungeness, which has been described by Mr. Cornish and also by Dr. T. P. Gulliver. ${ }^{2}$

1 It must be noted that the existence of a stable beach does not imply that the land is not undergoing denudation. As Mr. Cornish observes, "The erosion of the sea-bottom seaward of the beach, which is really a slow waste of the land, pushes landward the proper and stable position of the beach. Thus, unless shingle be supplied in such quantity as to produce a shingle ness or foreland, the barrier is not fixed in position, although it be stable."

${ }^{2}$ Gulliver, T. P., Geographical Journal, May, 1897 . 
Should a coast be subjected to marine action without further change, the salients will gradually become eroded and the embayments filled, and the curvature will thereby diminish, until a state of equilibrium is attained. Before this equilibrium has been attained it will be approached more closely when other conditions are similar, if the difference of hardness of the rocks is not very marked.

In a country like our own additional complication is introduced by change in the relative level of land and sea in comparatively recent times. A movement of upheaval will give rise to a simple coast-line formed largely of sediment, upon which denudation will operate, but our country has recently undergone a movement of depression, and this renders conditions much more complex. Inequalities have been produced by subaerial denudation, and the hollows excavated by subaerial agents when submerged give rise to indentations of the coast which are occupied by the sea, and if the indentations are very long they may exist for a considerable time before they are destroyed or cut off by the formation of shingle barriers across the mouths, especially if the water is very deep at the mouth. To this cause we owe the great indentation of our western coasts, the sea-lochs of Scotland, the corresponding loughs of Ireland, and the long, winding estuaries of Wales, Devon, and Cornwall; and the fjords of Norway and of Greenland are due to the same thing. Many of our smaller bays which occur along the line of the larger may have been initiated in the same way.

For instance, on the south-west coast of Anglesea, which forms part of the great bay between Holyhead and Bardsea Island, we find several bays-Cymmeran 
Bay, Aberffraw Bay, Malldraeth Bay, and, I may add, Carnarvon Bay-which at present present the normal concave curve, but the heads are filled in with shingle banks, blown sand, and marsh accumulation, and the outline of the original land is so irregular that it seems almost certain that it owes its origin to subaerial action, while in each case an important river runs into the bay (except in Carnarvon Bay, where the former river is now occupied by the south-western part of the Menai Straits). ${ }^{1}$

A few words concerning the formation of sandbanks may be of interest on account of the importance which they play upon the scenery of a coast at sunrise and sunset. The condition under which sand is deposited has already been briefly noted. Tidal movement produces a series of vibrating segments of water, which Mr. Cornish believes to be elongated ellipses, and nodes occur between the segments along which sand is deposited, especially along those nodes which separate the ellipses and lie parallel with their longer axes, thus producing longitudinal sandbanks.

${ }^{1}$ The origin of fjords is now generally admitted to be due to occupation by the sea of hollows originally formed by subaerial erosion. Various explanations have been offered to account for the original formation of the hollows, but any cause which produces a hollow on the land will naturally give rise to an indentation of the coast-line when that hollow is occupied by the sea. Professor Brögger has written an elaborate paper on the Christiania Fjord (Nyt Magazin for Naturvidenskabeme, 1886) in which he shows that the fjord lies in a broken anticline, affected by faults, which have let down softer rocks against harder ones, and that the softer rocks have been eroded by subaerial agencies in such a way that the major lines of the fjord coincide closely with the major faults, and in many cases the minor lines similarly coincide with minor faults. The same thing is observable to some extent on the north shore of Morecambe Bay with its estuaries. The coast-lines of the fjords of Western Greenland have been largely determined by erosion along the major joint-planes. 
"Such are the sandbanks parallel to the shore, which are numerous off the coasts from Flamborough Head to the South Foreland, and from Calais, at least, as far as the Zuyder Zee. These sandbanks are parallel to the main run of the along-shore tidal currents." Other sandbanks are formed on the lee side of headlands, "of which the Skerries shoal, eastward of Start Point, and the Shambles shoal, eastward of Portland Bill," are examples. Mr. Cornish terms these "banner sandbanks," inasmuch as they resemble cloud-banners in being formed by a moving current, their permanence being due to fresh supply of sand to compensate for the loss. Sand-bars off rivermouths are usually stated to be due to the checking of the river-current when it enters the sea, but $\mathrm{Mr}$. Cornish gives reasons for supposing that the action is not quite so simple, and is probably due to the motions which attend the mixing of the waters.

Hitherto we have considered chiefly the action of the sea along the actual shore-line, though we have noted that there is erosion on the seaward side of the beach accumulations. It has already been stated that the downward trend of this erosion is limited by the depth at which wave-action is efficacious as an agent of erosion, and that this depth is slight, although it probably varies somewhat according to the character of the waves. As the variations will not be great in the same locality, the ultimate result of marine erosion as the sea encroaches upon the land will be to reduce the destroyed land to the level at which the waves cannot any longer exert an erosive influence, that is to a level of at most a few score fathoms below the ocean surface. Such a 


\section{SCIENTIFIC STUDY OF SCENERY}

levelled tract is known as a plain of marine denudation, and its importance is well known to the geologist. To us it is important, because if upheaved by a gentle and extensive uplift it will give rise to a continental plain, thus adding another and very important cause to those which we have already considered as responsible for the formation of plains.

It has already been noted that the marine deposits when laid down, present a fairly level upper surface, which may be spoken of as a plain of marine deposition, and the upheaval of these plains of deposit furnishes yet another class of continental plains.

Oceanic Islands.-Islands are produced in the ocean in various ways. Many of them were originally portions of continents which have been separated at different times as the result of denudation or of depression of intervening tracts, or by a combination of the two processes. Others are due to upheaval of parts of the sea-floor, which, if continued, may result in the coalescence of the island with an adjoining continent. Others, again, are due to accumulation, either of detrital material derived from the denudation of continents, or of volcanic matter, or of the hard parts of organisms.

Islands which have been separated from the continents present the same features of coast-line as do the continental tracts. An island, like a continent, when undergoing submergence, is marked by fjord-like indentations of the coast-line, if the original slopes were steep. In this way has been produced the very remarkable shape of the island of Celebes, which is the relic of a mass of land of greater extent, much of which has been submerged.

Islands formed by upheaval are frequently found 
along lines of uplift, and run in linear groups, the line being often a curved one, with the concavity facing an adjoining continent. Such islands are known as festoon islands, and are the tops of uplifts, which as the process is continued may give rise to a continuous tract of land, and finally may be added to the adjoining continent. Examples of festoon islands are furnished by the West Indies and Japan and Sagalien Island.

Those islands which are formed by deposit of material derived from denudation of the land are usually low-lying, and are readily destroyed when conditions change, allowing of denudation to take place where deposition occurred previously. From a scenic point of view they are of little interest.

Islands which are wholly composed of volcanic rocks commence as submarine shoals, and if the action of the waves is not sufficiently strong to check the growth of the volcano above the water an island is formed. A large number of oceanic islands are of volcanic origin. When a volcanic island has been affected by paroxysmal eruptions, which have reduced the lower part of the crater to a depth below sea-level, and the sea has communication with the interior, we may have an island with a central lagoon of water communicating with the ocean by one channel, as was once, though erroneously, stated to be the case with Barren Island in the Bay of Bengal; the Lago del Bagno in Ischia fills an old crater, and has been converted into a harbour, but by artificial means. Other craters which are filled by the sea open to the ocean by several passages, for the old crater-ring has had gaps formed in various places. Thus the Archipelago of Santorin in the 


\section{SCIENTIFIC STUDY OF SCENERY}

Eastern Mediterranean consists of the three islands Thera, Therasia and Aspronisi, enclosing a roughly circular lagoon, in the centre of which rise the small Kaimenis, islands formed by minor cones in the middle of the ancient truncated cone, and Krakatoa forms a similar ring, consisting of the main island and Verlaten and Lang Islands.

There remain the coral islands, which have always exercised a fascination in the minds of travellers and those who are interested in scenery, on account of their nature and surroundings, and much attention has been directed to them during recent years, on account of the discussion which has arisen concerning their origin. It is unnecessary to enter into any detail concerning this discussion in a work like the present, all that we can do is to note the general characters of coral reefs, and briefly allude to their formation. It is well known that three kinds of reef are found, which differ in their character. Fringing reefs consist of a fringe of organicallyformed limestone, adhering to the side of an island usually composed of volcanic rock. Barrier reefs, or encircling reefs as those which encircle an island are termed, may extend along part of a continental mass, as the Great Barrier Reef which runs for I 100 miles off the north coast of Australia, or may surround, or partly surround, an island. They are characterised by the existence of a tract of water often of considerable depth lying between them and the land to which they form a barrier; when this is an island the water between the barrier and the island forms a lagoon. Lastly atolls are ring-shaped masses of coral surrounding a lagoon, with no island in the centre of the lagoon. The ring may be, and often 
is, very irregular, and though frequently approaching the form of a circle, often approximates to that of an ellipse. These coral-reefs are found only in clear seas, and in tropical or sub-tropical regions, and the fact that the distribution of reef-building corals is limited by temperature is further proved by the discovery that reef-building corals have a vertical limit; it was formerly stated that they could not flourish at a depth exceeding thirty fathoms, but they have been found at a greater depth, and their exact downward limit seems to be still undetermined. ${ }^{1}$

The rim of rock which forms the foundation of the island, and lies below high-water mark, is largely composed of various kinds of corals, both massive and branching, but calcareous nullipores also contribute very largely to its substance in many places. The actual islands, which lie on this submarine foundation, are composed of fragments piled up by the waves to form a beach, and cemented owing to the solvent action of percolating water. Between the islands are usually a number of passages, in the case of barrier reefs and atolls, which connect the lagoon with the open ocean. At low water considerable tracts of coral-rock with a flat surface are often exposed and extend some way seawards; they are usually terminated by very steep slopes, often extending downwards to great depths.

As these coral islands often rise from very deep

1 The structure and characters of coral-reefs are described in DARWIN's Coral Reefs and J. D. DANA's Corals and Coral Islands; beautiful illustrations of the appearance of coral-reefs accompany Mr. Savile Kent's work on the Great Barrier Reef; and an account of Sir J. Murray's views will be found in a paper by him in Nature, vol. xxii., p. 35 I. 


\section{SCIENTIFIC STUDY OF SCENERY}

parts of the ocean, and as the reef-forming coral has a downward limit not far removed from the surface, it becomes of importance to determine how the islands were formed. According to Darwin, atolls usually commenced as fringing reefs, and owing to depression of the island, and the building up of the corals in a nearly vertical direction, the outer margin of the reef gradually grew away from the island, and owing to the unfavourable state of the inner part of the reef for coral-growth, a lagoon was formed. When the island in the lagoon finally sank the barrier reef was converted into an atoll. Sir J. Murray, on the other hand, supposes that submarine platforms are raised by volcanic action and the accumulation of the tests of pelagic organisms floating in the upper waters of the ocean to the height of the downward limit of coral formation, when corals begin to build reefs. The inner portions of these reefs will be unfavourable to coral growth, and owing to this and to solution a lagoon will be formed. Fragments broken off by the waves will roll down the outer slope and raise portions of it to the requisite height for coral-growth, and the reefforming corals will extend outwards upon this raised portion. Thus Murray considers that the atoll does not grow from a barrier reef, but practically commences as an atoll, and that as the outer part of the reef expands outwards on the fallen blocks, the lagoon also expands by solution-in fact that an atoll commences as a small ring, which gradually grows in diameter, the width of the actual islets practically remaining constant during the process. It must be noted that Darwin actually took into consideration this mode of formation of atolls, and rejected it as 
inapplicable to the larger number of atolls on account of what he conceived to be the improbability of the formation of the requisite number of submarine platforms raised to the required height without emerging to the surface of the ocean. The relative applicability of the two theories to explain atoll formation is a matter which is still sub judice, but the words of Professor Huxley, quoted by Professor Judd, in a discussion to a recent paper at the Geographical Society, probably express the truth of the matter. Professor Judd remarked that he had been discussing the question with Professor Huxley, and that the latter observed, "I am convinced, from all that is being done now, that we shall not find any simple, easy explanation of all coral-reefs ; that the study of coral-reefs is one of the very greatest complexity; that the conditions under which they were formed would have varied greatly in different cases; and that one theory of their origin will probably not be found to suit all the cases"; and, adds Professor Judd, "I think that the experience of the last few years will tend to convince everyone of the truth of this observation."

The peculiar scenery of a coral-reef encircling a lagoon is dependent upon the dazzling whiteness of the beach, formed of broken calcareous fragments, upon the contrast between the still waters of the lagoon and the surge which breaks on the outer part of the reef, and upon the character of the vegetation, which soon springs up, owing to the seeds transported by the ocean, or probably more frequently by birds, which germinate, and grow into plants which gradually give rise to a soil capable of supporting the luxuriant vegetation which is so 


\section{SCIENTIFIC STUDY OF SCENERY}

frequently met with on, and forms so marked a character of, these coral islets.

Raised Sea-Margins.-As the result of uplift, or it may be in some cases of the retirement of the sea, the features which were noticed in the last chapter as characteristic of the action of the sea along the sea-coast, are often found some distance inland. We meet with raised sea-cliffs, frequently pierced by sea-caverns, and in other places with raised beaches. Each of these often forms a marked feature in the scenery of a district. Beginning with the cliffs - raised cliffs may be found on many parts of our coast, especially on the western side, far removed from the wash of the waves of the present ocean. They are frequently separated from the present cliff by a nearly flat or gently sloping terrace, which may be a plain of marine denudation, or a plain of deposition, or one due to the deposition of a thin deposit of sediment upon a plain of denudation. Of this nature are many of the carses of Scotland, well seen along the estuary of the Clyde, and frequently backed by the old sea-cliffs. When surrounding an island these carses give the isle a very characteristic appearance, the raised interior being surrounded by a low, flat terrace standing above a small modern cliff, as in the case of Great and Little Cumbrae, on the Clyde estuary. Among coral islands raised reefs often take the place of the sea-cliffs, and the ancient lagoon may be formed on the landward side of these reefs as a depression, as recently described by $\mathrm{Mr}$. Andrews in the case of Christmas Island. ${ }^{1}$

Raised beaches are very frequent, and often give

1 ANDREws, C. W., Geographical Journal, loc. cit. 
rise to terraced lines, resembling in general aspect those Parallel Roads of Glenroy to which reference has been already made. They are frequent along the coast of Scotland, often rising terrace above terrace to heights of 100 feet above present sea-level. In Norway they are frequently seen running in parallel lines around the fjords, and a magnificent series of terraces is found surrounding the shores of the White Sea. Some of the most remarkable of these terraces exist in South America, where they have been very fully described by Darwin. ${ }^{1}$ They occur, with well-marked features, to heights of over 300 feet above sea-level, and have been found at intervals along the Atlantic coast from Tierra del Fuego for a distance of I 80 miles northward, and along the Pacific coast have been traced for a distance of 2075 miles. For a length of 775 miles they occur on both sides of the Continent in the same latitude. In Greenland, again, these raised beaches have been described on the western coast, and they are also found in New Zealand and in many other areas.

Marine Vegetation.-The marine algæ, which have a prevalent olive-brown or olive-green hue, though many are red or violet, often produce a considerable effect upon marine scenery. At low water our shores are often seen to be densely clad with masses of algæ, and they may be seen waving on the shallows when a boat passes over them, many of them being buoyed up by the vesicles which they possess. In the southern polar seas grows the gigantic Macrocystis pyrifera, which sometimes attains a length of over 500 yards.

In addition to the algæ found around the coasts, 1 Geological Observations, p. 232. 


\section{SCIENTIFIC STUDY OF SCENERY}

attached to the sea-bottom, are others which float freely in the water, as the well-known Sargassum bacciferum, or gulf-weed, of which detached masses cover thousands of square miles of the oceans in those great central "whirls" of quiet water which lie inside, and are due to the circulating masses of oceanic water which, in the northern hemisphere, move in the direction of the hands of a clock, and in the southern hemisphere in the contrary direction. The best known of these areas is the Sargasso Sea, in the North Atlantic, though similar accumulations of "weed" and other flotsam are also formed in the Pacific Ocean, and form the home of countless animals, some of which are attached to the "weed," while others float and swim among it.

Ice in the Ocean.-We have already considered the mode of formation of icebergs, and made brief allusion to the pack-ice of Spitsbergen, but it yet remains to make a few remarks concerning this ice and its formation. The water on the coasts of Arctic regions freezes in winter, and forms a coating attached to the coasts known as coast-ice. It forms on the surface and beneath, and often attains a great thickness. Material falls on to it from cliffs, and is frozen into it when it forms against beaches, and when the ice breaks up in spring it floats away, transporting this material and depositing it elsewhere.

Further, the whole surface of great tracts of the ocean freezes in the winter in Arctic regions, and breaks up on the approach of summer along extensive lines of fissure, the detached portions floating off as ice-floes. These floes are often formed of great sheets of ice reared up edgewise, and piled up one on the top of the other to form pack-ice. It is this 
pack-ice which, forced through the narrow straits of Spitsbergen and elsewhere by currents and races of great velocity, and often of considerable constancy of direction, gives rise to those rounded and striated rocks which, in the present state of our knowledge, it is difficult, if not impossible, to distinguish from the rounded, smoothed, and striated rocks which have acquired their present shape as the result of the action of land-ice. 


\section{CHAPTER XX.}

\section{CONCLUSION}

A $\mathrm{N}$ attempt has been made in the foregoing A chapters to show that the various scenic features of the earth's surface were produced by the operation of agents, whose mode of action is familiar to us. We need not invoke the aid of any mysterious force, in order to account for these features; allow a sufficient amount of time, and the sea will receive enough sediment to supply material for the formation of fresh continents, the forces which are at work on the earth's interior will elevate these sediments above the level of the sea, converting them into dry land, and the incessant action of the sculpturing tools, of wind, rain, frost, rivers, glaciers, sea-waves, and the like, will carve out the continents into those shapes whose origin it has been our task to consider. The nature of these changes and their effects are so clearly understood that they have become the very alphabet of modern geological science, but there is yet much work to be done in working out the details, and also in discussing the causes of many of the changes.

As the student of scenery pursues his inquiries into the origin of the earth's features, he will find that he is led into many by-paths, of whose existence he was previously unaware. Roaming 
among the sand-dunes of the coast, he is first led to inquire how the sand was heaped up to form the crescentic ridges, but when he has done this he will not be content until he has gained some knowledge of the history of the individual sand-grains, and here he will find a story so strange that it seems at first well nigh incredible. The grain was perhaps brought into existence as a grain long, long ages ago, upon the consolidation of a mass of molten rock deep down within the bowels of the earth. The crystalline forces which called it into being were capable of giving it a shape as definite as the form of a living organism, but the conditions were perhaps unfavourable for the assumption of that shape. Ages roll by, and the grain is locked up in the earth's interior, until the slow upheaval of part of the crust, and the removal by denudation of the exterior of that crust, expose it upon the surface. Acidulated water may corrode it, fragments of it may be chipped off during its passage down some river to the sea, and it may be deposited in its altered form at the sea-bottom, perhaps to be uplifted and again denuded time after time. In its present state on the dune it may become rounded by friction against other grains when blown along by the wind, until it has been materially reduced in size. We can destroy it now, as a grain of sand, by immersing it in an acid which will dissolve silica -it would be killed-but if we do not thus destroy it the crystalline forces which called it into existence may act upon it at some future time under circumstances favourable to its completion as a crystal of definite outline. After long ages of unfavourable existence it will then have attained its full growth, 


\section{SCIENTIFIC STUDY OF SCENERY}

and its decay may be prolonged through ages as vast as those which have been required for its growth. There are thus many analogies between the growth and decay of a crystal and the growth and decay of an organism; but how insignificant is the period of duration of the organism as compared with that of the crystal! Another grain we may discover composed of a fragment of an organism, or fragments of many organisms, and we are thus led to inquire into the life of the globe in past times. We may discover that the apparently structureless limestone which, after accumulating to a thickness of thousands of feet on the ocean floor, has been reared up and sculptured into mighty hills and strange pinnacles, is a mosaic composed of particles so small that they can only be seen beneath the microscope, and yet each particle consists of the exquisitely ornate shell of a lovely creature which once existed in a longdeparted ocean. We thus learn that the present earth-features are but records of a brief period; that past periods have succeeded one another before the present, each marked by features of the earth's surface, in many respects similar to those which are at present in being, but each probably characterised by something belonging to the period, which never occurred before and will never occur again. One is thus led to pass in review in one's imagination the whole of the earth's history, from the time when the earth was a formless nebula, to a later period when it was a molten mass; yet later, when, though solid, it was a lifeless desert; and so through the long ages of geological time until one arrives at the contemplation of the present condition of things. And the future? The geologist has no direct 
evidence of the beginning of things. When the first sediments of which we have any certain knowledge were deposited, the condition of the earth had in many ways approximated so nearly to existing conditions that we feel that the time that had elapsed before this was enormous as compared with the time which has since passed by, vast as this must be. And, as the geologist has no direct knowledge of the beginning of things, he sees no signs of an approaching end; he turns to the physicist and astronomer for information of the death of the earth as of its birth. But he sees no reason for supposing that that death is imminent ; the earth's surface may be sculptured and upheaved through long æons of time to come before the end.

But let us leave this subject of geological time, a subject so awe-inspiring that the brain reels when contemplating it too closely, and turn to take a last look at the condition of things as they now are.

We have noted a difference in the operation of the dominant agents which give rise to the varied scenic features of the earth's surface, when we study different parts of the earth's surface. The desert, the seacoast, the arctic uplands, the river-plain, each has its own particular features. Now some of these features are due to climatic conditions, and we accordingly find definite types of scenery which are apt to occur in similar latitudes. We may divide the earth's surface into seven belts, namely, the tropical belt, the north and south sub-tropical belts, the north and south temperate belts, and the arctic and antarctic belts.

Commencing with the tropical belt, we find that its characteristic features are largely dependent upon the excessive rainfall, which is due to the great 
evaporation caused by the sun's heat in equatorial regions. This rainfall, combined with the heat, is favourable for the growth of luxuriant vegetation, and accordingly the tropical zone is specially marked by its extensive forests, and these in turn, for reasons which we have already given, tend to produce a certain sameness of outline in the country, which is not greatly diversified by the work of erosive agents, as is the case with countries which are not so extensively covered with vegetation.

Many people have exaggerated ideas of the beauty of tropical vegetation, and I am tempted to quote Mr. A. R. Wallace's descriptions of the tropical forests of South America :" "The beauty of the palmtrees can scarcely be too highly drawn; they are peculiarly characteristic of the tropics, and their varied and elegant forms, their beautiful foliage, and their fruits .... give them a never-failing interest to the naturalist, and to all who are familiar with descriptions of the countries where they most abound. The rest of the vegetation was hardly what I expected. We found many beautiful flowers and climbing plants, but there are also many places which are just as weedy in their appearance as in our own bleak climate." And again, "A few forest trees were .... in blossom; and it was a truly magnificent sight to behold a great tree covered with one mass of flowers, and to hear the deep, distant hum of millions of insects gathered together to enjoy the honeyed feast. But all is out of reach of the curious and admiring naturalist. It is only over the outside of the great dome of verdure exposed to the vertical rays of the sun that flowers are produced, and on

1 Waldace, A. R., Travels on the Amazon, chaps. i. and ii. 
many of these trees there is not a single blossom to be found at a less height than a hundred feet. The whole glory of these forests could only be seen by sailing gently in a balloon over the undulating flowery surface above; such a treat is perhaps reserved for the traveller of a future age."

It is in the sub-tropical belts, as has already been stated, that the main deserts of the earth's surface occur, and present characters which have been considered in the chapter devoted to the desert-regions. It is not to be supposed that the whole of the sub-tropical regions are occupied by desert, any more than that the whole of the tropical belt is covered by forest-growth, but when the physical conditions are such as are necessary for the existence of deserts, the sub-tropical climate specially favours desert formation.

In these desert regions, the operation of agents in a dry way is very marked, and the scenic features are largely due to change of temperature, and the action of wind.

In the temperate belts, the climate is of a nature specially suited for cultivation, and accordingly it is in these regions that man has most thickly congregated, and has produced most influence upon the scenery of the earth's surface, owing to the modifications brought about by his labours. In these belts, owing to the abundant rainfall, denudation is usually carried on in the wet way, especially by streams and rivers, but, owing to the less dense growth of vegetation, as compared with that of tropical regions, the effect of denudation is to produce greater superficial inequalities than those which are carved out in the forestclad belt on either side of the equator. 
In the arctic and antarctic regions, the scenery is essentially affected, so far as sculpture is concerned, by the action of frost. It is in these regions that the house-roof type of mountain with straight sides is carved out with greatest frequency.

The above remarks concerning the influence of climate have been inserted, because we are too prone to consider the physical features of our own area to be typical of those which are found elsewhere, and to overlook the fact that climatic conditions play so important a rôle in the production of scenic features that different belts of the earth's surface have different kinds of scenery, partly due directly to difference in the character of the vegetation, and partly indirectly to the same difference, but partly also to the difference in the relative importance of the different denuding agents as sculpturing tools.

Allusion has just been made to the influence of man in modifying the scenery of the earth's surface. Perhaps too marked a contrast has been drawn between the work of man and of other animals in affecting the appearance of the outer surface of the globe, as indicated by the use of the expression " natural" scenery, and by talk of "artificial" changes made therein; some writers indeed speak of the work of man as though it generally tended to mar the aspect of a country. When speaking enthusiastically to a Scotch boatman of the beautiful hill scenery of the north end of the Isle of Arran, I was at first somewhat surprised at his remark that I should see the flatter south end with its cornfields; I was not prepared for the influence of contrast with the normal surroundings, in determining a man's ideas of what is beautiful. Anyone who had 
journeyed long in a desert region would no doubt be more profoundly affected by the sight of the cultivated fields of our own country, with the rustic cottages nestling here and there among their orchards, than by the finest "natural" scenery in the world. Nevertheless, one would regret the obliteration of all "natural" scenery, even if it were replaced by a harmonious substitute, due to the labours of man. Much more does one regret the mutilation of a district rich in natural beauty, by works which produce a feeling of discord-works which are often wrought, not for the general advantage of man, but for the sake of benefiting the pockets of greedy speculators to the extent of a few pounds. And yet this mutilation of some of the fairest scenes of our own country has proceeded, and is proceeding, unnoticed save for the words of regret of a few lovers of Nature, whose protests are, alas! unheeded by the great mass of our countrymen. America has its National Park set aside for ever, as a thing of beauty, owing to the far-sighted intelligence of its legislators. We too have our exquisite jewels of natural beauty, jewels so exquisite that they are prized not only by hosts of our own countrymen, but by others who come from afar to gaze at them. Devon and Cornwall, Wales, the Highlands of Scotland, and perhaps, above all, the Lake District of Cumberland and Westmorland, are glorious possessions of the English people, where the jaded dweller in towns may find an exceeding great peace. Do we appreciate these as we should? Alas! the very stones cry out against us. The two lakes of Llanberis, things of beauty at a time within the recollection of the present generation, are now receptacles of slate rubbish, extracted 
from the adjoining hills, which are marked by scars that cannot be effaced till long ages have rolled by. One of the most beautiful upland hollows of Wales, which nestles under the glorious precipice of Snowdon, has been sadly despoiled for the sake of a few pounds of copper ore; the curved bays of Thirlmere -effect of wave-lapping along the beach for many a long day-are replaced by angular indentations of the banks of a reservoir, made to supply the thirsty folk of a large town. This conversion of lake into reservoir is justifiable on the ground of necessity, but who can look without indignation on the unsightly heaps of slate refuse which have sullied the beauty of that fair valley which was the chosen home of Wordsworth?

The library of Alexandria was burnt down, and men have not ceased to bewail its loss, though the chief thoughts of men which were embodied in its tomes have doubtless been since recorded. The work of nature is being daily mutilated, and men look upon the havoc with indifference. Man can here destroy, but he cannot replace. Ages ago the almost structureless masses of jelly living in a bygone ocean, built up an exquisite mosaic of rock, formed with almost inconceivable slowness. Other ages pass away, and the delicate graving tools of Nature carve out this rock into spiry pinnacles and impending cliffs, wreathed with ivy and roses and many another plant. Then comes man, and with a few pounds of gunpowder destroys this work of ages in a moment, and the white cliffs of Derbyshire are marked by a hideous, indelible scar.

Will this go on always, and will the English people look on with indifference while their glorious heritage, 


\section{CONCLUSION}

due to the toil of Nature's servants through the countless æons of geological time, is slowly but surely squandered? Let us hope not; let us rather believe that the time is now at hand when the national importance of the question of our natural scenery will be fully appreciated, and when the study of natural scenery will be looked upon as one of the most beneficial of our means of education. 



\section{N DEX}

A.

Ablation, 289.

Accumulation, Mountains of, 55 . Acid rocks, 99.

Agre, 323.

Agassiz, A., 31 I.

Aiguilles, 9I.

Aitken, J., 32.

Alkali deserts, 265, 270.

Alluvial cones, 137, 142.

- flats, 132, 196, 233, 235.

Alpine type of mountains, 62,63 .

Andrews, C. W., 328.

Antecedent drainage, 144.

Anticline, 14.

Anti-cyclone, 43.

Åsar, 318 .

Ashes, Volcanic, 225.

Atmosphere, 29-45.

Atolls, 344, 346, 347 .

Attributes of scenery, 2-7.

Avalanches of rock, 196. of snow, 279.

\section{B.}

Bad Lands, 256, 269.

Ball, J., 30.

Barchanes, 262.

Bars, 34I.

Basalt, 99.

Base-line (of erosion), 84, 86.

Basic rocks, 99.

Basin (of strata), 14.

Bays, 192, 193, 335.

Beaches of lakes, 188, 194, 265.

- sea, 332-335.

- raised, 348 .

Beaver-dams, 164.
Beheaded rivers, $\mathbf{1 4 2 .}$

Belloc, E., 196.

Bergschrund, 285.

Blanford, W. T., 145, 244, 262.

Blocs perchés, 316.

Plow-holes, 330 .

Bonney, T. G., 186.

Bore, 323.

Boulder-clay, 316-319.

Breakers, 325 .

Broads, 165.

Brögger, W. C., 340.

Browne, G. F., 157.

Buckland, W., 3 rr.

Buttes, 247, 256, 258, 259.

C.

Calderas, $217,218$.

Cañons, 129, 259.

Carses, 348.

Cascades, 150.

Caves, I 53-157.

- in glaciers, 29I, 302. Sea, 329, 330.

Chinese walls, 298.

Cinder-cones, 213, 214.

Circumdenudation, Mountains of, 55 .

Cirques, 75.

Cirrus, $33,37,38$.

Cleavage-planes, 18.

Cliffs, Subaqueous, 190.

- of erosion, 193.

Sea, 327-332.

Climate, Effect of, 355-358.

Clints, 108, 246.

Clouds, 3I-45. Classification of, 32.

Collingwood, W. G., 22. 
Colour, Effect of, 4.

- in the sky, 29.

__ of lakes, 198-20I.

- of ice, 308 .

Cols, 75-77.

- in meteorology, 43.

Columnar structure, I03.

Combes, 75.

Consequent river-systems, 139.

- streams, I 2 I.

Continents, Structure of, 46-54.

Contraction theory, 47 .

Coral-islands, 344-348.

Cornish, V., 260, 276, 333, 338341 .

Corrasion, $8 \mathbf{I}-84$.

- Lateral, 130 .

Crater lakes, I8I, 188.

Craters, 214-219.

Crevasses, 286-289.

Cumulus, 33, 34 .

Currents of ocean, 324 .

Cushing, H. P., 162, I85, 300.

Cuts-off, 165 .

Cwms, 75 .

Cyclones, 40-43.

\section{D.}

Dana, J. D., 345.

Darwin, C., 345, 349.

Daubrée, A., 3 I 4 .

Davis, W. M., 97, I 21, 124, 139, I42, I45, 147 .

Davy, Sir H., 199, 204.

Dawkins, W. B., 152.

Deeley, R. M., 282.

De la Beche, Sir H., II 5 .

Delabecque, A., I58, I63, 170 , I7I, I73, I75, 181, I82, 184, 186, 191, 196, 200.

Deltas, 236-238.

- of lakes, 194-196.

Denudation, 70.

- Processes of, 80.

Derivative rocks, 9 .

Deserts, 248-27 I.

Desor, E., 172.

Dewar, J., 30.

Dip-slope, I 24.

Dirt-bands, 295.
Diversion of river-drainage, 140143.

Dolomite mountains, J08, 109.

Domes, Drainage of, 78 .

- Volcanic, 211 .

- of strata, 14.

Drumlins, 217.

Dry deltas, 137, 168, 196.

Dunes, 260-264, 270.

Dutton, C. E., 212, 2 I8, 220.

Dykes, 100.

\section{E.}

Earth-pillars, 128, 129.

Earthquakes, 229, 230.

Ellis, W., 222.

Englacial rivers, 302.

Escarpments, 124.

Eskers, 318.

Etangs, I64

Everett, Professor, 266.

F.

Falaises, 164.

Fan-structure, 63 .

Fata morgana, 202.

Faulted mountains, 65-69.

Fault-planes, 17.

- Influence of, 109.

Fens, 239-24I.

Firn, 28I.

Fissure-eruptions, 224, 225.

Fjords, 236, 339.

Fletcher, G., 282.

Floating islands, 198.

Floe-ice, 350.

Fluvio-glacial deposits, 294, 307.

Folded mountains, 59-65.

— strata, 14.

Foliation-planes, 19.

Forbes, J. D., 167, 281, 284, $285,295,297$.

Forel, F. A., I58, 191, 199, 200, 202.

Forelands, 338.

Frost, 89, 90, 92, 272-274.

Fuljes, 263. 
G.

Garwood, E. J., 175, 274, 283, 298, 299, 302.

Geikie, Sir A., 92, I64, 224, 266, $269,325,329$.

Gemmellaro, M., 120.

Geysers, 226, 229.

Giants' kettles, 3 I5.

Gilbert, G. K., 60, 69, 71, 122, I 39, I40, 143, I 45, I47, I 78, $179,182,252,254,333$.

Gilpin, W., I 19.

Glacier-canals, 300.

Glacieres, 157.

Glaciers, 279-320.

- Movement of, 284.

- Remaniés, 297.

Erosion by, 31 I-3 I 5 .

Glacier-tables, 294.

Gorges, I 18.

Granite, 99.

Gregory, J. W., 165, 166, I77, $283,298,299$.

Gulliver, T. P., 338 .

Guthrie, Professor, 205.

\section{H.}

Heim, A, 62, 180.

Ierschel, J., 34 .

Hoar-frost, 273.

Hogbacks, 14,64 .

Holmes, W. H., 259.

Hopkins, W., 287.

House-roof structure, 90, 254.

Howard, L., 32.

Hummel, D., 318.

Huxley, T. H., 347.

I.

Ice, $272-320,350,351$.

Icebergs, 307,308 .

Ice-cap, 298.

- of Greenland, 303-307.

Ice-sheet, 298.

Icicles, 275 .

Igneous rocks, 9, 98 .

Inclination of slopes, I I4-1 17 .

Islands in lakes, 197, 198.
Islands, Oceanic, 342-348.

Volcanic, 343,344 .

Coral, 344,348 .

J.

Joint-planes, 16.

Judd, J. W., 179, I8 I, 205, 208, 2 I $1,347$.

Jukes, J. B., 330.

K.

Kames, 318.

Kendall, P. F., 312.

Kent, S , 345.

Kettle-holes, 159.

Kornerup, A., 90, 9 I.

Kryokonite, 305.

L.

Laccolite, 6o, 100.

Lagoons, 335, 344 .

Lakes, 158, 202.

- without outlet, 265.

Lamination, Planes of, I 2.

Landslips, 163, $230,332$.

Lapworth, C., 48, 62, 207.

Lava, 219-22I.

Lewis, H. C., 319.

Ley, C., 33-35, 44.

Limestone, Influence of, 107-109, 246.

Livingstone, D., 92.

Llanos, 243.

Lochs, Sea, 339.

Loess, 264.

Lubbock, Sir J., I86.

Lyell, Sir C., I18, 120, 128, 132, 150, 176, $219,238$.

\section{M.}

Mallet, R., 205.

Massive eruptions, 224, 225.

Master-joints, 16.

Mc Mahon, A. H., 263, 264, 266.

Medanos, 262. 
Medlicott, H., 145, 244.

Meres, I 59, 174, I 86.

Mesas, 247.

Metamorphic rocks, Io.

Mill, H. R., 158, I84, 189, 193, 194, 197.

Miller, S. H., 239.

Milne, J., 96, 213.

Mirage, 202, 266.

Moels, 87 .

Monadnocks, 147 .

Monoclinal faults, 66 .

Monocline, I 4.

Moraine lakes, 159.

Moraines, 292-295, 306, 315, 316.

Mortillet, G. de, I83.

Moulins, 290, 303.

Mountain-range, 62.

Mountains, 55-II 2.

- of deserts, 254.

Movements, Effect of, 7 .

Mud-volcanoes, 229.

Murray, Sir J., 345.

N.

Nansen, F., 303.

Needles, 332.

Neulinge, 260.

Névé, 281.

Nimbus, 33.

Nordenskjold, Baron A. E., 300.

Nunataks, 305, 306.

\section{O.}

Oases, 270.

Obsequent streams, I 24.

Oceans, 46-54, 321-351.

Oldham, R. D., I80, I85.

Osler, A. F., 33, 36 .

Otley, J., 198.

Outcrop, I3.

Overfault, 66.

Overfold, 66.

P.

Pack-ice, 350.

Pampas, 243.

Parallel roads of Glen Roy, 162.
Parasitic cones, 219.

Passes, 75-77.

Peat-mosses, 17 1, 197, 235.

Penck, A., 173 .

Peneplains, 97, 247.

Perched blocks, 316 .

Piedmont glaciers, 298, 300, 301 .

Plains, 231-243, 319, 342.

Planation, 145.

Planes of lamination, 12.

Planes of stratification, 12.

Plateaux, 23I, 243-247.

Polders, 243.

Ponding, $143,176$.

Potholes, II 8 , I 53 .

Powell, J. W., 67, 145, 244.

Prairies, 243.

Puffing-holes, 330.

Puys, 219.

Pyramidal hills, I 10.

Q.

Quartz-veins, I09.

\section{R.}

Race, 323.

Ramsay, Sir A. C., 115, 176, 183 , 3 I3.

Reclus, E., 236.

Reefs, Coral, 344-348.

Reid, C., 153.

Richthofen, Baron von, 2 I0, 264.

Rivers, erosion of, 8o, 232.

- Deposits, 232.

River-terraces, 234.

Roches moutonnées, 312, 313 .

Rock-basins, 181-187.

Rock-structure, II.

- Influence of, on denudation, 97.

Rock-texture, II.

Roflas, 172, 3 I4.

Ruskin, J., 3, 4, 6, 19.

Russell, I. C., I 78, 300.

S.

Sand-banks, 334, 340, $34 \mathrm{I}$.

Sand-dunes, 260-264, 270. 
Sand-pillars, 266.

Sand-storms, 266.

Sandstone hills, 105-107.

Savannahs, 243.

Schist-hills, 104, 105.

Scott, R. H., 33, 34, 45, 274, 276.

Screes, 90, 96, 168, 196.

Scrope, G. P., 182, 204, 2 I I, 212.

$\mathrm{S}$-curve (of rivers), I3I.

Selvas, 243.

Septum (of fold), 48, 49.

Shales, Influence of, 107, 134 .

Sheets (of igneous rock), I0o.

Shores, of lakes, I88, 191-197.

Sigmoidal folds, 66 .

Sills, 100.

Sinter-terraces, 228, 229.

Size, effect of, 3 .

Skertchly, S. B. J., 239.

Slate-hilis, I05.

Smith, E. A., 177.

Snow, 275-279.

- Cornices of, 276. Red, 309.

Snowflakes, 273.

Snow-line, 277.

Sollas, W. J., 319.

Spencer, J. W., I79, 190.

Spring, Professor, 200, 201.

Springs, 73 .

- Hot, 226-229.

Stacks, 332.

Stalactites, 155 .

Stalagmite, 155.

Steenstrup, K. J. V., 288.

Steppes, 264.

Strahan, A., I 19.

Stratification-planes, 12.

Stratified rocks, Io.

Stratus, 33, 35-37.

Striation (glacial), $311,312,351$.

Subsequent streams, I21.

Superinduced drainage, 144.

Swallow-holes, 153, 154, 173 .

Symmetrical mountains, 64 .

Syncline, I4.

\section{T.}

Tarai, 243.

Tarns, 166.

Terraced hills, I03.
Terraces, River, 234.

Texture, Effect of, 7 .

Thalweg, 126.

Thunderstorms, 44 .

Thrust-faults, 66 .

Till, 316.

Tors, IO3.

Transportation, $8 \mathrm{r}$.

Tundras, 243.

Turbary, 197, 235.

Tyndall, J., 24, 34, 287.

U.

Uinta type, 64 .

Unconfornity, $5 \mathrm{I}$.

Underground rivers, I 52-1 57.

Unsymmetrical mountains, 64 .

Upheaval, Mountains of, $55,5^{8-}$ 69.

\section{V.}

Valleys, I 13-157.

Classification of, I 13 .

Vallot, J., 196.

Vegetation on mountains, II I,

II2.

- in lakes, 197, 235.

- on deltas, 238 .

- of fens, $240,24 \mathrm{I}$.

- in arctic regions, 243.

— of deserts, 267-27o.

— on glaciers, 302, 304, 309.

- on nunataks, 306 .

- alpine, $3 \mathbf{1} 9$.

- marine, 349, 350.

Verglas, 274.

Volcanoes, 203-230.

- Mud, 229.

$V$-shaped depression, 43.

Vulcanicity, Causes of, 203-210.

W.

Wadys, 259.

Wallace, A. R., 356.

Waltershausen, $\mathrm{S}$. von, 218.

Walther, J., 253-258, 260.

Ward, J. C., IO2, 184, 316.

Warming, E., 270. 
Warping, 175.

Waterfalls, 147-152.

Watersheds, 52, 54, 71-80.

Watts, W. W., 169.

Waves, $32 \mathrm{I}$.

Erosion by, 324-332, 337 .

Weathering, 81.

Weed, W. H., 228.

Whirlpools, 323.

Whymper, E., I I4, 208, 209.
Wilkes, Lieutenant, 218.

Wind, Action of, 93, 182, 219.

Wordsworth, W., 3, 5, 6 .

$\mathrm{X}$.

Xerophilous plants, 268.

Z.

Zeugen, 256, 257. 



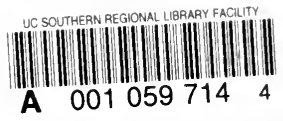


